FOR THE USE OF NTS TENANT ORGANIZATIONS AND THE U.S. DOE NEVADA OFFICE

\title{
NV/YMP RADIOLOGICAL CONTROL MANUAL
}

DISTAIBUTION OF THIS DOCUMENT IS UNLMITED

NOVEMBER 1996

MASTER REVISION 2

Coordinated and compiled by:

A. L. Gile

Bechtel Nevada

2621 N. Losee Road

N. Las Vegas, NV 89030

Under Contract No. DE-AC08-94NV11718 
REVISION/DISTRIBUTION LOG

\begin{tabular}{|l|l|l|}
\hline $\begin{array}{c}\text { Revision Number } \\
0\end{array}$ & & \\
\hline $\begin{array}{l}\text { Training Required: N/A } \\
\text { Brief Description of Revision: Initial Issue }\end{array}$ & & \\
\hline
\end{tabular}

\begin{tabular}{|c|c|c|}
\hline $\begin{array}{c}\text { Revision Number } \\
1\end{array}$ & $\begin{array}{c}\text { Pages Affected } \\
\text { All }\end{array}$ & \\
\hline \multicolumn{3}{|c|}{$\begin{array}{l}\text { Brief Description of Revision: A complete revision to reflect the recent changes in mission and } \\
\text { organizational structure at the NTS and YMP; to anticipate imminent changes in contracts and } \\
\text { contractual obligations; to be in agreement with Revision } 1 \text { of the DOE Radiological Control } \\
\text { Manual (April 1994); for use as proof of compliance with } 10 \text { CFR } 835 \text {; and for use as a } \\
\text { reference document for Contractor/User ("Tenant Organization") Radiological Protection } \\
\text { Programs. }\end{array}$} \\
\hline
\end{tabular}

\begin{tabular}{|l|c|c|c|}
\hline \begin{tabular}{|l|l|} 
Revision Number \\
2
\end{tabular} & $\begin{array}{c}\text { Pages Affected } \\
\text { All }\end{array}$ & & \\
\hline $\begin{array}{l}\text { Brief Description of Revision: A complete revision to reflect the recent changes in mission and } \\
\text { organizational structure at the NTS and YMP; for use as proof of compliance with 10 CFR 835 } \\
\text { and DOE N 441.1; for use as a reference document for Tenant Organization Radiological } \\
\text { Protection Programs. }\end{array}$ \\
\hline
\end{tabular}

\section{DISTRIBUTION}

The organization responsible for establishing the distribution for this document is the Bechtel Nevada, Environment, Safety, Security \& Health Division, Health Physics Department.

Distribution information shall be forwarded, in writing, to the Bechtel Nevada Master Document Control \& Distribution Center, 2621 Losee Road, N. Las Vegas, NV 89030-4129, Mail Stop NLV049.

Revisions affecting this document shall follow the review and approval requirements of Company Procedure C-J15.002, "Development and Approval of Policies, Plans, and Procedures."

The Distribution Code for this document is " $\mathrm{M}$ " plus individuals identified by the Health Physics Department Manager. To receive a distribution list, contact the Master Document Control \& Distribution Center at (702) 295-0113.

Additional Copies of this document may be obtained by completing a "Document Authorization," BN-0218 and forwarding it to the Bechtel Nevada Master Document Control \& Distribution Center, 2621 Losee Road, N. Las Vegas, NV 89030-4129, Mail Stop NLV049. 


\section{DISCLAIMER}

This report was prepared as an account of work sponsored by an agency of the United States Government. Neither the United States Government nor any agency thereof, nor any of their employees, make any warranty, express or implied, or assumes any legal liability or responsibility for the accuracy, completeness, or usefulness of any information, apparatus, product, or process disclosed, or represents that its use would not infringe privately owned rights. Reference herein to any specific commercial product, process, or service by trade name, trademark, manufacturer, or otherwise does not necessarily constitute or imply its endorsement, recommendation, or favoring by the United States Government or any agency thereof. The views and opinions of authors expressed herein do not necessarily state or reflect those of the United States Government or any agency thereof. 


\section{DISCLAIMER}

Portions of this document may be illegible electronic image products. Images are produced from the best available original document. 
TENANT ORGANIZATION MANAGEMENT CONCURRENCE

NVIYMP RADIOLOGICAL CONTROL MANUAL ACRONYMS

NVMMP SITE and RADIOLOGICAL CONTROL MANUAL OVERVIEW

\section{CHAPTER 1 EXCELLENCE IN RADIOLOGICAL CONTROL}

PART 1 NV/YMP Radiological Control Manual

PART 2 Leadership in Radiological Control

PART 3 Improving Radiological Performance

PART 4 Contractor Radiological Control Organization

PART 5 DOE Management

APPENDIX 1-A Suggested Radiological Performance Indicators

APPENDIX 1-B Nevada Test Site (NTS) Site-Wide ALARA Committee (SWAC)

Charter

\section{CHAPTER 2 RADIOLOGICAL STANDARDS}

PART 1 Administrative Control Levels and Dose Limits

PART 2 Contamination Control and Control Levels

PART 3 Posting

APPENDIX 2A Guidelines for control of Emergency Exposures

APPENDIX 2B Weighting Factors for Organs and Tissues

APPENDIX 2C Non-Uniform Exposure of the Skin

\section{CHAPTER 3 CONDUCT OF RADIOLOGICAL WORK}

PART 1 Planning Radiological Work

PART 2 Work Preparation

PART 3 Entry and Exit Requirements

PART 4 Radiological Work Controls

PART 5 Reserved

PART 6 Special Applications

PART 7 Construction and Restoration Projects

APPENDIX 3A Checklist for Reducing Occupational Radiation Exposure

APPENDIX 3B Physical Access Controls for High and Very High Radiation Areas APPENDIX 3 C Contamination Control Practices

APPENDIX 3D Guidelines for Personnel Contamination Monitoring with Hand-Held Survey Instruments

\section{CHAPTER 4 RADIOACTIVE MATERIALS}

PART 1 Radioactive Material Identification, Storage, and Control

PART 2 Release and Transportation of Radioactive Material 
PART 3 Radioactive Source Controls

PART 4 Solid Radioactive Waste Management

PART 5 Control of Radioactive Liquids and Airborne Radioactivity

PART 6 Support Activities

APPENDIX 4A Values for Exemption of Sealed Radioactive Sources from Inventory and Integrity Testing

\section{CHAPTER 5 RADIOLOGICAL HEALTH SUPPORT OPERATIONS}

PART 1 External Dosimetry

PART 2 Internal Dosimetry

PART 3 Respiratory Protection Program

PART 4 Handling Radiologically Contaminated Personnel

PART 5 Radiological Monitoring and Surveys

PART 6 Instrumentation and Calibration

\section{CHAPTER 6 TRAINING AND QUALIFICATION}

PART 1 Radiological Control Training and Qualification

PART 2 General Employee Radiological Training

PART 3 Radiological Worker Training

PART 4 Radiological Control Technician Qualification

PART 5 Other Radiological Training

PART 6 Training For Special Applications

\section{CHAPTER 7 RADIOLOGICAL RECORDS}

PART 1 Requirements

PART 2 Employee Records

PART 3 Visitors

PART 4 Radiological Control Procedures

PART 5 Radiological Surveys

PART 6 Instrumentation and Calibration Records

PART 7 Records Management

PART 8 Radiological Reporting

REFERENCES

GLOSSARY

INDEX

REFERENCE APPENDIX: 10 CFR 835 (with appendices A through D inclusive)

REFERENCE APPENDIX: DOE N 441.1 
REFERENCE APPENDIX: DOE N 441.2

REFERENCE APPENDIX: Nevada Test Site Performance Objective for Certification of Nonradioactive Hazardous Waste

\section{TABLES}

1-1 Suggested Radiological Performance Indicators

2-1 Summary of Dose Limits

2-2 Summary of Contamination Values

2-3 Criteria for Posting Radiation Areas

2-4 Criteria for Posting Contamination, High Contamination, and Airborne Radioactivity Areas

2A-1 Guidelines for Control of Emergency Exposures

2B-1 Weighting Factors for Organs and Tissues

2C-1 Non-Uniform Exposure of the Skin

3C-1 Guidelines for Selecting Protective Clothing (PC)

4-1 Labeling Requirements for Radioactive Materials

6-1 Radiological Worker Entry Training Requirements

\section{FIGURES}

\section{0-1 NTS Location}

O-II NTS Area Designations, Principal Facilities, and Testing Areas

2-1 Establishing Posted Areas

3-1 NVMMP Radiological Work Permit 
NV/YMP Radiological Control Manual, Rev. 2:

November 13, 1996

CONCURRENCE

CONCURRENCE

NV/YMP Radiological Control Manual, Revision 2

TENANT ORGANIZATION MANAGEMENT CONCURRENCE

SENIOR SITE EXECUTIVES:
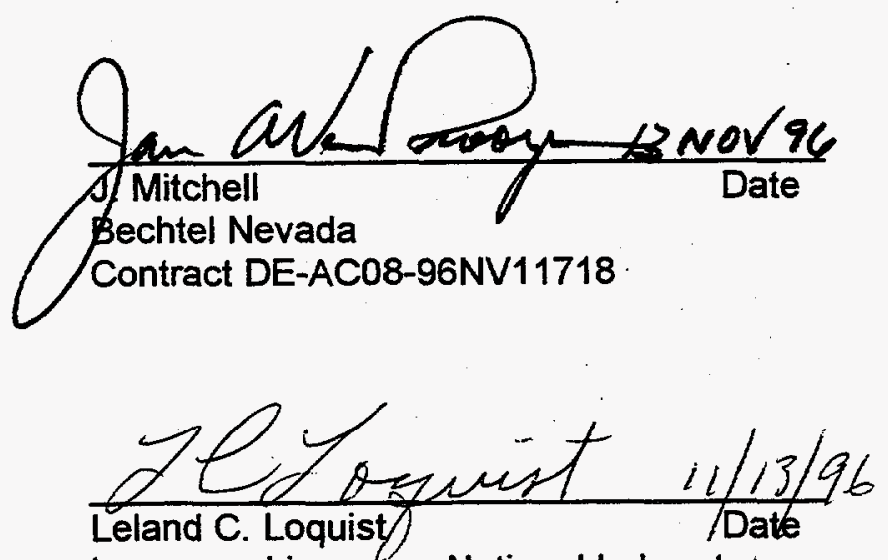

Lawrence Livermore National Laboratory Contract W7045-ENG-48 09/30/97

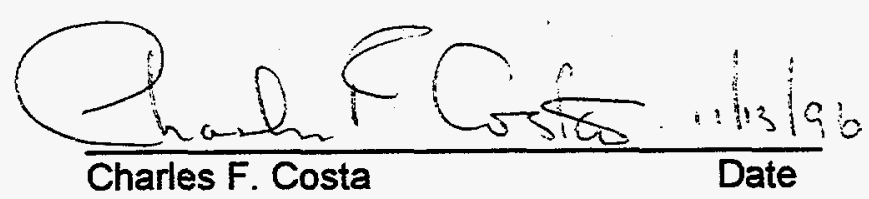

Los Alamos National Laboratory

Contract W7045-ENG-36 09/30/97

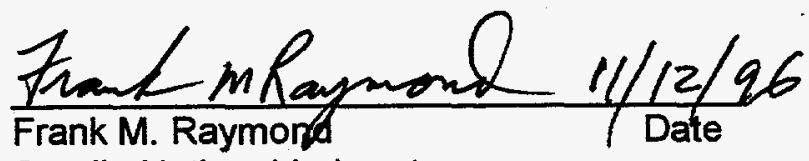

Candia National Laboratory

Contract DE-AC04-94AL85000

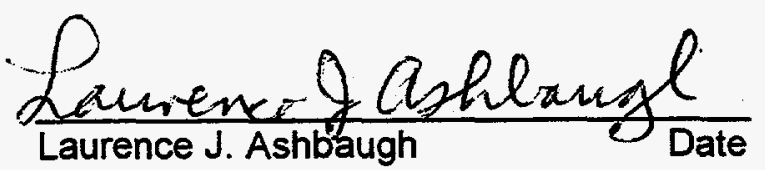

Defense Special Weapons Agency
RADIOLOGICAL CONTROL MANAGERS:

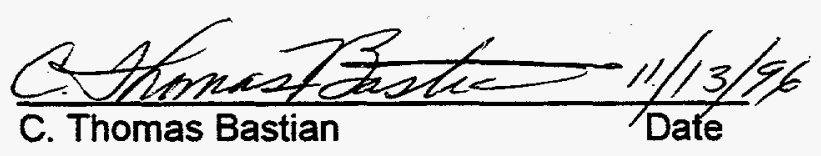

(BN)

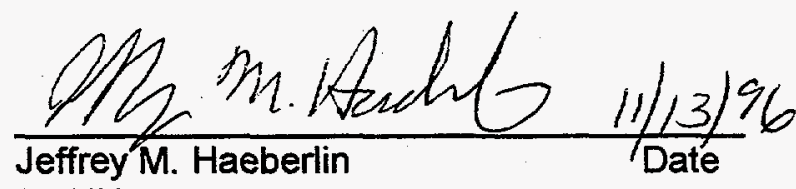

(LLNL)
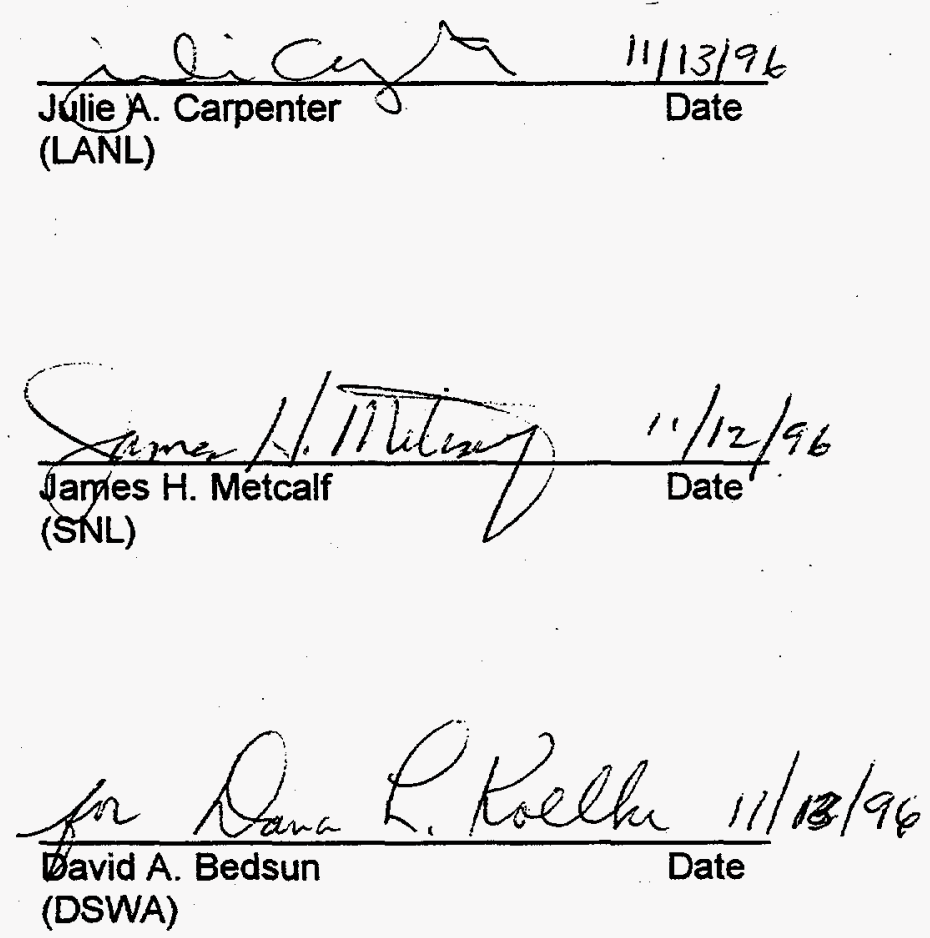

C-1 
SENIOR SITE EXECUTIVES:

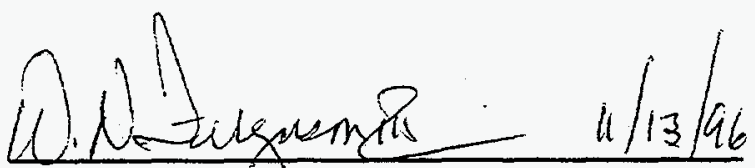

W. N. Ferguson, III. Date

Wackenhut Services incorporated

Contract DE-AC08-93NV11011

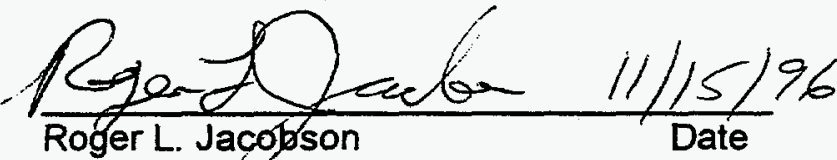

Desert Research Institute, University

Community College System of Nevada

Contract DE-AC08-95NV11508
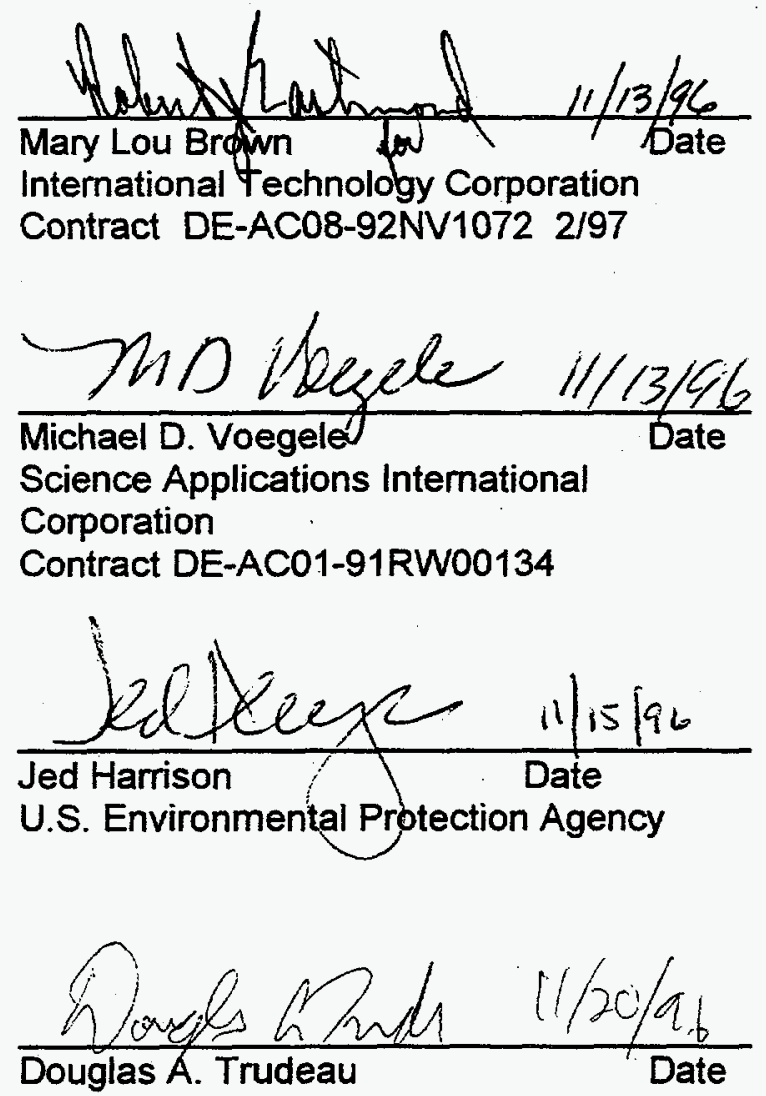

U.S. Geological Survey

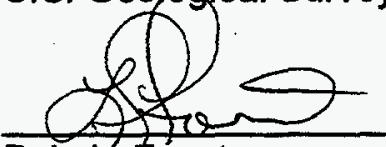

Dale L. foust 11.14 .96

Civilian Radioactive Waste Management System/Management and Operating Contractor/Yucca Mountain Project
RADIOLOGICAL CONTROL MANAGERS:

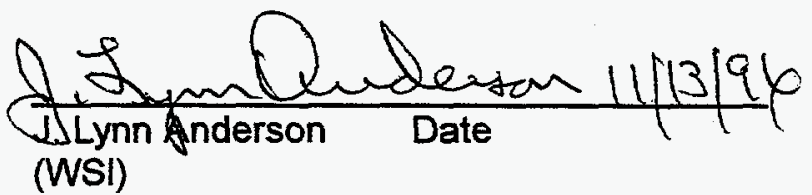
(WSI) $\frac{\text { Dewin } C l i-13-96}{\text { Dennis Chin }}$ (DRI)
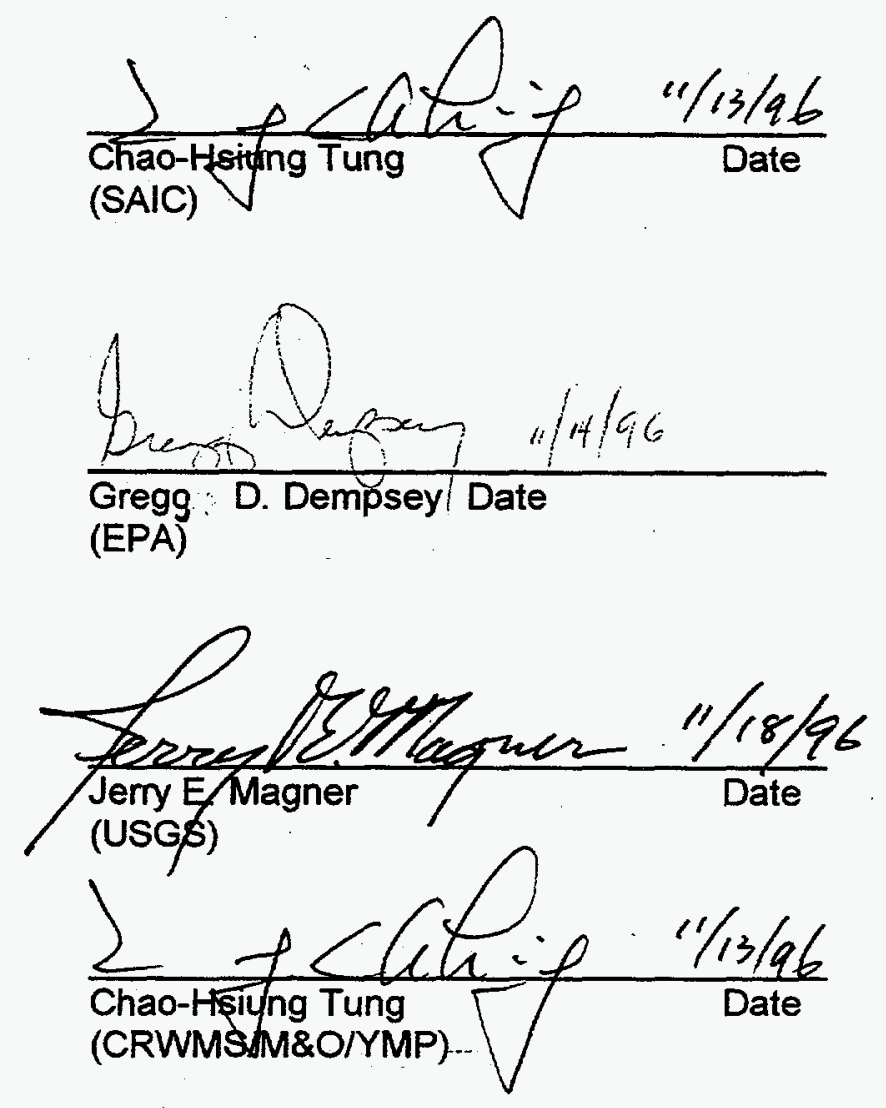


\section{NV/YMP Radiological Control Manual ACRONYMS}

ALARA

ALI

AMD

ANSI

ASTM

BN

CAM

CEDE

CFR

CP

CRWMS/M\&O/YMP

$D \& D$

DAC

DOE

DOELAP

DOE/NV

DOE/NV/SHD

DOT

DSWA

EDE

ERDA

FEMA

FOC

GERT

HEPA

HPD

ICRP

LANL

LLNL

MIRD

NAFR

NCRP

NIST

NRC

NRRPT

NTS

NV

NV/YMP

OCC

ORPS
As Low As Reasonably Achievable Annual Limit of Intake Assets Management Division American National Standards Institute American Society of Testing and Materials

Bechtel Nevada Continuous Air Monitor Committed Effective Dose Equivalent Code of Federal Regulations Control Point Civilian Radioactive Waste Management System/Management \& Operating Contractor/Yucca Mountain Project Decontamination and Decommissioning Derived Air Concentration Department of Energy DOE Laboratory Accreditation Program DOE Nevada Operations Office DOE/NV/Safety and Health Division Department Of Transportation Defense Special Weapons Agency Effective Dose Equivalent Energy Research and Development Agency Federal Emergency. Management Agency Field Operations Center General Employee Radiological Training High Efficiency Particulate Air Health Physic Department International Commission on Radiation Protection Los Alamos National Laboratory Lawrence Livermore National Laboratory Medical Internal Radiation Dose Nellis Air Force Range National Council on Radiation Protection and Measurements National Institute of Standards and Technology Nuclear Regulatory Commission National Registry of Radiological Protection Technologists Nevada Test Site Nevada Operations Office NTS and Yucca Mountain Project site operation/control Operations Coordination Center Occurrence Reporting and Processing System 
PC

PPE

Protective Clothing

RadCon

Personnel Protective Equipment

RAMATROL

Radiological Control

RMA Radioactive Material Control

RCO Radioactive Material Area

RCT

Radiological Control Organization

REIRS

Radiological Control Technician

RPP Radiation Exposure Information Reporting System

RSPC

Radiation Protection Program

RWI

Radiological Safety Prime Contractor

RWII

Radiological Worker I

RWP

Radiological Worker II

SCL

Radiological Work Permit

SI

Special Control Levels

Systems International

SNL

Sandia National Laboratory

SNM

Special Nuclear Material

SOP Standard Operating Procedure

SSE

Senior Site Executive

SWAC Site Wide ALARA Committee

TEDE Total Effective Dose Equivalent

TLD Thermoluminescent Dosimeter

TO(s) Tenant Organization(s)

WSI

Wackenhut Services Incorporated

YMP

Yucca Mountain Project 


\section{NTS/YMP SITE \\ and \\ NVIYMP RADIOLOGICAL CONTROL MANUAL OVERVIEW}

The Nevada Test Site (NTS) and the adjacent Yucca Mountain Project (YMP) are located in Nye County, Nevada. The NTS is located approximately 105 kilometers (65 miles) northwest of Las Vegas. It is a remote facility that covers approximately 3500 square kilometers ( 1350 square miles) of land. The dimensions of the NTS vary from 46 to 56 kilometers ( 28 to 35 miles) in width (eastern to western border) and from 64 to 88 kilometers ( 40 to 55 miles) in length (northern to southern border).

The NTS and the YMP (located within and immediately adjacent to the western portion of NTS Area 25) is surrounded to the west, north, and east by additional thousands of acres of land withdrawn from the public domain for use as a protected wild life range and as a military gunnery range. These public exclusion areas comprise the Nellis Air Force Range (NAFR) complex, previously designated as the Nellis Air Force Base Bombing and Gunnery Range, and the Tonopah Test Range. These two areas provide a buffer zone between the test areas and public lands administered by the federal Bureau of Land Management.

The population density within 150 kilometers (93 miles) of the NTS is only 0.5 persons per square kilometer versus approximately 29 persons per square kilometer in the 48 contiguous states. The combination of the NAFR and the NTS is one of the largest unpopulated land areas in the United States, comprising some 14,200 square kilometers (5470 square miles). The predominant land use surrounding the NAFR is open range used for livestock grazing, mining, and recreation.

The NTS has been the primary location for testing nuclear explosives in the continental United States since 1951. The topographical and geological characteristics of the NTS afford some protection to the inhabitants of the surrounding areas from potential radiation exposure as a result of release of radioactivity or contamination from nuclear testing operations. Historically, testing programs at the NTS have included atmospheric testing in the 1950 s and early 1960s; underground testing in drilled, vertical holes and horizontal tunnels; earth cratering experiments; and open air nuclear reactor and engine testing. Current activities include operating low-level radioactive and mixed waste disposal facilities for U.S. defense-generated waste, assembly/disassembly of special experiments, surface cleanup and site characterization of contaminated land areas, and non-nuclear test operations such as controlled spills of hazardous materials at the Hazardous Materials (HAZMAT) Spill Center (HSC). Currently, the major potential for occupational radiation exposure is associated with the burial of low-level nuclear waste and the handling of radioactive sources. Planned future remediation of contaminated land areas may also result in radiological exposures. 
The YMP is involved with the characterization and suitability testing of a rolling volcanic ridge named "Yucca Mountain," near the western boundary of the NTS, as the future repository for high-level nuclear waste generated within the U.S. Current activities include test hole drilling and underground mining. The major potential for radiation exposure is from using sealed radioactive sources and possible future nuclear waste handling. Activities at the NTS and YMP involve the application of many different skills and occupational specialties typically dispersed over a large geographical area. Several different organizations frequently perform work either as a closely integrated team or concurrently at any one location. In order to assure that the appropriate procedures and policies are uniformly considered and applied by all of the program participants, one responsible organization is assigned radiological coordination responsibility by DOE/NV/YMP for a specific area or facility.

NTS radiological coordination responsibility for a facility (building or complex) is delegated to the Facility Manager by U. S. Department of Energy (DOE)/Nevada Operations Office (NV) through a "Facility Use Permit" as described in NTS-SOP-4001. NTS radiological coordination responsibility for an area is delegated via NTS-SOP6405 , which requires an organization to request coordination responsibility for an area from DOE/NV in writing. Bechtel Nevada (BN) is presently responsible to DOE/NV for the coordination of the radiological safety aspects of NTS operations not specifically transferred to another organization.

YMP-specific activities are coordinated through the DOE/YMP Field Operation Center (FOC).

The NV/YMP Radiological Control Manual, Revision 2, represents DOE-accepted guidelines and best practices for implementing NTS and YMP Radiation Protection Programs (RPPs) in accordance with the requirements of Title 10 Code of Federal Regulations Part 835 (10CFR835), Occupational Radiation Protection. These programs provide protection for approximately 3000 employees and visitors annually and include coverage for the on-site activities for both personnel and the environment. The personnel protection effort includes a DOE Laboratory Accreditation Program (DOELAP) accredited dosimetry and personnel bioassay programs including in-vivo counting, routine workplace air sampling, personnel monitoring, and programmatic and job-specific "As Low as Reasonably Achievable" (ALARA) considerations. 


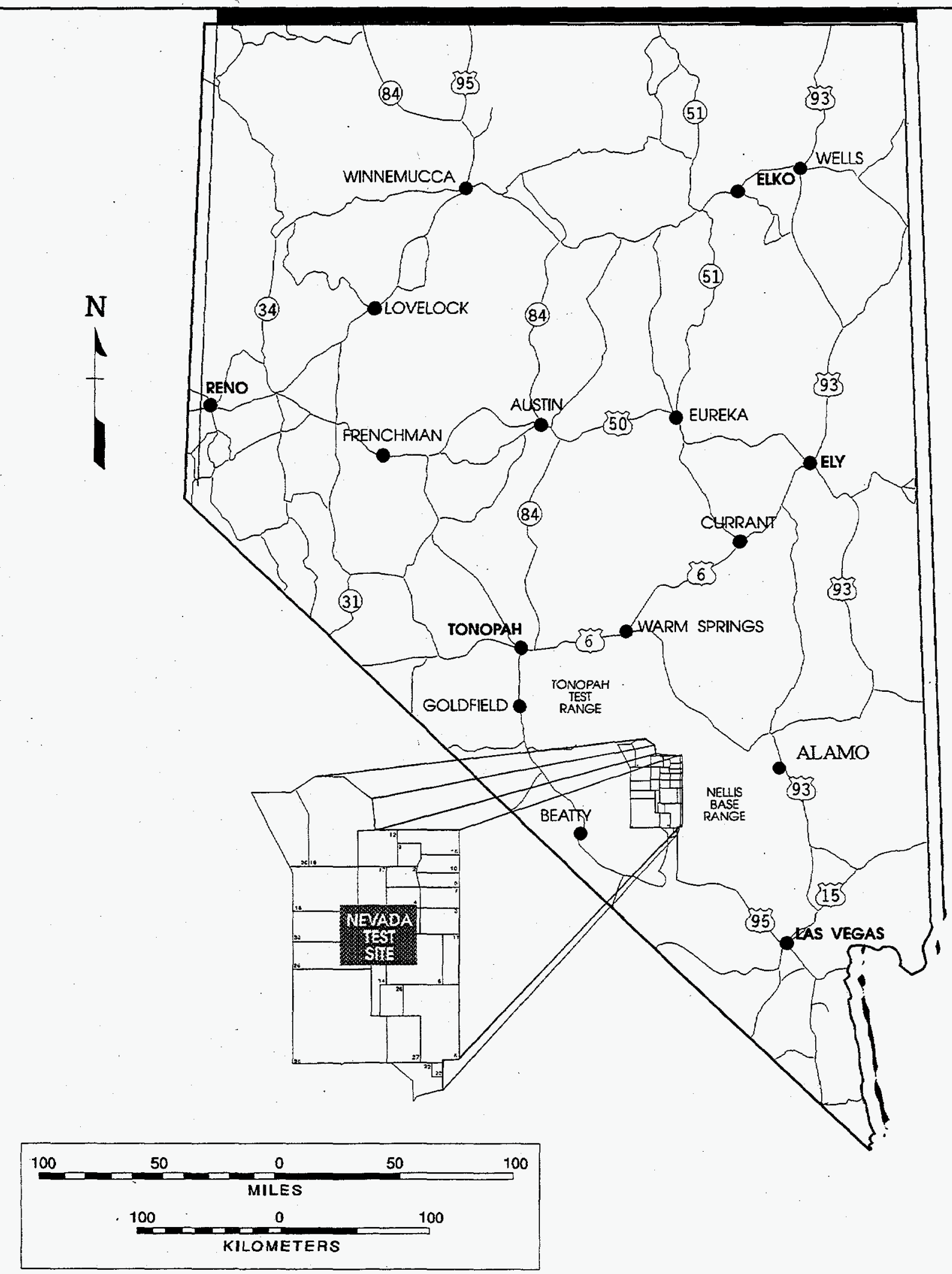

FIGURE O.I: NTS LOCATION 


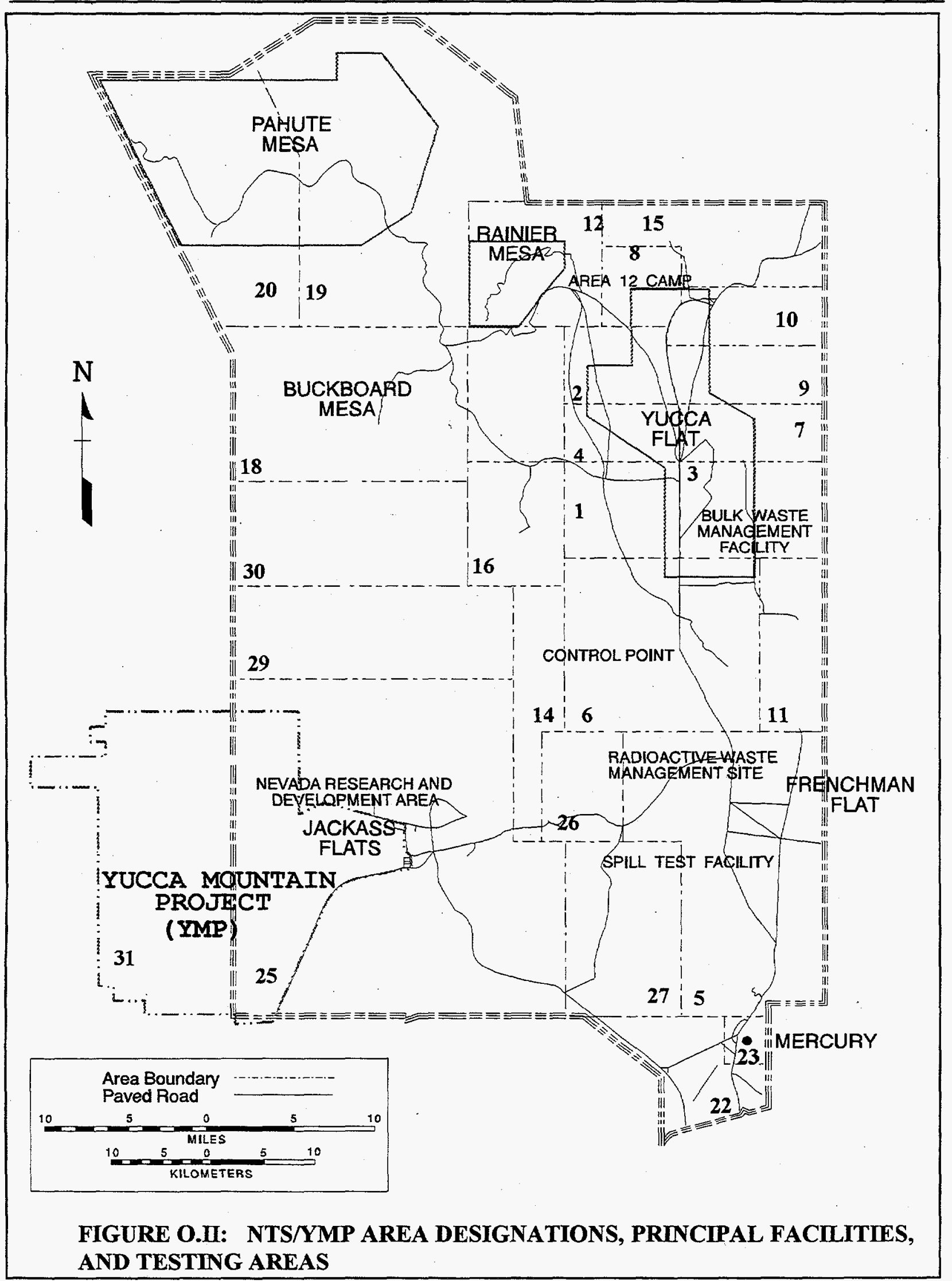




\section{CHAPTER 1 EXCELLENCE IN RADIOLOGICAL CONTROL}

\section{TABLE OF CONTENTS}

Article

Page

PART 1 NV/YMP Radiological Control Manual . . . . . . . . . . . . . . . . . . 1-1

111 Radiological Control Policy . . . . . . . . . . . . . . . . . . 1-1

112 Manual Applicability and Control . . . . . . . . . . . . . . . . . 1-2

113 Compliance . . . . . . . . . . . . . . . . . . . . . . . . 1-3

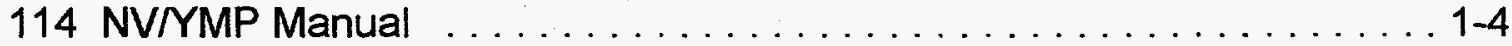

115 [Reserved] . . . . . . . . . . . . . . . . . . . . . . . 1-4

116 User Groups . . . . . . . . . . . . . . . . . . . . . 1-4

PART 2 Leadership in Radiological Control . . . . . . . . . . . . . . . . . . . . . 1-4

121 Senior Management Commitment . . . . . . . . . . . . . . . . . . 1-4

122 Worker Responsibilities . . . . . . . . . . . . . . . . . 1-5

123 [Reserved] . . . . . . . . . . . . . . . . . . . . . . . . . 1-7

124 [Reserved] . . . . . . . . . . . . . . . . . . . . . . . . . . . 1-7

125 Conduct of Radiological Operations . . . . . . . . . . . . . . 1-7

126 [Reserved] . . . . . . . . . . . . . . . . . . . . . . . . . 1-8

127 [Reserved] . . . . . . . . . . . . . . . . . . . . . . . . . . . 1-8

128 Facility Modifications and Radiological Design Considerations . . . . . 1-8

PART 3 Improving Radiological Performance . . . . . . . . . . . . . . . . . . 1-9

131 Radiological Performance Goals . . . . . . . . . . . . . . . . . . . . . . 1-9

132 Management of Radiological Performance Goals . . . . . . . . . . . . . 1-9

133 [Reserved] . . . . . . . . . . . . . . . . . . . . . . . . . . . 1-10

134 Assessments . . . . . . . . . . . . . . . . . . . . . . 1-10

135 [Reserved] . . . . . . . . . . . . . . . . . . . . . . . . . . . . 1-10

136 [Reserved] . . . . . . . . . . . . . . . . . . . . . . . . . 1-10

137 [Reserved] . . . . . . . . . . . . . . . . . . . . . . . 1-11

138 ALARA Committee . . . . . . . . . . . . . . . . . 1-11

PART 4 Contractor Radiological Control Organization . . . . . . . . . . . . . . 1-12

141 Radiological Control Organization . . . . . . . . . . . . . . . . 1-13

142 Radiological Control Manager Qualifications . . . . . . . . . . . . . . . 1-13

143 Radiological Control Organization Functions and Staffing . . . . . . . 1-13

144 [Reserved] . . . . . . . . . . . . . . . . . . . . . . . . 1-13

145 [Reserved] . . . . . . . . . . . . . . . . . . . . . . . 1-13

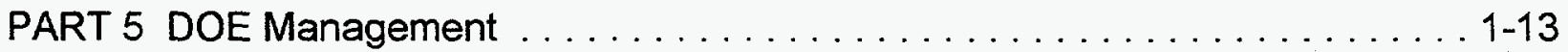


151 [Reserved]

152 [Reserved]

153 [Reserved]

154 [Reserved]

155 [Reserved]

156 DOE Employees in the Workplace

157 Radiation Protection Programs

APPENDIX 1-A

SUGGESTED RADIOLOGICAL PERFORMANCE INDICATORS $1-15$

APPENDIX 1-B

NEVADA TEST SITE (NTS) SITE-WIDE ALARA COMMITTEE (SWAC)

CHARTER

Table 


\title{
PART 1 NV/YMP Radiological Control Manual
}

\section{Radiological Control Policy}

A key element of the Radiation Protection Guidance to the Federal Agencies for Occupational Exposure approved by President Reagan on January 20, 1987, and a fundamental principle underlying this Manual is:

"There should not be any occupational exposure of workers to ionizing radiation without the expectation of an overall benefit from the activity causing the exposure."

NV/YMP organizations are firmly committed to providing a radiological control program that meets the "Best Practices" level of performance. The NV/YMP Radiological Control Policy shown below is intended to guide the actions of every person involved in radiological work throughout NV/YMP facilities.

Table 1-1

\section{NV/YMP RADIOLOGICAL CONTROL POLICY}

\begin{abstract}
ALARA
During routine operations, the combination of design features and administrative control procedures shall provide that: Exposure levels are As Low As Reasonably Achievable (ALARA). Radiation exposure of the work force and public shall be controlled such that radiation exposures are well below regulatory limits and that there is no radiation exposure without commensurate benefit.

\section{OWNERSHIP}

Each person involved in radiological work is expected to demonstrate responsibility and accountability through an informed, disciplined, and cautious attitude toward radiation and radioactivity.

\section{EXCELLENCE}

Excellent performance is evident when radiation exposures are maintained well below regulatory limits, contamination is minimal, radioactivity is well controlled and radiological spills or uncontrolled releases are prevented. Continuing improvement is essential to excellence in radiological control.
\end{abstract}




\section{Manual Applicability and Control}

This Manual establishes practices for the conduct of NV/YMP radiological control activities by the NV/YMP Tenant Organizations (TO[s]). The Manual states NV/YMP's positions and views on the best courses of action currently available in the area of radiological controls. Accordingly, the provisions in this Manual should be viewed by TOs as an acceptable technique, method, or solution for fulfilling their duties and responsibilities.

1. The provisions of this Manual apply to DOE-funded activities performed at NV/YMP sites or facilities where radiation or radioactive material is present or being used. A NV/YMP activity shall be conducted in compliance with a documented Radiological Protection Program (RPP) as approved by the DOE.

2. The provisions of this Manual also apply in those cases where contractors or subcontractors are used to conduct DOE-funded radiological activities at nonDOE sites or facilities, and such organizations do not possess one of the following:
a. A U.S. Nuclear Regulatory Commission (NRC) license
b. An Agreement state license
c. An appropriate state license, registration, or certification with a documented radiation protection program, plan, and procedures which provide a level of protection equivalent to that required by DOE, NRC, or other appropriate federal standards.

In those cases at non-DOE sites or facilities where a specific radiological activity is being conducted pursuant to an NRC or Agreement state license, or appropriate state license, registration, or certification, the provisions of this Manual are not binding to that activity.

3. The provisions of this Manual are not binding upon activities at NV/YMP sites that are mandated by legislation to be performed pursuant to an NRC license including activities certified by the NRC under section 1701 of the Atomic Energy Act. For the purposes of implementing the NV/YMP Radiological Control Programs, which this Manual supports, certain site-specific requirements of DOE/NV/YMP, and this Manual, should be adhered to by certified NRC license holders, specifically those requirements dealing with dosimetry, radioactive source registration and control, radiography, well-logging, and NTS or YMP specific training. See also NTS Standard Operating Procedures (SOPs) 4001, 5402,6401 , and 6405. 
4. This Manual is a living document. The NVMMP TOs Radiological Control (RadCon) Managers intend to review and update provisions on a periodic basis to incorporate lessons learned and suggestions for improvement.

Recommendations to correct or improve this Manual are encouraged and should be sent to the appropriate NV/YMP TO's RadCon Manager. The recommended wording of the change, as well as the basis and justification for the change, shall be included.

5. This Manual shall be kept current and should be entered into each TO's document control system.

\section{Compliance}

1. This Manual sets forth NV/YMP's views on the proper course of action in the area of radiological control within the scope of DOE sponsored activities. If a user fully implements a provision, the user will have complied with, and most likely exceeded, any related statutory, regulatory, or contractual requirement. When incorporated into contracts, the provisions of the Manual are binding requirements. The words "shall" and "should" have the meaning below when a provision is incorporated into a contract.

2. The word "shall" identifies those elements and requirements that have been considered mandatory. If a TO wishes to implement an alternative approach, they shall submit the suggested alternative approach to the NVIMMP RadCon Managers Council for review. The submittal shall contain the description of the alternative approach, the technical rationale and basis, and the suggested wording and justification that the alternative will achieve equal or improved performance employing equal or better techniques, solutions, or methods.

3. The word "should" means the TO has the responsibility of either following the provision or demonstrating technical equivalency by an alternative solution. The use of "should" recognizes that there may be site- or facility-specific attributes that warrant special treatment and that literal compliance with the elements and requirements of the provision may not achieve the desired level of radiological control performance. In those cases where a TO decides to follow an alternative technique, approach, or method in lieu of the "should" provision, the following actions are required:

a. The alternative solution shall be documented, with supporting technical basis, analysis, and justification to demonstrate technical equivalency.

b. Prior to implementation, the approval of the TO RadCon Manager and senior line manager responsible for operations shall be required. 


\section{NV/YMP Manual}

1. This Manual incorporates facility, contractor, and building specific guidance to accommodate unique considerations; and is issued and endorsed by the TO senior site executives (SSEs), i.e. those persons at NV/YMP contractor-operated facilities or sites who have final on-site authority to act for that contractor.

2. Management policies, requirements, expectations, and objectives for the RPP should be clearly and unambiguously stated.

3. Subcontractors shall comply with this Manual.

\section{5 [Reserved]}

\section{User Groups}

1. The NV/YMP RadCon Managers should meet as the NV/YMP RadCon Managers Council at least quarterly to discuss and review issues relevant to radiological control at NVIYMP locations.

2. Periodically, the NV/YMP SSEs should meet jointly as a forum with the RadCon Managers Council to involve top management in status and issues relating to radiological control implementation. The RadCon Managers' Council should coordinate these joint sessions with the SSEs as site conditions warrant.

\section{PART 2 Leadership in Radiological Control}

Constant review and informed interest by senior management is required to achieve a superior Radiological Control Program. Management at all levels should emphasize the need for high standards for radiological control through direct communication, instruction, and inspection of the work space. NV/YMP RadCon professionals should provide technical support to all levels of management to assure excellence in program performance. The TO SSEs should have a basic knowledge of radiation, its effects, radiological control requirements, and should be familiar with their current radiological performance record.

\section{Senior Management Commitment}

1. Senior managers should state in writing their firm commitment to a Radiological Control Program of the highest quality. Management commitment and support are demonstrated by allocating sufficient resources including personnel and providing for training to ensure workers are qualified for their assigned duties. 
2. Managers should ensure that orientation, training, and indoctrination reinforce rules and guidelines for each worker to minimize radiation exposure and control radiological conditions.

3. Managers should hold workers and their supervisors accountable for radiological control performance.

4. Senior managers should adopt and promote a positive attitude toward radiological safety.

5. A performance indicator program for measuring and trending the effectiveness of the Radiological Control Program against predetermined goals should be established and maintained. The performance indicator program should be commensurate with the potential for radioactive material contamination and dose.

\section{Worker Responsibilities}

It is the responsibility of line management to ensure that each worker understands that proper radiological control is an integral part of his or her daily duties. Trained personnel should recognize that their actions directly affect contamination control, personnel radiation exposure, and the overall radiological environment associated with their work. The following radiological control rules are applicable to each person in the workplace. A poster that displays the worker responsibilities listed below should be produced and displayed at appropriate access points and work areas.

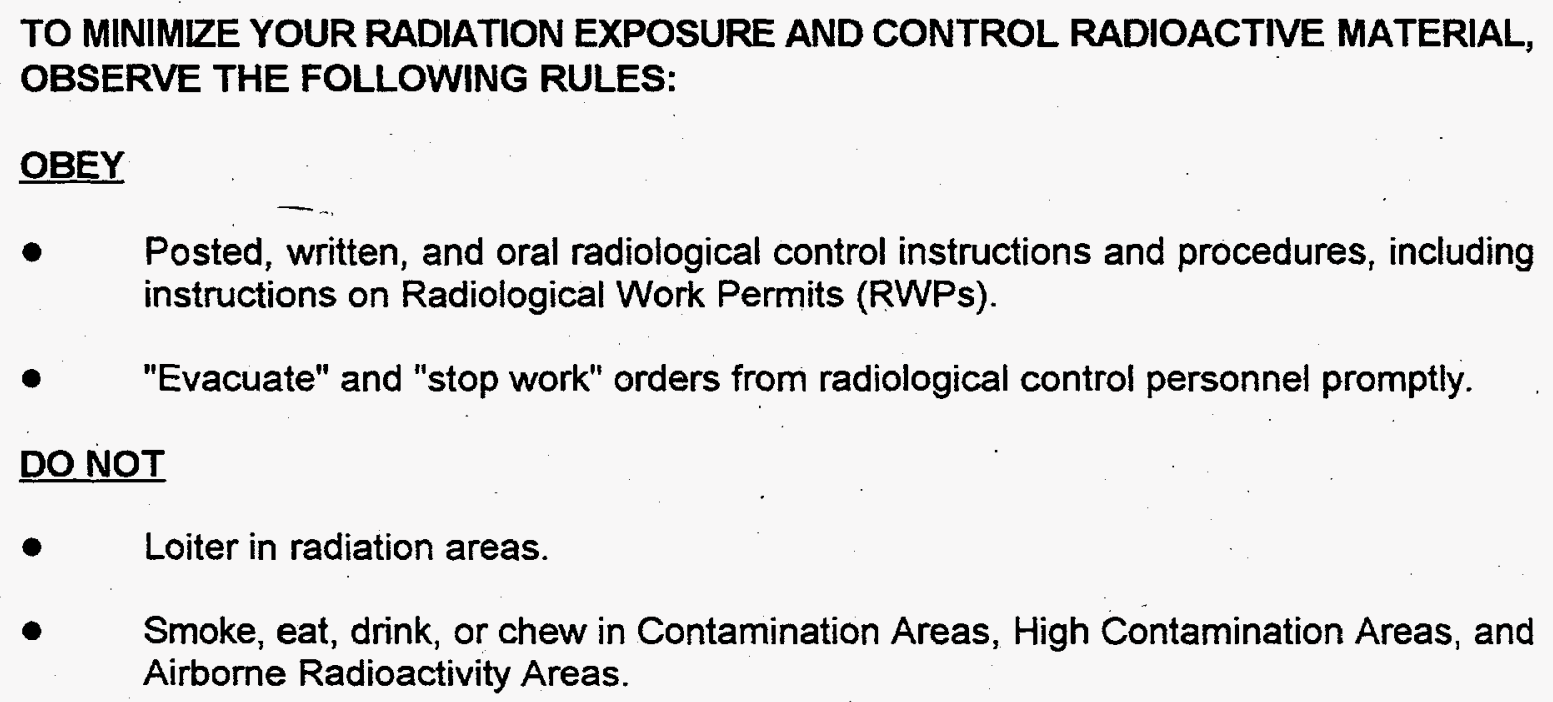

- Smoke, eat, drink, or chew in Contamination Areas, High Contamination Areas, and Airborne Radioactivity Areas. 


\section{BE SURE TO}

- Wear personnel monitoring devices where required by RWPs, signs, procedures, or by radiological control personnel. Report immediately the loss, damage, or unexpected exposure of personnel monitoring devices or off-scale readings of selfreading dosimeters to the responsible Radiological Control Organization.

\section{BE SURE TO (continued)}

- Keep track of your radiation exposure status and avoid exceeding radiological Administrative Control Levels.

- Wear Personal Protective Equipment (PPE) and Protective Clothing (PC) properly whenever required by RWPs or postings.

- Minimize the spread of potential radioactive spills and promptly notify the appropriate personnel of all spills.

- Avoid contact of skin, clothing, and equipment with contaminated surfaces.

- Place contaminated tools, equipment, and solid waste items on disposable surfaces, such as plastic sheets, when not in use.

- Notify radiological control personnel of alarming or faulty radiological control equipment.

- Notify radiological control personnel of off-site occupational radiation exposures so that worker dosimetry records can be updated.

\section{PRIOR TO ENTERING AREA}

- Assure that you are mentally alert and in physically sound condition.

- Limit the amount of material taken into contaminated areas to minimize radioactive waste and future decontamination.

- Have necessary materials and equipment on hand to complete your task, thereby minimizing time and exposure.

- Notify radiological control personnel of the presence of open wounds, sores, or rashes before entering an area where contamination exists and exit immediately if a wound occurs while in such an area.

\section{UPON LEAVING AREA}

- Properly remove PPE and PC to minimize the spread of contamination.

Frisk or be frisked for contamination when entering an uncontaminated area after exiting posted Contamination, High Contamination, or Airborne Radioactivity Areas and notify radiological control personnel when contamination is found. 


\section{3 [Reserved]}

\section{4 [Reserved]}

\section{Conduct of Radiological Operations}

1. This Manual is consistent with the guidance in DOE 5480.19, "Conduct of Operations Requirements for DOE Facilities." The concepts of all chapters of DOE 5480.19 apply to the conduct of radiological control.

2. Managers at all levels are expected to be involved in the planning, scheduling, and conduct of radiological work. Assuring adequate radiological safety should not be compromised to achieve production, remediation, or research objectives.

3. Supervisors should be technically knowledgeable and should ask questions of the work force concerning radiological work details to verify worker comprehension.

4. Line managers should periodically monitor work areas to observe personnel at work and to identify radiological deficiencies and concerns. Frequent inspections and walk-throughs, including off-hours and weekends (where appropriate), are essential to reinforce management expectations to the work force.

5. Managers, supervisors, and workers should be involved in developing accurate, clear, written procedures for performing radiological work. If during the use of procedures a written requirement cannot be responsibly followed, the work should be stopped and guidance obtained.

6. Supervisors and managers should encourage the work force to identify radiological control deficiencies and concerns. Prompt action should be taken to address and eliminate identified issues and prevent recurrence. Retraining, indoctrination, and procedure review are useful in addressing these issues.

7. Managers and supervisors should establish working conditions that encourage improved radiological control. This includes temperature, humidity, and lighting as well as the more difficult considerations of accessibility. Work conditions should be considered in planning work.

8. Subcontractors and subcontracted employees should be treated the same as facility staff in the area of radiological matters, should have comparable training, and shall meet the same requirements and expectations. 
9. Conditions that could cause or promote the spread of contamination should be identified and corrected on a priority basis.

\section{6 [Reserved]}

\section{7 [Reserved]}

\section{Facility Modifications and Radiological Design Considerations}

1. Radiological control performance is affected by human performance and engineered design features. This Manual primarily addresses the way people operate and use existing facilities and sites. General design criteria for new facilities and major modifications to existing facilities are contained in 10 CFR 835 and DOE 6430.1A. In addition, the following radiological control design criteria are provided for new facilities and major modifications to existing facilities:
a. Individual worker dose shall be ALARA, should be less than 500 mrem per year, and shall not exceed 20 percent of the applicable standards found in 10 CFR 835.202.
b. Components should be selected to minimize the buildup of radioactivity.
c. Controlling contamination should be achieved by containing radioactive material.
d. Efficiency of maintenance, decontamination, operations, and decommissioning shall be maximized.
e. Support facilities should be provided for donning and removal of protective clothing and for personnel monitoring, when required.

2. Facilities currently under construction should be evaluated and the above criteria applied where practicable.

3. Facility designs that have office space within Radiation Areas, Contamination and High Contamination Areas, Airborne Radioactivity Areas, and Radioactive Material Areas (RMAs) require priority attention. Requirements are:
a. Locating lunch rooms or eating areas, restrooms, drinking fountains, showers (other than emergency showers), and similar facilities is prohibited within these areas.
b. Locating office spaces within these areas is strongly discouraged; to the extent that such space is essential to support radiological work, steps should be taken to preclude unnecessary occupancy.




\section{PART 3 Improving Radiological Performance}

\section{Radiological Performance Goals}

Goals are intended as a measure of and a motivation for improvement. These indicators should be used as tools to assist management in focusing their priorities and attention. The following are examples of goals that may be appropriate:

1. Collective Dose (person-rem): This goal should be based upon planned activities and historical performance. For those areas that have neutron radiation, a goal for collective neutron dose should also be established.

2. Skin and Personal Clothing Contamination Occurrences (number): Personnel contaminations may indicate a breakdown of controls intended to prevent the spread of contamination.

3. Intakes of Radioactive Material (number): Personnel intakes of radioactive material should be minimized and management should focus attention on any failure of the controls that results in intakes.

4. Contaminated Area Within Buildings (square feet): Operating with a smaller contaminated area results in less radioactive waste, fewer personnel contaminations, and improved productivity. Reducing existing contaminated areas needs to be balanced by the recognition that this generates radioactive waste. Goals for both should be correlated.

5. Radioactive Waste (cubic feet): Minimizing the generation of radioactive waste reduces the environmental impact of NV/YMP operations, helps reduce personnel exposure, and reduces costs associated with handling, packaging, and disposal.

6. Liquid and Airborne Radioactivity Released (curies): Minimizing effluent reduces the environmental impact of NV/YMP operations and reduces the costs associated with remediation.

\section{Management of Radiological Performance Goals}

1. Each TO SSE should establish, approve, and maintain a radiological performance goals program.

2. The performance goals should be measurable, achievable, auditable, challenging, and meaningful in promoting improvement. 
3. Goals need to be developed primarily by those responsible for performing the work.

4. Radiological performance goals should be reviewed at least annually and revised as appropriate. Normally, more stringent goals should be set annually to reflect the improved radiological performance at the facility. Occasionally, a goal may be made less stringent to accommodate changes in work load or mission.

\section{3 [Reserved]}

\section{Assessments}

Assessment, as used in this Manual, refers to the process of providing independent feedback to senior line managers to indicate the adequacy of the Radiological Control Program.

1. Inspections, audits, reviews, investigations, and self-assessments are part of the numerous checks and balances needed in a good RadCon Program. Internal audits of the RadCon Program shall be conducted such that over a 3-year period, all functional elements are assessed for program performance, applicability, content, and implementation. These should be performed by the Radiological Control Organization (RCO), the Quality Assurance Organization, and other organizations.

2. Results of assessments should be incorporated into the ongoing process of improving radiological control.

3. Managers should encourage the positive view that identifying even minor deficiencies represents an opportunity for further improvement. A prioritization system to implement actions for resolving the deficiencies should be implemented.

4. In developing corrective actions for assessment activities, managers should address basic underlying reasons for the identified deficiencies or concerns, not just the specific symptoms identified by the reviewer.

5. Feedback on findings from assessments, root-cause analysis; status of corrective actions, and adherence to action plan schedules should be frequently provided to management.

\section{5 [Reserved]}

136 [Reserved] 


\section{7 [Reserved]}

\section{ALARA Committee}

Elements of a successful ALARA program include management commitment, ALARA training for employees/workers, administrative control levels for control of radiation exposure to workers, ALARA goals/radiological performance goals, ALARA design review where applicable, ALARA job/experiment planning review, and records of these ALARA program elements. The NTS TOs are committed to conduct their operations in a manner that protects the safety and health of their employees and the public, minimizes damage or loss to government and company-owned property, and protects the environment. These organizations are further committed to ensure that potential safety and health risks, such as exposure to ionizing radiation, are reduced to ALARA.

A NVMMP Site-Wide ALARA Committee (SWAC) has been established, and provides oversight of ALARA activities at the NTS. It is an independent, multi-organizational group that reviews performance and advises NTS TOs on improving progress toward minimizing radiation exposure and radiological releases. The SWAC Charter outlines the Committee's staffing, responsibilities, and functions. The SWAC Charter (Appendix $1-B)$ results from the well-recognized practice in the scientific and radiation protection community of avoiding unnecessary exposure to ionizing radiation. It is the responsibility of the RadCon Managers Council to convene the SWAC when appropriate.

TOs may establish and form their own ALARA Committees to address specific projects; a TO Committee Charter may be in the form of a written Company ALARA Policy or Procedure. The membership should include managers, workers from the line, the technical support organization, and the RCO. It is more effective if a line manager serves as the Chair. This Committee may be part of a general safety or radiation safety committee whose functions include ALARA activities.

The ALARA Committee should make recommendations to management to improve progress toward minimizing radiation exposure and radiological releases. The Committee should evaluate items such as construction and design of facilities and systems, planned major modifications or work activities, as well as experimental test plans for exposure, waste, and release minimization. The Committee should also receive, as a minimum, the results of all reviews and audits, both internal and external, and should review the overall conduct of the RadCon Program.

In addition to the NTS Contractor's SWAC, some individual NTS contractors have elected to form organizational ALARA Committees. 


\section{PART 4 Contractor Radiological Control Organization}

NV/YMP TOs maintain distinct organizations which exercise technical and programmatic control over their specific purview of radiological authority or interest. These administrative organizations are referred to in this Manual as RCOs. The TOs which have dedicated RCOs operating at the NTS and YMP are: Bechtel Nevada (BN), currently serving as the Radiological Safety Prime Contractor (RSPC); Los Alamos National Laboratory (LANL); Lawrence Livermore National Laboratory (LLNL); Defense Special Weapons Agency (DSWA); Sandia National Laboratory (SNL); IT Corporation (IT); Desert Research Institute, University Community College System of Nevada (DRI); Wackenhut Services Incorporated (WSI); Civilian Radioactive Waste Management System/Management and Operating Contractor/Yucca Mountain Project (CRWMS/M\&O/YMP); U.S. Environmental Protection Agency (EPA); and U.S. Geological Survey (USGS). TOs not exercising their option to form an RCO shall comply with all applicable requirements of this Manual.

\section{Radiological Control Organization}

1. An RCO should be established to provide relevant support to line managers and workers. To effectively function, the RCO should be independent of the line organizational elements responsible for production, operation or research activities, and should have an equivalent reporting level. A single, dedicated $\mathrm{RCO}$ for radiological coordination of an activity, facility, or location is sufficient. The senior line manager responsible for operations at a facility should have assigned radiological control personnel dedicated to the facility.

2. Radiological control personnel shall monitor adherence to this Manual and be available to the facility line manager for radiological support to the work force. To effectively function in this capacity, they should receive their day-to-day priorities from facility managers. To ensure independence in making correct radiological decisions, the RCO should be accountable to the RadCon Manager.

3. Each RCO is managed by a designated RadCon Manager under the authority of the TO's SSE. Each SSE and RadCon Manager has radiological safety coordination responsibility, as directed in NTS SOP 6405, for each project under their control, and should be responsible for following the requirements of this Manual.

4. To ensure site-wide consistency of radiological control, NV/YMP TOs have agreed to matrixed support for RadCon services from the NTS or YMP RSPC, as requested. The RSPC should maintain a sufficient staff of site-trained Radiological Control Personnel to accommodate the needs of the TOs at the site. 


\section{Radiological Control Manager Qualifications}

1. The RadCon Managers should be experienced professionals in radiological control and be familiar with the design features and operations of the facility that affect the potential for exposures of persons to radiation.

2. The RadCon Managers should have the technical competence and experience to establish radiological control programs and the supervisory capability to direct the implementation and maintenance of radiological control programs.

3. The RadCon Managers should have a minimum of a bachelor's degree or the equivalent in science or engineering, including some formal training in radiological control. Advanced academic degrees can count as experience where course work related to radiological control is involved. At least three years of professional experience should be in applied radiological control work. Certification by the American Board of Health Physics provides equivalency to the above.

\section{Radiological Control Organization Functions and Staffing}

1. The senior staff of the RCO should include health physicists and other professionals with four-year degrees in science or engineering. A continuing training program for these personnel should be established. Pursuit of certification by the American Board of Health Physics for senior and professional staff members is encouraged.

2. Radiological support personnel provide health physics and radiological engineering, dosimetry, bioassay, independent oversight, and instrumentation and calibration functions. These personnel should have technical qualifications pertinent to their assigned duties.

\section{4 [Reserved]}

\section{5 [Reserved]}

\section{PART 5 DOE Management}

\section{1 [Reserved]}

152 [Reserved]

153 [Reserved] 


\section{4 [Reserved]}

\section{5 [Reserved]}

\section{DOE Employees in the Workplace}

DOE employees at NVIYMP sites or facilities are subject to, and shall adhere to the provisions of this Manual.

\section{Radiation Protection Programs}

1. Each NV/YMP TO shall submit an RPP to DOE which describes radiological work activities and radiological protection measures within the scope of its program. The content of each RPP shall be commensurate with the nature of the activities performed and shall include formal plans and measures for applying the ALARA process to occupational exposure. The RPP shall specify the existing and/or anticipated operational tasks that are intended to be within the scope of the RPP.

2. The content of the RPP shall address, but shall not necessarily be limited to, each requirement in $10 \mathrm{CFR} 835$. The RPP shall include plans, schedules, and other measures for achieving compliance with the regulations within $10 \mathrm{CFR}$ 835.

3. An update of the RPP shall be submitted to DOE whenever a change or addition to the RPP is made, and prior to the initiation of a task not within the scope of the RPP. An update of the RPP shall be submitted to DOE within 180 days of the effective date of any modification to 10 CFR 835 . Changes, additions, or updates to the RPP may become effective without prior DOE approval only if the changes do not decrease the effectiveness of the RPP, and the RPP, as changed, continues to meet the requirements of 10 CFR 835 . Proposed changes that decrease the effectiveness of the RPP shall not be implemented without submittal to and subsequent approval by DOE. An initial RPP or an update shall be considered approved 180 days after its submission unless rejected by DOE at an earlier date.

4. Except as provided in Article 157.3, any task outside the scope of an RPP shall not be initiated until an update of the RPP is approved by DOE. 


\begin{tabular}{lr}
\hline NV/YMP Radiological Control Manual, Rev. 2: & November 13, 1996 \\
EXCELLENCE IN RADIOLOGICAL CONTROL & CHAPTER 1 \\
\hline
\end{tabular}

APPENDIX 1-A

SUGGESTED RADIOLOGICAL PERFORMANCE INDICATORS

\begin{tabular}{|c|c|}
\hline \multicolumn{2}{|c|}{ Exposure control } \\
\hline a & Collective dose in person-rem \\
\hline & Average worker dose in rem \\
\hline & Maximum dose to a worker in rem \\
\hline & $\begin{array}{l}\text { Number of unplanned exposures resulting in doses greater than the } \\
\text { facility Administrative Control Level }\end{array}$ \\
\hline e & $\begin{array}{l}\text { Number of dose assessments for lost or damaged dosimeters } \\
\text { Maximum neutron dose to a worker in rem }\end{array}$ \\
\hline \multicolumn{2}{|c|}{ Personnel contamination } \\
\hline & Number of skin and personal clothing contaminations \\
\hline & Number of contaminated wounds \\
\hline & Number of facial contaminations \\
\hline \multicolumn{2}{|c|}{ Control of internal exposure } \\
\hline & Number of new confirmed depositions \\
\hline & Number of airborne events \\
\hline & Number of alarms on airborne monitors (actual and false) \\
\hline & Number of Airborne Radioactivity Areas \\
\hline$\underline{e}$ & Area of Airborne Radioactivity Areas in square feet \\
\hline \multicolumn{2}{|c|}{ Control of contaminated areas in operational areas } \\
\hline & Number of Contamination and High Contamination Areas \\
\hline & Area of Contamination Areas in square feet \\
\hline & Area of High Contamination Areas in square feet \\
\hline \multirow{2}{*}{\multicolumn{2}{|c|}{ Minimization of radioactive waste }} \\
\hline & \\
\hline & $\begin{array}{l}\text { Volume and activity of radioactive waste in cubic feet and curies, } \\
\text { respectively }\end{array}$ \\
\hline & $\begin{array}{l}\text { Number of cubic feet not subject to volume reduction by incineration, } \\
\text { compaction, or other means }\end{array}$ \\
\hline \multicolumn{2}{|c|}{ Control of radioactive discharges } \\
\hline b & $\begin{array}{l}\text { Activity of liquid radioactivity discharges in curies } \\
\text { Activity of airborne radioactivity discharges in curies }\end{array}$ \\
\hline
\end{tabular}




\section{APPENDIX 1-B}

\section{NEVADA TEST SITE (NTS) SITE-WIDE ALARA COMMITTEE (SWAC) CHARTER}

The ALARA concept is an approach to radiation protection to control or manage exposures (both individual and collective) to the work force and the general public to as low a level as social, technical, economic, practical, and public policy considerations permit. The ALARA concept also applies to the environment which establishes control and management of releases of radioactive material and radiation exposures of members of the public to radiation at levels ALARA. Reducing radiation exposures to levels that are ALARA has long been the goal at the NTS. It is the policy of the NTS TOs, contractors, sub-contractors, and users to conduct their operations, tests and test support, laboratory services, and research in a manner to protect the health and safety of employees, visitors, and members of the public. We are committed, in all of our activities, to reduce any safety or health risks associated with radioactive materials and ionizing radiation to levels that are ALARA. The following principles form the core fundamentals of the ALARA Program at the NTS:

- Radiological and other safety design considerations will be applied to the design and modification of facilities to reduce exposure to individuals and releases to the environment.

- Radiological controls will be carried out during operations, testing, maintenance, research, and other support activities to minimize exposures and releases to the environment.

- Monitoring of radioactive material and radiation (personnel and environmental), together with measurements of worker radiation dose, will be performed to verify and document that doses are being maintained ALARA.

It is recognized that each user organization at the NTS has needs specific and critical to its programs. Therefore, no single set of criteria can be prescribed for achieving all ALARA goals at the NTS. However, each user organization will present annual ALARA goals for their organization to the SWAC, if they vary from the goals listed in the NV/YMP Radiological Control Manual. It is the policy of each user organization at the NTS that those significant radiological operations conducted jointly by several contractors will benefit from peer review toward the ALARA goal of improving radiation safety and minimizing radiation exposure and releases to the environment. The organization that has radiological coordination of a project or facility has the responsibility to make a presentation to the NTS SWAC for review and shall abide by the guidance provided by the Committee. 
The NTS SWAC consists of representatives from, but not limited to, the following TOs:

- $\quad$ Bechtel Nevada (BN)

- Defense Special Weapons Agency (DSWA)

- Desert Research Institute, University Community College System of Nevada (DRI)

- $\quad$ IT Corporation (IT)

- $\quad$ Lawrence Livermore National Laboratory (LLNL)

- Los Alamos National Laboratory (LANL)

- $\quad$ Sandia National Laboratory (SNL)

- $\quad$ United States Geological Survey (USGS)

- Wackenhut Services, Incorporated (WSI)

- Yucca Mountain Project (YMP)

Members of the NTS SWAC are appointed by and report to the SSEs on matters pertaining to the NTS radiological control program. Membership includes senior line managers, senior representatives from technical support functions, and radiological control personnel. Representatives (members of the SWAC) are assigned coordination responsibilities to implement the policy of this ALARA Committee. The responsibilities are as follows:

- Review prospective radiological operations common to several contractors, critique the radiation safety of the operation, and establish worker dose levels and goals for the operation.

- Act as a review and advisory group whose primary functions are to review ALARA related topics (e.g., Radiological Work Permits, designs, plans, training, operations, summary data, and procedures) and major sources of radiation exposure with the intent of identifying means for their reduction and trending.

- Establish methods and guidelines for NTS organizations to improve progress toward minimizing radiation exposure to personnel and radiological releases to the environment.

- Establish and review the effectiveness of administrative radiological control levels and goals. Annually publish these goals in the SWAC minutes (e.g., radiological performance goals listed in Article 131 of the NV/YMP Radiological Control Manual are the minimum number of goals that the SWAC will address each year).

- Ensure goals are integrated into operations and mission objectives.

- $\quad$ Conduct meetings of the SWAC at least semi-annually; ensuring that minutes include actions taken, issues discussed, and resolutions. 
- The chairman of the SWAC shall be one of the designated representatives (elected by the Committee), and the chairmanship shall rotate annually throughout the TOs, contractors, and user organizations.

The ALARA process is applied to occupational exposure to personnel and radiological releases to the environment through implementation of the following subparts and subsections of 10 CFR 834 and 10 CFR 835 :

1. 834.2 Definitions.

2. 834.104 ALARA Considerations.

3. 834.201 Airborne Emissions of Radionuclides.

4. $835.101 \quad$ Radiation Protection Programs.

5. 835.102 Internal Audits.

6. 835.2 Definitions.

7. $\quad 835.202$ Occupational Exposure Limits for General Employees.

8. $835.204 \quad$ Planned Special Exposures.

9. $\quad 835.400 \quad$ Subpart F - Entry Control Program.

10. 835.704 Administrative Records.

11. $835.900 \quad$ Subpart J - Radiation Safety Training.

12. 835.1001 Design and Control.

13. 835.1002 Facility Design and Modification.

14. 835.1003 Control Procedures. 


\section{CHAPTER 2 RADIOLOGICAL STANDARDS}

\section{TABLE OF CONTENTS}

Article

Page

PART 1 Administrative Control Levels and Dose Limits . . . . . . . . . . . . . . . 2 2-1

211 Administrative Control Level . . . . . . . . . . . . . . . . . . . . 2-1

212 Lifetime Control Level . . . . . . . . . . . . . . . . . . 2-1

213 Radiological Worker Dose Limits . . . . . . . . . . . . . . . . . . . . 2-1

214 Visitor Dose Limit . . . . . . . . . . . . . . . . . . . . . . . . . . 2-5

215 Embryo/Fetus Dose Limits . . . . . . . . . . . . . . . . . . . . 2-5

216 Special Control Levels . . . . . . . . . . . . . . . . . . . . . . . 2-6

PART 2 Contamination Control and Control Levels . . . . . . . . . . . . . . . . . . 2-7

221 Personnel Contamination Control . . . . . . . . . . . . . . . 2-7

222 Contamination Control Levels . . . . . . . . . . . . . . . . . . . . . . . 2-8

223 Airborne Radioactivity Control Levels . . . . . . . . . . . . . . . 2-12

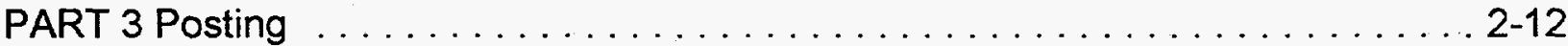

231 Posting Requirements ... . . . . . . . . . . . . . . . . . . . 2-12

232 Posting Controlled Areas . . . . . . . . . . . . . . . . . . . . . 2-14

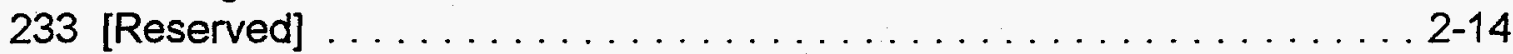

234 Posting Radiation Areas ... . . . . . . . . . . . . . . . . . . . . . . 2-14

235 Posting Contamination, High Contamination, and Airborne

Radioactivity Areas .......................... 2-16

236 Posting Radioactive Material Areas (RMAs) . . . . . . . . . . 2-17

237 Posting Underground Radioactive Material Areas . . . . . . . . . . . 2-18

APPENDIX 2A - GUIDELINES FOR CONTROL OF EMERGENCY EXPOSURES . 2-19

APPENDIX 2B - WEIGHTING FACTORS FOR ORGANS AND TISSUES . . . . . 2-20

APPENDIX 2C - NON-UNIFORM EXPOSURE OF THE SKIN . . . . . . . . 2-21

\section{Tables}

2-1 Summary of Dose Limits . . . . . . . . . . . . . . . . . . . . . . . 2-4

2-2 Summary of Surface Radioactivity Values . . . . . . . . . . . . . . . . . 2-11

2-3 Criteria for Posting Radiation Areas . . . . . . . . . . . . . . . . . . . 2 2-16

2-4 Criteria for Posting Contamination, High Contamination, and Airborne Radioactivity Areas . . . . . . . . . . . . . . . . . . . . . . . . . . . 2 2-17

2A-1 Guidelines for Control of Emergency Exposures . . . . . . . . . . . . . . . . . 2-19 
NV/YMP Radiological Control Manual, Rev. 2:

November 13, 1996

RADIOLOGICAL STANDARDS

CHAPTER 2

2B-1 Weighting Factors for Organs and Tissues . . . . . . . . . . . . . . . 2-20

2C-1 Non-Uniform Exposure of the Skin

$2-21$ 


\section{PART 1 Administrative Control Levels and Dose Limits}

\section{Administrative Control Level}

1. An annual facility Administrative Control Level shall be established by each contractor SSE based upon an evaluation of historical and projected radiation exposures, work load, and mission.

2. NVMMP SSEs have established the annual NVMMP facilities Administrative Control Level at 500 mrem. This control level should be reevaluated annually.

3. No person shall be allowed to exceed the facility Administrative Control Level without the prior approval of the TO SSE.

\section{Lifetime Control Level}

1. To administratively control a worker's lifetime occupational dose, a Lifetime Control Level of $\mathrm{N}$ rem shall be established where $\mathrm{N}$ is the age of the person in years. Special Control Levels (Article 216) shall be established for personnel who have doses exceeding $\mathrm{N}$ rem.

2. The internal contribution to lifetime occupational dose from intakes prior to January 1, 1989 should be calculated in terms of either cumulative annual effective dose equivalent or committed effective dose equivalent (CEDE). The internal contribution to lifetime occupational dose should continue to be reassessed as further bioassay results and improved methods for assessing internal dose become available.

\section{Radiological Worker Dose Limits}

1. Dose limits are provided in Table 2-1 and shall not be exceeded. Deep dose equivalent to the whole body may be used as the effective dose equivalent for external exposures. The total effective dose equivalent (TEDE) during a year shall be determined by summing the effective dose equivalent from external exposures and the CEDE from intakes during the year, and shall be used when demonstrating compliance with Table 2-1 dose limits. All occupational exposure received during the current year shall be included when demonstrating. compliance with 10 CFR 835.202(a) [Table 2-1 dose limits].

2. Radiological workers from other DOE or DOE contractor facilities may receive occupational exposure as a radiological worker if they:

a. Provide record of current Radiological Worker I or II (RW-I or RW-II) standardized core training. 
b. Receive site-specific RW-I or RW-II training at the facilities where they will be working.

c. Provide their radiation dose records for previous years and written estimates, signed by the individual, for the current year.

3. Proposed use of the Planned Special Exposure as specified in $10 \mathrm{CFR} 835$ shall be applied only in extraordinary situations and when the following requirements have been met:

a. The proposed activity has been reviewed by the RadCon Manager and submitted by the SSE to the lead Secretarial Officer for approval.

b. The proposed activity has been jointly approved by the Secretarial Officer and the Assistant Secretary for Environment, Safety, and Health. A description and justification for any planned special exposure should be provided to DOE/NV Safety and Health Division (SHD). This should include the reason for the exposure, a description of the situation that requires the exposure, personnel involved, estimated doses to be received, alternatives that were considered, and reasoning for the rejection of said alternatives.

c. Personnel dosimetry requirements as stated in 10 CFR 835.204(b-d) are complied with.

d. Prior to a planned special exposure, written consent shall be obtained from each individual involved. Each individual shall be:

(1) Informed of the purpose of the planned operations and procedures to be used.

(2) Informed of the estimated doses and associated potential risks and specific radiological conditions and other hazards which might be involved in performing the task.

(3) Instructed in the measures to be taken to keep the dose ALARA considering other risks that may be present.

e. Records of the conduct of a planned special exposure shall be maintained and a written report submitted within 30 days after the planned special exposure to the approving organizations identified in 10 CFR $835.204(a)(3)$.

4. Emergency exposure limits are not Planned Special Exposure limits. Guidelines for emergency exposures are provided in Appendix 2A. For compliance with 10 CFR 835.1302, in emergency exposure situations, the following must apply:

a. The risk of injury to those individuals involved in rescue and recovery operations shall be minimized. 
b. Operating management shall weigh actual and potential risks to rescue and recover individuals against the benefits to be gained.

c. Rescue action that might involve substantial personal risk shall be performed by volunteers.

d. The dose limits for individuals performing these operations are listed in 10 CFR 835.1302 table. NOTE: Same as Table 2A-1 in this manual.

e. Each individual selected shall be trained in accordance with $10 \mathrm{CFR}$ 835.902 and briefed beforehand of the known or anticipated hazards to which the individual will be subjected.

5. The radiological worker dose limits provided in Table 2-1 also apply to general employees. However, general employees who have not completed RW-I or RWII training are not permitted unescorted access to any area in which they are expected to receive doses in excess of 100 mrem in one year. General employees who have not received RW-I or RW-II training are not normally expected to exceed $100 \mathrm{mrem}$ in a year.

6. A general employee whose occupational exposure has exceeded any of the limits specified in Table 2-1 or Appendix $2 \mathrm{C}$, Table $2 \mathrm{C}-1$ may be permitted to return to work in radiological areas during the current year providing that all of the following conditions are met:
a. Approval is first obtained from the TO SSE and the DOE/NVMMP Manager.
b. The individual receives counseling from radiological protection and medical personnel regarding the consequences of receiving additional occupational exposure during the year.
c. The affected employee agrees to return to radiological work. 


\section{Table 2-1 Summary of Dose Limits}

Exposures shall be well below the limits in this table and maintained ALARA. The Administrative Control Levels for limiting exposure are described in Article 211.

\begin{tabular}{|ll|c||}
\hline \multicolumn{2}{|c|}{ TYPE OF EXPOSURE } & $\begin{array}{c}\text { ANNUAL } \\
\text { LIMIT }\end{array}$ \\
\hline \hline Radiological Workert: $\quad$ Whole Body (internal + external) & 5 rem \\
\hline Radiological Workert: $\quad$ Lens of Eye & 15 rem \\
\hline Radiological Workert: $\quad \begin{array}{l}\text { Extremity (hands and arms below the } \\
\text { elbow; feet, and legs below the knees) }\end{array}$ & 50 rem \\
\hline Radiological Workert: $\quad \begin{array}{l}\text { Any organ or tissue (other than lens of } \\
\text { eye) and skin }\end{array}$ & 50 rem \\
\hline Declared Pregnant Worker: Embryo/Fetus & $\begin{array}{c}0.5 \text { rem } \\
\text { per gestation } \\
\text { period }\end{array}$ \\
\hline $\begin{array}{l}\text { Minors and Students: } \\
\text { (under age 18) }\end{array}$ & $\begin{array}{l}\text { Whole Body (internal + external) } \\
0.1 \text { rem }\end{array}$ \\
\hline Visitors $\neq$ and Public: & Whole Body (internal + external) & 0.1 rem \\
\hline
\end{tabular}

$\dagger \quad$ Radiological Workers are General Employees authorized unescorted access to radiological areas per Articles 334 and 335.

$\ddagger \quad$ Applies to visitors who have not completed training in accordance with Articles 632 or 633 or have not met the special considerations of Article 657.

\section{Table 2-1 Notes:}

1. Internal dose to the whole body shall be calculated as a CEDE. The CEDE is the resulting dose committed to the whole body from internally deposited radionuclides over a 50-year period after intake. See Appendix 2-B for the weighting factors to be used in converting organ dose equivalent to effective dose equivalent for the whole body.

- It is the NV/YMP policy that internal dose calculations should utilize methods and models endorsed by national and international standards organizations such as the National Council on Radiation Protection and 
Measurements (NCRP), the International Commission on Radiation Protection (ICRP), and the Medical Internal Radiation Dose technique (MIRD) developed by the Society of Nuclear Medicine, etc.

2. The annual limit of exposure to "any organ or tissue" is based on the committed dose to that organ or tissue resulting from internally deposited radionuclides over a 50-year period after intake plus any external effective dose equivalent to that organ during the year.

3. Exposures due to background radiation, therapeutic and diagnostic medical procedures, and voluntary participation in medical research programs shall not be included in either personnel radiation dose records or assessment of dose against the limits in this Table.

4. See Appendix 2C for guidance on non-uniform exposure of the skin.

5. See Appendix 2A for guidance on permitted emergency exposure limits.

\section{Visitor Dose Limit}

Visitors to NVTMP sites shall be limited to an annual radiation dose of $100 \mathrm{mrem}$ from the sum of internal and external radiation sources unless they either qualify as radiological workers in accordance with Article 632 or 633 , or meet the special considerations of Article 657.

Minors: It is NV/YMP policy that no individual under age 18 be allowed to enter Controlled Areas, as defined in 10 CFR 835, without special approval from DOE/NV. Special arrangements have been made with the DOE/NV Office of External Affairs to allow minors on NTS tours.

\section{Embryo/Fetus Dose Limits}

It is NV/YMP policy that the dose calculated to the embryo/fetus from internally deposited radionuclides should be calculated directly if possible. If this is not possible, the CEDE determined for the mother resulting from incidents occurring during the gestation period should also be assigned to the embryo/fetus as a default value to be included in assessing compliance with the limits of this Article.

After a female worker voluntarily notifies her employer in writing that she is pregnant, for the purposes of fetal/embryo dose protection, she is considered a declared pregnant worker. This declaration may be revoked, in writing, at any time by the declared pregnant worker. 
1. The employer shall provide the option of a mutually agreeable assignment of work tasks, without loss of pay or promotional opportunity, such that further occupational radiation exposure is unlikely.

2. For a declared pregnant worker who chooses to continue working as a radiological worker:

a. The dose limit for the embryo/fetus from conception to birth (entire gestation period) is 500 mrem.

b. Measures shall be taken to avoid substantial variation above the uniform exposure rate necessary to meet the 500 mrem limit for the gestation period. Efforts should be made to avoid exceeding $50 \mathrm{mrem}$ per month to the declared pregnant worker.

3. If the dose to the embryo/fetus is determined to have already exceeded 500 mrem when a worker notifies her employer of her pregnancy, the worker shall not be assigned to tasks where additional occupational radiation exposure is likely during the remainder of the gestation period.

\section{Special Control Levels}

Certain situations require lower individualized exposure control levels. In addition to considering recommendations from senior radiological control and medical officials, the contractor SSE should obtain advice from professionals in other disciplines such as human resources and legal in establishing special control levels (SCLS).

1. A SCL for annual occupational exposure shall be established for each radiological worker with a lifetime occupational dose exceeding $\mathrm{N}$ rem, where $\mathrm{N}$ is the age of the person in years. The SCL shall not exceed 1 rem and should allow the person's lifetime occupational dose to approach $\mathrm{N}$ rem as additional occupational exposure is received.

2. It is NVMMP policy to provide workers qualifying for SCLs with counseling to explain the basis for the SCL, the relative risks of additional exposure, and the risk estimates for their lifetime occupational exposure. It is the employee's right to choose to continue work with the potential for additional exposure or to work in areas of minimal or no potential occupational exposure. This decision should be documented and retained in the individual worker's radiological record. 


\section{PART 2 Contamination Control and Control Levels}

Control of radioactive contamination is achieved by using engineering controls and worker performance to contain contamination at the source, reducing existing areas of contamination, and promptly decontaminating areas that become contaminated.

It is NV/MP policy to minimize the amount of removable, fixed, and airborne contamination. Engineering controls, and possible contamination-minimizing actions and processes should be considered, verified, and documented during the planning stages and prior to the approval of any activity anticipated to contribute to contamination.

NTS areas scheduled for drilling sites or construction activities should be cleared through the DOE/NV Assets Management Division (AMD) per NTS-SOP 6401 to ensure radiological safety. YMP activities are to be cleared through the DOE/YMP FOC.

\section{Personnel Contamination Control}

1. Personnel exiting Contamination Areas, High Contamination Areas, or Airborne Radioactivity Areas shall frisk for contamination as required by Article 338 . This does not apply to personnel exiting areas containing only radionuclides, such as tritium, that cannot be detected using hand-held or automatic frisking equipment.

2. Monitoring for contamination should be performed using frisking equipment that under laboratory conditions can detect total contamination of at least the values specified in Table 2-2. Use of automatic monitoring units that meet the above requirements is encouraged.

3. Personnel found with detectable contamination on their skin or personal clothing, should be promptly decontaminated as described in Article 541.

4. Access to radiological areas should be restricted. At NV/YMP facilities, only RW-Is, RW-Ils or RCTs, or GERT trained personnel accompanied by RW-Is, RW-lls or RCTs, should be allowed to enter a radiological area. If the area is under direct and manned control, entry permission should be obtained from the controlling organization. Permission to enter an unattended and barricaded radiological area shall be obtained from the responsible RCO or DOE/NV Operations Coordination Center (OCC). Under no circumstances shall entry into any radiological area be made without first obtaining proper approval from the appropriate individual or office.

a. Manned Radiological Area Control: Personnel entering a manned radiological area should enter through a control station or checkpoint: 
Personnel should be provided PC, special dosimeters, or respiratory equipment, as appropriate, for the particular work activity and potential radiation hazard. Persons leaving the area should remove all PC at the checkpoint, turn in any special dosimeters or respiratory gear, and be monitored and decontaminated as necessary. Nasal or facial swipes and urine samples should be collected when required by radiation protection personnel. All manned radiological areas should have auditable records.

b. Unmanned Radiological Area Control: An unmanned radiological area should be appropriately posted and have some form of physical barricade limiting entry (road barricades, ropes, fencing, warning signs, etc.). The type of posting and/or barricade should be determined by the TO responsible for the area. Where possible, appropriate signs should be posted at 100 foot intervals, or so that at least one sign can be seen from any approach. Signs in remote areas or areas of difficult terrain should be posted on the road barricades or on each side of the access roads. If the area requires fencing, the fence should consist of, as a minimum, two strands of yellow, or yellow and magenta, wire rope or chain.

5. Smoking, eating, and chewing gum or tobacco are prohibited in radiological areas. Signs should be prominently displayed informing workers of the requirement. Drinking of water per RWP is permitted under strict supervision when necessary to prevent heat stress. Each TO shall satisfy the requirements of article 342.11 before providing drinking water in these areas.

\section{Contamination Control Levels}

1. A surface shall be considered contaminated if radioactivity is detected above the levels in Table 2-2. If an area cannot be decontaminated promptly, it shall be posted as specified in Article 235.

2. Any area in which contamination levels exceed Table 2-2 limits shall be controlled in a manner commensurate with the physical and chemical characteristics of the contaminant, the radionuclide(s) present, and the fixed and removable contamination levels. Surfaces exceeding the values of Table 2-2 for total contamination may be covered with a fixative coating consisting of two layers of different colors to prevent the spread of contamination. However, reasonable efforts should be made to decontaminate an area before a coating is applied. A fixative coating shall not be applied without the approval of the cognizant RadCon Manager.

3. In addition to the posting criteria in Article 235, the conditions for establishing and maintaining Fixed Contamination Areas include all of the following: 
a. Radiological surveys shall be performed to detect contamination that may become removable over time.

b. A formal inventory shall be maintained of Fixed Contamination Areas.

c. Markings shall be kept legible.

d. Removable contamination shall not exceed Table 2-2 values and should be reduced as far below Table 2-2 values as is reasonably achievable before a fixative coating is applied.

e. Markings should include the standard radiation symbol, be clearly visible from all directions, and contrast with the colors of the surface coatings.

f. A plan for identifying and adding to the inventory of existing areas of fixed contamination not included in the initial inventory should be developed.

4. A Fixed Contamination Area may be located outside Controlled Areas unless unrestricted access is likely to result in a dose to any person greater than 100 mrem in a year.

5. A Fixed Contamination Area is exempt from the general posting requirements of Article 231 and entry and exit requirements of Chapter 3.

6. For contaminated soil that is not releasable to uncontrolled areas in accordance with DOE 5400.5, a Soil Contamination Area shall be established that:

a. Is posted as specified in Article 222.7. Posting should include instructions or special warnings to workers such as "Consult With Radiological Control Organization Before Digging" or "Subsurface Contamination Exists."

b. Meets the requirements of Article 231.1 through 231.8.

7. NVMMP has established the following requirements to control contaminated soil areas at the NTS.

a. POSTING.

(1) Contaminated soil areas are posted when $\beta+\gamma$ activity levels exceed $0.5 \mathrm{mrem}$ per hour at $30 \mathrm{~cm}$ from the ground surface, and do not result in foot or clothing contamination exceeding Table 2-2 limits, as detected by routine personnel surveys. Signs indicating a contamination control area should be posted (e.g., CAUTIONSOIL CONTAMINATION AREA).

(2) Posting of contaminated soil areas is required when concentrations of $\alpha$-emitting radionuclides exist, averaged over 100 -square meters, which could result in airborne radioactivity levels greater than $1 / 50$ of a Derived Air Concentration (DAC). 
b. FENCING.

To limit the spread of contamination and reduce the potential for worker exposure, contaminated soil areas are fenced when:

(1). $\beta+y$ exposure rate levels equal or exceed $5 \mathrm{mrem} / \mathrm{hr}$ at $30 \mathrm{~cm}$ from the soil.

(2) Soil concentrations of $\alpha$-emitting radionuclides exist which could result in measured airborne radioactivity levels greater than onetenth $(1 / 10)$ of a DAC, or calculated air concentration levels greater than $1 / 10$ of a DAC based on appropriate resuspension factors, and averaged over 100-square meters. These levels will result in a 500 mrem dose (the NV/YMP Administrative Control Level) if occupied for 2000 hours.

c. In remote areas appropriate posting may be substituted in lieu of fencing. The RSPC should request the exemption from DOE/NV/SHD. 
Table 2-2 Summary of Surface Radioactivity Values

\begin{tabular}{|c|c|c|c|}
\hline $\begin{array}{c}\text { NUCLIDE } \\
\text { (See Note 1) }\end{array}$ & $\begin{array}{l}\text { REMOVABLE } \\
\left(\text { dpm } / 100 \mathrm{~cm}^{2}\right) \\
(\text { See Note 2) }\end{array}$ & $\begin{array}{l}\text { TOTAL (FIXED + } \\
\text { REMOVABLE) } \\
\text { (dpm/100 } \mathrm{cm}^{2} \text { ) } \\
\text { (See Note 3) }\end{array}$ & $\begin{array}{c}\text { ALLOWABLE } \\
\text { FIXED +. } \\
\text { REMOVABLE } \\
\text { (AVERAGED } \\
\text { PER NOTE 3) }\end{array}$ \\
\hline $\begin{array}{l}\text { U-natural, }{ }^{235} \mathrm{U},{ }^{238} \mathrm{U} \text { and } \\
\text { associated decay } \\
\text { products }\end{array}$ & $1,000 \alpha$ & $5,000 \alpha$ & $15,000 \propto$ \\
\hline $\begin{array}{l}\text { Transuranics, }{ }^{226} \mathrm{Ra}, \\
{ }^{228} \mathrm{Ra},{ }^{230} \mathrm{Th},{ }^{228} \mathrm{Th},{ }^{231} \mathrm{~Pa}, \\
{ }^{227} \mathrm{Ac},{ }^{129}{ }^{129},{ }^{125}\end{array}$ & 20 & 500 & 1,500 \\
\hline $\begin{array}{l}\text { Th-nat, }{ }^{232} \mathrm{Th},{ }^{90} \mathrm{Sr},{ }^{223} \mathrm{Ra}, \\
{ }^{224} \mathrm{Ra},{ }^{232} \mathrm{U},{ }^{126} \mathrm{l},{ }^{131} \mathrm{I},{ }^{133} \mathrm{I}\end{array}$ & 200 & 1,000 & 3,000 \\
\hline $\begin{array}{l}\beta+y \text { emitters (nuclides } \\
\text { with decay modes other } \\
\text { than } \alpha \text {-emission or } \\
\text { spontaneous fission) } \\
\text { except }{ }^{90} \mathrm{Sr} \text { and others } \\
\text { noted above. Includes } \\
\text { mixed fission products } \\
\text { containing }{ }^{90} \mathrm{Sr} \text {. }\end{array}$ & $1,000 \beta+\gamma$ & $5,000 \beta+\gamma$ & $15,000 \beta+\gamma$ \\
\hline $\begin{array}{l}\text { Tritium organic } \\
\text { compounds, surfaces } \\
\text { contaminated by HT, HTO } \\
\text { and metal tritide aerosols }\end{array}$ & 10,000 & 10,000 & 30,000 \\
\hline
\end{tabular}

\section{Table 2-2 Notes:}

1. The values in this Table apply to radioactive contamination deposited on, but not incorporated into the interior of the contaminated item. Where surface contamination by both alpha- and beta-gamma-emitting nuclides exists, the limits established for the alpha- and beta-gamma-emitting nuclides apply independently.

2. The amount of removable radioactive material per $100 \mathrm{~cm}^{2}$ of surface area should be determined by swiping the area with dry filter or soft absorbent paper 
while applying moderate pressure and then assessing the amount of radioactive material on the swipe with an appropriate instrument of known efficiency. NOTE: Filters used for tritium sampling should be moistened with tritium-characterized water prior to swiping. For objects with a surface area less than $100 \mathrm{~cm}^{2}$, the entire surface should be swiped, and the activity per unit area should be based on the actual surface area. Except for transuranics, Ra-228, Ac-227, Th-228, Th-230, Pa-231, and alpha emitters, it is not necessary to use swiping techniques to measure removable contamination levels if direct scan surveys indicate that the total residual contamination levels are below the values for removable contamination.

3. The levels shall be averaged over one-square meter provided the maximum activity in any area of $100 \mathrm{~cm}^{2}$ is less than three times the values in Table $2-2$.

\section{Airborne Radioactivity Control Levels}

1. Use of engineering and administrative controls to reduce the potential for internal exposure should be evaluated before allowing personnel to enter areas with airborne radioactivity with or without respiratory protection.

2. Occupied areas with airborne concentrations of radioactivity that are greater than or potentially greater than 10 percent of a DAC shall be posted as specified in Article 235, Table 2-4, and fenced in accordance with Article 222. Values of DACs are provided in 10 CFR 835, Appendices A \& C (see Reference Appendix). For most radionuclides, air containing 10 percent of a DAC results in a committed effective dose equivalent of approximately $10 \mathrm{mrem}$ if inhaled continuously for one work week.

3. For known mixtures of radionuclides, the sum of the ratio of the observed concentration of a particular radionuclide and its corresponding DAC, for all radionuclides in the mixture must not exceed 1.0. For unknown radionuclides, the most restrictive DAC (lowest value) for those isotopes not known to be absent shall be used.

\section{PART 3 Posting}

\section{Posting Requirements}

1. Radiological posting shall be used to alert personnel to the presence of radiation and radioactive materials and to aid them in minimizing exposures and preventing the spread of contamination. DOE approved signs, labels, and radiation symbols shall be used to identify controlled areas and radiological areas. 
2. Each access point to a radiological area shall be posted according to Tables 2-3 and 2-4. Signs shall contain the standard radiation symbol ("trefoil") colored magenta or black on a yellow background. Lettering shall be either magenta or black. Due to the extreme weathering conditions, BLACK ON YELLOW is the preferred color combination on radiological signs and tags.

3. Signs shall be conspicuously posted, clearly worded, and may include radiological control instructions, where appropriate. Radiological postings should be displayed only to signify actual or potential radiological conditions. Signs used for training should be clearly marked, such as "For Training Purposes Only."

4. Posted areas should be as small as practicable. Signs should be attached at 100-foot intervals, or at access points for remote locations.

5. Postings should be maintained in a legible condition and updated based upon the results of the most recent surveys.

6. If more than one radiological condition (such as contamination and high radiation) exists in the same area, each condition should be identified.

7. In areas of ongoing work activities, the dose rate (in $\mathrm{mrem} / \mathrm{hr}$ ) and contamination level or range of each should be included on or in conjunction with each posting at access points.

8. Entrance points to areas of ongoing work activities controlled for radiological purposes should state basic entry requirements, such as dosimetry, RWP, and respirator required.

9. Rope, tape, chain, and similar barriers used to designate the boundaries of posted areas should be yellow and/or magenta in color. Existing barbed wire, chain link, yellow rope, or snow fencing is acceptable at NV/YMP facilities.

10. Physical barriers shall be placed so that they are clearly visible from all directions and at various elevations. They shall not be easily walked over or under, except at identified access points. These barriers shall be set up such that they do not impede the intended use of emergency exits or evacuation routes.

11. Posting of doors or access gates should be such that the postings remain visible when they are open or closed. 
12. A radiological posting that signifies the presence of an intermittent radiological condition should include a statement specifying when the radiation is present, such as "CAUTION: RADIATION AREA WHEN RED LIGHT IS ON."

13. The RSPC should maintain the capability of providing radiological assistance upon request for TOs, specifically:
a. Provide survey and swipe testing services.
b. Provide decontamination services and facilities.
c. Provide personnel entry control services.
d. Have available and provide signs and fencing that have been approved for use in posting and fencing different types of radiological areas.
e. Maintain a list of radiological and contaminated facilities and areas, to include the location and type of contamination present; over which the $\mathrm{RCO}$ has radiological safety responsibility.

\section{Posting Controlled Areas}

1. Each access point to a Controlled Area shall be posted, identifying it as a Controlled Area, whenever radioactive materials and/or radiation fields which would require posting under Articles 234 or 235 (except for Fixed Contamination Areas) may be present in the area. Persons who enter only the Controlled Area without entering Radiation, Contamination, or Airborne Radioactivity Areas are not expected to receive more than $100 \mathrm{mrem}$ in a year.

2. The approved NV/YMP posting shall contain the wording "CONTROLLED AREA THIS AREA IS CONTROLLED FOR THE PURPOSE OF LIMITING ACCESS TO RADIATION OR RADIOACTIVITY. GENERAL EMPLOYEE RADIOLOGICAL TRAINING (GERT) IS REQUIRED FOR ACCESS."

3. When any other radiological warning signs are present, the "Controlled Area" sign is not required.

\section{3 [Reserved]}

\section{Posting Radiation Areas}

1. Areas shall be posted to alert personnel to the presence of external radiation in accordance with Table 2-3 and Article 231.

2. Dose rate measurements used to determine Radiation Areas and High Radiation Areas should be made at a distance of 30 centimeters from the radiation source or from any surface through which the radiation penetrates. For Very High Radiation Areas, the measurement should be made at $100 \mathrm{~cm}$. 
3. Contact readings should be used to determine the need for posting Hot Spots. Measures taken to identify sources of elevated general area radiation levels while conducting routine radiation surveys should be sufficient to identify hot spot locations. Special surveys for the sole purpose of identifying hot spots should not be required.

4. A label marking the location of the Hot Spot should be placed on or as near the spot as practical. The provisions of Article 231.7 through 231.11 do not apply to the Hot Spot posting. Posting of Hot Spots is not required in areas with general area dose rates greater than $1 \mathrm{rem} / \mathrm{hr}$.

5. Dose received in an hour may be used as the criterion for posting (Column 2 of Table 2-3). In this table, the unit "rad" is associated with dose rates that pose an immediate danger. 
Table 2-3 Criteria for Posting Radiation Areas

\begin{tabular}{|c|c|c|}
\hline AREA & $\begin{array}{l}\text { DOSE RATE } \\
\text { CRITERIA }\end{array}$ & POSTING \\
\hline Radiation Area & $\begin{array}{l}>0.005 \mathrm{rem} / \mathrm{hr} \text { at } 30 \\
\mathrm{~cm} .\end{array}$ & "CAUTION, RADIATION AREA" \\
\hline $\begin{array}{c}\text { High } \\
\text { Radiation Area }\end{array}$ & $\begin{array}{l}>0.1 \mathrm{rem} / \mathrm{hr} \text { at } 30 \\
\mathrm{~cm} .\end{array}$ & "DANGER, HIGH RADIATION AREA" \\
\hline $\begin{array}{l}\text { Very High } \\
\text { Radiation Area }\end{array}$ & $\begin{array}{l}>500 \mathrm{rad} / \mathrm{hr} \text { at } 100 \\
\mathrm{~cm} . \text { (Absorbed } \\
\text { Dose) }\end{array}$ & $\begin{array}{l}\text { "GRAVE DANGER, VERY HIGH } \\
\text { RADIATION AREA" }\end{array}$ \\
\hline Hot Spot & $\begin{array}{l}5 \text { times general area } \\
\text { dose rate and } \\
>0.1 \text { rem } / \mathrm{hr} \text { on } \\
\text { contact. }\end{array}$ & "CAUTION, HOT SPOT" \\
\hline
\end{tabular}

\section{Posting Contamination, High Contamination, and Airborne} Radioactivity Areas

1. Areas shall be posted to alert personnel to contamination in accordance with Table 2-4 and Article 231.

2. The requirement for an RWP should be included either on or in conjunction with each posting as applicable. The physical and chemical characteristics of, and the radionuclides present in the contamination will be considered in the determination of limiting conditions and/or access controls to be specified on the RWP.

3. DAC values for use with Table 2-4 as found in 10 CFR 835 shall be used in the control of occupational exposure to airborne radioactive material.

4. Areas meeting the criteria for Fixed Contamination Areas specified in Table 2-4 and Article 222.3 do not have to be posted as Contamination or High Contamination Areas. 
Table 2-4 Criteria for Posting Contamination, High Contamination, and Airborne Radioactivity Areas

\begin{tabular}{|c|c|c|}
\hline AREA & CRITERIA & POSTING \\
\hline Contamination & $\begin{array}{l}\text { Contamination levels } \\
\left(\mathrm{dpm} / 100 \mathrm{~cm}^{2}\right)>1 \text { time but } \\
\leq 100 \text { times Table } 2-2 \\
\text { values }\end{array}$ & $\begin{array}{l}\text { "CAUTION, CONTAMINATION } \\
\text { AREA" }\end{array}$ \\
\hline $\begin{array}{c}\text { High } \\
\text { Contamination }\end{array}$ & $\begin{array}{l}\text { Contamination levels } \\
\left(\mathrm{dpm} / 100 \mathrm{~cm}^{2}\right)>100 \text { times } \\
\text { Table } 2-2 \text { values }\end{array}$ & $\begin{array}{l}\text { "DANGER, HIGH } \\
\text { CONTAMINATION AREA" }\end{array}$ \\
\hline $\begin{array}{c}\text { Fixed } \\
\text { Contamination }\end{array}$ & $\begin{array}{l}\text { Removable contamination } \\
\text { levels }<\text { Table } 2-2 \\
\text { removable values and total } \\
\text { contamination levels } \\
>\text { Table } 2-2 \text { total values }\end{array}$ & $\begin{array}{l}\text { "CAUTION, FIXED } \\
\text { CONTAMINATION" }\end{array}$ \\
\hline $\begin{array}{c}\text { Airborne } \\
\text { Radioactivity }\end{array}$ & $\begin{array}{l}\text { Concentrations ( } \mu \mathrm{Ci} / \mathrm{cc}) \\
>10 \text { percent of any DAC } \\
\text { value }\end{array}$ & $\begin{array}{l}\text { "CAUTION, AIRBORNE } \\
\text { RADIOACTIVITY AREA" }\end{array}$ \\
\hline
\end{tabular}

\section{Posting Radioactive Material Areas (RMAs)}

1. Any accessible area where radioactive materials are used (not exempted by Article 412), handled, or stored shall be posted "CAUTION, RADIOACTIVE MATERIAL." The posting shall meet the requirements in Article 231.

2. The following RMAs are exempt from this posting requirement:

a. Areas containing 10 or fewer sealed radioactive sources with activities below the accountability criteria established in Appendix 4A, Values for Exemption of Sealed Radioactive Sources from Inventory and Source Integrity Testing.

b. Areas containing only materials that are properly packaged and labeled for transport in conformance with Department of Transportation (DOT) regulations or corresponding DOE directives and expected to enter into transportation in the immediate future (i.e., the current shift). 
c. Areas under continuous observation and control of an individual knowledgeable of and empowered to implement required access control measures.

d. An area posted as a radiological area in accordance with $10 \mathrm{CFR}$ 835.603.

e. Other areas posted with radiological warning signs meeting the criteria established in 10 CFR 835.601.

f. Areas containing radioactive materials in quantities below the site- or facility-specified posting threshold. This threshold shall be established at a level below that which is likely to cause any individual to receive a TEDE in excess of 0.1 rem in a year.

3. The definition of radioactive material and the requirements for labeling radioactive material are provided in Chapter 4 .

\section{Posting Underground Radioactive Material Areas}

1. Underground RMAs shall be established to indicate the presence of underground items that contain radioactive materials such as pipelines, radioactive cribs, covered ponds, covered ditches, catch tanks, inactive burial grounds, and sites of known, covered, unplanned releases (spills).

2. Underground RMA signs shall include the radiation symbol and the words "UNDERGROUND RADIOACTIVE MATERIAL." Posting should include instructions or special warnings to workers such as "Consult With Radiological Control Organization Before Digging" or "Subsurface Contamination Exists." The posting shall meet the applicable requirements of Article 231. It is not necessary to place a physical barrier around the boundary of Underground RMAs if appropriate signs are placed along the boundaries of the area.

3. Article 333.1 provides entry requirements for instances in which access is likely to result in individual doses greater than $100 \mathrm{mrem}$ in a year. 


\section{APPENDIX 2A - GUIDELINES FOR CONTROL OF EMERGENCY EXPOSURES}

In extremely rare cases, emergency exposure to radiation may be necessary to rescue personnel or to protect major property. Emergency exposures may be authorized in accordance with the provisions contained in 10 CFR 835 . These doses are in addition to and accounted for separately from the doses received under the limits in Table 2-1. The dose limits for personnel performing these operations are listed below.

Table 2A-1 Guidelines for Control of Emergency Exposures

\begin{tabular}{|c|c|c|}
\hline $\begin{array}{l}\text { DOSE LIMIT } \\
\text { (TEDE) }\end{array}$ & ACTIVITY PERFORMED & CONDITIONS \\
\hline $5 \mathrm{rem}$ & All & \\
\hline 10 rem & Protecting major property & $\begin{array}{l}\text { Only on a voluntary basis where } \\
\text { lower dose limit not practicable }\end{array}$ \\
\hline $25 \mathrm{rem}$ & $\begin{array}{l}\text { Lifesaving or protection of large } \\
\text { populations }\end{array}$ & $\begin{array}{l}\text { Only on a voluntary basis where } \\
\text { lower dose limit not practicable }\end{array}$ \\
\hline$>25$ rem & $\begin{array}{l}\text { Lifesaving or protection of large } \\
\text { populations }\end{array}$ & $\begin{array}{l}\text { Only on a voluntary basis to } \\
\text { personnel fully aware of the } \\
\text { risks involved }\end{array}$ \\
\hline
\end{tabular}

\section{Table 2A-1 Notes:}

1. The lens of the eye dose limit should be three times the listed values.

2. The shallow dose limit to the skin of the whole body and the extremities is 10 times the listed values.

3. Per 10 CFR 835.1301( $\mathrm{C}$ and d), "When the conditions under which the emergency or accident exposures were received have been eliminated, the responsible agency or TO management shall notify the DOE/NV/YMP Manager. Operations after an emergency or accidental exposure in excess of the limits specified in 10 CFR 835.202 or 10 CFR 835.205 [e.g. Table 2-1 and Appendix $2 \mathrm{C}$, this Manual] may be resumed only with the approval of the DOE.".

4. Per 10 CFR 835.1304:

a. Facilities possessing sufficient quantities of fissile material to potentially constitute a critical mass, such that the excessive exposure of personnel 
to radiation from a nuclear accident is possible, shall provide nuclear accident dosimetry for those personnel.

b. Nuclear accident dosimetry shall include the following:

1. A method to conduct initial screening of personnel involved in a nuclear accident to determine whether significant exposures to radiation occurred.

2. Methods and equipment for analysis of biological materials.

3. A system of fixed nuclear accident dosimeter units.

4. Personal nuclear accident dosimeters worn by all personnel who enter locations in which installed criticality alarm systems are required.

\section{APPENDIX 2B - TABLE 2B-1 WEIGHTING FACTORS FOR ORGANS AND TISSUES}

\begin{tabular}{|c|c|}
\hline ORGANS OR TISSUES & $\begin{array}{c}\text { WEIGHTING } \\
\text { FACTOR }\end{array}$ \\
\hline \hline Gonads $\ldots \ldots \ldots \ldots \ldots \ldots$ & 0.25 \\
Breasts $\ldots \ldots \ldots \ldots \ldots \ldots$ & 0.15 \\
Red bone marrow $\ldots \ldots \ldots$ & 0.12 \\
Lungs $\ldots \ldots \ldots \ldots \ldots \ldots$ & 0.12 \\
Thyroid $\ldots \ldots \ldots \ldots \ldots$ & 0.03 \\
Bone surfaces $\ldots \ldots \ldots \ldots$ & 0.03 \\
Remainder $\ldots \ldots \ldots \ldots \ldots$ & 0.30 \\
Whole Body $\ldots \ldots \ldots \ldots$ & 1.0 \\
\hline
\end{tabular}

Table 2B-1 Notes:

1. Weighting factors as defined in ICRP Publication 26 and NCRP Report 91 which are used to convert organ or tissue dose equivalent to effective dose equivalent for the whole body. The effective dose equivalent is obtained by multiplying the organ dose by the weighting factor.

2. "Remainder" means the five other organs or tissues with the highest dose (e.g. liver, kidney, pancreas, stomach, small intestine, and upper large intestine). The weighting factor of 0.3 results from 0.06 for each of the five remainder organs.

3. For the case of uniform external irradiation of the whole body, a weighting factor equal to 1 may be used in the determination of the effective dose equivalent. 


\section{APPENDIX 2C - NON-UNIFORM EXPOSURE OF THE SKIN}

Non-uniform exposures of the skin from x-rays, beta radiation, and radioactive materials on the skin, including hot particles shall be assessed and recorded as specified in the table below.

Table 2C-1 Non-Uniform Exposure of the Skin

\begin{tabular}{||l|l||}
\hline $\begin{array}{c}\text { AREA OF } \\
\text { SKIN } \\
\text { IRRADIATED }\end{array}$ & $\begin{array}{c}\text { METHOD OF AVERAGING, ADDING TO OTHER DOSES } \\
\text { RECEIVED, AND RECORDING NON-UNIFORM SKIN DOSE }\end{array}$ \\
\hline \hline $100 \mathrm{~cm}^{2}$ & $\begin{array}{l}\text { Averaged over the } 100 \mathrm{~cm}^{2} \text { of skin receiving the maximum dose } \\
\text { Added to any uniform dose equivalent also received by the skin } \\
\text { Recorded as the annual extremity or skin (shallow) dose } \\
\text { equivalent (H) }\end{array}$ \\
\hline $10 \mathrm{~cm}^{2}$ and & $\begin{array}{l}\text { Averaged over the } 1 \mathrm{~cm}^{2} \text { of skin receiving the maximum dose (D), } \\
\text { reduced by the fraction (f) which is the irradiated area in cm } \\
\text { divided by } 100 \mathrm{~cm} \text { (i.e. H=fD). "In no case shall a value of ' } \mathrm{H} \\
\text { less than 0.1 be used." [10 CFR 835.205(b)(2)] } \\
\text { Added to any uniform dose equivalent also received by the skin } \\
\text { Recorded as the annual extremity or skin (shallow) dose } \\
\text { equivalent (H) }\end{array}$ \\
\hline$<10 \mathrm{~cm}^{2}$ & $\begin{array}{l}\text { Averaged over the 1 } \mathrm{cm}^{2} \text { of skin receiving the maximum dose } \\
\text { Not added to any other dose equivalent, extremity or shallow } \\
\text { dose equivalent (skin) recorded for the annual dose equivalent } \\
\text { Recorded in a person's radiation dose record as a special entry }\end{array}$ \\
\hline
\end{tabular}


NV/YMP Radiological Control Manual, Rev. 2:

November 13, 1996

RADIOLOGICAL STANDARDS

CHAPTER 2

THIS PAGE INTENTIONALLY LEFT BLANK 


\section{CHAPTER 3 CONDUCT OF RADIOLOGICAL WORK}

\section{Article}

\section{TABLE OF CONTENTS}

PART 1 Planning Radiological Work $\ldots \ldots \ldots \ldots \ldots \ldots \ldots \ldots \ldots \ldots$ 3-1

311 Requirements . . . . . . . . . . . . . . . . . . . . 3-1

312 Planning for Maintenance, Operations, and Modifications . . . . . . . 3-1

313 Infrequent or First-Time Activities $\ldots \ldots \ldots \ldots \ldots \ldots \ldots . . . \ldots \ldots$

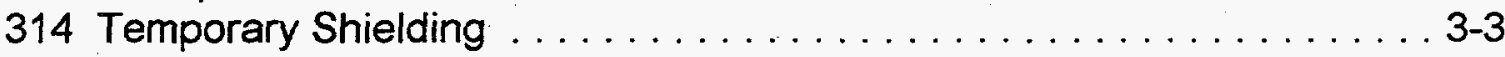

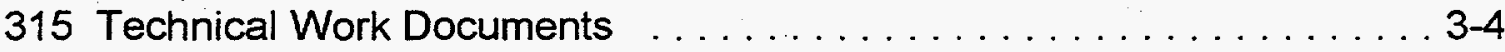

316 Control of Internal Exposure . . . . . . . . . . . . . . . . . 3-4

317 Heat Stress . . . . . . . . . . . . . . . . . . . . . . 3-5

PART 2. Work Preparation . . . . . . . . . . . . . . . . . . . . . . . .

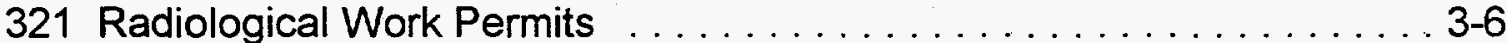

322 Using Radiological Work Permits . . . . . . . . . . . . . . . 3-8

323 Radiological Work Permit Preparation . . . . . . . . . . . . . . . . 3-9

324 Pre-Job Briefings . . . . . . . . . . . . . . . . . . . . . . . . . 3-9

325 Personal Protective Equipment and Protective Clothing . . . . . . . . . 3-10

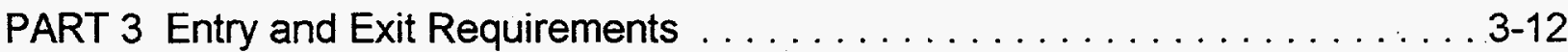

331 Controlled Areas . . . . . . . . . . . . . . . . . . . . . . . . 3-12

332 [Reserved] . . . . . . . . . . . . . . . . . . . . . . . . . 3-12

333 Radioactive Material Areas, Soil Contamination Area, and Underground Radioactive Material Areas . . . . . . . . . . . . . . . . . . . . 3-12

334 Radiation, High Radiation, and Very High Radiation Areas . . . . . . . 3-12

335 Contamination, High Contamination, and Airborne Radioactivity Areas

336 Visitor Entry Requirements . . . . . . . . . . . . . . . . . . 3-15

337 Controlling the Spread of Contamination . . . . . . . . . . . . . 3-15

338 Monitoring for Personnel Contamination . . . . . . . . . . . 3-16

PART 4 Radiological Work Controls . . . . . . . . . . . . . . . . . . . . 3-17

341 Requirements . . . . . . . . . . . . . . . . . . . . . . . . . 3-17

342 Work Conduct and Practices . . . . . . . . . . . . . . . . . . . . . 3-17

343 Logs and Communications . . . . . . . . . . . . . . . . . . 3-19

344 Review of Work in Progress . . . . . . . . . . . . . . . . . . . . 3-19

345 Stop Radiological Work Authority . . . . . . . . . . . . . . . . 3-19

346 Response to Abnormal Situations . . . . . . . . . . . . . . 3-20

347 Controls for Bench-top Work, Laboratory Fume Hoods, Sample Stations, and Glove Boxes

348 Controls for Hot Particles . . . . . . . . . . . . . . . . . . . . . . . . . . . 3-22 


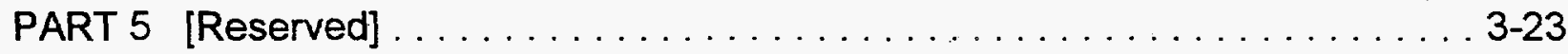

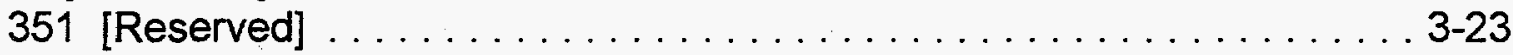

352 [Reserved] . . . . . . . . . . . . . . . . . . . . . . 3.23

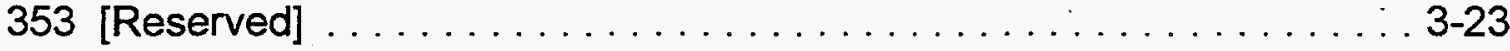

PART 6 Special Applications . . . . . . . . . . . . . . . . . . . . . . . 3-24

361 Plutonium Operations $\ldots \ldots \ldots \ldots \ldots \ldots \ldots \ldots \ldots \ldots \ldots . .24$

362 Uranium Operations . . . . . . . . . . . . . . . . . . . . 3-24

363 Tritium Operations . . . . . . . . . . . . . . . . . . . . . . . . 3-24

364 Accelerator Operations . . . . . . . . . . . . . . . . . . . . 3-25

365 Radiation Generating Devices $\ldots \ldots \ldots \ldots \ldots \ldots \ldots \ldots . . \ldots \ldots$

PART 7 Construction and Restoration Projects . . . . . . . . . . . . . 3 3-26

371 Requirements . . . . . . . . . . . . . . . . . . . . . . . . . . 3-26

372 Environmental Conditions . . . . . . . . . . . . . . . . . . . . . . 3-28

373 Other Workplace Hazards . . . . . . . . . . . . . . . . . . . . 3-28

Appendix 3A

Checklist for Reducing Occupational Radiation Exposure . . . . . . . . . . 29

Appendix 3B

Physical Access Controls for High and Very High Radiation Areas

Appendix 3C

Contamination Control Practices

Appendix 3D

Guidelines for Personnel Contamination Monitoring

with Hand-Held Survey Instruments

Figure

3-1 NV/YMP Radiation Work Permit (RWP)

Table

3C-1 Guidelines for Selecting Protective Clothing 


\section{PART 1 Planning Radiological Work}

\section{Requirements}

Technical requirements for the conduct of work, including construction, modifications, operations, maintenance, and decommissioning shall incorporate radiological criteria to ensure safety and maintain radiation exposures ALARA. The primary methods used to maintain exposures ALARA shall be facility and equipment design features. These features shall be augmented by administrative and procedural requirements. To accomplish this, the design and planning processes shall incorporate radiological considerations in the early planning stages. The checklist in Appendix $3 \mathrm{~A}$ is helpful in reducing occupational radiation exposure.

\section{Planning for Maintenance, Operations, and Modifications}

1. Maintenance and modification plans and procedures shall be reviewed to identify and incorporate radiological requirements, such as engineering controls and dose and contamination reduction considerations. Performing this review is the responsibility of line management, with support and concurrence from the RCO.

2. For routine tasks, such as surveillance, tours, and minor nonradiological maintenance performance of the above reviewing and documenting identified radiological requirements should be conducted as part of the RWP process (see Article 321).

3. NVMMP-specific trigger levels requiring formal radiological review of nonroutine or complex work activities are:

a. Estimated individual/whole-body dose of greater than $100 \mathrm{mrem}$.

b. Estimated collective whole-body dose of greater than $500 \mathrm{mrem}$.

c. Estimated individual extremity dose of greater than 1 rem.

d. Estimated collective extremity dose of greater than 10 rem.

e. Predicted airborne radioactivity concentrations which could result in $\mathbf{4 0}$ DAC hours of inhalation exposure.

f. Work area removable contamination greater than 100 times the values in Table 2-2.

g. Entry into areas where dose rates could result in an exposure greater than 1 rem in one hour.

h. Potential radioactive releases to the environment.

I. Source handling operations where accidental exposure could result in an exposure exceeding 5 rem. 
4. Tasks with the potential to exceed the above trigger levels shall undergo a formal, documented radiological or ALARA review. At a minimum, this review should consider the following:
a. Including RadCon Hold Points in the technical work documents.
b. Eliminating or reducing radioactivity through line flushing and decontamination.

c. Using work processes and special tooling to reduce time in the work area.

d. Using engineered controls to minimize the spread of contamination and generation of airborne radioactivity.

e. Specifying special radiological training or monitoring requirements.

f. Using mock-ups for high exposure or complex tasks.

g. Engineering, designing, and using temporary shielding to reduce radiation levels.

h. Walkdown or dry-run of the activity using applicable procedures.

I. Staging and preparing necessary materials and special tools.

j. Maximizing prefabrication and shop work.

k. Reviewing abnormal and emergency procedures and plans.

I. Identifying points where signatures and second party or independent verifications are required.

m. Establishing success or completion criteria, with contingency plans to anticipate difficulties.

n. Developing a pre-job estimate of collective dose to be incurred for the job.

o. Provisions for waste minimization and disposal.

5. Radiological requirements identified as part of the above radiological review should be documented in the job plans, procedures, or work packages.

6. Radiological work anticipated to exceed individual or collective dose criteria established in this Manual should be reviewed and approved by the appropriate ALARA Committee.

7. Optimization techniques, including cost-benefit analysis, represent a fundamental part of radiological design analysis and work review. For review of minor activities with low associated doses, a cost-benefit evaluation is an intrinsic part of the engineering review process and a detailed evaluation is not necessary. For review and planning of major tasks involving higher collective dose expenditures, a detailed and documented evaluation shall be performed. Optimization methodology is extensively discussed in ICRP Publication 55, "Optimization and Decision-Making in Radiological Protection." Section 3.0 ("Optimization") of PNL-6577, "Health Physics Manual of Good Practices for Reducing Radiation Exposure to Levels that are As Low As Reasonably Achievable (ALARA)," contains additional guidance. 


\section{Infrequent or First-Time Activities}

At those facilities with routine, recurring process operations, special management attention should be directed to radiological activities that are infrequently conducted or represent first-time operations. Planning for such activities should include:

1. Formal radiological review in accordance with Article 312.4.

2. Senior management review.

3. Review and approval by the appropriate ALARA Committee.

a. NV/MP operations involving single organizations require review and approval by their internal ALARA committee (or its equivalent).

b. NV/YMP operations involving multiple organizations require review and approval by the SWAC.

4. Enhanced line and RadCon management oversight during the initiation and conduct of the work.

\section{Temporary Shielding}

1. Temporary shielding is interpreted for NV/YMP operations to mean shielding installed to reduce exposure rates for specific jobs which have an expected duration of less than one year, and/or shielding installations which have not been engineered to be an integral part of a structure. The installation, use, and removal of temporary shielding should be controlled by procedure.

2. The effects of the additional weight of temporary shielding on systems and components should be evaluated and established to be within the design basis prior to installation.

3. Installed temporary shielding should be periodically inspected and surveyed to verify effectiveness and integrity.

4. Radiation surveys should be performed during the alteration or removal of installed temporary shielding.

5. Installed temporary shielding should be visibly marked or labeled with the following or equivalent wording: "Temporary Shielding - Do Not Remove Without Permission from the RCO."

6. Installed temporary shielding should be periodically evaluated to assess the need for its removal or replacement with permanent shielding. 
7. Procedures may identify specific shielding applications, such as the shielding of low activity sources or samples, that fall outside the recommendations of this Article.

\section{Technical Work Documents}

1. Technical work documents, such as procedures, work packages, or job or research plans should be used to control hands-on work with radioactive materials addressed in DOE N 441.1, or materials in excess of Table 2-2 limits. Technical work documents are not required for incidental or routine work activities that involve a low potential of worker exposure or workplace contamination, such as the collection of trash or used PC.

2. Technical work documents used to control radiological work activities should be reviewed and approved by the RCO.

3. RadCon Hold Points should be incorporated into technical work documents for steps that require action by the RCO or RSPC to prevent radiation exposures in excess of Administrative Control Levels, high airborne radioactivity concentrations, or the release of radioactivity to the environment.

\section{Control of Internal Exposure}

The control of internal exposure should be conducted in accordance with the following hierarchy of controls. These controls should be applied for specific isotopes when the internal committed dose is greater than the annual internal dose:

1. Engineering controls, including containment of radioactive material at the source wherever practicable, shall be the primary method of minimizing airborne radioactivity and internal exposure to workers.

2. Administrative controls, including access restrictions and the use of specific work practices designed to minimize airborne contamination, shall be used as the secondary method to minimize worker internal exposure.

3. When engineering and administrative controls have been applied and the potential for airborne radioactivity still exists, respiratory protection should be used to limit internal exposures. Use of respiratory protection should be considered under the following conditions:

a. Entry into posted Airborne Radioactivity Areas.

b. During breach of contaminated systems or components.

c. Work in areas or on equipment with removable contamination levels greater than 100 times the values in Table 2-2. 
d. During work on contaminated or activated surfaces with the potential to generate airborne radioactivity.

4. Selecting respiratory protection equipment should include consideration of worker safety, comfort, and efficiency. Using positive pressure respiratory protection devices is recommended wherever practicable to alleviate fatigue and increase comfort.

5. In specific situations, using respiratory protection may be contraindicated due to physical limitations or the potential for significantly increased external exposure. In such situations, written authorization should be obtained from the line organization manager and the RadCon Manager prior to incurring internal exposure. Specific justification of the need to accept the exposure, including a description of measures taken to mitigate the airborne radioactivity, should be documented as part of the authorization process.

6. The following controls are applicable for activities authorized in accordance with the above:

a. Stay time controls to limit intake should be established for the entry;

b. Evaluating workplace airborne radioactivity levels should be provided through the use of continuous air monitors (CAMs) or air-samplers with expedited assessment and analysis of results.

\section{Heat Stress}

Heat stress (hyperthermia) may result from working in areas of high heat, humidity, and radiant heat; working in PC; and using respirators, particularly where other PPE is required. Heat stress has occurred at ambient temperatures less than $70^{\circ} \mathrm{F}$ when multiple sets of PC were in use or strenuous work was required. The planning stages for work in hot environments should address heat stress controls. Recommended work time limits and use of body cooling devices should be considered to reduce heat stress. Job supervisors should inform their personnel of heat stress precautions prior to work on job assignments in hot environments. If a person begins to feel symptoms of heat illness, the person should immediately notify the nearest co-worker, exit the area, remove PPE, notify the supervisor, and rest in a cool area. In such cases, medical assistance should be provided. 


\section{PART 2 Work Preparation}

\section{Radiological Work Permits}

The RWP (Figure 3-1) is an administrative mechanism used to establish radiological controls for intended work activities. The RWP informs workers of area radiological conditions and entry requirements and provides a mechanism to relate worker exposure to specific work activities.

A site-wide RWP format has been approved by the RadCon Managers' Council, and NV/YMP TOs have agreed to use it whenever more than one TO is involved in a radiological operation. They reserve the right to substitute equivalent formal written procedures as authorized by Article 322.9 for strictly organization-internal projects.

Format for add-on sheets for additional authorization signatures and/or worker acknowledgment signatures, as well as appendices containing information not addressed in the RWP, should be determined per the TO RCO standard operating procedure.

The RWP should include the following information:

a. Work description.

b. Work area radiological conditions.

c. Dosimetry requirements.

d. Pre-job briefing requirements, as applicable.

e. Training requirements for entry.

f. $\quad$ PC and respiratory protection requirements.

g. RadCon coverage requirements and stay time controls, as applicable.

h. Limiting radiological conditions that may void the RWP.

I. Special dose or contamination reduction considerations.

j. Special personnel frisking consideration.

k. Technical work document number, or procedure, as applicable.

I. Unique identifying number.

m. Date of issue and expiration.

n. Authorizing signatures and concurrence signatures of RadCon Managers (or their designated alternates) of all organizations involved in the work project covered by the RWP. 
Figure 3-1

NV/YMP RADIOLOGICAL WORK PERMIT

\begin{tabular}{|c|c|c|c|}
\hline \multirow{4}{*}{$\begin{array}{l}R \\
\mathbf{E} \\
\mathbf{Q} \\
\mathbf{U} \\
\mathbf{E} \\
\mathbf{S} \\
\boldsymbol{T} \\
\mathbf{E} \\
\mathbf{R}\end{array}$} & FWP No.: & \multirow{3}{*}{$\begin{array}{l}\text { Requester Ninme: } \\
\text { Phono No: } \\
\text { MS: }\end{array}$} & $\begin{array}{l}\text { Location: } \\
\text { (Bida/Area) }\end{array}$ \\
\hline & issue Date: & & \multirow[t]{3}{*}{ Work Description Procedure No:: } \\
\hline & Expirs Date: & & \\
\hline & $\begin{array}{l}\square \text { STANDNG RWP } \\
\square \text { OPERATLNPRQSCT RWP }\end{array}$ & USER OAGANIZATION: & \\
\hline
\end{tabular}

RADIOLOGICAL INFORMATION

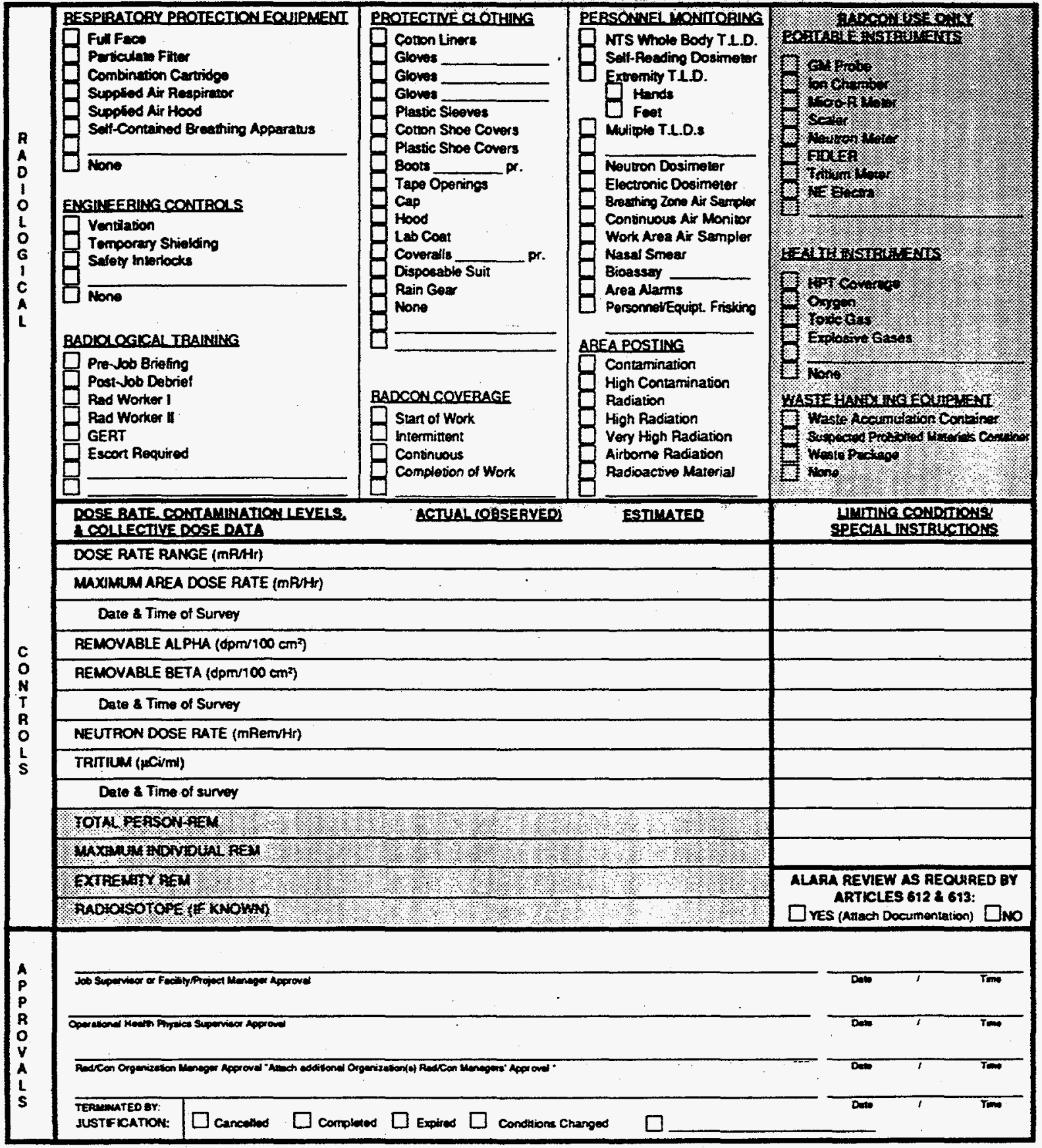




\section{Using Radiological Work Permits}

1. RWPs shall be used to control the following activities:
a. Entry into High and Very High Radiation Areas.
b. Entry into High Contamination Areas.
c. Entry into Airborne Radioactivity Areas.

2. RWPs should be used to control the following activities:
a. Entry into Radiation Areas.
b. Entry into Contamination Areas.
c. Handling of materials with removable contamination that exceed the values of Table 2-2.

3. Job-specific RWPs shall be used to control nonroutine operations or work in areas with changing radiological conditions. The job-specific RWP shall remain in effect only for the duration of the job.

4. Standing RWPs may be used to control routine or repetitive activities, such as tours and inspections, analytical laboratory work, handling of small sources, routine decontamination and laundry operations, specific waste stream handling operations, or other minor work activities, in areas with well-characterized and stable radiological conditions. They may also be used for training exercise scenarios which are a standard part of DOE or Federal Emergency Management Agency (FEMA) sanctioned radiological, hazardous materials, and emergency. response courses, if RadCon Manager oversight and procedural documentation are in place. Standing RWPs should not be approved for periods longer than one year.

5. Radiological surveys shall be routinely reviewed at least once each work shift to evaluate adequacy of RWP requirements. RWPs shall be updated if radiological conditions change to the extent that protective requirements need modification.

6. RWPs should be posted at the access point to the applicable radiological work area.

7. Workers shall acknowledge by signature or through electronic means where automated access systems are in place that they have read, understand, and will comply with the RWP prior to initial entry to the area and after any revisions to the RWP. 
8. Worker pocket or electronic dosimeter readings should be recorded in a format that identifies and provides linkage to the applicable RWP.

9. An alternative formal mechanism, such as written procedures or experiment authorizations, may be used in lieu of an RWP as the administrative control over radiological work activities. If an alternative mechanism is used, it should meet the requirements of this Article and Articles 321 and 323.

10. RWPs for training exercises may be prepared in a way that will not compromise the location or precise subject matter of a training scenario, giving students only the information they need to safely enter and perform required tasks in a temporary training exercise radiation area. Trainers should permit their students to read and sign the RWP. Training staff and supporting Radiological Control Technicians (RCTs) shall satisfy Article 334 requirements. Training personnel should notify the RSPC in advance to provide necessary RCT support during the exercise. Training shall not be conducted within High Radiation Areas or Very High Radiation Areas.

11. The degree of personnel entry control for radiological areas shall be commensurate with existing and potential radiological hazards within the area.

\section{Radiological Work Permit Preparation}

1. The responsibility for ensuring adequate planning and control of work activities resides with line management. The TO responsible for the planned activity or for the area should initiate the preparation of the RWP. The RWP should then be reviewed and signed by all organizations having any assigned responsibility during the activity.

2. The RWP shall be based on current radiological surveys and anticipated radiological conditions.

3. The RWP, including any revisions or extensions, shall be approved by the supervisor responsible for the work or area and the appropriate RadCon Manager.

\section{Pre-Job Briefings}

1. At a minimum, pre-job briefings should be held prior to the conduct of work anticipated to exceed the trigger levels identified in Article 312.3. Each NV/YMP TO having responsibility for radiological work should conduct these briefings within their area of delegated RadCon responsibility. 
2. At a minimum the pre-job briefing should include:
a. Scope of work to be performed.
b. Radiological conditions of the workplace.
c. Procedural and RWP requirements.
d. Special radiological control requirements.
e. Radiologically limiting conditions, such as contamination or radiation levels that may void the RWP.
f. RadCon Hold Points.
g. Communications and coordination with other groups.
h. Provisions for housekeeping and final cleanup.
i. Emergency response provisions.

3. Pre-job briefings should be conducted by the cognizant work supervisor.

4. Workers and supervisors directly participating in the job, cognizant RadCon personnel, and representatives from involved support organizations should attend the briefing.

5. A summary of topics discussed and attendance at the pre-job briefing should be documented. This documentation should be maintained with the technical work document.

\section{Personal Protective Equipment and Protective Clothing}

References in this manual to PPE and PC use pertain only to radiological work activities, operations, or areas. Each TO should determine PPE requirements for each radiological area (to be recorded on the RWP), and inform all workers of the RWP requirements for radiological areas under their responsibility. The issue and use of PPE for non-radiological situations falls outside the scope of this Manual.

1. Personnel shall wear PC during the following activities:
a. Handling of contaminated materials with removable contamination in excess of Table 2-2 levels.
b. Work in Contamination, High Contamination, and Airborne Radioactivity Areas.
c. As directed by the RCO or as required by the RWP.

2. PC and shoes designated for RadCon shall be:
a. Marked in accordance with Article 461.
b. Used only for RadCon purposes. 
3. $\quad$ PC dress-out areas should be established directly adjacent to the work area. Workers should proceed directly to the radiological work area after donning PPE and PC.

4. General guidelines for PC selection and use are provided in Appendix $3 \mathrm{C}$ and in Table 3C-1.

5. The use of lab coats as radiological PC are appropriate for limited applications such as those discussed in Appendix $3 \mathrm{C}$ where the potential for personal contamination is limited to the hands, arms, and upper front portion of the body. Lab coats should not be used as PC for performing physical work activities in Contamination, High Contamination, or Airborne Radioactivity Areas.

6. Instructions for donning and removing PC should be posted at the dress-out and step-off pad areas.

7. The use of PPE or PC (including respiratory protection) beyond that authorized by the RCO detracts from work performance and is contrary to ALARA principles and waste minimization practices. Such use should not be authorized.

8. Company-issued clothing, such as work coveralls and shoes, should be considered the same as personal clothing. Company-issued clothing should not be used for RadCon purposes. The RSPC issues climate-appropriate "Modesty Garments" to be worn under PC in lieu of outer personal and/or.Company issued clothing, due to the temporary and sometimes outdoor nature of Hot Line undress locations at the NTS. They are not to be considered "Company-issued clothing" for the purposes of this Article. They will be collected upon final exit from the Controlled Area for disposal or laundering, depending on the type issued.

9. The RSPC is required to:

a. Provide all PPE at the NTS, and any other NV/YMP facility, that are to be used within radiological areas, unless provided by the responsible TO.

b. Operate a laundry facility that can effectively decontaminate PPE to release levels given in Article 461.5.

c. Maintain radiological access ("base") stations.

d. Supply respiratory protection equipment to all NV/YMP TOs, upon request. 


\section{PART 3 Entry and Exit Requirements}

\section{Controlled Areas}

Successful completion of Visitor Orientation or GERT is required for unescorted entry into Controlled Areas.

Permission to enter an unattended and posted or barricaded Controlled Area is required from the organization with RadCon responsibility.

\section{2 [Reserved]}

333 Radioactive Material Areas, Soil Contamination Area, and Underground Radioactive Material Areas

1. RW-I training shall be required for unescorted entry into RMAs containing either of the following:

a. Sealed radioactive sources.

b. Radioactive material labeled and packaged in accordance with Articles 412 and 413.

2. Entry into RMAs where whole-body dose rates exceed $5 \mathrm{mrem} / \mathrm{hr}$ or removable contamination levels exceed Table 2-2 values shall be in accordance with the requirements of Articles 334.1 and 335.1 , respectively.

3. RW-I training shall be required for unescorted entry into soil contamination areas and underground RMAs in which the individual is expected to receive more than 100 mrem in a year.

\section{Radiation, High Radiation, and Very High Radiation Areas}

1. Minimum requirements for unescorted entry into Radiation Areas shall include the following:
a. RW-I training.
b. Worker's signature on the RWP, as applicable.
c. Personnel dosimetry.

2. Physical controls to prevent inadvertent or unauthorized access to High and Very High Radiation Areas shall be maintained in accordance with Appendix 3B.

3. Minimum requirements for unescorted entry into High Radiation Areas shall include the following: 
a. RW-II training (or RW-I with HighNery High Radiation Area access training in accordance with Article 632.5) and training in the use of a survey meter or dose rate indicating device.

b. Worker's signature on the RWP (or procedure) sign-in sheet.

c. Personnel and supplemental dosimeters.

d. Survey meter or dose rate indicating device available at the work area.

4. Minimum requirements for unescorted entry into High Radiation Areas where dose rates exist such that a worker could exceed a whole-body dose of 1 rem in one hour shall include those items listed in Article 334.3 and the following:

a. A determination of the worker's current exposure, based on primary and supplemental dosimeter readings.

b. Pre-job briefing, as applicable.

c. Review and determination by the RCO regarding the required level of RCT coverage.

5. Workers shall be prevented from entry to Very High Radiation Areas when the radiation source is exposed and very high radiation fields are present. In addition to the controls required in Articles 334.2 and 334.3, a survey shall be made prior to the first entry to the area after the source has been secured or shielded to verify the very high radiation field has been terminated.

6. Facility operations personnel should be notified prior to personnel entry to areas where operational or system changes made by operations personnel could result in significantly increased area dose rates.

7. The number, issue, and use of keys shall be strictly controlled by facility personnel where locked entryways are used to control access to High and Very High Radiation Areas.

8. The RCO should maintain an inventory of High and Very High Radiation Areas at fixed facilities such as source ranges and fixed radiography facilities.

9. Weekly inspections of the physical access controls to High and Very High Radiation Areas should be made to verify controls are adequate to prevent unauthorized entry. If High and Very High Radiation Areas generated by source ranges, sealed source radiography, or radiation producing machines are used infrequently, physical access controls should be tested before each use of the facility.

10. Administrative procedures shall be developed as necessary to implement area access controls. These procedures shall address measures implemented to ensure the effectiveness and operability of entry control devices, such as 
barricades, alarms, and locks. The degree of control shall be commensurate with existing and potential radiological hazards in the area.

\section{Contamination, High Contamination, and Airborne Radioactivity Areas}

1. Minimum requirements for unescorted entry into Contamination Areas shall include the following:
a. RW-Il training.
b. Worker's signature on the RWP, as applicable.
c. PC.
d. Personnel dosimetry, as appropriate.

2. Minimum requirements for unescorted entry into High Contamination or Airborne Radioactivity Areas shall include the following:
a. RW-Il training.
b. Worker's signature on the RWP (or procedure) sign-in sheet.
c. PC and respiratory protection when specified by the RWP.
d. Pre-job briefing for High Contamination or Airborne Radioactivity Areas, as applicable.
e. Personnel dosimetry, as appropriate.

3. Personnel exiting Contamination, High Contamination, or Airborne Radioactivity Areas shall: from the Contamination Area rather than the exit from the High
Contamination to Contamination Area, if both Areas have the same exit point to the uncontaminated area.
a. Remove PC as specified in Appendix 3C. PC may be removed at the exit
b. When entering an uncontaminated area, perform whole-body frisking to detect personnel contamination in accordance with Article 338.

4. Exit points from Contamination, High Contamination, or Airborne Radioactivity Areas should include the following:
a. Step-off pad located outside the exit point, contiguous with the area boundary.
b. Step-off pads maintained free of radioactive contamination.
c. Labeled containers inside the area boundary for the collection of PC and equipment.
d. Contamination monitoring equipment located as close to the step-off pad as background radiation levels permit.


5. Multiple step-off pads should be used at the exits from High Contamination Areas. Use of multiple step-off pads is described in Appendix 3C.

6. $\quad P C$ and monitoring requirements specific to bench-top work, laboratory fume hoods, sample stations, and glove boxes are identified in Article 347.

7. Tools or equipment being removed from areas posted for surface or airborne radioactivity control shall be monitored for release in accordance with Article 421 or for retention in the contaminated tool crib in accordance with Article 442.5.

8. Administrative procedures shall be developed as necessary to implement area access controls. These procedures shall address measures implemented to ensure the effectiveness and operability of entry control devices, such as barricades, alarms, and locks.

\section{Visitor Entry Requirements}

1. Procedures shall identify area entry requirements and access restrictions for visitors.

2. Visitors with a demonstrated need to enter the following areas may be allowed access if such access is controlled with a combination of training and the use of escorts trained for the specific area:
a. Controlled Areas
b. : Radiation Areas
c. Contamination Areas
d. Radioactive Material Areas

3. Visitors shall be prevented from entering Very High Radiation Areas in accordance with Article 334.5 and should be prohibited access to High Radiation, High Contamination, and Airborne Radioactivity Areas.

4. Training requirements for visitors are identified in Articles 622 and 657.

\section{Controlling the Spread of Contamination}

The following measures shall be used in fixed facilities and transient operations as appropriate to prevent the spread of contamination across the boundary of Contamination Areas, High Contamination Areas, and Airborne Radioactivity Areas:

1. Use solid barriers to enclose areas wherever practicable.

2. Mark and secure items such as hoses and cords that cross the boundary. 
3. Control and direct airflow from areas of lesser to greater removable contamination or airborne radioactivity.

4. Use engineering controls and containment devices such as glove bags, glove boxes, local exhaust ventilation systems, and tents.

\section{Monitoring for Personnel Contamination}

1. Personnel shall undergo a whole-body frisk under the following conditions:
a. Immediately upon entry into an uncontaminated area after exiting Contamination Areas, High Contamination Areas, and Airborne Radioactivity Areas.
b. As directed by the RWP or the RCO.

2. In addition to the above, personnel exiting a Controlled Area containing Contamination, High Contamination, or Airborne Radioactivity Areas should, at a minimum, perform a hand and foot frisk. This frisk is an RCO option if the Controlled Area exit is immediately adjacent to the location where an exiting worker has already received a whole-body frisk.

3. Where frisking cannot be performed at the exit from Contamination Areas, High Contamination Areas, or Airborne Radioactivity Areas due to high background radiation levels, personnel shall:
a. Remove all protective equipment and clothing at the exit.
b. Proceed directly to the nearest designated monitoring station.
c. Perform a whole-body frisk, or exit through a portal monitor.

4. Personnel frisking shall be performed after removal of $P C$ and prior to washing or showering. Contamination on a person's skin or hair should be removed by appropriate decontamination methods. Contamination levels should be reduced below those specified in Table 2-2. Decontamination should continue until subsequent surveys can no longer detect contamination, but without causing skin abrasion. The individual should be counseled on good health physics practices and associated health hazards to address his/her personal concerns.

5. Personnel frisking shall be performed using instruments that meet the minimum detection requirements of Article 221.2. Guidelines for personnel frisking are provided in Appendix 3D. Individuals who have received instruction in proper frisking procedures may self-frisk.

6. The use of automated personnel contamination monitors is encouraged. 
7. Personal items, such as notebooks, papers and flashlights, shall be subject to the same frisking requirements as the person carrying them. Contamination detected on items of personal clothing or property should be removed by the appropriate decontamination methods to the levels specified in Article 461.4. If decontamination to these levels cannot be accomplished, then the item(s) should be confiscated, provisions should be made to provide suitable outer clothing or shoes to be worn home, and the individual should be reimbursed for the replacement cost of confiscated articles.

8. Instructions for personnel frisking should be posted adjacent to personnel frisking instruments or monitors, unless frisking is to be performed by a qualified RCT. At remote NV/YMP locations, frisking should be performed according to RCO procedure by personnel trained to do so.

9. The personnel frisking requirements contained in this Article are not applicable at those facilities that contain only radionuclides, such as tritium, that cannot be detected by currently available hand-held or automated frisking instrumentation. At such facilities, additional emphasis should be placed on worker bioassay programs and routine contamination and air sampling programs.

\section{PART 4 Radiological Work Controls}

\section{Requirements}

1. Radiological work activities shall be conducted as specified by the controlling technical work document and RWP.

2. Prerequisite conditions, such as tag-outs and system isolation, should be verified in accordance with the technical work documents before work is initiated.

\section{Work Conduct and Practices}

1. Contamination levels caused by ongoing work shall be monitored. Work should be curtailed and decontamination performed at preestablished levels, taking into account worker exposure.

2. Tools and equipment should be inspected to verify operability before being brought into Contamination, High Contamination, or Airborne Radioactivity Areas.

3. The use of radiologically clean tools or equipment in Contamination, High Contamination or Airborne Radioactivity Areas should be minimized by the implementation of a contaminated tool crib in accordance with Article 442.5. 
When such use is necessary, tools or equipment with complex or inaccessible areas should be wrapped or sleeved to minimize contamination.

4. Engineering controls, such as containment devices, portable or auxiliary ventilation and temporary shielding, should be installed in accordance with the technical work documents and inspected prior to use.

5. Hoses and cables entering the work area should be secured to prevent the spread of contamination or safety hazards.

6. The identity of components and systems should be verified prior to work.

7. Work activities and shift changes should be scheduled to prevent idle time in radiation areas.

8. Where practicable, parts and components should be removed to areas with low dose rates to perform work.

9. Upon identification of radiological concerns, such as inappropriate work controls or procedural deficiencies, workers should immediately report the concern to line supervision and the assigned RCTs or the RCO.

10. Requirements for area cleanup should be included in the technical work documents. Work activities should not be considered complete until support material and equipment have been removed and the area has been returned to at least prework status.

11. To minimize intakes of radioactive material by personnel, smoking, eating, or chewing shall not be permitted in Contamination, High Contamination, or Airborne Radioactivity Areas. When a potential exists for personnel heat stress, drinking of water may be permitted within a Contamination Area under the following documented conditions and controls:

a. The potential for heat stress cannot be reduced by the use of administrative or engineering controls.

b. All drinking is from approved containers or sources.

c. At a minimum, workers' hands and faces are monitored for contamination prior to drinking.

d. Participating workers are monitored as part of the bioassay program.

e. The applicable requirements and controls are described in approved procedures. 


\section{Logs and Communications}

1. RadCon personnel should maintain logs to document radiological occurrences, status of work activities, and other relevant information.

2. During continuous or extended daily operations, oncoming RadCon personnel should review logs and receive a turnover briefing from the personnel they are relieving.

3. Communication systems required by the RWP or technical work document should be checked for operability before being brought into the work area and periodically during work.

4. Workers should keep RadCon personnel informed of the status of work activities that affect radiological conditions.

\section{Review of Work in Progress}

1. As part of their normal work review, work supervisors should periodically review ongoing jobs to ensure prescribed radiological controls are being implemented.

2. RadCon personnel should conduct frequent tours of the workplace to review the adequacy of radiological work practices, posting, and area controls.

3. During the performance of jobs for which a pre-job dose estimate was made, the $\mathrm{RCO}$, in cooperation with line management, should periodically monitor collective dose accumulation and compare it with the pre-job dose estimate. Differences should be reviewed to identify causes and assess the need for corrective actions.

\section{Stop Radiological Work Authority}

1. Any worker has the authority and responsibility to stop radiological work activities for any of the following reasons:

a. Inadequate radiological controls.

b. Radiological controls not being implemented.

c. RadCon Hold Point not being satisfied.

2. Stop radiological work authority shall be exercised in a justifiable and responsible manner.

3. Once radiological work has been stopped, it shall not be resumed until proper RadCon has been reestablished. 
4. Resumption of radiological work requires the approval of the line manager responsible for the work, and the RadCon Manager; this approval may be delegated in writing.

\section{Response to Abnormal Situations}

1. This Manual, or procedures for responding to abnormal situations, shall establish requirements for alarm response procedures. Alarm response procedures should address the general actions in items 2 through 6 below, modified as necessary to reflect specific facility conditions.

2. At NV/YMP facilities, response to a CAM alarm should include the following actions:

a. Immediately stop and secure all work activities.

b. Evacuate unnecessary personnel.

c. Notify line management and RCO, if available.

d. Line management in consultation with RadCon personnel, and RCO, if available, immediately assess the situation.

3. Response to increasing or unanticipated radiation levels, as identified by a supplemental dosimeter, area radiation monitor alarm, or by the assigned RCTs, should include the following actions:

a. Stop work activities.

b. Alert others.

c. Affected personnel immediately exit the area.

d. Notify RadCon personnel.

e. RadCon personnel will investigate, and take action as necessary.

4. Response to a criticality or tunnel evacuation alarm should include the following actions:

a. Immediately evacuate the area without stopping to remove PC or perform exit monitoring.

b. Keep personnel that are wearing PC together until monitoring can be performed.

c. Report to designated assembly area.

5. Response to a personnel contamination monitor alarm should include the following actions:

a. Remain in the immediate area.

b. Notify RadCon personnel. 
c. Take actions that may be available to minimize cross-contamination, such as putting a glove on a contaminated hand.

d. Take follow-up actions in accordance with Article 541.

6. a. Response to a spill of radioactive material (or toxic chemicals within a radiological area) should include the following actions:

(1) Stop or secure the operation causing the spill.

(2) Warn others in the area.

(3) Isolate the spill area if possible.

(4) Minimize individual exposure and contamination.

(5) Secure unfiltered ventilation.

(6) Notify RadCon personnel.

b. For spills involving highly toxic chemicals, workers should immediately exit the area without attempting to stop or secure the spill. They should then promptly notify the RSPC, Industrial Hygiene Section, who will determine the proper course of action in consultation with line management. YMP personnel are to notify the DOEMMP FOC.

\section{Controls for Bench-top Work, Laboratory Fume Hoods, Sample Stations, and Glove Boxes}

The following requirements are applicable to radiological work which has the potential to generate radioactive contamination in localized bench-top areas, laboratory fume hoods, sample stations, and glove-box operations located in areas that are otherwise contamination free.

1. An RWP should be issued to control radiological work in localized bench-top areas, laboratory fume hoods, sample sinks, and glove boxes.

2. The following controls apply to localized bench-top and laboratory fume hood operations:

a. PC shall, at a minimum, include lab coats and gloves. Gloves should be secured at the wrist as necessary.

b. Shoe covers should be considered based on the potential for floor contamination.

c. Workers should periodically monitor their hands during work.

d. Upon completion of work or prior to leaving the area, workers shall monitor those areas of their body that are potentially contaminated. At a minimum, this includes hands, arms, and front portions of the body. Workers should perform a whole-body frisk. 
3. The following controls apply to sample station operations:

a. PC shall, at a minimum, include lab coats and gloves. Gloves should be secured at the wrist as necessary.

b. Shoe covers should be considered based on the potential for floor contamination.

c. If there is a potential for splashing or airborne radioactivity, such as when taking pressurized samples, additional controls such as rubber aprons, face shields, full PC, or respiratory protection should be instituted.

d. Workers should periodically monitor their hands during work.

e. Upon completion of work or prior to leaving the area, workers shall monitor those areas of their body that are potentially contaminated. At a minimum, this includes hands, arms, and front portions of the body. Workers should perform a whole-body frisk when required by the RWP, or its equivalent.

4. The following controls apply to glove-box operations:

a. Glove boxes should be inspected for integrity and operability prior to use.

b. Glove boxes should be posted to identify whole body and extremity dose rates.

c. PC shall, at a minimum, include lab coats and gloves. Gloves should be secured at the wrist as necessary.

d. Shoe covers should be considered based on the potential for floor contamination.

e. Workers should periodically monitor their hands during work.

f. Upon completion of work or prior to leaving the area, workers shall monitor those areas of their body that are potentially contaminated. At a minimum, this includes hands, arms, and feet. Workers should perform a whole-body frisk when required by the RWP, or its equivalent.

\section{Controls for Hot Particles}

Hot particles are small, discrete, highly radioactive particles capable of causing extremely high doses to a localized area in a short period of time. Hot particle contamination may be present or be generated when contaminated systems are opened or when operations such as machining, cutting, or grinding are performed on highly radioactive materials.

1. This Manual defines hot particles as those capable of producing a shallow dose equivalent greater than $100 \mathrm{mrem}$ in one hour. Operational work experience has demonstrated that hot particles are not generated at the NTS. However, if during the work review process a potential for the generation of hot particles is identified, then the measures identified in items 3 through 7 will be followed. 
2. Measures for controlling hot particles, as identified in items 3 through 7 of this Article, should be implemented under the following conditions:

a. Upon identification of hot particles.

b. During new or nonroutine operations with a high potential for hot particles, based on previous history.

c. Upon direction of the RCO.

3. Areas or operations with the potential for hot particle contamination should be surveyed in accordance with Article 554.7.

4. Contamination Area posting should be annotated to specifically identify the presence of hot particles.

5. Access to hot particle areas should be controlled by a job-specific RWP. The following controls should be considered for inclusion on the RWP:

a. Periodic personnel monitoring during the work activity, at a frequency based on the potential magnitude of skin exposure.

b. Additional PPE and PC.

c. Direct RadCon coverage during work or assistance during PC removal.

d. Use of sticky pads or multiple step-off pads.

6. PPE and PC used in hot particle areas should be segregated from other radiological protective equipment and clothing during laundering and surveyed prior to reuse.

7. Response to hot particle skin contamination of personnel should include the following:

a. Immediate removal and retention of the hot particle for subsequent analysis.

b. Analysis of the particle.

c. Assessment of worker dose.

d. Evaluation of work control adequacy.

\section{PART 5 [Reserved]}

\section{1 [Reserved]}

\section{2 [Reserved]}

353 [Reserved] 


\section{PART 6 Special Applications}

This Part provides supplemental information to augment the basic requirements of this Manual. This Part is not intended to apply to facilities that use the subject radionuclides in limited or tracer amounts, such as analytical laboratories.

\section{Plutonium Operations}

NV/YMP does not include facilities or operations which are considered Plutonium Operations. This Article does not apply to NV/YMP.

\section{Uranium Operations}

NV/YMP does not include facilities or operations which are considered Uranium Operations. This Article does not apply to NV/YMP.

\section{Tritium Operations}

The following characteristics of tritium require consideration in implementing the RadCon Program at tritium facilities:

1. Tritium emits low-energy beta particles which cannot be monitored using external dosimeters, consequently requiring the use of bioassay measurements to evaluate worker dose.

2. Worker exposure to tritium as water vapor causes a much greater dose than exposure to elemental tritium gas.

3. Normal personnel frisking techniques are ineffective for tritium. Consequently, a high reliance is placed on worker bioassay and routine contamination and air monitoring programs.

4. Due to its ability to permeate substances which it contacts, tritium is difficult to contain. Special attention should be directed to the selection of PPE and PC.

For the above reasons, guidance contained in the document "Health Physics Manual of Good Practices at Tritium Facilities, MLM-3719," should be considered for tritium operations. This manual provides specific guidance related to internal dosimetry, contamination and air monitoring, tritium containment practices and techniques, and PPE and PC. 


\section{Accelerator Operations}

NV/YMP does not include facilities or operations which are considered Accelerator Operations. This Articles does not apply to NVMMP.

\section{Radiation Generating Devices}

Special considerations associated with the use of radiation generating devices include the presence of extremely high dose rates and the potential for uncontrolled exposures. Operation of these devices requires stringent physical and administrative controls to prevent overexposure to operating and support personnel and those in adjacent work areas. The following provisions shall apply to radiation generating devices operated within NV/YMP:

1. DOE 5480.4 mandates the use of American National Standards Institute (ANSI) N43.3 entitled, "American National Standard for General Radiation SafetyInstallations Using Non-Medical X-Ray and Sealed Gamma-Ray Sources, Energies up to $10 \mathrm{MeV}$, for operations involving the irradiation of materials and on-site operations involving devices other than sealed sources.

2. DOE 5480.4 mandates the use of ANSI N43.2 entitled, "Radiation Safety for XRay Diffraction and Fluorescence Analysis Equipment," for operations involving the following devices:
a. Analytical diffraction and fluorescence.
b. Flash $x$-ray.
c. Sealed source irradiators used for diffraction studies.

3. Line management in conjunction with the RCO shall establish the RadCon requirements for incidental $\mathrm{x}$-ray devices such as electron microscopes and electron beam welders.

4. Devices for medical use shall be registered with the appropriate regulatory agency.

5. Control requirements for radiographic devices are:

a. On-site operations with devices containing sealed sources should be conducted in accordance with the requirements contained in 10 CFR 34 entitled, "Licenses for Radiography and Radiation Safety Requirements for Radiographic Operations."

(1) Permanent radiographic installations, structures, or areas in which radiography is regularly performed should be equipped with control 
devices to protect against unauthorized or accidental entry as directed by those orders.

(2) Temporary radiographic operations that are performed in locations that were not designed for radiography and do not contain built-in physical or engineering controls should have the entire radiation exclusion area barricaded and/or roped off, to prevent inadvertent personnel access. Additionally, positive control of the "High Radiation Areas" and "Very High Radiation Areas," should be demonstrated by the use of visual surveillance and/or locked entryways. This visual control should be demonstrated from the time the area is cleared until radiography is completed and the source has been secured. Person(s) performing visual control should have no other responsibility during the radiography operation and should be person(s) other than the radiographers actually involved in performing radiography.

b. On-site operations conducted by off-site contractors shall be approved by line management and be coordinated with Radioactive Material Control (RAMATROL), operated in Mercury by the RSPC, Building 180. This process shall ensure the contractor has a valid NCR or Agreement State license and that the operational and emergency procedures are current and available.

6. Safety devices and interlocks at fixed installations shall be operational prior to and during generation of a radiation field. Operational status shall be verified by testing.

7. The provisions of this Article apply to the $24 \mathrm{MeV}$ betatron operated in Able compound in Area 27.

\section{PART 7 Construction and Restoration Projects}

Construction and restoration projects, including decontamination and decommissioning (D\&D), remedial action, or other actions involving materials which contain low levels of radioactivity may present special problems and require program-specific control methods. Health and Safety Plans are normally developed to specify controls for all types of restoration programs.

\section{Requirements}

Radiological operations and work activities at construction and environmental restoration projects shall be conducted in accordance with this Manual. In light of the special nature of these activities, which typically involve low-levels of radioactivity and 
the use of heavy construction or earth-moving equipment, these projects require some radiological considerations different from other activities governed by this Manual.

Areas scheduled for drilling sites or construction activities shall be cleared through the DOEIAMD to ensure radiological safety per NTS-SOP 6401. YMP activities need to be cleared through DOE/YMP FOC.

For the following specific subject areas, the radiological requirements of this Manual may be modified by the limited application of the provisions of Article 113.3. The TO RadCon Manager is authorized to change mandatory "shall" requirements to "should" to facilitate implementation of radiological controls in the following specific subject areas. The contractor has the responsibility to document the technical equivalency of alternative solutions.

1. Performance goals and indicators appropriate to remedial activities.

2. PPE requirements and practices to accommodate other hazards on the site. At NV/YMP facilities, these hazards may include heat stress (hyperthermia), cold stress (hypothermia), and any other dangers commonly associated with outdoor work environments.

3. Using respiratory protection as normal conduct of operations due to lack of engineering controls and temporary nature of the work.

4. Using Contamination Reduction Corridors to accommodate moving personnel and heavy equipment through a variety of decontamination stations.

5. Methods to obtain representative samples for releasing equipment and material from the work areas

6. Surveying materials released from soil contamination areas that exhibit significant contamination transfer properties.

7. Presiding state and federally mandated soil cleanup criteria over surface contamination criteria that otherwise apply.

8. Monitoring and survey frequency for inactive facilities or large areas that are infrequently occupied.

9. Outdoor storage of uncontained, bulk radioactive materials such as contaminated soil.

10. Posting privately owned and adjacent property. 
11. Evaluating outdoor air monitoring methodologies that take into account dust loading, environmental factors, and supplemental breathing zone sampling.

12. Criteria for suspending operations under inclement conditions, such as wind or rain.

\section{Environmental Conditions}

Inclement weather or other environmental conditions may disrupt radiological controls. If that occurs, the following actions should be considered:

1. Using covers, wind screens, and runoff collection basins to prevent spreading radioactive material.

2. Provisions for worksite personnel to assemble and be monitored prior to release or reestablishing work.

3. Evaluating work areas to determine if a need exists for modified work controls or decontamination.

4. RSPC issuing winter weight modesty garments to shield personnel from cold stress while wearing PC outdoors in inclement weather.

\section{Other Workplace Hazards}

Radiological controls should be administered in a way to ensure that protection from other workplace hazards can also be achieved. Other workplace hazards to consider include but are not limited to the following:

1. General construction hazards.

2. Confined spaces.

3. Flammable and combustible materials.

4. Hazardous materials.

5. Toxic substances.

6. Electrical systems.

7. Heat stress and cold stress.

8. Biological hazards.

9. Noise and vibration.

10. Machinery and machine guarding.

11. Excavations and trenches.

12. High explosives and blasting.

13. Hand and portable powered tools.

14. Walking-working surfaces.

15. Means of egress. 


\section{Appendix 3A \\ Checklist for Reducing Occupational Radiation Exposure}

\section{Preliminary Planning and Scheduling}

- Plan in advance

- Delete unnecessary work

- Determine expected radiation levels

- Estimate collective dose

- Sequence jobs

- Schedule work

- Select a trained and experienced work force

- Identify and coordinate resource requirements

\section{Preparation of Technical Work Documents}

- Include special RadCon requirements in technical work documents

- Perform ALARA pre-job review

- Plan access to and exit from the work area

- Provide for service lines (air, welding, ventilation)

- Provide communication (sometimes includes closed-circuit television)

- Remove or shield sources of radiation

- Plan for installation of temporary shielding

- Decontaminate

- Work in lowest radiation levels

- Perform as much work as practicable outside radiation areas

- State requirements for standard tools

- Consider special tools, including robots

- State staging requirements for materials, parts, and tools

- Incorporate RadCon Hold Points

- Minimize discomfort of workers

- Revise estimates of person-rem

- Prepare RWPs

\section{Temporary Shielding}

- Design shielding to include stress considerations

- Control installation and removal by written procedure

- Inspect after installation

- Conduct periodic radiation surveys

- $\quad$ Prevent damage caused by heavy lead temporary shielding

- Balance radiation exposure received in installation against exposure saved by installation

- $\quad$ Shield travel routes 
- Shield components with abnormally high radiation levels early in the maintenance period

- Shield position occupied by worker

- Perform directional surveys to improve design of shielding by locating source of radiation

- Use mock-ups to plan temporary shielding design and installation

- Consider use of water-filled shielding

\section{Rehearsing and Briefing}

- Rehearse

- Use mock-ups duplicating working conditions

- Use photographs and videotapes

- Supervisors conduct briefings of workers

\section{Performing Work}

- Comply with technical work documents and RWPs

- Post radiation levels

- Keep excess personnel out of radiological areas

- Minimize radiation exposure

- $\quad$ Supervisors and workers keep track of radiological exposure

- Workers assist in radiation and radioactivity measurements

- Assign RadCon monitoring responsibilities

- Evaluate use of fewer workers

- Reevaluate reducing radiation exposures

- Compare actual collective dose against pre-job estimate

- Review work practices to see if changes will reduce dose

- Coordinate personnel at the job site to reduce nonproductive time 
Appendix 3B

Physical Access Controls for High and Very High Radiation Areas

1. One or more of the following features should be used for each entrance or access point to a High Radiation Area and shall be used for each entrance or access point to a High Radiation Area where radiation levels exist such that a person could exceed a whole-body dose of 1 rem in any one hour:

a. A control device that prevents entry to the area when high radiation levels exist or upon entry causes the radiation level to be reduced below that level defining a High Radiation Area.

b. A device that functions automatically to prevent using or operating the radiation source or field while personnel are in the area.

c. A control device that energizes a conspicuous visible or audible alarm signal so that the person entering the High Radiation Area and the supervisor of the activity are made aware of the entry.

d. Entryways that are locked, except during periods when access to the area is required, with positive control over each entry.

e. Continuous direct or electronic surveillance that is capable of preventing unauthorized entry.

f. A control device that automatically generates audible and visual alarm signals to alert personnel in the area before use or operation of the radiation source and in sufficient time to permit evacuation of the area or activation of a secondary control device that will prevent using or operating the source.

2. In addition to the above requirements, additional measures shall be implemented to ensure personnel are not able to gain access to Very High Radiation Areas when dose rates are in excess of the posting requirements of Table 2-3.

3. Physical access controls over High and Very High Radiation Areas shall be established in such a way that does not prevent a person from leaving the area. 
NV/YMP Radiological Control Manual, Rev 2:

November 13, 1996

CONDUCT OF RADIOLOGICAL WORK CHAPTER 3

THIS PAGE INTENTIONALLY LEFT BLANK 
Appendix 3C

Contamination Control Practices

\section{Selection of PC}

1. Workers should inspect PC prior to use for tears, holes, or split seams that would diminish protection. Any defective items should be replaced with intact PC.

2. PC as prescribed by the RWP should be selected based on the contamination level in the work area, the anticipated work activity, worker health considerations, and regard for nonradiological hazards that may be present. Table $3 \mathrm{C}-1$ provides general guidelines for selection.

Table 3C-1 Guidelines for Selecting Protective Clothing

\begin{tabular}{|c|c|c|c|}
\hline \multirow[b]{2}{*}{$\begin{array}{l}\text { WORK } \\
\text { ACTIVITY }\end{array}$} & \multicolumn{3}{|c|}{ REMOVABLE CONTAMINATION LEVELS } \\
\hline & $\begin{array}{c}\text { LOW } \\
\text { (1 to } 10 \text { times Table } \\
2-2 \text { values) } \\
\end{array}$ & $\begin{array}{c}\text { MODERATE } \\
\text { (10 to } 100 \text { times } \\
\text { Table } 2-2 \text { values) } \\
\end{array}$ & \begin{tabular}{l}
\multicolumn{1}{c}{ HIGH } \\
(> 100 times Table 2-2 \\
values)
\end{tabular} \\
\hline Routine & Full set of PC & Full set of PC & $\begin{array}{l}\text { Full set of PC, double } \\
\text { gloves, double shoe } \\
\text { covers }\end{array}$ \\
\hline Heavy work & $\begin{array}{l}\text { Full set of PC, work } \\
\text { gloves }\end{array}$ & $\begin{array}{l}\text { Double set of PC, } \\
\text { work gloves }\end{array}$ & $\begin{array}{l}\text { Double set of PC, work } \\
\text { gloves }\end{array}$ \\
\hline $\begin{array}{l}\text { Work with } \\
\text { pressurized or } \\
\text { large volume } \\
\text { liquids, closed } \\
\text { system breach }\end{array}$ & $\begin{array}{l}\text { Full set of } \\
\text { non-permeable PC }\end{array}$ & $\begin{array}{l}\text { Double set of PC } \\
\text { (outer set non- } \\
\text { permeable), rubber } \\
\text { boots }\end{array}$ & $\begin{array}{l}\text { Double set of } \mathrm{PC} \text { and } \\
\text { non-permeable outer } \\
\text { clothing, rubber boots }\end{array}$ \\
\hline
\end{tabular}

\section{Table 3C-1 Notes:}

1. For hands-off tours or inspections in areas with removable contamination at levels 1 to 10 times the values in Table 2-2, labcoats, shoe covers, and gloves may be used instead of full PC.

\section{Full Set of PC}
a. Coveralls
b. Cotton glove liners (optional)
c. Inner gloves (surgical, Pylox, or Nitrile)
d. Outer gloves
e. Plastic bags for shoe covers 
f. Rubber totes

g. Hood (if required by RWP)

h. Sleeve covers (if required by RWP)

i. Modesty garments, at the option of the wearer, or if required by RWP (summer or winter weight, depending on environmental conditions)

\section{Double Set of PC}
a. Two pairs of coveralls
b. Glove liners (cotton, optional)
c. Two pairs of gloves
d. Two pairs Plastic bags for shoe covers; or one pair each, plastic bags and lightweight rubber boots
e. One pair rubber boots
f. Two Hoods
g. Sleeve covers
h. Modesty garments, at the option of the wearer, or if required by RWP

3. Cotton glove liners may be worn inside gloves for comfort, but should not be worn alone or considered as a layer of protection. Plastic gloves may be worn alone under certain conditions requiring extreme manual dexterity to minimize doses to the hands.

4. Shoe covers and gloves should be sufficiently durable for the intended use. The appropriate safety gear should be worn for work activities requiring additional strength, abrasion resistance, or when required by other, non-radiological, NV/YMP safety procedures.

5. NV/YMP personnel working in Contamination Areas use company-issued hard hats designated for normal use when protective headgear is required. If these become contaminated, they are either decontaminated by RSPC personnel to below Table 2-2 limits, or disposed of as contaminated waste.

6. Shoe covers and gloves should be secured or taped at the coverall legs and sleeves when necessary to prevent worker contamination. Tape should be tabbed to permit easy removal.

7. Supplemental pocket or electronic dosimeters should be worn outside the PC, in a manner accessible to the worker. Workers should protect such dosimeters from contamination by placing them in an outer coverall pocket or in plastic bags or pouches. 
8. Outer personal clothing should not be worn under PC for entry to High

Contamination Areas or during work conditions requiring a double set of PC.

Specified RWP requirements shall be followed by all personnel.

\section{Removal of PC}

Potentially contaminated PC should be removed without spreading contamination and in particular without contaminating the skin. Workers should be instructed not to touch the skin or place anything in the mouth during PC removal. Instructions for PC removal comparable to the sequence presented below should be posted adjacent to the step-off pad in accordance with Article 325.6.

\section{Recommended Sequence for Removing a Full Set of PC at the Step-Off Pad}

Before stepping out of the Contamination Area or Airborne Radioactivity Area to the step-off pad, the worker should:

1. Remove exposed tape.

2. Remove sleeve covers.

3. Remove rubber totes, placing shoes one at a time onto step-off pad, or designated contamination-free hotline area as each tote is removed.

4. Remove outer gloves.

5. Remove hood from front to rear, as applicable.

6. Remove coveralls, inside out, touching inside only.

7. Remove respiratory protection, as applicable.

8. Remove inner gloves.

9. Take down barrier closure, as applicable.

10. Remove tape or fastener from inner shoe cover (boot bag).

11. Remove each shoe cover, placing shoe onto clean step-off pad.

12. Remove cotton glove liners, if worn.

13. Replace barrier closure, as applicable.

14. Commence whole-body frisking.

15. Monitor badge and dosimeter for contamination.

The sequence for the removal of primary and supplemental dosimetry is dependent upon where the dosimetry was worn and the potential for contamination. 


\section{Recommended Sequence for Removing a Double Set of PC using Two Step-Off} Pads

Before stepping to the inner step-off pad, the worker should:

1. Remove exposed tape.

2. Remove sleeve covers.

3. Remove outer rubber totes, stepping one foot at a time onto step-off pad, or designated contamination-free hotline area as each outer tote is removed.

3. Remove each outer glove.

4. Remove hoods from front to rear.

5. Remove outer coveralls, inside out, touching inside only.

6. Remove respiratory protection, as applicable.

7. Remove tape from inner coveralls.

8. Remove each outer shoe cover, stepping on inner step-off pad as each is removed.

Before stepping to the outer step-off pad, the worker should:

9. Remove inner coveralls, inside out, touching inside only.

10. Remove inner rubber gloves.

11. Take down barrier closure, as applicable.

12. Remove tape or fastener from inner shoe cover or boot bag.

13. Remove each inner shoe cover or boot bag, placing shoe on clean outer step-off pad.

14. Remove cotton glove liners.

15. Replace barrier closure, as applicable.

16. Commence whole-body frisking.

17. Monitor badge and dosimeter for contamination.

The sequence for the removal of primary and supplemental dosimetry is dependent upon where the dosimetry was worn and the potential for contamination.

\section{Using Multiple Step-Off Pads}

1. Multiple step-off pads should be used to control exit from High Contamination Areas. These pads define interim control measures within the posted area to limit the spread of contamination. The following controls apply:

a. The inner step-off pad should be located immediately outside the highly contaminated work area, but still within the posted area.

b. The worker should remove highly contaminated outer clothing prior to stepping on the inner step-off pad. 
c. Additional secondary step-off pads, still within the posted area, may be utilized as necessary to restrict the spread of contamination out of the immediate area.

d. The final or outer step-off pad should be located immediately outside the Contamination Area. 
THIS PAGE INTENTIONALLY LEFT BLANK 


\section{Appendix 3D \\ Guidelines for Personnel Contamination Monitoring with Hand-Held Survey Instruments}

Comparable instructions to those presented here should be posted adjacent to monitoring instruments in accordance with Article 338.8.

\section{General Requirements}

1. Verify that the instrument is in service, set to the proper scale, and verify that the audio output can be heard during frisking.

2. Hold probe less than $1 / 2$ inch from surface being surveyed for beta and gamma contamination, approximately $1 / 4$ inch for alpha contamination.

3. Move probe slowly over surface, approximately 2 inches per second.

4. If the count rate increases during frisking, pause for 5 to 10 seconds over the area to provide adequate time for instrument response.

5. If the count rate increases to a value greater than the preestablished contamination limit or the instrument alarms, remain in the area and notify RadCon personnel.

6. The whole-body frisk should take at least two to three minutes.

\section{Performance of Monitoring}

1. Frisk the hands before picking up the probe.

2. Perform the frisk in the following order:
a. Head (pause at mouth and nose for approximately 5 seconds).
b. Neck and shoulders.
c. Arms (pause at each elbow).
d. Chest and abdomen.
e. Back, hips, and seat of pants.
f. Legs (pause at each knee).
g. Shoe tops.
h. Shoe bottoms (pause at sole and heel).
i. Personnel and supplemental dosimeters. 
NV/YMP Radiological Control Manual, Rev 2:

November 13, 1996

CONDUCT OF RADIOLOGICAL WORK CHAPTER 3

3. Return the probe to its holder and leave the area. The probe should be placed on the side or face up to allow the next person to monitor their hands before handling the probe. 


\section{CHAPTER 4 RADIOACTIVE MATERIALS}

Article

\section{TABLE OF CONTENTS}

PART 1 Radioactive Material Identification, Storage, and Control

411 Requirements . . . . . . . . . . . . . . . . . . . . . . . 4-1

412 Radioactive Material Labeling . . . . . . . . . . . . . . . . . 4-2

413 Radioactive Material Packaging $\ldots \ldots \ldots \ldots \ldots \ldots \ldots \ldots .4 . \ldots \ldots$

414 Radioactive Material Storage $\ldots \ldots \ldots \ldots \ldots \ldots \ldots \ldots .4 .4$

PART 2 Releasing and Transporting Radioactive Material . . . . . . . . . . . . . . 4-4

421 Release to Controlled Areas . . . . . . . . . . . . . . . . . . . 4-4

422 Release to Uncontrolled Areas . . . . . . . . . . . . . . . . 4-5

423 Transporting Radioactive Material . . . . . . . . . . . . . . 4-6

PART 3 Radioactive Source Controls . . . . . . . . . . . . . . . . . . . 4-6

431 Radioactive Source Controls . . . . . . . . . . . . . . . . . . 4-6

PART 4 Solid Radioactive Waste Management . . . . . . . . . . . . . . 4-8

441 Requirements . . . . . . . . . . . . . . . . . . . . . . 4-8

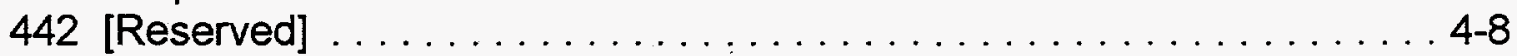

443 Mixed Waste . . . . . . . . . . . . . . . . . . . . . . . . . 4-8

PART 5 Controlling Radioactive Liquids and Airborne Radioactivity . . . . . . . . 4-8

451 Minimizing and Controlling Radioactive Liquid Wastes . . . . . . . . . . 4-8

452 Controlling Radioactive Drains . . . . . . . . . . . . . . . . . . 4-8

453 Controlling Airborne Radioactivity . . . . . . . . . . . . . 4-9

PART 6 Support Activities . . . . . . . . . . . . . . . . . . . . . . . . . . . . 4-9

461 Personal Protective Equipment and Protective Clothing . . . . . . . . 4-9

462 [Reserved] . . . . . . . . . . . . . . . . . . . . . . . . . 4-10

463 [Reserved] . . . . . . . . . . . . . . . . . . . . . . . . . 4-10

464 Vacuum Cleaners and Portable Air-Handling Equipment ...... . . 4-10

Appendix 4-A Values for Exemption of Sealed Radioactive Sources from Inventory and Integrity Testing

Table

4-1 Labeling Requirements for Radioactive Materials 


\section{PART 1 Radioactive Material Identification, Storage, and Control}

Radioactive material includes activated material, sealed and unsealed sources, and materials that emit radiation. RMA means any area, accessible to individuals, in which items or containers of radioactive material exist and the quantities of radioactive material exceed ten times the applicable values provided in $10 \mathrm{CFR} 835$ Appendix E. Controls for sealed sources are described in Article 431. Items located in known or suspected Contamination, High Contamination, or Airborne Radioactivity Areas and having the potential to become contaminated are considered radioactive material.

\section{Requirements}

1. Radioactive materials and debris in RMAs and Soil Contamination Areas shall not be removed without the approval of the RSPC or the cognizant Radiological Control Organization.

2. Materials in Contamination, High Contamination, or Airborne Radioactivity Areas shall be considered contaminated until surveyed and released. Any equipment or system component removed from a process that may have had contact with radioactive material should be considered internally contaminated until disassembled to the extent required to perform an adequate survey, surveyed, and shown to be free of contamination. These survey and release requirements do not apply to Airborne Radioactivity Areas where only gaseous, short-lived (half-life of 1 hour or less) activation products are present.

3. Except for accountable sealed radioactive sources, radioactive material located within Contamination, High Contamination, or Airborne Radioactivity Areas does not require specific labeling or packaging.

4. Each TO should develop response and notification requirements associated with a loss of radioactive material, including searches, internal investigations, documentation, and reporting. The RCO shall be notified in the event of a loss of radioactive material. 


\section{Radioactive Material Labeling}

1. Individual containers of radioactive material and radioactive items shall be labeled if existing postings and control measures do not provide adequate warning to personnel [10 CFR 835.601(a)]. Postings and access control requirements for Contamination, High Contamination, and Airborne Radioactivity Areas provide sufficient personnel protection to negate the need for individual container or item labeling. Radioactive material outside Contamination, High Contamination, or Airborne Radioactivity Areas shall be labeled in accordance with Table 4-1.

2. The following are not subject to labeling requirements:

a. Material surveyed and determined to have contamination levels lower than Table 2-2 values.

b. Radioactive material or containers packaged and labeled for off-site shipment in accordance with DOT Regulations.

c. Unused PPE and PC.

d. Radiological samples such as air, process and soil samples or swipes that are in the custody of RadCon personnel or personnel properly trained in the handling, packaging, and transport of these samples.

e. Equipment or installed system components undergoing maintenance covered by an RWP.

f. Portable tools and equipment with fixed contamination permanently marked or painted with yellow or magenta and maintained in a contaminated tool crib or storage and distribution area.

g. Installed system components located within an area, the entrance to which is posted in accordance with Table 2-3.

h. Items excluded by the Nuclear Explosive Safety Study.

i. Historical items, such as uranium hexafluoride cylinders and large items used in demonstration projects, located within an RMA; such items shall be properly labeled when they are removed from an RMA.

j. Short-lived (half-life of 1 hour or less) radioactive material generated during an irradiation (i.e., research samples while an experiment is being conducted, etc.) that is immediately used.

3. Labels shall have a yellow background with a magenta or black standard radiation symbol. Lettering shall be magenta or black.

4. Radioactive material at a minimum, should be labeled with the words "CAUTION RADIOACTIVE MATERIAL" and the standard radiation symbol.

5. Packaged radioactive material should have the label visible through the package or affixed to the outside. 
Table 4-1 Labeling Requirements for Radioactive Materials

\begin{tabular}{||l|l||}
\hline \multicolumn{1}{|c|}{ ITEM/MATERIAL } & \multicolumn{1}{|c|}{ REQUIRED LABELING } \\
\hline $\begin{array}{l}\text { Equipment, components, and other items } \\
\text { that are radioactive, potentially } \\
\text { radioactive, or have been exposed to } \\
\text { radioactive contamination or activation } \\
\text { sources }\end{array}$ & $\begin{array}{l}\text { "CAUTION, RADIOACTIVE } \\
\text { MATERIAL" }\end{array}$ \\
\hline $\begin{array}{l}\text { Sealed and unsealed radioactive } \\
\text { sources or associated storage } \\
\text { containers }\end{array}$ & $\begin{array}{l}\text { "CAUTION, RADIOACTIVE } \\
\text { MATERIAL" or standard radiation } \\
\text { symbol }\end{array}$ \\
\hline $\begin{array}{l}\text { Equipment, components, and other items } \\
\text { with actual or potential internal } \\
\text { contamination }\end{array}$ & $\begin{array}{l}\text { "CAUTION, INTERNAL } \\
\text { CONTAMINATION" or "CAUTION, } \\
\text { POTENTIAL INTERNAL } \\
\text { CONTAMINATION" }\end{array}$ \\
\hline $\begin{array}{l}\text { Components, equipment, or other items } \\
\text { with fixed contamination }\end{array}$ & "CAUTION, FIXED CONTAMINATION" \\
\hline
\end{tabular}

\section{Radioactive Material Packaging}

1. Radioactive material that is outside Contamination, High Contamination, or Airborne Radioactivity Areas and is confirmed or suspected of having removable radioactive contamination levels greater than Table $2-2$ values shall be securely wrapped in plastic or placed in a container. Approved compensatory radiological controls where wrapping or containerizing is not practical are as follows:

a. Prior to movement, equipment will be surveyed for contamination.

b. Field decontamination will be performed to remove identified contamination. Past experience indicates that residual contamination remaining after such decontamination is typically $<10$ times Table $2-2$ levels, and is either fixed or mixed with grease or other viscous materials.

c. Surveys will be performed to verify the adequacy of the field decontamination and subsequent spot decontamination will be performed as appropriate if significant levels of general area contamination remain. The equipment will then be transported to a Decontamination Facility. 
d. For moving equipment with general area residual contamination levels $>20$ times Table 2-2 levels, the use of localized coverings will be considered and appropriate spot surveys of the route will be performed. Equipment will then be labeled as potentially contaminated or contaminated based on its status.

2. Radioactive material with sharp edges or projections should be taped or additionally protected to ensure package integrity.

3. Radioactive material with removable or potentially removable contamination levels in excess of 100 times Table 2-2 values should have additional packaging controls such as double-wrapping or the use of plastic bags inside containers.

4. Yellow plastic wrapping material should be used for packaging radioactive material. Yellow plastic sheets or bags should not be used for nonradiological purposes.

\section{Radioactive Material Storage}

1. Radioactive material should be stored in a designated RMA.

2. Decontaminating or disposing of radioactive material is the preferred alternative to long-term storage.

3. RMAs should be approved by the responsible TO RadCon Manager, or designee.

4. A custodian should be assigned responsibility for each RMA.

5. Each RMA should be inspected at least annually.

6. Storing nonradioactive material in an RMA is discouraged.

\section{PART 2 Releasing and Transporting Radioactive Material}

\section{Release to Controlled Areas}

1. Radioactive material in Contamination, High Contamination, or Airborne Radioactivity Areas shall be surveyed prior to release. Unpackaged radioactive material to be released to Controlled Areas shall be demonstrated to have contamination levels less than Table 2-2 values. Radioactive material to be released to uncontrolled areas shall be surveyed in accordance with Article 422 . 
2. Material with fixed contamination levels that exceed the total contamination limits specified in Table 2-2, and that have removable contamination less than Table 2-2 levels, may be released for use in Controlled Areas outside of the radiological areas. These items shall be routinely monitored and controlled in accordance with administrative procedures.

3. Radioactive material with removable contamination levels greater than Table 2-2 values shall be packaged prior to release to Controlled Areas. These items shall be routinely monitored and controlled in accordance with administrative procedures.

4. Material not immediately removed from Contamination, High Contamination, or Airborne Radioactivity Areas after survey should be controlled to prevent contamination while awaiting release.

5. Records for release of surveyed materials shall describe the property, date of last survey, identity of the person who performed the survey, type and identification number of the survey instruments used, and survey results.

6. Materials released to Controlled Areas shall be labeled in accordance with Article 412.

\section{Release to Uncontrolled Areas}

1. DOE 5400.5 describes radiological criteria for releasing material to uncontrolled areas.

2. DOE 5400.5 provides guidance for releasing radioactive material that has been contaminated in depth or volume, such as activated material or smelted contaminated material.

3. The criteria for unrestricted release of materials established in DOE 5400.5 may be more stringent than those established for release to Controlled Areas. If surveys conducted to release materials from radiological areas are sufficient to meet the requirements of DOE 5400.5, then additional surveys are not required prior to releasing the material from the Controlled Area. Otherwise, an additional survey to ensure compliance with DOE 5400.5 shall be performed.

4. Material not immediately released after survey should be controlled to prevent contamination while awaiting release.

5. Radiological labeling shall be removed from or defaced on material prior to release for unrestricted use. 


\section{Transporting Radioactive Material}

1. 49 CFR 170 through 180 describe requirements for inspecting and surveying packages, containers, and transport conveyances prior to off-site transport. The 49 CFR 173 contamination values shall be used as controlling limits for all offsite shipments.

a. The "NTS Hazardous Material Onsite Transportation Safety Manual" (DOE/NV 356, Revision 3) contains the onsite transportation requirements for the NTS.

b. RAMATROL should provide the necessary shipping forms, upon request, to individuals or organizations so that radioactive materials can be shipped.

2. Off-site shipments of radioactive material, including subcontractors' handling of off-site shipments, shall be controlled and conducted in accordance with applicable federal, state, and local regulations.

3. Prior to, and upon receipt of any radioactive shipment, a visual inspection of packages should be performed to ensure they are not damaged.

4. Commercial transport conveyances should be radiologically surveyed before loading.

5. The site emergency plan should describe appropriate responses for potential on-site radioactive materials transportation accidents.

\section{PART 3 Radioactive Source Controls}

\section{Radioactive Source Controls}

The following provisions apply to sealed and unsealed radioactive sources.

All DOE N 441.1 registerable or accountable radioactive sources used at NV/YMP facilities shall be registered with RAMATROL.

1. DOE N 441.1 describes how sealed radioactive sources shall be controlled and maintained, and specifies requirements for receipt, inventory, storage, transfer, disposal, and integrity testing. Unsealed sources shall be controlled and maintained in a similar manner except for integrity testing.

2. Procurement of radioactive sources shall be coordinated with the respective TO RCO. 
3. Receipt surveys of radiological material shipments shall be performed or coordinated by the responsible TO RCO.

4. Radioactive sources, including radiography sources, shall not be allowed on-site by non-TOs without the prior written approval of the cognizant TO RCO.

5. Each TO shall provide the following:

a. Contact RAMATROL for registration of any nonexempt radioactive source or radiation-producing equipment prior to its arrival on site, or as soon thereafter as possible. Provide to RAMATROL the proper shipping papers for radioactive materials.

b. Provide RAMATROL with information on source activity, isotope, location, user, photographs, drawings (if available), and/or technical data.

c. At NV/YMP facilities, perform or request from RAMATROL semiannual radiation surveys and/or swipe tests, and furnish RAMATROL with the results and documentation of the tests. Annually provide RAMATROL with updated information on the location of radiation-producing equipment.

d. Inform RAMATROL of changes in permanent location (longer than 60 days) or the movement of registered radioactive materials and ionizingradiation-producing equipment.

e. Withdraw from use any sealed source that is determined to be leaking.

f. For all radiation-producing machines, submit to RAMATROL the following information: output of the beam, locking or interlocking procedures, manufacturer's description of the equipment, leakage rate at maximum power, and documentation of compliance with the appropriate ANSI standards. This compliance inspection will be performed or arranged by the TO for all $x$-ray or radiation-producing equipment.

6. RAMATROL is required to:

a. Register all radioactive sources. Maintain and update semiannually, a source locator report (inventory) listing the location and users of all accountable and registered (licensable) quantities of radioactive materials and/or sources including all sealed sources that meet DOE N 441.1 requirements.

b. Register all $x$-ray or radiation-producing equipment. Maintain and update annually an inventory of all $x$-ray and radiation-producing equipment.

c. Maintain copies of NRC or state licenses for NV/YMP TOs.

d. Upon request provide leak-test services for NV/YMP TOs. 


\section{PART 4 Solid Radioactive Waste Management}

\section{Requirements}

DOE 5820.2A describes how solid radioactive waste is treated, packaged, stored, transported, and disposed.

\section{2 [Reserved]}

\section{Mixed Waste}

Requirements specified in the RCRA and Toxic Substances Control Act apply to waste that contains both radioactive and hazardous materials. DOE 5400.3 and $5820.2 \mathrm{~A}$ describe controls for mixed waste.

Technical and administrative controls should be established to minimize the volume of mixed waste generated and the amount of radioactivity in such waste. Volume reduction methods include process optimization, materials substitution, and new technology development.

\section{PART 5 Controlling Radioactive Liquids and Airborne Radioactivity}

\section{Minimizing and Controlling Radioactive Liquid Wastes}

1. DOE 5820.2A provides criteria for minimizing the generation of radioactive liquid waste.

2. DOE 5400.5 provides radioactive liquid waste discharge requirements.

3. Radioactive liquid waste discharges should be analyzed prior to release.

4. Radioactive liquid waste that cannot be discharged should be solidified and disposed of as solid radioactive waste.

\section{Controlling Radioactive Drains}

Radioactive drain systems are designed to transport radioactive liquids.

1. Radioactive drain systems should not discharge to the environment nor be used for the disposal of nonradioactive liquids.

2. Existing radioactive drains should be evaluated to ensure the following:

a. Verification of the existing radioactive drain piping configuration. 
b. Installation of flow-indicating devices in leak-off lines.

c. Use of plugs to prevent nonradioactive input.

d. Consideration of alternative work controls before systems are drained for maintenance.

e. Controls prohibiting unauthorized use of drains.

3. Modifications to the design or operation of existing radioactive drain systems should be controlled to include:

a. Design considerations that prevent nonradioactive drain connections into radioactive drains.

b. Procedural and design controls to prevent cross-connections of radioactive drains with nonradioactive systems.

c. Management review of subsequent changes to the design of radioactive drain systems or radioactive drain controls.

d. Management controls to restrict the introduction of hazardous wastes into radioactive drain systems.

\section{Controlling Airborne Radioactivity}

1. Processes and activities with the potential for producing airborne radioactivity shall include engineering controls to limit releases whenever appropriate. The requirements of 40 CFR 61 shall be included in the evaluation.

2. The responsible RCO shall be notified when engineering controls that prevent worker exposure to airborne radioactivity are compromised. An evaluation. should be made of continuing operations with compromised engineering controls.

3. Preventive maintenance and surveillance procedures shall be established to ensure equipment controls are maintained in an operable condition for containing airborne radioactivity.

\section{PART 6 Support Activities}

\section{Personal Protective Equipment and Protective Clothing}

1. PC designated for RadCon use shall be specifically identified by color, symbol, or appropriate labeling.

2. PC designated for RadCon use shall not be used for nonradiological work.

3. PPE and PC shall not be stored with personal street clothing. 
4. Laundry and decontamination services should be provided by the RSPC.

5. Cleaned PPE that comes into contact with the wearer's face, and companyissued non-personal PC shall be surveyed. Contamination levels should be below Table 2-2 total contamination values prior to reuse. Using statistically representative sampling is acceptable.

6. Laundered PC should be surveyed using statistically representative sampling and should meet the following criteria prior to reuse:

a. Beta-gamma radioactivity less than $10,000 \mathrm{dpm} / 100 \mathrm{~cm}^{2}$.

b. Alpha radioactivity less than $1,000 \mathrm{dpm} / 100 \mathrm{~cm}^{2}$ for transuranics and other alpha emitters in the same Table 2-2 category, and less than 10,000 $\mathrm{dpm} / 100 \mathrm{~cm}^{2}$ for uranium.

7. Laundry activities should be performed using processes that minimize both potential worker exposure and the volume of waste generated.

8. Cleaned PPE and laundered PC shall be inspected prior to use. PC should be free of tears, separated seams, deterioration, and damage, or repaired in a manner that provides the original level of protection.

\section{2 [Reserved]}

\section{3 [Reserved]}

\section{Vacuum Cleaners and Portable Air-Handling Equipment}

1. Vacuum cleaners and portable air-handling equipment used in areas established to control removable surface contamination or airborne radioactivity (except areas where only tritium is present) shall be equipped with High-Efficiency Particulate Air (HEPA) filters. If the material to be vacuumed is wet enough to preclude resuspension, then HEPA filters are not necessary.

2. HEPA filters used in vacuum cleaner and portable air-handling equipment shall meet the efficiency and construction requirements for HEPA filters in MIL-F51068. The maximum flow rate of the device shall not exceed the flow rate at which the HEPA filter was efficiency tested. In addition, the device shall be leak tested prior to initial use, when units have been opened, and annually. ERDA 76-21, Section 8.3.1, provides additional information on in-place testing of HEPA filters. 
3. Vacuum cleaners used for radiological work shall be:

a. Uniquely marked and labeled.

b. Controlled by an RWP.

c. Designed to ensure HEPA filter integrity under conditions of use.

d. Designed to prevent unauthorized or accidental access to the inner surfaces of the vacuum.

4. Airborne radioactivity levels shall be monitored when a vacuum cleaner is used in a High Contamination Area. 


\section{Appendix 4-A}

Values for Exemption of Sealed Radioactive

Sources from Inventory and Integrity Testing

Less than $300 \mu \mathrm{Ci}(10 \mathrm{Mbq})$

$\begin{array}{lll}\mathrm{H}-3 & \mathrm{Be}-7 & \mathrm{C}-14 \\ \mathrm{Fe}-55 & \mathrm{Ni}-59 & \mathrm{Ni}-63 \\ \mathrm{Cd}-113 & \mathrm{In}-115 & \mathrm{Te}-123\end{array}$

Ta-180

Less than $30 \mu \mathrm{Ci}(1 \mathrm{Mbq})$

$\begin{array}{ll}\text { Cl-36 } & \text { K-40 } \\ \text { Y-91 } & \text { Zr-95 } \\ \text { Sn-113 } & \text { Sn-119m } \\ \text { I-125 } & \text { La-137 } \\ \text { Eu-149 } & \text { Eu-155 } \\ \text { Lu-174 } & \text { Lu-174m } \\ \text { Pt-193 } & \text { Au-195 }\end{array}$

Fe-59

$\mathrm{Nb}-93 \mathrm{~m}$

$\mathrm{Sn}-121 \mathrm{~m}$

Ce-139

Gd-151

Hf-175

$\mathrm{Hg}-203$

Co-57
Nb-95
$\mathrm{Sn}-123$
$\mathrm{Pm}-143$
$\mathrm{Gd}-153$
$\mathrm{Hf}-181$
$\mathrm{~Pb}-205$

S-35

As-73

Cs-135

W-188

\section{Ca-45}

Rb-87

Gd-152

TI-204
$V-49$

Tc-99

Tb-157

Re-187

Se-75

Tc-97m

Te-123m

Pm-145

Dy-159

Ta-179

NP-235

Rb-84
Ru-103
Te-125m
Pm-147
Tm-170
Re-184
Pu-237

Ti-44

$\mathrm{Rb}-83$

TC-98

Sn-126

Ce-144

Gd-146

Re-184m

$\mathrm{Bi}-210$

Lu-177m

$\mathrm{Hg}-194$

Ho-166m

Lu-176

Ir $-194 m$

Less than $0.3 \mu \mathrm{Ci}(10 \mathrm{kBq})$

$$
\begin{array}{lll}
\text { Sr-90 } & \text { Cd-113m } & \text { La-138 } \\
\text { Pu-241 } & \text { Bk-249 } & \text { Es-254 }
\end{array}
$$

Less than $0.03 \mu \mathrm{Ci}(1 \mathrm{kBq})$

Sm-146

Sm-147

Pb-210

$\mathrm{Np}-236$

$\mathrm{Cm}-242$

Cf-248

Less than $0.003 \mu \mathrm{Ci}(100 \mathrm{~Bq})$

$\begin{array}{lll}\text { Gd-148 } & \text { Th-228 } & \text { Th-230 } \\ \text { U-238 } & \text { Np-237 } & \text { Pu-236 } \\ \text { Am-241 } & \text { Am-242m } & \text { Am-243 }\end{array}$

Bk-247

Cf-249

Cf- 250

U-232
Pu-238
Cm-243
Cf-251

U -233

Pu-239

Cm-244

Cf-252

Pu-240

$\mathrm{Cm}-245$

Cf-254

Less than $0.0003 \mu \mathrm{Ci}(10 \mathrm{~Bq})$

Pu-244
Fm-257

Md-258

$\mathrm{Mn}-53$

Pd-107

Tm-171

$\begin{array}{ll}\text { Sr-85 } & \text { Sr-89 } \\ \text { Ag-105 } & \text { In-114m } \\ \text { Te-127m } & \text { Te-129m } \\ \text { Sm-145 } & \text { Sm-151 } \\ \text { Yb-169 } & \text { Lu-173 } \\ \text { Re-186m } & \text { Ir-192 }\end{array}$

Mn-54

$Y-88$

Sb-124

Pm-144

Tb-158

Os-185

Cm-241

$\mathrm{Fe}-60$

$\mathrm{Zr}-88$

Rh-101

Sb-125

Pm-146

Tb-160

Os-194

Ra-228

U-235

Pu-242

$\mathrm{Cm}-246$

U-236

$\mathrm{Cm}-247$ 


\section{CHAPTER 5 RADIOLOGICAL HEALTH SUPPORT OPERATIONS}

\section{TABLE OF CONTENTS}

Article

PART 1 External Dosimetry . . . . . . . . . . . . . . . . . . . . . . . 5-1

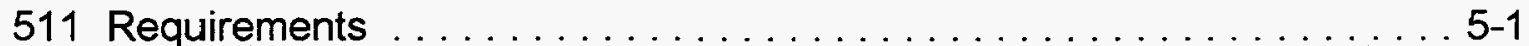

512 Technical Requirements for External Dosimetry . . . . . . . . . . . . 5-3

513 Supplemental Dosimeters . . . . . . . . . . . . . . . . . . . . . . 5-4

514 Area Monitoring Dosimeters . . . . . . . . . . . . . . . . . . 5-4

515 Nuclear Accident Dosimeters . . . . . . . . . . . . . . . . . . . . 5-4

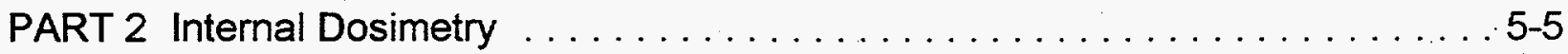

521 Requirements . . . . . . . . . . . . . . . . . . 5-5

522 Technical Requirements for Internal Dosimetry . . . . . . . . . . . 5-5

523 Technical Requirements for Dose Assessment . . . . . . . . . . . . 5-6

PART 3 Respiratory Protection Program . . . . . . . . . . . . . . . . . . . 5-6

531 Requirements . . . . . . . . . . . . . . . . . . . . . . . 5-7

532 [Reserved] . . . . . . . . . . . . . . . . . . . . 5-7

533 Using Respiratory Protection . . . . . . . . . . . . . . . . . 5-7

534 [Reserved] . . . . . . . . . . . . . . . . . . . . . . . .

535 Half-Face Respirators . . . . . . . . . . . . . . . . . . . . . . 5-8

PART 4 Handling Radiologically Contaminated Personnel . . . . . . . . . . . . 5-8

541 Skin Contamination . . . . . . . . . . . . . . . . . . . . . . . . . . . 5-8

542 Contaminated Wounds . . . . . . . . . . . . . . . . . . . . . . . . 5-8

543 Evaluating Intakes of Radioactivity . . . . . . . . . . . . 5-9

PART 5 Radiological Monitoring and Surveys . . . . . . . . . . . . . . . . . . . 5-9

551 Requirements . . . . . . . . . . . . . . . . . . . . 5-9

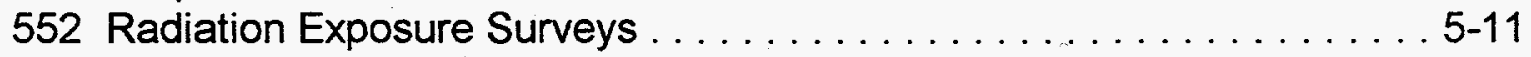

553 Area Radiation Monitors . . . . . . . . . . . . . . . . . . . . 5-12

554 Contamination Surveys . . . . . . . . . . . . . . . . . . . . . . . . . 5-12

555 Airborne Radioactivity Monitoring . . . . . . . . $\ldots \ldots \ldots \ldots \ldots$

PART 6 Instrumentation and Calibration . . . . . . . . . . . . . . . . . 5-15

561 Standardization . . . . . . . . . . . . . . . . . . . . . . 5-15

562 Inspection, Calibration, and Performance Tests . . . . . . . . . 5-15

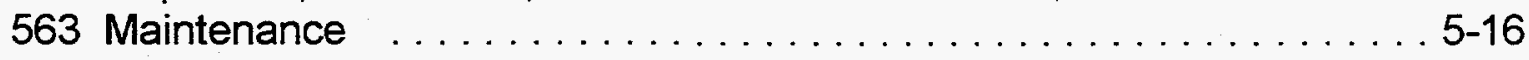

564 Calibration Facilities . . . . . . . . . . . . . . . . . . . . . . 5-17 


\section{PART 1 External Dosimetry}

The DOE/NV dosimeter holder is designed to accommodate both a thermoluminescent dosimeter (TLD) and a track-etch neutron dosimeter. Personnel and visitors who enter radiological areas administered by NV/YMP shall be required to wear this TLD, which measures radiation exposures from gamma, beta, and $x$ rays. The dosimeter is to be removed from the dosimeter holder by authorized personnel only. At no time shall any employee tamper with the dosimeter. Different-colored dosimeter stickers are used for each quarter to permit positive verification of current dosimetry.

\section{Requirements}

1. Personnel dosimetry shall be required for the following:

a. Personnel who are expected to receive an annual external whole-body dose greater than 100 mrem or an annual dose to the extremities, or organs and other tissues (including lens of the eye and skin) greater than 10 percent of the corresponding limits specified in Table 2-1.

b. Declared pregnant workers who are expected to receive from external sources a dose equivalent of 50 mrem or more to the embryo/fetus during the gestation period.

c. Minors and students, visitors and public expected to receive an annual external whole-body dose equivalent of $50 \mathrm{mrem}$ or more in a year.

2. Neutron dosimetry shall be provided when a person is likely to exceed $100 \mathrm{mrem}$ annually from neutrons.

3. Dosimeters shall be issued only to personnel knowledgeable in their proper use and worn only by those to whom the dosimeters were issued.

4. Personnel shall exchange dosimeters for processing as scheduled or upon request, and should be restricted by line management from continued radiological work until dosimeters are returned.

5. Personnel shall wear their primary dosimeters on the chest area, or between the waist and the neck, in the manner prescribed by RadCon personnel.

6. NV/YMP personnel are permitted to carry their dosimeter off site.

7. Personnel shall not wear dosimeters issued by their resident facilities while being monitored by a dosimeter at another facility unless authorized by the RadCon Manager. Personnel shall not expose their dosimeters to security $\mathrm{x}$-ray devices, excessive heat, or medical sources of radiation. 
8. A person whose dosimeter is lost, damaged, or contaminated should place work in a safe condition, immediately exit the area and report the occurrence to the $\mathrm{RCO}$. Reentry of the person into radiological areas should not be made until a review has been conducted and the RCO has approved reentry.

9. NV/YMP Worker Responsibilities

It is the responsibility of each NVMMP employee to:

a. Take their dosimeter and holder to the appropriate badge office, dosimetry office, or other exchange location at the NTS or in Las Vegas for dosimeter change-out during the first two weeks of the calendar quarter. Special processing and/or more frequent processing may be performed as required or upon termination of the employee.

b. Turn in the dosimeter at the main gate before leaving if they anticipate being away from NV/YMP facilities for more than two months.

10. TO Responsibilities

All NVMMP TOs, including subcontractors, should:

a. Designate to the RSPC one person to be responsible for dosimetry coordination. This includes locating and retrieving non-returned dosimeters.

b. Prescribe required dosimetry for radiological activities or areas under their control and ensure that the dosimeters are properly worn.

11. RSPC Responsibilities

The RSPC is responsible for the following:

a. Identifying dosimeters that have not been exchanged or returned. Within the first month after the close of each quarter, the RSPC should issue a non-returned dosimeter report to the designated person in each organization.

b. Annually update the list of TO codes and names of persons within NV/YMP organizations who are to receive the processed, positive, and non-returned dosimeter reports. 
12. Security Organization Responsibilities

Wackenhut Services, Inc. (WSI) has responsibilities for the following dosimetry support:

a. Issue and collect personnel dosimeters at the NTS and Las Vegas Badge Offices.

b. Provide accurate personnel identification information to the RSPC.

\section{Technical Requirements for External Dosimetry}

1. DOE STD-1095-95 specifies the requirements for accreditation of personnel external dosimetry monitoring programs by the DOELAP. A technical basis document shall be maintained for the external dosimetry program. Personnel external dosimeters include but are not limited to TLDs and track etch dosimeters.

2. The technical basis document shall also address dosimeters monitoring radiation outside the scope of DOELAP.

3. The RSPC should participate in intercomparison studies for external dosimetry programs.

4. Personnel exposures to the skin, lens of the eye, and extremities shall be reported separately.

5. Multiple dosimeters should be issued to personnel to assess whole-body exposure in non-uniform radiation fields or as required on RWPs. Non-uniform radiation fields exist when the dose to a portion of the whole body will exceed the dose to the primary dosimeter by more than 50 percent and the anticipated whole-body dose is greater than $100 \mathrm{mrem}$. The technical basis document should describe the methodology used in determining the dose of record when multiple dosimeters are used.

6. A dose assessment shall be performed for each instance of a lost, damaged, or contaminated personnel dosimeter. 


\section{Supplemental Dosimeters}

1. Supplemental dosimeters shall be issued to personnel prior to entry into a High Radiation or Very High Radiation Area (see Article 334 for entry requirements) when a person could exceed 10 percent of an Administrative Control Level from external radiation in one work day or when required by an RWP.

2. Supplemental dosimeters shall be worn simultaneously with the primary dosimeter and located in accordance with Article 511.5.

3. Supplemental dosimeters shall be read more frequently than the primary dosimeter. Pocket dosimeters shall be read periodically while in use and should not be allowed to exceed 75 percent of full scale.

4. Work authorized by an RWP shall be stopped when supplemental dosimeter readings indicate total exposure greater than planned. The RCO shall be consulted prior to continuation of work.

\section{Area Monitoring Dosimeters}

A comprehensive area monitoring program minimizes the number of areas requiring the issuance of personnel dosimeters and demonstrates that doses outside radiological areas are negligible.

1. Area monitoring dosimeters should be used to record and document radiation levels in routinely occupied areas adjacent to areas where radiation or operations with radiation exist.

2. Area monitoring dosimeter results should be used to support dosimetry investigations where personnel express concerns about their work environments and exposure to ionizing radiation.

3. Area monitoring dosimeters should be used in Controlled Areas to supplement existing monitoring programs and to provide data in the event of an emergency.

\section{Nuclear Accident Dosimeters}

10 CFR 835.1304 specifies the requirements for a Nuclear Accident Dosimetry Program, where the potential exists for excessive exposure of personnel to radiation from a nuclear accident. 


\section{PART 2 Internal Dosimetry}

\section{Requirements}

1. The following personnel shall participate in an internal dosimetry program:

a. Personnel entering radiological areas who have the potential to receive intakes resulting in a CEDE of 100 mrem or more in a year.

b. Declared pregnant workers likely to receive intakes resulting in a dose equivalent to the embryo/fetus of 50 mrem or more during the gestation period.

c. Minors and students, visitors and public likely to receive intakes resulting in a CEDE of 50 mrem or more in a year.

2. The estimation of internal dose shall be based on bioassay data rather than air concentration values unless bioassay data are:

a. Unavailable.

b. Inadequate.

c. Internal dose estimates based on representative air concentration values are demonstrated to be as or more accurate.

3. Personnel should participate in follow-up bioassay monitoring when their routine bioassay results indicate an intake in the current year with a CEDE of $100 \mathrm{mrem}$ or more.

4. Personnel whose routine duties may involve exposure to surface or airborne contamination or to radionuclides readily absorbed through the skin, such as tritium, should be considered for participation in the bioassay program.

5. Personnet shall submit bioassay samples, at the frequency required by the TO's bioassay program.

6. Personnel shall be notified promptly of positive bioassay results and the results of dose assessments and subsequent refinements (Article 543). Dose assessment results shall be provided in terms of rem or mrem.

\section{Technical Requirements for Internal Dosimetry}

1. A technical basis document shall be maintained for the internal dosimetry program. 
2. Baseline bioassay monitoring of personnel who are likely to receive intakes resulting in a CEDE greater than 100 mrem shall be conducted before they begin work that may expose them to internal radiation exposure.

3. Bioassay monitoring methods and frequencies shall be established for personnel who are likely to receive intakes resulting in a CEDE greater than $100 \mathrm{mrem}$. The technical basis for the methods and frequency of bioassay monitoring should be documented.

4. Management shall require termination bioassay monitoring when a person who participated in the routine bioassay program terminates employment or concludes work involving the potential for internal exposure. It is NV/YMP policy to make reasonable attempts to perform bioassay monitoring on terminating employees who have participated in the routine bioassay program. Terminating employees who refuse to submit samples shall be required to sign a statement of refusal.

5. Bioassay analyses shall also be performed when any of the following occurs:

a. Facial or nasal contamination is detected that indicates a potential for internal contamination.

b. Airborne monitoring indicates the potential for intakes exceeding 100 mrem CEDE.

c. Upon direction of the RCO when an intake is suspected.

6. A preliminary assessment of any intakes detected should be conducted prior to permitting an employee to return to radiological work.

\section{Technical Requirements for Dose Assessment}

Interpreting bioassay results and subsequent dose assessments should include the following:

1. Characteristics of the radionuclide, such as chemical and physical form.

2. The person's previous exposure history.

3. Exposure information, such as route of intake and time and duration of exposure.

4. Models to estimate intake or deposition, and to assess dose.

\section{PART 3 Respiratory Protection Program}

Respiratory protection equipment includes respirators with particulate or gas-filtering cartridges, supplied air respirators, self-contained breathing apparatus, and airline supplied-air suits and hoods. 


\section{Requirements}

1. Using respiratory protection shall be reduced to the minimum practicable by implementing engineering controls and work practices to contain radioactivity at the source.

2. The requirements are contained in ANSI Z88.2, ANSI Z88.6, and 29 CFR 1910.134 for implementation of the Respiratory Protection Program and associated training of personnel.

3. Respirators shall be issued only to personnel who are trained, quantitative fit tested, and medically qualified to wear the specific type of respirator. Training and qualification testing shall be performed annually.

The RSPC is responsible for providing the following services unless provided by the responsible TO:

a. Fit testing respirators to each worker that needs to wear such equipment.

b. Conducting respiratory protection training classes.

c. Providing medical evaluations for personnel that need to wear respiratory equipment.

d. Issuing respiratory protection equipment.

4. Controls shall be maintained for the issue, use, and return of respirators to ensure that only qualified personnel wear respirators.

\section{2 [Reserved]}

\section{Using Respiratory Protection}

The RSPC is normally responsible for providing and issuing the respiratory protection equipment to personnel at the NTS. However, the user organization may issue equipment under certain conditions. The RSPC offers complete training, conducts respiratory fit testing, and performs medical evaluations on individuals requiring respiratory equipment. Other TOs may conduct similar testing/training for identical equipment, provided that the requirements listed in Chapter 5, Part 3, of this Manual are met. Respirator protection equipment is available from the Respirator Shop at the CP-50 facility, and in all RSPC base stations, check stations, and other work locations as deemed necessary by the TO RadCon Manager or Health Physicist. Issuing respiratory protection equipment requires the worker to have a current mask fit card.

\section{4 [Reserved]}




\section{Half-Face Respirators}

Half-face respirators shall not be used on a routine basis for radiological work. Using half-face respirators is permissible in situations where intakes of radioactive material will be low, and where industrial and safety considerations warrant.

\section{PART 4 Handling Radiologically Contaminated Personnel}

\section{Skin Contamination}

1. Survey techniques shall be established to determine the extent of skin contamination.

2. When personnel detect skin contamination, they shall notify the RCO.

3. The extent of skin contamination should be determined prior to initiating decontamination procedures.

4. Skin decontamination methods should be established for site-specific radionuclides. Skin abrasion should be avoided during the decontamination process. Intrusive decontamination methods, such as tissue removal, require medical assistance.

5. A trigger level of $300,000 \mathrm{dpm} / 100 \mathrm{~cm}^{2}$ has been established for mixed fission products. This trigger level shall remain in effect unless the exact radionuclide content has otherwise been specified on the RWP or alternative document.

6. Personnel with skin contamination that triggers the need for dose assessment should be informed of the initial dose estimate to their skin as soon as practicable, preferably prior to the end of their work day.

7. Personnel with skin contamination for which dose assessment was not performed should be informed of the nature of the contamination and an upper estimate on the potential dose as soon as practicable, preferably prior to the end of their work day.

\section{Contaminated Wounds}

1. Emergency medical care should be administered immediately for injuries involving radioactive materials in accordance with NCRP Report Number 65. Medical treatment of injuries takes precedence over radiological considerations.

2. The treatment of contaminated injuries should include the following: 

a. Treatment of contaminated wounds by medically qualified personnel.
b. Monitoring of wounds and associated bandages for contamination, including alpha emitters if applicable.
c. Identification of the radionuclides involved.
d. Initiation of appropriate bioassay monitoring.
e. Determination of need for work restrictions.

3. An injured person should be counseled on the medical and radiological implications resulting from contaminated wounds that result in internal doses greater then 2 percent of the Table 2-1 limits. The counseling should be performed by senior RadCon and medical professionals.

\section{Evaluating Intakes of Radioactivity}

If intakes of radioactive material are indicated which could result in an individual receiving a CEDE greater than 100 mrem, the following actions should be taken:

1. Identify personnel potentially exposed to radioactivity.

2. Obtain nasal smears for qualitative indication of intakes as appropriate.

3. Analyze air samples to determine airborne concentrations where appropriate.

4. Determine duration of potential internal exposure to radioactivity.

5. Collect bioassay appropriate for the type and quantity of radionuclides involved.

6. Evaluate dose prior to permitting the worker to return to radiological work as referenced in Article 522.6.

\section{PART 5 Radiological Monitoring and Surveys}

\section{Requirements}

Monitoring of individuals and areas shall be performed to demonstrate compliance with the regulations in 10 CFR 835 - Subpart E - Monitoring in the Workplace.

1. Radiological monitoring of radiation exposure/dose rates, contamination, and airborne radioactivity shall be conducted to:
a. Characterize workplace conditions and detect changes in those conditions [10 CFR 835.401(a)(2) \& (3)].
b. Verify the effectiveness of physical design features, engineering and process controls, [10 CFR 835.401(a)(5), and administrative control procedures [10 CFR 835.1003 (b)].
c. Demonstrate regulatory compliance [10 CFR 835.401(a)(1)].
d. Detect the gradual buildup of radioactive material in the workplace [10 CFR 835.401(a)(4)].
e. Identify areas requiring postings.


2. Monitoring shall be performed only by trained and qualified personnel. The instruments used shall be [10 CFR 835.401(c)]:

a. Periodically maintained and calibrated at least once each year.

b. Appropriate for the types, levels, and energies of radiation to be detected and the existing environmental conditions.

c. Routinely tested for operability.

3. Surveys for radiation exposure/dose rates, contamination, and airborne radioactive materials shall be performed as specified in Technical Work Documents (Article 315) and RWPs.

4. The RCO should perform and document a review of the adequacy of sampling and monitoring systems as part of any facility or operational changes affecting radiological control. In the absence of such changes, a review should be conducted annually.

5. Instruments used to perform radiation surveys shall be readily available and response-checked daily or prior to operation. When response checks are not within \pm 20 percent of the expected value, the instrument should be taken out of service. When response checks are not feasible, such as with instruments used to measure neutrons or tritium, compensatory actions should be established to ensure proper instrument performance.

6. Assessment of radiological conditions should include a sufficient number of survey points to characterize the radiation present and to verify boundaries.

7. Surveys shall be performed before, during, and at the completion of work that has the potential for causing changes in radiation exposure/dose rates or contamination levels.

8. Survey frequencies should be established based on potential radiological conditions, probability of change in conditions, and area occupancy factors.

9. Monitoring results should be reviewed by the cognizant RadCon representative to assure that the documentation is accurate and complete.

10. Results of current surveys of radiological areas or survey maps should be conspicuously posted to inform personnel of the radiological conditions.

11. Monitoring results should be made available to line management and used in support of pre- and post-job evaluations, ALARA preplanning, contamination control, and management of radiological control operations. 
12. NV/YMP TOs should do the following:

a. Provide instrumentation and methods necessary to detect and accurately assess external and internal radiation hazards associated with their operations, or request the RSPC to provide this service. As a minimum, the radiation detection instruments should be capable of measuring levels of contamination defined in Table 2-2.

b. Provide an ambient workplace air monitoring program in occupied areas that have the potential to exceed 10 percent of any DAC value given in Appendix A of 10 CFR 835.

13. The RSPC should:

a. Provide radiation monitoring services upon request.

b. Provide radiation detection instruments and calibration services upon request.

c. Provide survey and monitoring records upon request.

d. Provide personnel and equipment decontamination services upon request.

\section{Radiation Exposure Surveys}

1. In addition to the requirements of Article 551, routine radiation surveys should be performed in accordance with the following minimum frequencies:
a. Weekly, in routinely occupied Radiation Areas.
b. Upon initial entry and when levels are expected to change in High Radiation Areas.
c. Initially and when configuration changes are made to Radiation and High Radiation Area boundaries to ensure that radiation areas do not extend beyond posted boundaries.
d. Monthly, or upon entry, if entries are less frequent than monthly for RMAs.
e. Upon entry, for Radiation, High Radiation, and Very High Radiation Areas when remotely operated radioactive sources or when radiation-producing equipment have been in use.

2. Surveys should include exposure/dose rate measurements of the general area and at a distance of 30 centimeters from a source of radiation.

3. An initial dose rate evaluation should be made on contact with radioactive materials where there is a potential for hands-on work.

4. Surveys should be conducted whenever operations are being performed that might result in personnel being exposed to small intense beams of radiation, 
such as those generated by shielded $x$-ray devices or by removal or alteration of shielding.

5. Radiation monitoring instruments shall be capable of measuring ambient radiation dose rates for the purpose of controlling radiation exposures.

\section{Area Radiation Monitors}

1. Area radiation monitors (not to include area monitoring dosimeters discussed in Article 514) should be installed in frequently occupied locations with the potential for unexpected increases in dose rates.

2. In addition to the requirements of Article 562, area radiation monitors should be tested at least quarterly to verify audible alarm system operability and audibility under ambient working conditions and operability of visual alarms when so equipped.

3. Where an area radiation monitor is incorporated into a safety interlock system, the circuitry shall be such that a failure of the monitor shall either prevent entry into the area or prevent operation of the radiation producing device.

\section{Contamination Surveys}

1. In addition to the requirements of Article 551, routine contamination surveys should be conducted in radiological areas established for controlling contamination, and other areas with the potential for spread of contamination as follows:

a. Prior to transfer of equipment and material from one radiological area to another.

b. Prior to transfer of equipment and material from High Contamination Areas within radiological areas, unless precautions such as bagging or wrapping are taken prior to transfer.

c. Daily, at Contamination Area control points, change areas, or step-off pads when in use, or per shift in high use situations.

d. Daily, in office space located near radiological areas.

e. Daily, in lunch rooms or eating areas near radiological areas.

f. Weekly, in routinely occupied radiological areas.

g. Weekly, or upon entry if entries are less frequent, in areas where radioactive materials are handled or stored.

h. Weekly, or upon entry if entries are less frequent, where contamination boundaries or postings are located.

i. During initial entry into a known or suspected contamination area, periodically during work, at completion of job, or as specified in an RWP 
j. After a leak or spill of radioactive materials.

2. Articles 421 and 422 establish requirements for material release surveys.

3. Contamination surveys should incorporate techniques to detect both removable and fixed contamination.

4. Items with inaccessible surfaces which were located in known or suspected contamination areas and had the potential to become contaminated at levels likely to exceed Table 2-2 values shall be treated as potentially contaminated and subject to administrative controls unless the items are dismantled and monitored or special survey techniques are used to survey all surfaces.

5. Swipe surveys for removable contamination should be recorded in units of disintegrations per minute per $100 \mathrm{~cm}^{2}\left(\mathrm{dpm} / 100 \mathrm{~cm}^{2}\right)$. For swipe surveys of small items covering less than $100 \mathrm{~cm}^{2}$, the results should be recorded in units of dpm per area swiped.

6. Large area wipes are encouraged and should be used to supplement standard swipe techniques in areas generally assumed not to be contaminated, such as entrances to radiological areas. If an evaluation indicates that an area wiped is contaminated, a thorough contamination swipe survey should be performed.

7. Areas identified as either contaminated with, or having the potential for being contaminated with, highly radioactive particles ("hot particles") should be surveyed weekly. These areas should be surveyed at least daily during periods of work that may result in the generation of hot particles. Special swipe techniques to collect hot particles, such as tape and large area wipes, should be used.

8. Vehicles, equipment, and material designated for government surplus or unrestricted release to the public shall be surveyed before being released. Release procedures are referenced in Article 422. All vehicle, equipment, and material surveys and findings shall be recorded, documented, and maintained by the RSPC.

9. The TO which operates or utilizes a facility or area is delegated radiological safety coordination responsibility at that facility/area. This responsibility may be implemented by establishing a Radiation Control Program, or by requesting the RSPC to conduct the program. The contractor/user should have a documented system for tracking the status of each facility under its control. When using a facility or area is terminated by a TO, the health and safety coordination responsibility for the facility/area should be returned in a timely fashion to DOE/NV. 
a. DOE/NV has several inactive facilities, and numerous event areas that are posted as contaminated and require access control. Inactive areas or facilities not delegated to a TO are assigned to the RSPC.

b. Inactive facilities are exempt from periodic resurvey. The responsible RCO controls and conducts all entries into inactive facilities.

\section{Airborne Radioactivity Monitoring}

1. In addition to the requirements of Article 551, air monitoring equipment should be used in situations where airborne radioactivity levels can fluctuate and early detection of airborne radioactivity could prevent or minimize inhalation of radioactivity by personnel. Selecting air monitoring equipment should be based on the specific job being monitored. Air monitoring equipment includes portable and fixed air sampling equipment and CAMs.

2. Air sampling equipment shall be used in occupied areas where, under normal operating conditions, a person is likely to receive an annual intake of 2 percent or more of the specified Annual Limit of Intake (ALI) values (40 DAC hours). An annual intake of 2 percent of a specified ALI generally represents a CEDE to a person of approximately $100 \mathrm{mrem}$.

3. CAM equipment shall be installed in occupied areas where a person is likely to be exposed to a concentration of radioactivity in air exceeding 1 DAC or where there is a need to alert potentially exposed workers to unexpected increases in the airborne radioactivity levels. The protection afforded by use of respiratory protection devices may be considered in determining monitoring requirements. A person exposed continuously to a concentration of radioactivity in air of 1 DAC for 1 work week would generally receive a CEDE of approximately 100 mrem.

4. Air sampling equipment should be positioned to measure air concentrations to which persons are exposed. If this cannot be achieved, a program of personal breathing-zone air sampling should be initiated.

5. Air monitoring equipment shall be routinely calibrated and maintained at a frequency of at least once per year. CAMs should be capable of measuring 1 DAC when averaged over 8 hours ( 8 DAC-hours) under laboratory conditions.

6. CAM equipment required by Article 555.3 shall have alarm capability and sufficient sensitivity to alert personnel that immediate action is necessary in order to minimize or terminate inhalation exposures.

7. The proper operation of CAM equipment should be verified daily by performing an operational check. Operational checks should include positive air-flow indication, non-zero response to background activity, and internal check sources 
or 60 Hertz electronic checks when available. CAM equipment operation should be verified weekly by checking for instrument response with a check source or with ambient levels of radon and thoron daughters.

8. Preliminary assessments of air samples utilizing field survey techniques should be performed promptly upon removal. In situations where background levels of radon and thoron daughters interfere with evaluation of alpha air samples, prompt field assessments may not be possible.

9. Air sample results should be evaluated as quickly as practicable for evaluation of the need for respiratory protection; area evacuation (if necessary), worker intake, and worker relief from respirator use.

\section{PART 6 Instrumentation and Calibration}

\section{Standardization}

Standardization on the use of commercially available radiological instrumentation in the DOE is highly encouraged. To assist in the selection of appropriate instrumentation, DOE intends to establish a formal program to evaluate and test each type of radiological instrumentation used throughout the DOE complex.

\section{Inspection, Calibration, and Performance Tests}

1. Radiological instruments shall be used only to measure the radiation for which their calibrations are valid. DOE 5480.4 mandates the requirements contained in ANSI N323 for radiological instrumentation calibration. Calibrations shall use NIST traceable sources.

2. Calibration procedures shall be developed for each radiological instrument type and should include frequency of calibration, precalibration requirements, primary calibration requirements, periodic performance test requirements, calibration record requirements, and maintenance requirements.

3. Pocket and electronic dosimeters and area radiation monitors shall be calibrated at least annually and in accordance with Article 562.1.

4. The effects of environmental conditions, including interfering radiation, on an instrument shall be known prior to use.

5. Functional tests should be used to assess instrumentation designs that include alarms or that involve a process control. A functional test should be developed to test all components involved in an alarm or trip function and performed at least annually. 
6. In unusual and limited situations, it may be necessary to use an instrument in an application other than that envisioned by the manufacturer. Special calibrations should be performed for use of instrumentation outside manufacturer's specifications. The instrument should be adjusted, calibrated, and labeled to identify the special conditions and used only under the special conditions for which it was calibrated.

7. All equipment used to measure radiation should be calibrated and have a current calibration sticker which states the performance and expiration dates of the current calibration. For large stationary equipment (not portable instruments) it is acceptable to have primary calibration records readily available within the same location as the equipment, in lieu of a current calibration sticker. The frequency of calibration should be determined by the user and be based on the equipment use, manufacturer's instructions, and the individual history of the equipment. Instruments used for monitoring and contamination control shall be periodically maintained and calibrated on an established frequency of at least once per year.

8. Instruments whose calibration has expired should not be available for use; they should be separated, labeled as "expired" or "out of calibration," and stored in a secured manner to preclude inadvertent use.

9. Instruments whose "as found" readings indicate that the instrument may have been used while out of calibration shall be reported to the RCO. The RCO should review surveys performed with the instrument while it was out of calibration.

\section{Maintenance}

1. A program for preventive and corrective maintenance of radiological instrumentation should be established and documented.

2. Preventive and corrective maintenance should be performed using components and procedural recommendations at least as stringent as those specified by the manufacturer of the instrument.

3. Radiological instruments shall undergo calibration prior to use following any preventive or corrective maintenance or any adjustment that voids the previous calibration. A battery change is not considered maintenance. 


\section{Calibration Facilities}

1. Calibration facilities should take the following actions:

a. Locate activities in a manner to minimize radiation exposure to operating personnel and to personnel in adjacent areas.

b. Minimize sources of interference, such as back scatter and non-ionizing radiation during instrument calibration and correct for interferences as necessary.

c. Operate in accordance with the referenced standards.

d. Generate records of calibration, functional tests, and maintenance in accordance with the referenced standards.

2. For organizations that do not possess or use their own calibration facilities, contracted calibration services should be performed in accordance with the referenced standards. 


\section{CHAPTER 6 TRAINING AND QUALIFICATION}

Article

\section{TABLE OF CONTENTS}

PART 1 Radiological Control Training and Qualification . . . . . . . . . . 6-1

611 Purpose ............................. 6.1

612 Standardization . . . . . . . . . . . . . . . . . . . 6-1

613 Requirements . . . . . . . . . . . . . . . . . . . . 6-2

614 Qualification Standards for Radiological Control Technicians . . . . . . . 6-4

615 Oral Examination Boards . . . . . . . . . . . . . . . . . . . 6-4

616 Instructor Training and Qualifications $\ldots \ldots \ldots \ldots \ldots \ldots \ldots .4$

PART 2 General Employee Radiological Training $\ldots \ldots \ldots \ldots \ldots \ldots \ldots \ldots$. . . . . . . . . .

621 Site Personnel . . . . . . . . . . . . . . . . . . . . 6

622 Radiological Orientation for Members of the Public . . . . . . . . . 6-5

PART 3 Radiological Worker Training $\ldots \ldots \ldots \ldots \ldots \ldots \ldots \ldots$ 6-6

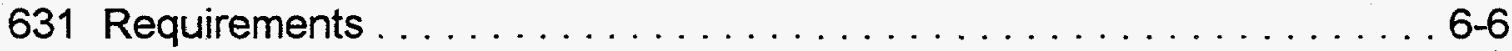

632 Radiological Worker I . . . . . . . . . . . . . . . . . . 6-7

633 Radiological Worker II . . . . . . . . . . . . . . . . . . . 6-8

634 Specialized Radiological Worker Training . . . . . . . . . . . . 6-8

PART.4 Radiological Control Technician Qualification . . . . . . . . . . . . . . 6-9

641 Requirements . . . . . . . . . . . . . . . . . . . . 6-9

642 Radiological Control Technician . . . . . . . . . . . . . . . 6-9

643 Continuing Training and Requalification . . . . . . . . . . . . $6-10$

644 Radiological Control Technician Supervisors . . . . . . . . . . . 6-10

645 Subcontracted Radiological Control Technicians . . . . . . . . . . 6-11

PART 5 Other Radiological Training . . . . . . . . . . . . . . . . . . . . . 6-11

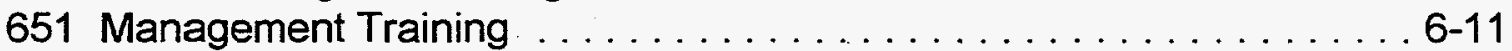

652 Technical Support Personnel . . . . . . . . . . . . . . . . . . 6-12

653 Planners . . . . . . . . . . . . . . . . . . . . . . . . 6-12

654 Radiological Control Personnel . . . . . . . . . . . . . . . 6 6-12

655 Radiographers and Radiation Generating Device Operators . . . . . 6-12

656 Emergency Response Personnel ................... . 6-13

657 Training for Visiting Scientists and Specialists . . . . . . . . . 6-13

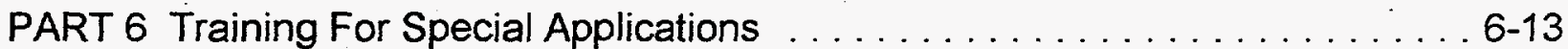

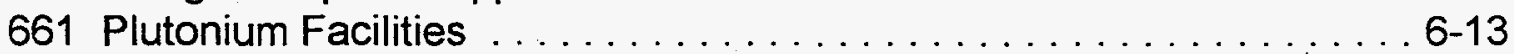

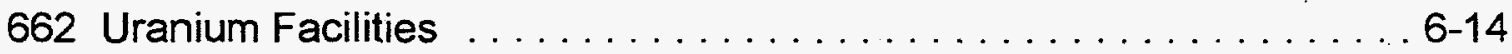

663 Tritium Facilities . . . . . . . . . . . . . . . . . . . . . . . . . . 6-14 
NV/YMP Radiological Control Manual, Rev. 2:

November 13, 1996

TRAINING AND QUALIFICATION

CHAPTER 6

664 Accelerator Facilities

6-15

Table

$6-1$

Radiological Worker Entry Training Requirements 6-7 


\section{PART 1 Radiological Control Training and Qualification}

\section{Purpose}

This chapter establishes the requirements to ensure that personnel have the training to work safely in and around radiological areas and to maintain their individual radiation exposure and the radiation exposures of others ALARA.

It is NVMMP policy that all radiation worker and management personnel share the responsibility for the implementation of ALARA principles and philosophy, commensurate with the degree of ALARA training each individual receives.

1. All NV/YMP TOs should comply with the following requirements regarding employee classification:

a. Line Managers should review each employee's (including subcontractor's) job function, determine the potential for radiation exposure and necessity for entry into contamination areas, and classify the employee as a General Employee, RW-I, or RW-II.

b. Line Managers should maintain and periodically review the current list of the names of General Employees, RW-Is, RW-IIs, and RCTs.

2. Assigning personnel as Radiological Workers should be commensurate with the potential for actual dose consequences.

3. Training requirements in this chapter apply to personnel entering Controlled Areas at DOE/NV sites.

\section{Standardization}

1. Standardized core courses and training materials are used to achieve consistency DOE-wide. The standardized core courses are presented and sitespecific information is added.

2. Standardized core course training material developed and maintained by $\mathrm{DOE} / \mathrm{HQ}$ consists of lesson plans, designated viewgraphs, student handbooks, qualification standards, question banks, and wallet-sized training certificates.

3. Standardized core course training material shall be used for GERT, RW-I and RW-II training, and RCT training.

4. Wallet-sized training certificates that identify current training status should be provided. 
5. Successful completion of the standardized courses for GERT, RW-I, RW-II, and RCT training at one DOE site within the past two years shall be recognized by DOE/NV. Documentation of previous training shall include the individual's name, date of training, topics covered, and name of the certifying official. Sitespecific aspects of the radiological training shall be completed. Site-specific training for GERT, RW-I, and RW-II training may be included with other site orientation training.

6. At sites where there are multiple facilities, the training may be facility-specific if personnel access is limited to those facilities for which training has been completed.

7. The TO RadCon Managers or designees shall concur in site-generated RadCon training material.

\section{Requirements}

1. Examinations for GERT, RW-I, and RW-Il training, and RCT qualification shall be used to demonstrate satisfactory completion of theoretical and classroom material. Examinations should be written; however, the RadCon Manager may approve alternatives to accommodate special needs. Alternative examinations should be equivalent in content to written examinations. The examination process should require:

a. A minimum score of 80 percent to pass the exam. If this minimum standard is not met, the worker's management should be notified in writing within 3 working days. Within 10 working days of the training date, the employee should be scheduled to retake the exam. Failure to reschedule an exam date or failure to achieve the minimum standard upon reexamination necessitates repetition of the full training session.

b. That true/false questions not be included.

c. Using questions randomly selected from the question bank.

d. Acknowledgment by signature that the student participated in a postexamination review.

e. That competence in required skills be measured using performancebased examinations.

f. Remedial actions for failure to meet the minimum score.

g. That the question bank contain questions that test what the student is expected to remember months after the training rather than to test short term memory of theoretical material.

2. Training should address both normal and abnormal situations in radiological control. 
3. GERT, RW-I, and RW-II shall be completed every 24 months. Changes to the program shall be incorporated as they are identified and a decision made if retraining prior to the 24 -month period is needed.

4. Site-specific training shall include changes in requirements and updates of lessons learned from operations and maintenance experience and occurrence reporting for DOE/NV.

5. Verifying the effectiveness of radiological control training shall be accomplished by evaluating the performance of radiological workers by RadCon personnel. This evaluation should include observation of practical applications and discussions of work practices. The results should be documented.

6. Reading and comprehension skills in the English language are generally necessary for GERT. The RadCon Manager is authorized to approve alternative temporary training methods for those lacking reading and comprehension skills in the English language until adequate English language skills can be achieved. Training in an alternate language should be equivalent to training in English. At NV/YMP sites, oral GERT exams may be substituted for written exams at the request of the applicable RadCon Manager. A notation shall be made on the examination that it was given orally.

7. RW-Is, RW-Ils, RCTs, or NRC-qualified personnel who have received sitespecific training within the last $\mathbf{2 4}$ months are eligible to escort visitors into radiological areas commensurate with their training. Visitor orientation and using trained escorts provide an alternate to training with the concurrence of the RadCon Manager.

8. Requirements for training records and course documentation are provided in Article 725.

9. NV/YMP personnel who have successfully completed and have maintained current qualifications in a particular course meet the requirements for any lesser course.

10. DOE-equivalent radiological training completed within the last 24 months meets the requirements of non-site-specific portions of GERT, RW-I, or RW-II courses (subject to TO RadCon Manager approval), provided that site-specific training is subsequently received. 


\section{Qualification Standards for Radiological Control Technicians}

1. Qualification Standards define the requirements for demonstrating training completion. Signatures on the forms in Qualification Standards provide documentation of satisfactory proficiency.

2. The Qualification Standards from the standardized core course shall be supplemented to include site-specific elements.

3. Qualification Standards for the RCT position shall include on-the-job practical training to provide hands-on experience directly applicable to the job.

4. Prior to performing a job function without direct supervision, a trainee with partially completed qualifications shall have completed the qualifications for that task.

\section{Oral Examination Boards}

The Oral Examination Board provides an opportunity to identify areas of strengths and weaknesses related to performance of RCT duties and RCT Supervisor functions. The Oral Examination Board also provides the opportunity to identify additional training needs to enhance RCT and RCT Supervisor training programs.

1. An Oral Examination Board shall determine the initial qualification and is encouraged for requalification of RCT and RCT Supervisor positions.

2. The RadCon Manager shall designate the Board members and appoint a chairperson.

3. The Board constituted to evaluate RCT qualification should be composed of at least three persons to include an RCT Supervisor, RadCon staff, and/or line management, operations department supervisors and staff personnel, as applicable. Instructors may participate as nonvoting members.

4. The Board should assess the candidate's response to normal and emergency situations.

5. The Board constituted to evaluate RCT Supervisor qualification should not include peers or subordinates as voting members.

\section{Instructor Training and Qualifications}

1. All instructors should be qualified in accordance with the TO's Instructor Qualification Program or possess equivalent qualifications. 
2. Instructors should have the technical knowledge, experience, and instructional skills required to fulfill their assigned duties.

3. Instructors-in-training shall be monitored by a qualified instructor.

4. Subject matter experts without instructor qualification may provide training in their areas of expertise. However, these subject matter experts should be trained as instructors when this occurs routinely.

\section{PART 2 General Employee Radiological Training}

\section{Site Personnel}

General Employees who may enter Controlled Areas and encounter radiological barriers, postings, or radioactive materials shall complete GERT unless RW-I, RW-II, or RCT training is current. This training shall be successfully completed prior to potential occupational radiation exposure.

1. GERT includes the standardized core course training materials expanded to include site-specific information, such as site-specific radiation types, alarm responses, and policies.

2. Workers may challenge GERT standardized core knowledge requirements by passing a comprehensive examination. If unsuccessful in one attempt, the entire GERT standardized core training shall be completed. Challenges do not apply to the site-specific portions.

3. Expected time to complete the standardized core and site-specific GERT is approximately 1 hour.

4. Additional training beyond GERT is necessary for unescorted entry into radiological areas or areas posted for radiological control other than Controlled Areas.

5. Information may be communicated by classroom lecture, videotape, or other applicable methods.

6. Escorted General Employees who enter radiological areas to do work shall have GERT as a minimum training requirement.

\section{Radiological Orientation for Members of the Public}

1. Members of the public, including tour groups and visiting dignitaries, who enter Controlled Areas shall receive a radiological safety orientation that should 
include the following topics and be commensurate with the hazards present in the areas to be entered:

a. Risk of low-level occupational radiation exposure, including cancer, genetic effects, and risk of prenatal radiation exposure.

b. Visitor and management responsibilities for radiation safety.

c. Applicable emergency procedures.

d. Training for issuance of dosimeters, where applicable.

2. Information may be communicated by videotape or handout. An examination is not required.

3. Visitor sign-in logs may be used as orientation records as required by Article 725.

4. Members of the public shall be continuously escorted in Controlled Areas. The TO RadCon Manager may approve exceptions to the escort requirements provided that:

a. Appropriate limitations are established on the areas to be entered and the activities to be undertaken.

b. The individual does not receive occupational radiation exposure.

c. The individual receives an enhanced orientation providing information commensurate with the areas to be entered and activities to be undertaken while unescorted.

5. Requirements for visiting scientists and specialists are addressed in Article 657 .

\section{PART 3 Radiological Worker Training}

\section{Requirements}

1. RW-I training is required for unescorted entry into areas as stated in Table 6-1.

2. RW-Il training is required for unescorted entry into areas as stated in Table 6-1. Additional training is required for special job functions with radiological consequences per Article 634.1.

3. Workers may challenge RW-I or RW-II standardized core knowledge requirements by passing a comprehensive examination. If unsuccessful in one attempt, the entire standardized core RW-I or RW-II training shall be completed.

4. RW-I training is not a prerequisite for RW-II training (see Article 613.9). 
NV/YMP Radiological Control Manual, Rev. 2:

November 13, 1996

TRAINING AND QUALIFICATION

CHAPTER 6

5. Individuals with current RW-I training may be upgraded to allow unescorted access to other areas by completing only the additional training provided in RWII training.

Table 6-1 Radiological Worker Entry Training Requirements

\begin{tabular}{||l|c|c|c||}
\hline \multicolumn{1}{|c|}{ AREAS } & GERT & RW-I & $\begin{array}{c}\text { RW-II and } \\
\text { RCT }\end{array}$ \\
\hline \hline Entry into Controlled Areas & YES & YES & YES \\
\hline Entry into Radiation Areas & $\begin{array}{c}\text { NOT } \\
\text { PERMITTED }\end{array}$ & YES & YES \\
\hline $\begin{array}{l}\text { Entry into High or Very High } \\
\text { Radiation Areas }\end{array}$ & $\begin{array}{c}\text { NOT } \\
\text { PERMITTED }\end{array}$ & $\begin{array}{c}\text { NOT } \\
\text { PERMITTED }\end{array}$ & YES \\
\hline $\begin{array}{l}\text { Entry into Contamination Areas } \\
\text { and High Contamination Areas }\end{array}$ & $\begin{array}{c}\text { NOT } \\
\text { PERMITTED }\end{array}$ & $\begin{array}{c}\text { NOT } \\
\text { PERMITTED }\end{array}$ & YES \\
\hline $\begin{array}{l}\text { Entry into Soil Contamination } \\
\text { Areas (to perform work that } \\
\text { disturbs soil) }\end{array}$ & $\begin{array}{c}\text { NOT } \\
\text { PERMITTED }\end{array}$ & $\begin{array}{c}\text { NOT } \\
\text { PERMITTED }\end{array}$ & YES \\
\hline $\begin{array}{l}\text { Entry into Airborne } \\
\text { Radioactivity Areas }\end{array}$ & $\begin{array}{r}\text { NOT } \\
\text { PERMITTED }\end{array}$ & $\begin{array}{c}\text { NOT } \\
\text { PERMITTED }\end{array}$ & YES ${ }^{3}$ \\
\hline
\end{tabular}

${ }^{1}$ Entry requirements further restricted by Article 334 .

${ }^{2}$ Entry prohibited unless trained in accordance with Article 632.4.

${ }^{3}$ Requires respiratory protection qualification (Article 531).

\section{Radiological Worker I}

1. Workers whose job assignments require access to radiological areas shall complete DOE standardized core RW-I training and site-specific RW-I training before being permitted to enter these areas without a qualified escort.

2. RW-I training shall use the DOE standardized core course training materials and in addition shall include site-specific information and radiological procedures specific to an individual's job assignment.

3. RW-I training, including High/Nery High Radiation Area training (Article 632.5), should encompass at a minimum the following practical factors: 
a. Entering and exiting simulated Controlled Areas and Radiation Areas (and HighNery High Radiation Areas when such training is included).

b. Performing frisking for personnel contamination, as applicable.

c. Verifying instrument response and source check, as applicable.

d. Anticipated response to alarm situations.

4. Unescorted worker access to High or Very High Radiation Areas is permitted upon successful completion of RW-I training and HighNery High Radiation Area supplemental training. Completing this training does not authorize access to Contamination, High Contamination, Soil Contamination, or Airborne Radioactivity Areas.

\section{Radiological Worker II}

Workers whose job assignments involve entry to High and Very High Radiation Areas, Contamination Areas, High Contamination Areas and Airborne Radioactivity Areas shall complete RW-Il training. RW-II training is not required for access limited to High or Very High Radiation Areas for workers trained in accordance with Article 632.4. Further, workers who have potential contact with hot particles shall complete RW-II training.

1. RW-Il training shall use the standardized core course training materials and in addition shall include site-specific information and radiological procedures specific to an individual's job assignment.

2. RW-Il training shall encompass, at a minimum, the following practical factors:

a. Donning protective clothing.

b. Entering a simulated Controlled Area, Contamination Area, and High Radiation Area to perform a task.

c. Anticipated response to simulated abnormal situations.

d. Anticipated response to simulated alarms or faulty radiological control equipment.

e. Removing protective clothing and equipment and subsequently exiting the simulated area.

f. Performing frisking for personnel contamination, as applicable.

g. Verifying instrument response and source check, as applicable.

\section{Specialized Radiological Worker Training}

1. Specialized Radiological Worker training should be completed for nonroutine operations or work in areas with changing radiological conditions. This training is in addition to RW-Il training and is required for personnel planning, preparing, and performing jobs that have the potential for high radiological consequences. 
Such jobs may involve special containment devices, the use of mockups, and ALARA considerations.

2. Additional training for employees of specialized facilities is contained in Part 6 of this Chapter, as applicable.

\section{PART 4 Radiological Control Technician Qualification}

\section{Requirements}

$\mathrm{RCT}$ is a radiological worker whose primary job assignment involves assessing workplace radiological conditions, specifying protective measures, and providing assistance and guidance to other individuals in implementing radiological controls. Each RCT and RCT Supervisor shall demonstrate knowledge of the radiation safety training topics established in 10 CFR $835.901(\mathrm{~b})$, commensurate with the hazards in the areas and required controls, by successful completion of examinations and performance demonstrations prior to performing unsupervised assignments.

Training and qualification of RCTs and their immediate supervisors shall address routine operations and also focus on recognizing and handling situations in both normal and changing radiological conditions. Newly qualified technicians and those still in training should work with qualified, experienced technicians.

\section{Radiological Control Technician}

1. Initial RCT qualification requires successful completion of the standardized core course training material including emphasis on site-specific information (Phase I), on-the-job practical training (Phase II), and an Oral Examination Board (Phase III).

2. RCT candidates who have prerequisite knowledge, such as college credit, operational experience, or related qualifications may satisfy individual sections of the standardized core course training requirements by passing comprehensive challenge examinations.

3. Entry-level prerequisites shall be established to ensure that RCTs meet the standards for physical condition and education. At a minimum, these standards should include the following:
a. High school education or equivalency.
b. Fundamental knowledge of mathematics, physics, chemistry, and science.
c. Systems and fundamentals of process, operations, and maintenance. 
d. Reading and comprehension level sufficient to follow procedures, write permits, prepare survey maps, write reports, and prepare shipping and transfer permits.

e. Ability to work in a support role, including communicating verbal instructions to others.

f. Physical requirements to handle PPE and other equipment and assist others in work locations commensurate with assignment.

4. RCTs are encouraged to pursue registration by the National Registry of Radiation Protection Technologists (NRRPT).

5. TOs are encouraged to give credit toward completing standardized core training requirements for NRRPT registration.

\section{Continuing Training and Requalification}

1. Following qualification, RCTs and their supervisors shall begin a 24-month cycle of continuing training required for requalification. Biennial requalification requires completing practical training and a comprehensive written examination encompassing a representative cross-section of Phase I learning objectives and a final Oral Examination Board.

2. Continuing training should provide continued improvement in the knowledge and skills of the RCT.

3. Continuing training should include written examinations as applicable, demonstrations of proficiency controlled by Qualification Standards, and oral examinations, if needed, to prepare for the comprehensive biennial requalification.

4. Infrequently performed tasks, such as those for emergency response, may require annual training. Other tasks may require retraining prior to initiation.

\section{Radiological Control Technician Supervisors}

1. RCT Supervisors shall have qualified as an RCT or shall have a minimum of a bachelor's degree or the equivalent experience in radiological protection. The RCT Supervisor should be an experienced professional in radiological control and familiar with the design features and operations of the facility or site where work is being performed.

2. RCT Supervisors should have supervisory and leadership capabilities to direct the work of technicians; effectively interacting with crafts, line-supervisors, professional staff, and other managers. RCT Supervisors should have adequate 
knowledge of operations and site specific information to respond and direct others in emergency and abnormal situations.

3. RCT Supervisors shall be requalified every 24 months. Comprehensive Oral Examination Boards in accordance with Article 615 are encouraged for requalification. Their Oral Boards should focus on the ability to analyze radiological situations, unusual situations, and supervise subordinates.

4. The RCT Supervisor's depth of knowledge should exceed that expected of an RCT.

\section{Subcontracted Radiological Control Technicians}

Subcontractor RCTs are individuals who are not DOE or DOE contractor employees and normally have not completed the DOE RCT training program.

1. Subcontracted RCTs should have the same knowledge and qualifications required of facility technicians performing the same duties. At a minimum, the training and qualification program should include the following:

a. Reviewing resumes to identify technicians with experience in jobs similar to those for which they will be employed.

b. Written examination and oral evaluation to verify appropriate level of knowledge.

c. Identifying the duties technicians will be authorized to perform.

d. Training in facility procedures and equipment associated with the authorized duties.

e. Training on recent site or facility operating experience.

f. Observing on-the-job performances by the RCT Supervisor.

2. Subcontracted technicians who work at the facility for extended time periods (more than 6 months) should receive continuing training commensurate with their assigned duties. Completing an oral examination in accordance with Article 615 is encouraged.

\section{PART 5 Other Radiological Training}

\section{Management Training}

Line Managers who manage, supervise, or provide oversight of operations involving radiological controls should be trained in the principles of this Manual. 


\section{Technical Support Personnel}

Appropriate technical support personnel should be trained in the principles of ALARA and dose reduction techniques.

\section{Planners}

Planners who develop detailed work plans involving or associated with radioactivity or radioactive materials should have radiological worker training to the level required by the workers using the work plans.

\section{Radiological Control Personnel}

1. RadCon technical staff and management should have:

a. A combination of education and experience commensurate with their job responsibilities.

b. Continuing training based on an assessment of job responsibilities to maintain and enhance proficiency.

c. Continuing training to remain cognizant of changes to the facility, operating experience, procedures, regulations, and quality assurance requirements.

2. Radiological support personnel may include but are not limited to: dosimetry technicians, instrument technicians, medical personnel, records clerks, whole body counter technicians, and laboratory personnel.

3. Radiological support personnel should have:

a. Applicable training on standardized core course topics from RW-I, RW-II, RCT training, and additional job-specific topics.

b. Training appropriate to the tasks to be performed.

c. Continuing training to provide continued improvement in knowledge and skills.

\section{Radiographers and Radiation Generating Device Operators}

Radiographers shall have training in accordance with 10 CFR 34.31. Radiation Generating Device Operators should have training appropriate for the radiation source involved and commensurate with the level described in 10 CFR 34.31. Radiographers and Radiation Generating Device Operators should receive site-specific portions of RWI or RW-Il training through their responsible TO RCO prior to performing NV/YMP job assignments (see Article 613.9). 


\section{Emergency Response Personnel}

Provisions shall be in place to accommodate rapid site and radiological area access by on-site and off-site emergency workers such as firefighters, medical personnel, and security personnel.

1. Emergency response personnel, from both on site and off site, may be required to work in radiological areas.

2. Emergency response personnel should receive specialized radiological worker training commensurate with the situations they are likely to encounter.

3. Such training should be based on the radiological worker standardized core course and site-specific training materials.

4. If such workers are not trained, trained escorts should be assigned.

5. Training should make it clear that lifesaving has priority over radiological controls.

6. Records of this training should be maintained.

\section{Training for Visiting Scientists and Specialists}

Visiting scientists and specialists who enter posted areas other than Controlled Areas should receive the NTS Visitor Radiological Safety Guide pamphlet. This pamphlet is intended for individuals not performing hands-on work. Training should be commensurate with the work to be performed. If visiting scientists or specialists are to do hands-on radiological work while unescorted, consideration should be given to providing full RW-I or RW-Il training. Records of this training should be maintained.

\section{PART 6 Training For Special Applications}

\section{Plutonium Facilities}

The following topics should be considered in addition to standardized core training requirements at plutonium facilities:

1. Plutonium properties.

2. Special radiological surveys and techniques.

3. External exposure control (neutrons).

4. Internal exposure control.

5. Containment and glove box operations and procedures.

6. Special instruments and measurement techniques. 
7. Personnel protection.

8. Inventory control and accountability.

9. Criticality safety.

10. Biological effects.

\section{Uranium Facilities}

The following topics should be considered in addition to standardized core training requirements at uranium facilities:

1. Uranium properties.

2. Special radiological surveys and techniques.

3. External exposure control.

4. Toxicological properties and behavior of uranium.

5. Releasing uranium-contaminated materials.

6. Instruments and measurement techniques.

7. Personnel protection.

8. Inventory control and accountability.

9. Criticality safety.

10. Biological effects.

\section{Tritium Facilities}

The following topics should be considered in addition to standardized core training requirements at tritium facilities:

1. Tritium properties.

2. Sources of tritium.

3. Exposure pathways and forms of tritium.

4. Exposure control.

5. Tritium containment.

6. Special instruments and measurement techniques.

7. Personnel protection.

8. Inventory control and accountability.

9. Airborne tritium measurements.

10. Airborne tritium controls.

11. Effluent recovery systems.

12. Tritium releases.

13. Bioassay program.

14. Biological effects. 


\section{Accelerator Facilities}

The following topics should be considered in addition to standardized core training requirements at accelerator facilities:

1. Activation products.

2. Special radiological surveys and techniques.

3. Component source terms.

4. Interlock and warning devices and systems.

5. Access to beam and beam containment.

6. Special instruments and measurement techniques.

7. Biological effects. 


\section{CHAPTER 7 RADIOLOGICAL RECORDS}

\section{TABLE OF CONTENTS}

Article

PART 1 Requirements . . . . . . . . . . . . . . . . . . . . . . . 7-1

711 Purpose . . . . . . . . . . . . . . . . . . . . . . . . . 7-1

712 Records Management Program . . . . . . . . . . . . . . . .

713 Recordkeeping Standards $\ldots \ldots \ldots \ldots \ldots \ldots \ldots \ldots \ldots \ldots \ldots \ldots \ldots .2$

PART 2 Employee Records . . . . . . . . . . . . . . . . . . . . . . . . . 7-2

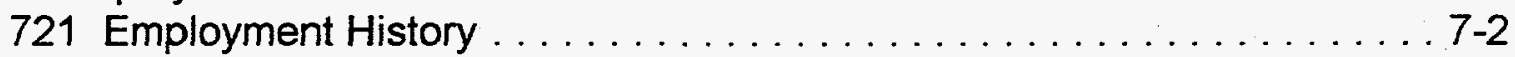

722 Personnel Radiological Records . . . . . . . . . . . . . . . 7-2

723 Other Personnel Radiological Records . . . . . . . . . . . . . . . . . 7-4

724 [Reserved] . . . . . . . . . . . . . . . . . . . . . . .

725 Radiological Training and Qualification Records . . . . . . . . 7-4

PART 3 Visitors . . . . . . . . . . . . . . . . . . . . . . . . . . . 7-5

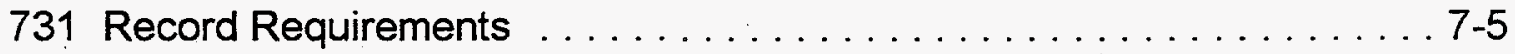

732 Reports .......................... $7-5$

PART 4 Radiological Control Procedures . . . . . . . . . . . . . . . . . . . . 7-6

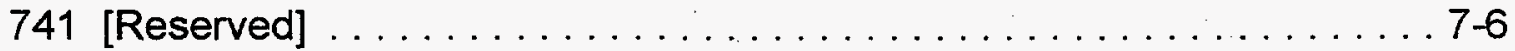

742 ALARA Records . . . . . . . . . . . . . . . . . . . . . . 7-6

743 Quality Assurance Records . . . . . . . . . . . . . . . . 7-6

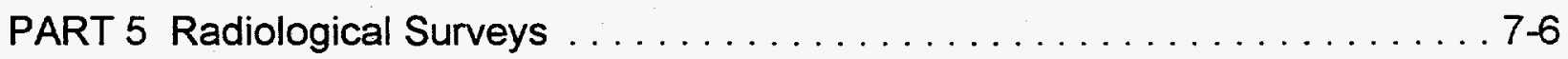

751 Requirements . . . . . . . . . . . . . . . . . . .

752 Radiation Surveys . . . . . . . . . . . . . . . . . . . . . . 7-6

753 Airborne Radioactivity . . . . . . . . . . . . . . . . . . . . . .

754 Contamination Surveys . . . . . . . . . . . . . . . . 7-7

PART 6 Instrumentation and Calibration Records . . . . . . . . . . . . . . . . . . 7-7

761 Calibration and Operational Checks . . . . . . . . . . . . . . . . . 7-7

762 [Reserved] . . . . . . . . . . . . . . . . . . . . . .

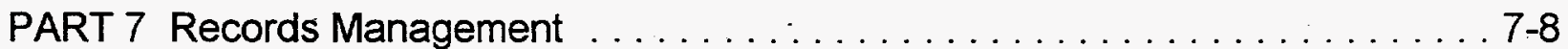

771 [Reserved] . . . . . . . . . . . . . . . . . . . . . . . . . . . . 7-8

772 [Reserved] . . . . . . . . . . . . . . . . . . . . . . . . . . 7-8

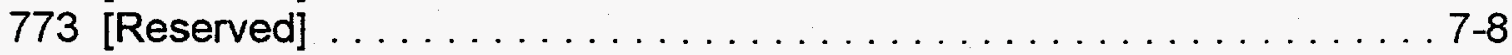

774 Retention . . . . . . . . . . . . . . . . . . . . . . . . . . . . 7-8

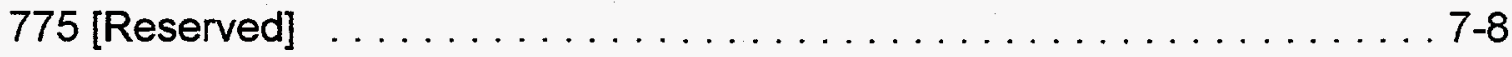


NV/YMP Radiological Control Manual, Rev. 2:

November 13, 1996

RADIOLOGICAL RECORDS

CHAPTER 7

PART 8 Radiological Reporting . . . . . . . . . . . . . . . . . . . . . . . . 7-8

781 Reports to Individuals . . . . . . . . . . . . . . . . . . . . . 7-8

782 Annual Radiation Report . . . . . . . . . . . . . . . . 7-10 


\section{PART 1 Requirements}

\section{Purpose}

Radiological control records shall be maintained as necessary to document compliance with the requirements of $10 \mathrm{CFR} 835$. Records should be handled such that personal privacy is protected. Unless otherwise specified in this section, records shall be retained until final disposition is authorized by DOE.

\section{Records Management Program}

1. A radiological records management program shall be established by each NV/YMP TO. This program shall ensure that auditable records and reports are controlled through the stages of creation, distribution, use, arrangement, storage, retrieval, media conversion (if applicable) and disposition. The records management program shall include items $a$ and $b$, below, and should include the remaining items:

a. Individual Radiological Doses.

b. Radiological Incident and Occurrence Reports (and Critique Reports, if applicable).

c. Radiological Control Procedures.

d. Internal and External Dosimetry Policies and Procedures (including technical basis documents).

e. Personnel Training Records.

f. ALARA Records.

g. Radiological Instrumentation Test, Maintenance, and Calibration Records.

h. Radiological Surveys (including material release surveys).

i. Area Monitoring Dosimetry Results.

j. RWPs.

k. Accountability records for sealed radioactive sources.

2. Where radiological services (for example, dosimetry and laboratory analyses) are purchased, there should be a clear agreement regarding records responsibility during performance of the service. Records of results should reside in the custody of the originating contract organization.

3. DOE 1324.2A provides implementing instructions, records inventory requirements, disposition schedules, and provisions for the transfer of records.

4. Detailed information concerning an individual's exposure shall be made available to that individual, upon request, consistent with the-Privacy Act of 1974, which contains requirements to protect the privacy of individual records. 


\section{Recordkeeping Standards}

1. Radiological control records should include the following:

a. Identying the facility, specific location, general function and process.

b. Signature or other identifying code of the preparer and date:

c. Legible entries in black ink.

d. Corrections identified by a single line-out, initialed and dated.

e. Supervisory signature to ensure review and proper completion of forms.

2. Radiological control records shall not include:

a. Opaque substances for corrections.

b. Shorthand or other nonstandardized terms.

c. The use of Systems International (SI) units (such as Becquerel, Gray, Sievert).

\section{PART 2 Employee Records}

\section{Employment History}

Records detailing an employee's pre-employment (to the extent practical), employment history, and the associated occupational radiation dose shall be maintained. Efforts shall be made to obtain records of prior years occupational internal and external exposure.

\section{Personnel Radiological Records}

1. Records of doses received by all individuals for whom individual monitoring was performed shall be maintained. These records shall be sufficient to evaluate compliance with all applicable dose limits and monitoring and reporting requirements.

2. Radiation dose records shall contain information sufficient to identify each person, including social security or employee number.

3. Routine and special records related to radiation doses shall be retained for each person monitored. This shall include records of zero dose. Procedures, data, and supporting information needed to reconfirm a person's dose at a later date shall be maintained. 
4. External dose records shall include the following:
a. Applicable extremity, skin, eye, and whole body dose results measured with personnel dosimeters, including all multiple dosimeter badging results.
b. Evaluations resulting from anomalous dose results such as unexpected high or low doses.
c. Dose reconstructions from lost or damaged dosimeters, or for unbadged workers.
d. Evaluating nonuniform radiation doses.

5. Internal dose records shall include the following:
a. Applicable whole body and lung counting results (including chest wall thickness measurements where applicable).
b. Applicable urine, fecal, and specimen analysis results, including estimated intake and identity of radionuclides.
c. Dose assessment, as required.

6. Records of the summation of external dose and committed dose equivalent to any organ receiving a reportable dose shall be maintained for the individual receiving such dose.

7. The TEDE received by each monitored individual shall be maintained for each year the individual is monitored.

8. The dose equivalent to the embryo/fetus of a declared pregnant worker shall be maintained with the occupational exposure records for that worker.

9. Records of lifetime occupational dose, including cumulative TEDE since January 1,1989 , should be maintained with the individual's occupational exposure records.

10. Records of authorization to exceed Administrative Control Levels shall be retained.

11. Emergency doses and planned special exposures shall be accounted for separately but maintained with the individual's occupational exposure records.

12. Records of non-uniform dose to the skin caused by contamination on the skin need not be retained in personnel dose records if the dose is less than 2 percent of the limit for the skin in Table 2-1 (see Article 723 for requirements for records of radiological incidents and occurrences). 


\section{Other Personnel Radiological Records}

1. The complete records of radiological incidents and occurrences involving personnel dose shall be retained.

2. Records of the formal written declaration of pregnancy shall be maintained. Records of revocations of such declarations, as well as records indicating that the pregnancy has concluded should also be maintained.

\section{4 [Reserved]}

\section{Radiological Training and Qualification Records}

1. Records of training and qualification in radiological control shall be maintained to demonstrate that a person received appropriate information to perform the work assignment in a safe manner. Qualification Standard records should be retained for on-the-job and practical factor training as well as for formal classroom training.

2. Formal records of training and qualification shall be readily available to supervision of involved personnel to aid in making work assignments.

3. Personnel training records should include the following:
a. Course title.
b. Attendance sheets with instructor's name.
c. Employee's name, identification number, and signature.
d. Date of training.
e. Identification of the examination or evaluation form, including sufficient data to identify which test each person completed.
f. Verification document or record confirming satisfaction of the training requirement.
g. Documentation related to exceptions for training requirements and qualification extensions.
h. Quizzes, tests, responses, and acknowledgments of training, with the date and signature of the person trained.
i. Special instructions to females, their supervisors, and coworkers concerning prenatal radiation dose, acknowledged by the worker's signature.

4. Records shall be retained for the following types of training:
a. GERT.
b. RW-I and RW-II training.
c. Periodic retraining. 
d. Emergency response personnel training.

e. Radiological control personnel training.

f. Instructor training.

g. Qualifications for special tests or operations.

5. The following instructional materials shall be maintained:

a. Instructor's manuals, course content, or lesson plans containing topical outlines.

b. Job-specific training documents, such as instrument use, radiological procedures, RWP special training requirements, pre-job briefings, and mock-up training.

6. NVMMP TOs delegated with radiological training responsibilities are required to:

a. Maintain the worker classification automated tracking system for DOE/NV and NVIMMP TOs within their purview.

b. Document all required training using approved forms, and enter these data into a computer database. This database provides the basis to determine if the appropriate training has been provided to the individual workers at the required intervals.

c. Maintain a copy of all worker classification records, training materials, and revisions.

7. All NVMMP TOs should ensure that radiological training is documented on approved forms, and transmitted to their designated responsible training TO for inclusion into the database.

\section{PART 3 Visitors}

\section{Record Requirements}

1. Documentation of completion of Radiological Orientation shall be maintained for visitors entering an area where radiation monitoring is required.

2. Records of doses, including zero dose, received by all visitors for whom monitoring was performed shall be maintained. These records shall be sufficient to evaluate compliance with all applicable dose limits and monitoring and reporting requirements.

\section{Reports}

Monitoring results, including zero dose, should be reported to each visitor monitored. 


\section{PART 4 Radiological Control Procedures}

\section{1 [Reserved]}

\section{ALARA Records}

Records of ALARA plans and goals shall be maintained to demonstrate the adequacy of the ALARA Program.

\section{Quality Assurance Records}

Records of quality assurance reviews and audits developed for radiological control functions shall be retained to ensure that sufficient records are specified, prepared, reviewed, approved, and maintained to accurately reflect completed work.

\section{PART 5 Radiological Surveys}

\section{Requirements}

1. Radiological Control Programs require the performance of radiation, airborne radioactivity, and contamination surveys to determine existing conditions in a given location. Radiological surveys should be recorded and include the following:
a. Date, time, and purpose of the survey.
b. General and specific location of the survey.
c. Name and signature of the surveyor.
d. Pertinent information needed to interpret the survey results.
e. Reference to a specific RWP if the survey is performed to support the permit.

\section{Radiation Surveys}

1. In addition to the elements provided in Article 751 , records of radiation surveys shall include, at a minimum, the following information:

a. Instrument model and serial number.

b. Measurement results of area dose rates.

\section{Airborne Radioactivity}

1. In addition to the elements provided in Article 751, airborne radioactivity records shall include, at a minimum, the following information: 
a. Model and serial numbers of the sampler and laboratory counting instrument when available or unique identifier of each sampler and instrument.

b. Location of fixed air samplers.

c. Location of portable air samplers used for a survey.

d. Air concentrations in general airborne areas and breathing zones.

e. Supporting parameters, including collection efficiency, flow rate, duration of sampling, correction factors, and filter medium.

\section{Contamination Surveys}

1. In addition to the elements required by Article 751 , contamination survey records shall include, at a minimum, the following information:

a. Model and serial number of counting equipment.

b. Contamination levels (using appropriate units) and appropriate supporting parameters including counting efficiency, counting time, correction factors, type of radiation, and whether the contamination was fixed or removable.

c. Area location found to contain hot particles or high concentrations of localized contamination.

d. Follow-up survey results for decontamination processes cross-referenced to the original survey.

\section{PART 6 Instrumentation and Calibration Records}

\section{Calibration and Operational Checks}

1. Calibration records for fixed, portable, and laboratory radiation measuring equipment and individual monitoring devices, shall be maintained and include frequencies, method, dates, personnel, training, and traceability of calibration sources to NIST (see Article 562.2) or other acceptable standards.

2. Calibration records shall be maintained for the equipment listed below:

a. Pocket and electronic dosimeters.

b. Bioassay measurement equipment.

c. Laboratory, counting room, and fixed radiation measuring equipment.

d. Process and effluent monitors and sampling equipment.

e. Radiation area monitors.

f. Portal monitors and other personnel contamination monitors.

g. Portable survey instruments.

h. Air sampling equipment.

i. $\quad$ PC and equipment monitors. 
3. Documentation of instrument operational checks shall be maintained for a period not less than the calibration period of the instrument.

4. Maintenance histories, including the nature of any defects and corrective actions taken, and calibration results for each instrument shall be created and retained.

762 [Reserved]

PART 7 Records Management

\section{1 [Reserved]}

772 [Reserved]

773 [Reserved]

\section{Retention}

DOE $1324.2 A$ and 10 CFR 835 describe procedures for retaining records. Upon cessation of activities that could result in the occupational exposure of individuals, all required records shall be transferred to DOE.

\section{5 [Reserved]}

\section{PART 8 Radiological Reporting}

\section{Reports to Individuals}

1. Annual and Current Dosimetry Reports

a. Personnel who are monitored by the personnel dosimetry program shall be provided an annual report of their dose.

b. All NV/YMP TOs should provide a summary of the annual, cumulative, and CEDE to all of their current monitored employees by September 30 of the following year.

c. Upon request, an individual shall receive a current radiation dose record.

2. Termination Dosimetry Reports

Upon the request from an individual terminating employment, records of exposure shall be provided to that individual as soon as the data are available, but not later than 90 days after termination. A written estimate of the radiation dose received by that employee based on available information shall be provided at the time of termination, if requested. 
3. Other Personnel Reports

a. Positive Dose Report. The RSPC should issue a positive dose report at least monthly to all TOs that have personnel whose name appears on the Positive Dose Report.

b. Processed Dose Report. Additionally, the RSPC should provide a Processed Dose Report within 2 months after the close of each quarter, which is submitted to DOE/NV SHD and each TO.

c. Blind Audit Dosimeter Report. The RSPC should conduct a quarterly blind audit dosimetry program to ensure that a correct dose is calculated from raw dosimeter results. A quarterly Blind Audit Dosimeter Report should be generated by the RSPC and sent to each dosimetry user no later than 3 months after the end of the quarter.

d. Non-Returned Dosimeter Report. The RSPC provides a Non-Returned Dosimeter Report listing the name of each individual who did not return or change out his/her dosimeter during the previous quarter. The report should be distributed within 15 days of the end of the issue period.

4. All TOs should:

a. Review each monthly Positive Dose Report, verify those persons listed under the pertinent organization are correct, that the exposures are as expected, and investigate any anomalies.

b. Review the quarterly Processed Dose Report for any errors (names or organization identification) and give this information to the RSPC.

c. Evaluate the quarterly Blind Audit Report, determine if any adjustments are necessary in the assignment of personnel doses, and report any adjustments to the RSPC.

d. Retrieve all non-returned dosimeters and return to the RSPC for processing.

5. Reports of individual doses shall include the site or facility name, the individual's name and social security or employee number, and all dose information required by Article 722 .

6. Reports of individual exposure to radiation or radioactive material required under DOE 232.1 or as a result of a planned special exposure (10 CFR 835.204[e]) shall be submitted to DOE in accordance with departmental occurrence reporting requirements. Copies of the individual dose information contained in these reports shall be provided to the affected individual at a time not later than transmittal of the report to the DOE. 


\section{Annual Radiation Report}

1. DOE 5484.1 provides reporting requirements for the "Annual Radiation Dose Summary." This report includes internal and external radiation dose results for monitored DOE and DOE contractor employees, and for monitored visitors.

2. The RSPC should submit the annual Radiation Exposure Information Reporting System (REIRS) report for radiation workers and visitors with positive exposures to Science Applications International Corporation (SAIC) at Oakridge, Tennessee by March 31 of the following year. This report includes DOE/NV/YMP and all TO employees whose employing organization(s) do not themselves submit an annual report to SAIC. 


\section{REFERENCES}

The following references contain additional information pertinent to the provisions incorporated in this Manual. Those persons responsible for the Site-Specific Manual should have these references readily available. The citing Article is noted in brackets ([ ]) following each reference. See "Additional References" for addresses of organizations.

\section{FEDERAL}

Atomic Energy Act of 1954, as amended. Public Law 83-703. [112.1]

Resource Conservation and Recovery Act of 1976, as amended. Public Law 94580. [443]

10 CFR 20 "Standards for Protection Against Radiation." [535]

10 CFR 34 "Licenses for Radiography and Radiation Safety Requirements for Radiographic Operations." [365.5]

10 CFR 34.31 "Personal Radiation Safety Requirements for Radiographers and Radiographers Assistants - Training." [655]

10 CFR 834 "Radiation Protection of the Public and the Environment; Proposed Rule."

10 CFR 835 "Occupational Radiation Protection." [Part 1, Ch 1; 113.3e, 128.1a, 213.3, 221.4, 223.2, 232.3, 235.3, Appendix 2A, 325.9, 521.2, 551.13b, 713.3c, 774.1, 781.2]

29 CFR 1910.134 "General Industry Standards - Respiratory Protection." [531.5]

49 CFR 172 "Hazardous Materials Tables, Hazardous Materials Communications, Requirements and Emergency Response Information Requirements." [423.1]

49 CFR 173 "Shippers - General Requirements for Shipments and Packaging." [423.1]

52 CFR 1716 "Radiation Protection Guidance to Federal Agencies for Occupational Exposure," signed by President Reagan, January 20, 1987. [111, 213.1]

ERDA 76-21 "Nuclear Air Cleaning Handbook, Design, Construction, and Testing of High-efficiency Air Cleaning Systems for Nuclear Application." [464.2]

MIL-F-51068 "Particulate Filters (High Efficiency Fire Resistant)," [464.2] 


\section{DEPARTMENT OF ENERGY}

The following DOE Orders have been referenced. Reader should verify that the latest version of the referenced Order is used.

DOE N 441.1 (9-30-95) "Radiological Protection for DOE Activities."

DOE N 441.2 (9-19-96) "Extension of DOE N 441.1, Radiological Protection for DOE Activities."

DOE 5400.5 (2-8-90) "Radiation Protection of the Public and the Environment." [222.6, Table 2-4, 411.5, 422.1-3, 451.4, 554.4]

DOE 5480.4 (1-7-93) "Environmental Protection, Safety, and Health Protection Standards." [365.1, 365.2, 365.5, 531.5, 562.1]

DOE N 5480.8 (6-8-93) "Radiological Health and Safety Policy."

DOE 5480.18A (7-19-91) "Accreditation of Performance-Based Training for Category A Reactors and Nuclear Facilities." [612]

DOE 5480.19 (7-9-90) "Conduct of Operations Requirements for DOE Facilities." [125.1]

DOE 5480.20 (2-20-91) "Personnel Selection, Qualification, Training and Staffing Requirements at DOE Reactor and Non-Reactor Nuclear Facilities." [612.2, 613.8]

DOE 5480.25 (11-3-92) "Safety of Accelerator Facilities." [364.2]

DOE 5484.1 (10-17-90) "Environmental Protection Safety and Health Protection Information Reporting Requirements." [721, 782] (Change 7)

DOE 5700.6C. (8-21-91) "Quality Assurance." [743]

DOE 5820.2A (9-26-88) "Radioactive Waste Management." [222.8, 441.1, 443.1, 443.2, 451.1]

DOE 6430.1A (4-6-89) "General Design Criteria." [128.1] 


\section{DEPARTMENT OF ENERGY GUIDES TO GOOD PRACTICES}

EGG-2530 (1988) "Health Physics Manual of Good Practices for Uranium Facilities," EG\&G, Idaho Falls, Idaho 83415. [362]

MLM-3719 (1991) "Health Physics Manual of Good Practices for Tritium Facilities," (Replaces 1989 Draft - final publication expected 1992) EG\&G Mound Applied Technologies, Miamisburg, Ohio 45343. [363]

PNL-6534 (1988) "Health Physics Manual of Good Practices for Plutonium Facilities," Pacific Northwest Laboratory, Richland, Washington 99352. [361.2]

PNL-6577 (1988) "Health Physics Manual of Good Practices to Reducing Radiation Exposure to Levels that Are As Low As Reasonably Achievable (ALARA)," Pacific Northwest Laboratory, Richland, Washington 99352. [312.7]

SLAC-327 (1988) "Health Physics Manual of Good Practices for Accelerator Facilities," Stanford Linear Accelerator Center, Stanford, California 94305. [364.1]

\section{DEPARTMENT OF ENERGY STANDARDIZED CORE TRAINING MATERIALS}

DOE/EH-0258T-1 (1995) "General Employee Radiological Training and Radiological Worker Training, Program Management Manual."

DOE/EH-0258T-2 (1995) "General Employee Radiological Training and Radiological Worker Training, Training Aids."

DOE/EH-0259T-1 (1995) "General Employee Radiological Training, Lesson Plan." DOE/EH-0259T-2 (1995) "General Employee Radiological Training, Study Guide."

DOE/EH-0260T-1 (1995) "Radiological Worker Training, Radiological Worker I, Lesson Plans."

DOE/EH-0260T-2 (1995) "'Radiological Worker Training, Radiological Worker I, Study Guides."

DOE/EH-0261T-1 (1995) "Radiological Worker Training, Radiological Worker II, Lesson Plans."

DOE/EH-0261T-2 (1995) "Radiological Worker Training, Radiological Worker II, Study Guides." 
NV/YMP Radiological Control Manual, Rev. 2:

REFERENCES

November 13, 1996

REFERENCES

DOE/EH-0262T-1 (1995) "Radiological Control Technician, Training Program Management Manual."

DOE/EH-0262T-2 (1995) "Radiological Control Technician, Standardized Technician Qualification Standard."

DOE/EH-0262T-3 (1995) "Radiological Control Technician, Phase I, Core Academic Training Lesson Plans."

DOEJEH-0262T-4 (1995) "Radiological Control Technician, Phase I, Core Academic Training Study Guides."

DOEJEH-0262T-5 (1995) "Radiological Control Technician, Phase I, Site Academic Training Lesson Plans."

DOE/EH-0262T-6 (1995) "Radiological Control Technician, Phase I, Site Academic Training Study Guides."

DOE/EH-0262T-7 (1995) "Radiological Control Technician, Phase II, Core/Site Practical Training."

DOE/EH-0262T-8 (1995) "Radiological Control Technician, Phase III, Oral Examination Boards."

DOE/EH-0262T-9 (1995) "Radiological Control Technician, Phase IV, Facility Practical Training Attachment."

DOE/EH-0262T-10 (1995) "Radiological Control Technician, Training Aids."

\section{U.S. DEPARTMENT OF ENERGY, NEVADA OPERATIONS OFFICE}

ORDER NV 356, Revision 3, "DOE/NV/NTS Onsite Transportation Manual." [431]

ORDER NV 5480.11 \& Attachment 3 (9-28-94) "Radiation Protection for Occupational Workers."

NTS SOP 4001(08-17-95) "Nevada Test Site Infrastructure Management."

NTS SOP 5402 (1-13-92) "Radiological Safety." [112.3, 222.8, 311]

NTS SOP 6401 (2-4-94) "Engineering, Construction, and Support Services." [112.3; Part 2, Ch 2; 371] 
NV/YMP Radiological Control Manual, Rev. 2:

November 13, 1996 REFERENCES REFERENCES

NTS SOP 6405 (08-10-95) "Control of Nuclear Test Areas."

UCRL-JC DRAFT, revised 10-28-94, "Development of the Scientific Bases for Establishing the Boundary Conditions Between 'Unrestricted Use' and 'Posting' for Hazards due to Residual Contamination of Soil at the Nevada Test Site" by L.R. Anspaugh \& J.I. Daniels. (A paper prepared by LLNL for submittal to the Journal of Health Physics. [222.9]

\section{NUCLEAR REGULATORY COMMISSION}

Regulatory Guide 8.7 (1992) "Instructions for Recording and Reporting Occupational Radiation Exposure Data," Form 4, "Cumulative Occupational Exposure History." [721.2]

\section{AMERICAN NATIONAL STANDARDS INSTITUTE}

ASME N509 (1989) "Nuclear Power Plant Air-Cleaning Units and Components." [464.2]

ASME N510 (1989) "Testing of Nuclear Air Treatment Systems." [464.2]

CGA G-7.1 (1989) "Commodity Specification for Air." [531.5]

N13.6 (R1989) "Practice for Occupational Radiation Exposure Record Systems." [411.5]

N43.2 (R1989) "Radiation Safety for X-Ray Diffraction and Fluorescence Analysis Equipment." [365.2]

N43.3 (1993) "American National Standard for General Radiation Safety - Installations Using Non-Medical X-Ray and Sealed Gamma-Ray Sources, Energies up to $10 \mathrm{MeV}$." $[365.1,365.5]$

N323 (R1983) "Radiation Protection Instrumentation Tests and Calibrations." [562.1, 564]

N437 (1976) "Radiological Safety Standards for the Design of Radiographic and Fluoroscopic Industrial X-Ray Equipment." [431]

Z88.2 (1980) "Practices for Respiratory Protection." [531.2] 
NV/YMP Radiological Control Manual, Rev. 2:

November 13, 1996

REFERENCES

REFERENCES

Z88.6 (1984) "Physical Qualifications for Respirator Use." [532]

\section{AMERICAN SOCIETY FOR TESTING AND MATERIALS}

E 1168 (1987) "Radiological Protection Training for Nuclear Facility Workers." [612] INTERNATIONAL COMMISSION ON RADIOLOGICAL PROTECTION

ICRP Publication 26 (1977) "Recommendation of the International Commission on Radiological Protection." [Appendix. 2B]

ICRP Publication 55 (1990) "Optimization and Decision-Making in Radiological Protection." [312.7]

\section{NATIONAL COUNCIL ON RADIATION PROTECTION AND MEASUREMENTS}

NCRP Report No. 65 (1980) "Management of Persons Accidentally Contaminated with Radionuclides." [542.1]

NCRP Report No. 91 (1987) "Recommendations on Limits for Exposure to lonizing Radiation." [Appendix. 2B]

\section{ADDITIONAL REFERENCES}

Below is a selection of the many references used in developing this Manual:

\section{INTERNATIONAL COMMISSION ON RADIOLOGICAL PROTECTION}

Publications are available from Pergamon Press, Inc., Maxwell House, Fairview Park, Elmsford, New York, 10523.

ICRP Publication 23 (1974) "Reference Man Anatomical Physiological and Metabolic Characteristics."

ICRP Publication 30 (1978-1979) "Limits for Intakes of Radionuclides by Workers."

ICRP Publication 32 (1981) "Limits for Inhalation of Radon Daughters by Workers."

ICRP Publication 48 (1985) "The Metabolism of Plutonium and Related Elements." 
NV/YMP Radiological Control Manual, Rev. 2:

November 13, 1996

REFERENCES

REFERENCES

ICRP Publication 60 (1991) "1990 Recommendations of the International Commission on Radiological Protection."

\section{INTERNATIONAL ATOMIC ENERGY AGENCY}

Publications are available from the International Atomic Energy Agency,

Wagramerstrasse 5, P.O. Box 100, A-1400 Vienna, Austria.

IAEA No. 75-INSAG-3 (1988) "Basic Safety Principles for Nuclear Power Plants."

\section{NATIONAL COUNCIL ON RADIATION PROTECTION AND MEASUREMENTS}

Reports are available from the National Council on Radiation Protection and Measurements, 7910 Woodmont Avenue, Bethesda, Maryland 20814.

NCRP Report No. 53 (1977) "Review of NCRP Dose Limit for Embryo and Fetus in Occupationally Exposed Women."

NCRP Report No. 59 (1978) "Operational Radiation Safety Program."

NCRP Report No. 61 (1978) "Radiation Safety Training Criteria for Industrial Radiography."

NCRP Report No. 71 (1983) "Operational Radiation Safety Training."

NCRP Report No. 84 (1985) "General Concepts for Dosimetry of Internally Deposited Radionuclides."

NCRP Report No. 87 (1986) "Use of Bioassay Procedures for Assessment of Internal Radionuclide Deposition."

NCRP Report No. 106 (1989) "Limit for Exposure to 'Hot Particles' on the Skin."

NCRP Report No. 112 (1991) "Calibration of Survey Instruments Used in Radiation Protection for the Assessment of Ionizing Radiation Fields and Radioactive Surface Contamination."

NCRP Report No. 116 (1993) "Limitation of Exposure to lonizing Radiation." 


\section{FEDERAL}

Publications are available from the Superintendent of Documents, U.S. Government Printing Office, Washington, DC 20402.

29 CFR 1910 "Occupational Safety and Health Standards."

40 CFR 61, Subpart H "National Emission Standards for Emissions of Radionuclides Other Than Radon From Department of Energy Facilities."

Federal Guidance Report No. 11 (1988) "Limiting Values of Radionuclide Intake and Air Concentration and Dose Conversion Factors for Inhalation, Submersion, and Ingestion."

\section{DEPARTMENT OF ENERGY}

DOE 5480.3 (7-9-85) "Safety Requirements for the Packaging and Transportation of Hazardous Materials, Hazardous Substances, and Hazardous Wastes."

DOE 5480.8 (11-16-87) "Contractor Occupational Medical Program."

DOE 5482.1B (3-27-90) "Environment, Safety and Health Appraisal Program."

DOE/EH-0026 (1986) "Handbook for the Department of Energy Laboratory Accreditation Program for Personnel Dosimetry Systems."

DOE/EH-0027 (1986) "Department of Energy Standard for the Testing of Personnel Dosimetry Systems."

\section{DEPARTMENT OF ENERGY GUIDES TO GOOD PRACTICES}

PNL-6612 (1988) "Health Physics Manual of Good Practices for the Prompt Detection of Airborne Plutonium in the Workplace," Pacific Northwest Laboratory, Richland, Washington 99352.

TAP 1-88, 2-88, 3-88 (1988) "Training Accreditation Manuals," Training Resources and Data Exchange (TRADE), Oak Ridge Associated Universities, Oak Ridge, Tennessee 37831. 


\section{ENVIRONMENTAL PROTECTION AGENCY}

EPA 400-R-92-001 (1991) "Manual of Protective Action Guides and Protective Actions for Nuclear Incidents."

\section{NUCLEAR REGULATORY COMMISSION}

Regulatory Guide 1.8 (1987) "Qualification and Training of Personnel for Nuclear Power Plants."

\section{NATIONAL INSTITUTE FOR OCCUPATIONAL SAFETY AND HEALTH}

Publication No. 85-115 (1985) "Occupational Safety and Health Guidance Manual for Hazardous Waste Site Activities."

\section{AMERICAN NATIONAL STANDARDS INSTITUTE}

Standards are available from American National Standards Institute, Inc., 1430 Broadway, New York, New York 10018.

N2.1 (1989) "Radiation Symbol."

N2.3 (1979) "Immediate Evacuation Signal for Use in Industrial Installations Where Radiation Exposures May Occur."

N3.1 (1987) "Selection, Qualification and Training of Personnel for Nuclear Power Plants."

N8.3 (1979) "Criticality Accident Alarm."

N12.1 (1989) "Fissile Material Symbol."

N13.1 (1982) "Guide to Sampling Airborne Radioactive Material in a Nuclear Facility."

N13.2 (1982) "Administrative Practices in Radiation Monitoring (A Guide for Management)."

N13.3 (1981) "Dosimetry for Criticality Accidents."

N13.4 (1983) "Specifications of Portable X- or Gamma Radiation Survey Instruments."

N13.5 (R1989) "Performance Specification for Direct Reading and Indirect Reading Pocket Dosimeters for X-and Gamma Radiation." 
N13.11 (1983) "Personnel Dosimetry Performance - Criteria for Testing."

N13.15 (1981) "Performance of Personnel Thermoluminescence Dosimetry Systems."

N42.17B (1989) "Performance Specifications for Health Physics Instrumentation Occupational Airborne Radioactivity Monitoring Instrumentation."

N42.17C (1989) "Performance Specifications for Health Physics Instrumentation Portable Instrumentation for use in Extreme Environmental Conditions."

N317 (1985) "Performance Criteria for Instrumentation Used for In-Plant Plutonium Monitoring."

N319 (R1984) "Personal Neutron Dosimeters (Neutron Energies Less Than 20 MeV)."

N320 (1985) "Performance Specifications for Reactor Emergency Radiological Monitoring Instrumentation."

N322 (1983) "Inspection and Test Specifications for Direct and Indirect Reading Quartz Fiber Pocket Dosimeters."

N323 (1983) "Radiation Protection Instrumentation Test and Calibrations."

\section{AMERICAN SOCIETY FOR TESTING AND MATERIALS}

Standards are available from the ASTM Committee on Standards, 1916 Race St., Philadelphia, Pennsylvania 19103.

C-986 (1983) "Developing Training Programs in the Nuclear Fuel Cycle." 


\section{GLOSSARY}

\section{$A$}

abnormal situation: Unplanned event or condition that adversely affects, potentially affects, or indicates degradation in the safety, security, environmental or health protection performance or operation of a facility.

absorbed dose (D): The energy absorbed by matter from ionizing radiation per unit mass of irradiated material at the place of interest in that material. The absorbed dose is expressed in units of rad (or gray) ( $1 \mathrm{rad}=0.01$ gray).

accountable sealed radioactive source: A sealed radioactive source having a halflife equal to or greater than 30 days and an isotopic activity equal to or greater than the corresponding value provided in Appendix 4-A or Appendix E of 10 CFR 835.

activation: Process of producing a radioactive material by bombardment with neutrons, protons, or other nuclear particles.

administrative control level: A numerical dose constraint established at a level below the occupational exposure limits provided in 10 CFR 835 to administratively control and help reduce individual and collective doses.

airborne radioactive material or airborne radioactivity: Radioactive material dispersed in the air in the form of dusts, fumes, particulates, mists, vapors, or gases.

airborne radioactivity area: Any area, accessible to individuals, where the concentration of airborne radioactivity, above natural background, exceeds or is likely to exceed 10 percent of the derived air concentration (DAC) values that are listed in Appendix A or Appendix.C of 10 CFR 835.

ALARA: "As Low As is Reasonably Achievable," which is the approach to radiation protection to manage and control exposures (both individual and collective) to the work force and to the general public to as low as is reasonable, taking into account social, technical, economic, practical, and public policy considerations. As used in this part, ALARA is not a dose limit but a process which has the objective of attaining doses as far below the applicable limits of this part as is reasonably achievable.

annual limit on intake (ALI): The derived limit for the amount of radioactive material taken into the body of an adult worker by inhalation or ingestion in a year. ALI is the smaller value of intake of a given radionuclide in a year by the reference man (ICRP Publication 23) that would result in a committed effective dose equivalent of 5 rems ( 0.05 sievert) or a committed dose equivalent of 50 rems ( 0.5 sievert) to any individual organ or tissue. ALI values for intake by ingestion and inhalation of selected 
radionuclides are based on Table 1 of the U.S. Environmental Protection Agency's Federal Guidance Report No. 11, Limiting Values of Radionuclide Intake and Air Concentration and Dose Conversion Factors for Inhalation, Submersion, and Ingestion, published September 1988. This document is available from the National Technical Information Service, Springfield, VA.

ALARA Committee: Multidisciplined forum that reviews and advises management on improving progress toward minimizing radiation exposure and radiological releases. May be site-wide, to include representatives from all Tenant Organizations at the NTS, or Company or User specific.

anti-C: See Protective Clothing.

assessment: Evaluation or appraisal of a process, program, or activity to estimate its acceptability.

background: Means radiation from the following.

(I) Naturally occurring radioactive materials which have not been technologically enhanced;

(ii) Cosmic sources;

(iii) Global fallout as it exists in the environment (such as from the testing of nuclear explosive devices);

(iv) Radon and its progeny in concentrations or levels existing in buildings or the environment which have not been elevated as a result of current or prior activities; and

(v) Consumer products containing nominal amounts of radioactive material or producing nominal amounts of radiation.

becquerel $(\mathrm{Bq})$ : The International System $(\mathrm{SI})$ unit for activity of radioactive material. One becquerel is that quantity of radioactive material in which one atom is transformed per second or undergoes one disintegration per second.

bioassay: The determination of the kinds, quantities, or concentrations, and, in some cases, locations of radioactive material in the human body, whether by direct measurement or by analysis and evaluation of radioactive materials excreted or removed from the human body. 
calibration: The means to adjust and/or determine either:

(i) The response or reading of an instrument relative to a standard (e.g., primary, secondary, or tertiary) or to a series of conventionally true values; or

(ii) The strength of a radiation source relative to a standard (e.g., primary, secondary, or tertiary) or conventionally true value.

committed dose equivalent $\left(H_{T, 50}\right)$ : The dose equivalent calculated to be received by a tissue or organ over a 50-year period after the intake of a radionuclide into the body. It does not include contributions from radiation sources external to the body. Committed dose equivalent is expressed in units of rem (or sievert)( 1 rem $=0.001$ sievert).

committed effective dose equivalent $\left(H_{E, 50}\right)$ : The sum of the committed dose equivalents to various tissues in the body $\left(H_{T, 50}\right)$, each multiplied by the appropriate weighting factor $\left(w_{T}\right)$ - that is, $H_{E, 50}=\sum w_{T} H_{T, 50}$. Committed effective dose equivalent is expressed in units of rem (or sievert).

company-issued clothing: Clothing provided by the company, such as work coveralls and shoes. For radiological control purposes, company-issued clothing shall be considered the same as personal clothing. See "Modesty Garments."

containment device: Barrier such as a glove bag, glove box, or tent for inhibiting the release of radioactive material from a specific location.

contamination area: Any area, accessible to individuals, where removable contamination levels exceed or are likely to exceed the surface radioactivity values specified in Appendix D of 10 CFR 835 [and restated in Chapter 2, Table 2-2], but do not exceed 100 times those values.

contamination reduction corridor: A defined pathway though a hazardous waste site contamination reduction zone where decontamination occurs.

continuing training: Training scheduled over a specified time such as over a two-year period for the purpose of maintaining and improving technical knowledge and skills.

continuous air monitor (CAM): An instrument that continuously samples and measures the levels of airborne radioactive materials on a "real-time" basis and has alarm capabilities at preset levels.

contractor: Any entity under contract with the Department of Energy with the responsibility to perform activities at a DOE site or facility. 
contractor Senior Site Executive: The person at a DOE contractor-operated facility or site who has final on-site corporate authority and is often called President, General Manager, Site Manager, or Director.

controlled area: Any area to which access is managed in order to protect individuals from exposure to radiation and/or radioactive material. Individuals who enter only the controlled area without entering radiological areas are not expected to receive a total effective dose equivalent of more than $100 \mathrm{mrem}(0.001$ sievert) in a year.

critical mass: The smallest mass of fissionable material that will support a selfsustaining chain reaction under specified conditions.

critique: Meetings of personnel involved in or knowledgeable about an event (either a success or an abnormal event) to document a chronological listing of the facts.

cumulative total effective dose equivalent: The sum of all total effective dose equivalents values recorded for an individual, where available, for each year occupational exposure was received, beginning January 1, 1989.

\section{$D$}

declared pregnant worker: A woman who has voluntarily declared to her employer, in writing, her pregnancy for the purpose of being subject to the occupational exposure limits to the embryo/fetus as provided in 10 CFR 835.206. This declaration may be revoked, in writing, at any time by the declared pregnant worker.

decontamination: Process of removing radioactive contamination and materials from personnel, equipment, or areas.

deep dose equivalent: The dose equivalent derived from external radiation at a depth of 1 centimeter $(\mathrm{cm})$ in tissue.

deposition, new confirmed: A deposition of radioactive material in the body or any organ or tissue of an individual identified during the current reporting period, confirmed through bioassay results to be greater than the site-determined reportable level.

derived air concentration (DAC): Means, for the radionuclides listed in Appendix $A$ of 10 CFR 835, the airborne concentration that equals the ALI divided by the volume of air breathed by an average worker for a working year of 2000 hours (assuming a breathing volume of $2400 \mathrm{~m}^{3}$ ). For radionuclides listed in Appendix C of $10 \mathrm{CFR} 835$, the air immersion DACs were calculated for a continuous, non-shielded exposure via immersion in a semi-infinite atmospheric cloud. The values are based upon the derived airborne concentration found in Table 1 of the U. S. Environmental Protection Agency's Federal Guidance Report No. 11, Limiting Values of Radionuclide Intake and Air 
Concentration and Dose Conversion Factors for Inhalation, Submersion, and Ingestion, published September 1988 . This document is available from the National Technical Information Service, Springfield, VA.

derived air concentration-hour (DAC-hour): Is the product of the concentration of radioactive material in air (expressed as a fraction or multiple of the DAC for each radionuclide) and the time of exposure to that radionuclide in hours.

disintegration per minute (dpm): The rate of emission by radioactive material as determined by correcting the counts per minute observed by an appropriate detector for background, efficiency, and geometric factors associated with the instrumentation.

DOE activity: An activity taken for or by the DOE that has the potential to result in the occupational exposure of an individual to radiation or radioactive material. The activity may be, but is not limited to, design, construction, operation, decontamination or decommissioning. To the extent appropriate, the activity may involve a single DOE facility or operation or a combination of facilities and operations, possibly including an entire site.

DOELAP: Department of Energy Laboratory Accreditation Program for personnel dosimetry under DOE 5480.15.

dose: The amount of energy deposited in body tissue due to radiation exposure. Various technical terms, such as dose equivalent, effective dose equivalent and collective dose, are used to evaluate the amount of radiation an exposed worker receives. These terms are used to describe the differing interactions of radiation with tissue as well as to assist in the management of personnel exposure to radiation. Some types of radiation, such as neutron and alpha, deposit their energy more densely in affected tissue than gamma radiation and thereby causing more damage to tissue. The term dose equivalent, measured in units of rem, is used to take into account this difference in tissue damage. Therefore $1 \mathrm{rem}$ from gamma radiation causes damage equivalent to 1 rem from alpha radiation. However, it takes one-twentieth as much energy from alpha radiation, as compared with gamma radiation, to produce this 1 rem dose equivalent.

Definitions for dose terms necessary for various exposure calculations and record keeping purposes include the following:

absorbed dose (D): Energy absorbed by matter from ionizing radiation per unit mass of irradiated material at the place of interest in that material. The absorbed dose is expressed in units of rad (or gray) ( $1 \mathrm{rad}=0.01$ gray): collective dose: The sum of the total effective dose equivalent values for all individuals in a specified population. Collective dose is expressed in units of person-rem (or person-sievert). 
committed dose equivalent $\left(H_{T, 50}\right)$ : The dose equivalent calculated to be received by a tissue or organ over a 50-year period after the intake of a radionuclide into the body. It does not include contributions from radiation sources external to the body. Committed dose equivalent is expressed in units of rem (or sievert).

committed effective dose equivalent $\left(H_{E, 50}\right)$ : The sum of the committed dose equivalents to various tissues in the body $\left(H_{T, 50}\right)$, each multiplied by the appropriate weighting factor $\left(W_{T}\right)$ - that is $H_{E, 50}=\Sigma W_{T} H_{T, 50}$. Committed effective dose equivalent is expressed in units of rem (or sievert).

cumulative total effective dose equivalent: The sum of the total effective dose equivalents recorded for an individual for each year of employment at a DOE or DOE contractor site or facility, effective January 1, 1989.

deep dose equivalent: The dose equivalent derived from external radiation at a depth of $1 \mathrm{~cm}$ in tissue.

dose equivalent $(H)$ : The product of the absorbed dose (D) (in rad or gray) in tissue, a quality factor $(\mathrm{Q})$, and all other modifying factors $(\mathrm{N})$. Dose equivalent is expressed in units of rem (or sievert) ( $1 \mathrm{rem}=0.01$ sievert).

effective dose equivalent $\left(H_{E}\right)$ : The summation of the products of the dose equivalent received by specified tissues of the body $\left(H_{T}\right)$ and the appropriate weighting factors $\left(W_{T}\right)$ - that is $\left(H_{E}=\Sigma W_{T} H_{T}\right)$. It includes the dose from radiation sources internal and/or external to the body. The effective dose equivalent is expressed in units of rem (or sievert).

external dose or exposure: That portion of the dose equivalent received from radiation sources outside the body (e.g., "external sources").

internal dose or exposure: That portion of the dose equivalent received from radioactive material taken into the body (e.g., "internal sources").

lens of the eye dose equivalent: The external exposure of the lens of the eye and is taken as the dose equivalent at a tissue depth of $0.3 \mathrm{~cm}$.

quality factor: The principal modifying factor used to calculate the dose equivalent from the absorbed dose; the absorbed dose (expressed in rad or gray) is multiplied by the appropriate quality factor (Q). See 835 CFR 2 Quality Factor charts for determining quality factors for various radiation types.

shallow dose equivalent: The dose equivalent deriving from external radiation at a depth of $0.007 \mathrm{~cm}$ in tissue.

total effective dose equivalent (TEDE): The sum of the effective dose equivalent (for external exposures) and the committed effective dose equivalent (for internal exposures). Deep dose equivalent to the whole body may be used as effective dose equivalent for external exposures.

weighting factor $\left(w_{T}\right)$ : The fraction of the overall health risk, resulting from uniform, whole-body irradiation, attributable to specific tissue $(T)$. The dose equivalent to the affected tissue, $H_{T}$, is multiplied by the appropriate weighting factor to obtain the effective dose equivalent contribution from that tissue. See Table 2B-1, Appendix 2B, to determine weighting factors. 
whole body: For the purposes of external exposure, head, trunk (including male gonads), arms above and including the elbow, or legs above and including the knee.

dose assessment: Process of determining radiological dose and uncertainty included in the dose estimate, through the use of exposure scenarios, bioassay results, monitoring data, source term information and pathway analysis.

embryo/fetus: Developing human organism from conception until birth. Same as unborn child.

engineering controls: Using components and systems to reduce airborne radioactivity and the spread of contamination by using piping, containments, ventilation, filtration or shielding.

entrance or access point: Any location through which an individual could gain access to areas controlled for the purposes of radiation protection. This includes entry or exit portals of sufficient size to permit human entry, irrespective of their intended use.

external dose or exposure: That portion of the dose equivalent received from radiation sources (e.g., "external sources") outside the body.

extremity: Hands and arms below the elbow or feet and legs below the knee.

F

facility: For the purpose of this Manual, a facility includes systems, buildings, utilities, and related activities whose use is directed to a common purpose at a single location. Example include: accelerators, storage areas, test loops, nuclear reactors, radioactive waste disposal systems and burial grounds, testing laboratories, research laboratories, and accommodations for analytical examinations of components. Also includes: pipelines, ponds, impoundments, landfills and the like, and motor vehicles, rolling stock, and aircraft.

filter integrity test: Test performed on High-Efficiency Particulate Air (HEPA) filters to identify any damage to the filter or leakage around the filter.

fixed contamination: Radioactive material that cannot be readily removed from surfaces by nondestructive means, such as casual contact, wiping, brushing, or laundering.

flash $\mathrm{x}$-ray unit: Any device that is capable of generating pulsed $\mathrm{x}$ rays. 
frisk or frisking: Process of monitoring personnel for contamination. Frisking can be performed with hand-held survey instruments, automated monitoring devices, or by a Radiological Control Technician.

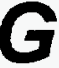

general employee: An individual who is either a DOE or DOE contractor employee; an employee of a subcontractor to a DOE contractor; or a visitor who performs work for or in conjunction with DOE or utilizes DOE facilities.

gestation period: The time from conception to birth, approximately 9 months.

gray (Gy): SI unit of absorbed dose. One gray is equal to an absorbed dose of 1 joule per kilogram (100 rads).

\section{H}

high-efficiency particulate air (HEPA) filter: Throwaway extended pleated medium dry-type filter with 91) a rigid casing enclosing the full depth of the pleats, (2) a minimum particle removal efficiency of 99.97 percent for thermally generated monodisperse di-octyl phlalate smoke particles with a diameter of 0.3 micrometer, and (3) a maximum pressure drop of 1.0 inch w.g. when clean and operated at its rated airflow capacity.

high contamination area: Any area, accessible to individuals, where removable contamination levels greater than 100 times the surface radioactivity values specified in Appendix D of 10 CFR 835.

high radiation area: Any area, accessible to individuals, in which radiation levels could result in an individual receiving a deep dose equivalent in excess of $0.1 \mathrm{rem}$ ( 0.001 sievert) in 1 hour at 30 centimeters from the radiation source or from any surface that the radiation penetrates.

high contamination area: Any area, accessible to individuals, where contamination levels exceed or are likely to exceed 100 times the surface radioactivity values specified in 835 CFR Appendix D, and restated in Chapter 2, Table 2-2, of this Manual.

high radiation area: Any area, accessible to individuals, in which radiation levels could result in an individual receiving a deep dose equivalent in excess of 0.1 rem ( $0.001 \mathrm{~Sv}$ ) in 1 hour at 30 centimeters from the radiation source or from any surface that the radiation penetrates.

hot particle: Fuel, activated corrosion product, or other particles of small size that have a high-specific activity as a result of nuclear fission or neutron activation. 
hot spot: Localized source of radiation or radioactive material normally within facility piping or equipment. The radiation levels of hot spots exceed the general area radiation level by more than a factor of 5 and are greater than $100 \mathrm{mrem}(1 \mathrm{mSv})$ per hour on contact.

hyperthermia: Heat stress, comprising "heat exhaustion," "heat stroke," and in extreme cases coma and death; a significant possibility at NTS especially while wearing anti-Cs in the summer months, if appropriate precautions are not taken.

hypothermia: Cold Stress--may include frostbite, or worse. Also a significant possibility at the NTS, especially during the winter months. Anti-C coveralls, alone, are not to be considered adequate protection for the skin of personnel working in outdoor radiological locations during inclement weather at the NTS.

\section{I}

individual: Any human being.

infrequent or first-time activities: Radiological work activities or operations that require special management attention and consideration of new or novel radiological controls. The designation of infrequent or first-time activities is specifically applicable to facilities that conduct routine and recurring process operations, and is not applicable to facilities that routinely conduct first-time activities, such as experimental or research facilities.

internal dose or exposure: That portion of the dose equivalent received from radioactive material taken into the body (e.g., "internal sources").

irradiator: Sealed radioactive material used to irradiate other materials that has the potential to create a radiation level exceeding 500 rad (5 grays) in 1 hour at 1 meter. Although not addressed in this Manual, acceptable radiological controls for irradiator use are specified in Title 10, Code of Federal Regulations, Part 20.1603.

\section{$L$}

lens of the eye dose equivalent: The external exposure of the lens of the eye and is taken as the dose equivalent at a tissue depth of $0.3 \mathrm{~cm}$.

lifetime dose: Total occupational exposure over a worker's lifetime, including external and committed internal dose.

low-level waste: Waste that contains radioactivity and is not classified as high-level waste, transuranic waste, spent nuclear fuel, or byproduct material as defined in Section $11 \mathrm{e}(2)$ of the Atomic Energy Act, as amended. Test specimens of fissionable 
material irradiated only for research and development and not for producing power or plutonium may be classified as low-level waste provided the concentration of transuranic activity is less than $100 \mathrm{nCi} / \mathrm{g}$.

\section{$M$}

member of the public: An individual who is not occupationally exposed to radiation or radioactive material. An individual is not a "member of the public" during any period in which the individual receives occupational exposure.

minor: An individual less than 18 years of age.

mixed waste: Waste containing both radioactive and hazardous components as defined by the Atomic Energy Act and the Resource Conservation and Recovery Act, respectively.

modesty garments: Disposable paper or launderable cloth garments issued by the RSPC, and worn under anti-Cs for the purpose of protecting the modesty of individuals during the (predominantly) outdoor, and temporary undress and Hot Line facilities typically available at the NTS during post-event related data acquisition work. Not to be considered "Company-Issued" garments for the purposes of this Manual. May-be issued as "winter weight" garments to help shield personnel from the effects of hypothermia during inclement weather conditions.

monitoring: Measuring radiation levels, airborne radioactivity concentrations, radioactive contamination levels, or quantities of radioactive material and using the results of these measurements to evaluate potential and actual exposures to ionizing radiation.

\section{$N$}

nonstochastic effects: Effects due to radiation exposure for which the severity varies with the dose and for which a threshold normally exists (e.g., radiation-induced opacities within the lens of the eye).

nuclear criticality: A self-sustaining chain reaction, i.e., the state in which the effective neutron multiplication constant of system of fissionable material equals or exceeds unity.

NV/YMP RadCon Managers Council: A chartered committee comprising the Radiological Control Program Managers of the respective NTS and YMP Tenant Organizations, whose purpose is to discuss issues and make decisions relevant to radiological control at the NTS and YMP. 
occupational dose: An individual's dose due to exposure to ionizing radiation dose (external and internal) as a result of that individual's work assignment. Occupational dose does not include dose received as a medical patient or doses resulting from background radiation or participation as a subject in medical research programs.

person: Any individual, corporation, partnership, firm, association, trust, estate, public or private institution, group, government agency, any sate or political subdivision of, or any political entity within a sate, any foreign government or nation or other entity, and any legal successor, representative, agent or agency of the foregoing; provided that person does not include the DOE or the United States Nuclear Regulatory Commission.

personnel dosimetry: Devices designed to be worn by a single person for the assessment of dose equivalent such as film badges, thermoluminescent dosimeters (TLDs), and pocket ionization chambers.

personnel monitoring: Systematic and periodic estimates of radiation dose received by personnel during working hours. Also, monitoring personnel, their excretions, skin, or any part of their clothing to determine the amount of radioactivity present.

personal protective equipment: Equipment such as respirators, face shields, and safety glasses used to protect workers from excessive exposure to radioactive or hazardous materials.

planned special exposure: Preplanned, infrequent exposure to radiation, separate from and in addition to the annual dose limits.

prefilter: Filter that provides first stage air filtration to remove larger particulates and prolong the efficient use of a HEPA filter.

prenatal radiation exposure: Exposing an embryo/fetus to radiation.

primary dosimeter: A dosimeter worn on the body used to obtain the formal record of whole-body radiation dose.

protective clothing: Clothing provided to personnel to minimize the potential for skin, personal, and company-issued clothing contamination. Also referred to as "anticontamination clothing," "anti-C" and "PC." 
public: Any individual or group of individuals who is not occupationally exposed to radiation or radioactive material. An individual is not a "member of the public" during any period in which the individual receives an occupational dose (exposure).

qualification standard: The explicit performance requirements for minimum proficiency in technical, academic, and site-specific knowledge and practical skills used in determining satisfactory completion of training programs. The qualification standard is used to qualify radiological control technicians (RCTs) at DOE facilities.

quality factor: The principal modifying factor used to calculate the dose equivalent from the absorbed dose; the absorbed dose (expressed in rad or gray) is multiplied by the appropriate quality factor $(Q)$.

(I) The quality factors to be used for determining dose equivalent in rem are shown below:

QUALITY FACTORS

Radiation type Quality factor

$x$ rays, gamma rays, positrons, electrons (including tritium beta particles)

Neutrons, $\leq 10 \mathrm{keV}$

Neutrons, $>10 \mathrm{keV}$

Protons and singly charged particles of unknown energy with rest mass greater than one atomic mass unit 10

Alpha particles and multiple-charged particles (and particles of unknown charge) of unknown energy 20

When spectral data are insufficient to identify the energy of the neutrons, a quality factor of 10 shall be used.

(ii) When spectral data are sufficient to identify the energy of the neutrons, the following mean quality factor values may be used:

\section{QUALITY FACTORS FOR NEUTRONS}

[Mean quality factors, $Q$ (maximum value in a $30-\mathrm{cm}$ dosimetry phantom), and values of neutron flux density that deliver in $\mathbf{4 0}$ hours a maximum dose equivalent of $100 \mathrm{mrem}$ (0.001 sievert).]

\begin{tabular}{lll|}
\hline $\begin{array}{l}\text { Neutron Energy } \\
\text { Density }\end{array}$ & $\begin{array}{c}\text { Mean Quality Factor } \\
(\mathrm{MeV})\end{array}$ & $\begin{array}{l}\text { Neutron Flux } \\
\left(\mathrm{cm}^{-2} \mathrm{~s}^{-1}\right)\end{array}$ \\
\hline $2.5 \times 10^{-8}$ thermal & 2 & 680 \\
$1 \times 10^{-2}$ & 2 & 680 \\
$1 \times 10^{-6}$ & 2 & 560 \\
$1 \times 10^{-5}$ & 2 & 560 \\
$1 \times 10^{-4}$ & 2 & 580 \\
\hline
\end{tabular}


$1 \times 10^{-3}$

$1 \times 10^{2}$

$1 \times 10^{-1}$

$5 \times 10^{-1}$

1

2.5

5

7

10

14

20

40

60

$1 \times 10^{2}$

$2 \times 10^{2}$

$3 \times 10^{2}$

$4 \times 10^{2}$
2

2.5

7.5

11

11

9

8

7

6.5

7.5

8

7

5.5

4

3.5

3.5

3.5
680

700

115

27

19

20

16

17

17

12

11

10

11

14

13

11

10

R

rad: Unit of absorbed dose. One rad is equal to an absorbed dose of 100 ergs per gram or 0.01 joules per kilogram (0.01 gray).

radiation (means ionizing radiation): Alpha particles, beta particles, gamma rays, $x$ rays, neutrons, high-speed electrons, high-speed protons, and other particles capable of producing ions. Radiation as used in this Manual and 10 CFR 835 does not include non-ionizing radiation, such as radio-, or microwaves, or visible, infrared, or ultraviolet light.

radiation area: Any area, accessible to individuals, in which radiation levels could result in an individual receiving a deep dose equivalent in excess of 0.005 rem $(0.05$ millisievert) in one hour at 30 centimeters from the source or from any surface that the radiation penetrates.

Radiation Protection Program (RPP): The documented program including, but not limited to, the plans, schedules, and other measures developed and implemented to achieve and ensure compliance with 10 CFR 835 and to apply the ALARA process to occupational exposure.

radioactive material: For the purposes of this Manual, radioactive material includes any material, equipment, or system component determined to be contaminated or suspected of being contaminated. Radioactive material also includes activated material, sealed and unsealed sources, and material that emits radiation.

radioactive material area: Any area, accessible to individuals, in which items or containers of radioactive material exist and the total activity of radioactive material 
exceeds then times the applicable values provided in appendix 4-A of this Manual, or appendix E of 10 CFR 835.

radioactive material transportation: The movement of radioactive material having a specific activity in excess of 0.002 microcurie per gram by aircraft, rail, vessel, or highway vehicle outside of a controlled area. Radioactive material transportation does not included preparing material or packagings for transportation, or conducting surveys required by 10 CFR 835 .

radioactive waste: Solid, liquid, or gaseous material that contains radionuclides regulated under the Atomic Energy Act, as amended, and is of negligible economic value considering the cost of recovery.

radioactivity: A natural and spontaneous process by which the unstable atoms of an element emit or radiate excess energy from their nuclei, and thus, change (or decay) to atoms of a different element or to a lower energy state of the same element.

radiography: Examination of the structure of materials by nondestructive methods, using a radioactive source or a radiation generating device.

radiological area: Means any area(s) within a controlled area which must be posted as a Radiation Area, High Radiation Area, Very High Radiation Area, Contamination Area, High Contamination Area, or Airborne Radioactivity Area in accordance with 10 CFR 835.

radiological control hold point: Cautionary step in a technical work document requiring the radiological control organization to perform some action or verification. The radiological control hold point requirements should be satisfactorily completed before the work is continued.

radiological control technician: A radiological worker whose primary job assignment involves monitoring workplace radiological conditions, specifying protective measures, and providing assistance and guidance to other individuals in implementing radiological controls.

radiological engineer: An individual who is responsible for providing technical support and assistance to supervisors, planners, schedulers, principle investigators, and design engineers to reduce occupational doses and the spread of radioactive materials.

radiological label: Label on an item which indicates the presence of radiation or radioactive materials. 
radiological performance goal: An administrative objective which focuses efforts on improving radiological performance.

radiological posting: Sign, marking, or label that indicates the presence or potential presence of radiation or radioactive materials.

radiological work: Any work that requires handling radioactive material or which requires access to Radiation Areas, High Radiation Areas, Contamination Areas, High Contamination Areas, Radioactive Material Areas, or Airborne Radioactivity Areas.

radiological work permit: An authorization to conduct work involving exposure to radiation or radioactive materials that identifies radiological conditions, establishes worker protection and monitoring requirements, and contains specific approvals.

radiological worker: A general employee whose job assignment involves operation of radiation producing devices or working with radioactive materials, or who is likely to be routinely occupationally exposed above $0.1 \mathrm{rem}(0.001$ sievert) per year total effective dose equivalent.

RAMATROL: Radioactive Materials Control, operated in Mercury by the RSPC.

refresher training: Training scheduled on the alternate year when full retraining is not completed for Radiological Worker I and Radiological Worker II personnel.

release to uncontrolled areas: Releasing material from administrative control after confirming that the residual radioactive material meets the guidelines in DOE 5400.5.

rem: Unit of dose equivalent. Dose equivalent in rem is numerically equal to the absorbed dose in rad multiplied by a quality factor, distribution factor, and any other necessary modifying factor ( $1 \mathrm{rem}=0.01$ sievert).

removable contamination: Radioactive material that can be removed from surfaces by nondestructive means, such as casual contact, wiping, brushing, or washing.

representative: As applied to the sampling of radioactive material, means sampling in such a manner that the sample closely approximates both the amount of activity and the physical and chemical properties of material (e.g., particle size and solubility in case of air sampling of the aerosol to which workers may be exposed).

respiratory protective device: An apparatus, such as a respirator, used to reduce the individual's intake of airborne radioactive materials.

respiratory protective equipment: Equipment used to protect personnel from inhalation of radioactive or hazardous materials. 
RSPC: Radiological Safety Prime Contractor.

sievert (Sv): SI unit of any of the quantities expressed as dose equivalent. The dose equivalent in sieverts is equal to the absorbed dose in grays multiplied by the quality factor ( $1 \mathrm{SV}=100$ rems). SI units are not to be used on any NTS records.

site: An area managed by DOE where access can be limited for any reason. The site boundary encompasses Controlled Areas.

sealed radioactive source: A radioactive source specifically manufactured, obtained, or retained for the purpose of utilizing the emitted radiation. The sealed radioactive source consists of a known quantity of radioactive material contained within a sealed capsule, sealed between layers of non-radioactive material, or firmly fixed to a nonradioactive surface by electroplating or other means intended to prevent leakage or escape of the radioactive material.

shallow dose equivalent: The dose equivalent deriving from external radiation at a depth of $0.007 \mathrm{~cm}$ in tissue.

source leak (integrity) test: A test to determine if a sealed radioactive source is leaking radioactive material.

standard radiation symbols: Symbols designed and proportioned as illustrated in accordance with ANSI N2.1 for radiation symbols and ANSI N12.1 for fissile material.

step-off pad: Transition area between contaminated and non-contaminated areas that is used to allow exit of personnel and removal of equipment.

sticky pad: Step-off pad provided with a tacky surface to reduce the potential for inadvertently tracking contamination out of a contaminated area.

stochastic effects: Malignant and hereditary diseases for which the probability of an effect occurring, rather than its severity, is regarded as a function of dose without a threshold for radiation protection purposes.

survey: Evaluating the radiological conditions and potential hazards incident to the production, use, transfer, release, disposal, or presence of radioactive material or other sources of radiation. When appropriate, such an evaluation includes a physical survey of the location of radioactive material and measurements or calculations of levels of radiation, or concentrations or quantities of radioactive material present. 


\section{$T$}

technical work document: A formally approved document that directs work, such as procedure, work package, laboratory protocol, or job or research plan that also identifies radiological conditions, establishes worker protection and monitoring requirements, and contains specific approvals.

tenant organization (TO): NTS user or contractor, e.g. any organization that maintains a permanent presence at the NTS or YMP.

thermoluminescent dosimeter (TLD): Radiation monitoring device used to record the radiological exposure of personnel or areas to certain types of radiation.

transuranic waste: Without regard to source or form, waste that is contaminated with alpha-emitting transuranic radionuclides having half-lives greater than 20 years and concentrations greater than $100 \mathrm{nCi} / \mathrm{g}$ at the time of assay.

total effective dose equivalent (TEDE): The sum of the effective dose equivalent (for external exposures) and the committed effective dose equivalent (for internal exposures). For purposes of compliance with this part, deep-dose equivalent to the whole body may be used as effective dose equivalent for external exposures.

\section{$U$}

unusual occurrence: Nonemergency occurrence that has significant impact or potential for impact on safety, environment, health, security, or operations. Examples of the types of occurrences that are to be categorized as unusual occurrences are contained in DOE 232.1.

very high radiation area: Any area, accessible to individuals, in which radiation levels could result in an individual receiving an absorbed dose in excess of 500 rads (5 grays) in one hour at 1 meter from a radiation source or from any surface that the radiation penetrates.

visitor: Person requesting access to Controlled Areas who has not been trained to the level required to permit unescorted access.

\section{$W$}

week: A period of seven consecutive days beginning on Sunday. 
weighting factor $\left(w_{T}\right)$ : The fraction of the overall health risk, resulting from uniform, whole-body irradiation, attributable to specific tissue $(T)$. The dose equivalent to tissue, $T$, is multiplied by the appropriate weighting factor to obtain the effective dose equivalent contribution from that tissue. The weighting factors are as follows:

WEIGHTING FACTORS FOR VARIOUS TISSUES

\begin{tabular}{ll|}
\hline Organs or tissues, $T$ & Weighting factor, $\mathrm{w}_{\mathrm{T}}$ \\
\hline Gonads & 0.25 \\
Breasts & 0.15 \\
Red bone marrow & 0.12 \\
Lungs & 0.12 \\
Thyroid & 0.03 \\
Bone surfaces & 0.03 \\
Remainder & 0.30 \\
Whole body $^{2}$ & 1.00 \\
\hline
\end{tabular}

1 "Remainder" means the five other organs or tissues with the highest dose (e.g., liver, kidney, spleen, thymus, adrenal, pancreas, stomach, small intestine, and upper large intestine). The weighting factor for each remaining organ or tissue is 0.06 .

2 For the case of uniform external irradiation of the whole body, a weighting factor $\left(w_{T}\right)$ equ ${ }^{\text {al to }}$ 1 may be used in determination of the effective dose equivalent.

whole body: Means, for the purposes of external exposure, head, trunk (including male gonads), arms above and including the elbow, or legs above and including the knee.

whole-body dose: The sum of the annual deep dose equivalent for external exposures and the committed effective dose equivalent for internal exposures.

year: The period of time beginning on or near January 1 and ending on or near December 31 of that same year used to determine compliance with the provisions of this Manual and with 10 CFR 835 . The starting and ending date of the year used to determine compliance may be changed provided that the change is made at the beginning of the year and that no day is omitted or duplicated in consecutive years. 


\section{INDEX}

Name

Article

abnormal situations, response to 346 accelerator facilities $364,612,664$ access controls 334, App 3B access points 232 accident dosimetry accountability 515 accreditation $111,423,431,661,662,663,712$ activation $512,522,612,613, \mathrm{G}-4$ administrative control $\ldots \ldots \ldots \ldots \ldots \ldots \ldots \ldots 133[$ Table 1-1], 2-Part 1, 211 ,
$213,223,315,316,321,322,364,365 ; 513,554,722, G-1, G-11$ 364, 4-Part 1, 412 [Table 4-1], 612, 664, G-1, G-7 Administrative Control Levels 133 [Table 1-1], 211, 2-Part 1, 212, 315, $513,722, \mathrm{G}-1$

air monitoring $316,346,363,371,521,551,555$ air sampling $316,338,555,761$ airborne concentration $136,223,535,543$ airborne contamination $316,361,521$

airborne monitoring 522 airborne monitors 133 [Table 1-1] airborne radioactivity 128, 131, 133 [Table 1-1], 221, $223,232,234,235$, Table 2-4, 236, 312, 315, 316, 322, 325, $333,335,336,337,338,342,347$, App 3C, 543, 551, 555, 663, Table 6-1, 751, 753, G-1, G-3, G-6, G-10

control levels ... 223 control of 223,453 monitoring of 555 personnel exposures to 543 airborne radioactivity areas

221,235 , Table $2-4,236,316,322,325,333,335,336,337$, 338, 342, App 3C, 663, Table 6-1, G-10 ALARA $111,128,138,311,313,325,342$, App 3A, 551,

ALARA committee $611,634,652,654,712,742, \mathrm{G}-1$

ALARA optimization $138,312,313,742, \mathrm{G}-1$

ALARA preplanning 312 ALARA program 551 ALARA records 654,742 ALARA training 712,742 alarm 654 alarm response procedures

346, App 3B, App 3D, 513, 553, 555, 562, 621, 632, 633, G-3 346 
alarming of faulty radiological control equipment

122 [Poster] alpha .................... Table 2-2, App 3D, 542, 555, 612, G-4, G-13 American Board of Health Physics

Annual Limit of Intake 555

appraisals 152

area monitoring

$514,553,712$

area monitoring dosimeter 514,553

area monitoring dosimetry 712 area monitoring program 514 area radiation monitor arms assessment

$346,553,562$ Table 2-1, 325, 347, App 3D, G-6 121, 133 [Table 1-1], 134, 21.3, 316, 348, 512, 521, $522,523,541,522,523,541,551,554,555,651,654$, $712,722, \mathrm{G}-1, \mathrm{G}-5, \mathrm{G}-8$

audit $113,121,132,134,138,712,743,772$

background radiation 335,338

beta 235 [Table 2-4], App 2C, 363, App 3D, 513 bioassay 133 [Table 1-1], 143, 212, 338, 343, 363, 521, 522, $523,542,543,663,761$

bioassay measurements 363,522 break area $342, \mathrm{G}-2$ breathing air (quality) 531

breathing zone 371,753

calibrated $551,555,562$

calibration $143,553,562,563,564,712,761,762$ calibration facilities 564

calibration procedures 562

calibration record 562 calibration sources 761 calibration standardization 561

check source 555

chest App 3D, 511, 722 collective dose $133,312,344$, App 3A, G-4 collective exposure 131 commitment

committed effective dose equivalent

2-Part 1, 521, 522, 543, 555, G-5,

G-11, G-13

committee $112,, 132,138,312, \mathrm{G}-1$

company-issued clothing $325, \mathrm{G}-2$ compressed air 531 computerization of records 773 Construction projects environmental conditions 
requirements for . . . . . . . . . . . . . . . . . . . . . . . . . . . . 371

workplace hazards . . . . . . . . . . . . . . . . . . . . 373

containers

containment

contaminated
$335,342,412$, Table 4-1, 413, 414 $128,316,337,342,363,453,643,661,663,664, \mathrm{G}-2$ 122 [Poster], 132, 133, 2-Part 2, 221, 222, Table 2-2, 235 [Table 2-4], 316, 325, 335, 342, 346, 347, App 3C, 4-Part 1, 411, 413, 412 [Table 4-1], 421, 422, 461, 511, 512, 542, 552, 554, 662, G-3, G-10, G-12, G-13

contaminated area contaminated hand/skin contaminated injuries contaminated materials contaminated personnel contaminated personnel dosimeters contaminated soil areas contaminated systems contaminated tools contaminated wounds contamination $131,133, \mathrm{G}-13$ 346,541

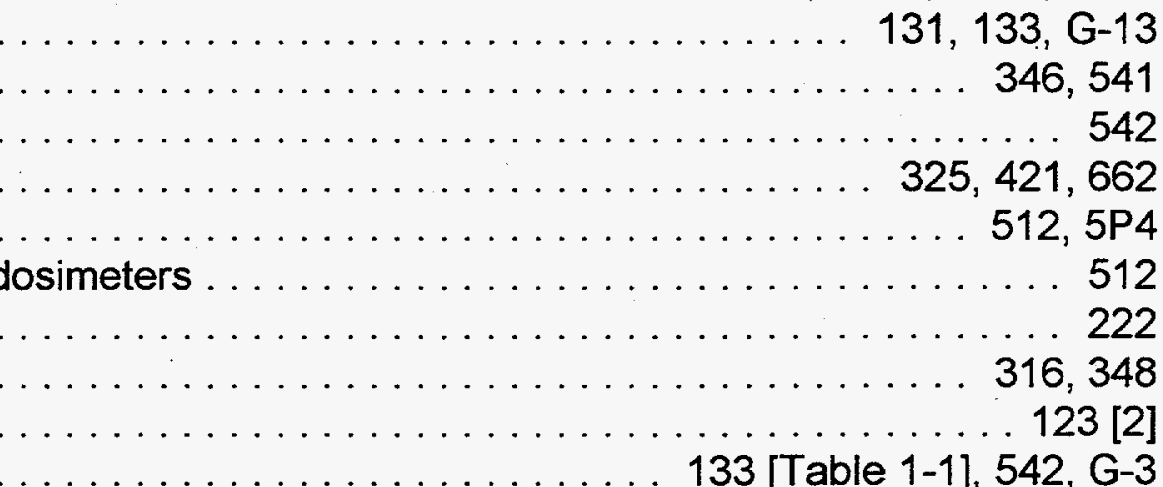

$111,121,125,128,131,133$

2-Part 2, 221, 222, Table 2-2, 231, 232, 235, Table 2-4, $236,312,315,316,321,322,324,325,333,335,336,337$, $338,342,346,347,348,361,362,363,3-P a r t 7,371$, App 3C, Table 3-1, App 3D, 4-Part 1, 411, 412, Table 4-1, 413, 421, 422, $423,461,463,464,521,522,531,541,542,551,554$, $611,621,631,633$, Table 6-1, 751, 754, 761, 783, G-2, G-3, G-6, G-7, G-9, G-10, G-12, G-13 physical \& chemical characteristics of, for RWP preparation . . . . . 235, 531 contamination area . . . . . . . . . . . . 221, 222, 223, 235 [Table 2-4], 322, 335, $336,337,338,342,348,371$, App 3C, 463, 554, 751, 754, G-2, G-7 contamination boundaries 554 contamination control 221, 222, Table 2-2, 337, App 3C contamination level Table 2-2, 231, 235 [Table 2-4], 316, 333, 342, App 3C, Table 3-1

contamination limit App 3D contamination monitor $335,338,346$ contamination monitoring 335 contamination reduction $312,321,371, \mathrm{G}-2$ contamination surveys 464,554 contamination swipe 554 continuing training $143,643,644,645,651,654, \mathrm{G}-3$ continuous air monitor $316,346, \mathrm{G}-3$ contract 112,113 contractor $112,113,114,116,121,125,132,133$ 
control level 133, 211, 212, Table 2-1, 2-Part 2 , $222,223, \mathrm{G}-1$

control of airborne 453

control of work activities 323

control points $554, \mathrm{G}-11$

controlled area

controlling $236,237,414,421,514,621,622, \mathrm{G}-3, \mathrm{G}-11$ corrective action 134 counseled person 722 counseling $216,542,722, \mathrm{G}-3$
$\ldots \ldots \ldots \ldots$
$2-3], 235$ [Table 2-4] course records $216,542,722, \mathrm{G}-3$
$2-3], 235$ [Table 2-4] criteria for posting critical mass criticality 222,232 $121,325,337,341,348,413,423, \mathrm{G}-1, \mathrm{G}-11$ critique 234 [Table 2-3], 235 [Table 2-4] cross-contamination $346,661,662, \mathrm{G}-8$ $351,712, \mathrm{G}-3$ declared pregnant worker decontaminate Table 2-1, 215 decontamination 2-Part 2, 221, 325, 541, 554 decontamination procedures deficiencies. Derived Air Concentration design diagnostic 346 director disintegration disposable surfaces document control DOE

$111,112,113,114,116,1$-Part $2,121,125,128,131,141$, 152, 156, 2-Part 1, 211, 213, 214, 216, 2-Part 2, 221, $222,223,231,232,235$, Table 2-4, 311, 312, 315, 316, 325, 331, $338,342,343,365,411,422,423,431,441,443,451,511,512,515$, $521,522,531,535,541,551,554,562,611,612,613,621,632,634$, $651,712,721,722,725,743,774,781,782,783$

DOELAP 128, 231, 312, 338, 342, 3-Part 7, 371, App 3A, 463, 541, 551, 754, G-2, G-3 $125,134,342$ 222, 223, 235, Table 2-4, 521, 555, G-1, G-4 $128,138,142,311,312,314,364$, App 3A, 431, 452 Table 2-1, 724 $138,781, \mathrm{G}-2$ $554, \mathrm{G}-2, \mathrm{G}-7$ . . . . $\therefore 113$

dose

116, 128, 133, Table 1-1, 2-Part 1, 212, 213,

Table 2-1, 214, 215, 216, 222, 223, 234, Table 2-3, App 2A, App 2B, App 2C, 312, 316, 321, 333, 334, 342, 344, 347, 348, 364, 365, App 3A, App 3B, 511, 512, 513, 514, 521, 522, 523, 541, 542, 543, 552, 552, $611,621,652,721,722,723,725,731,732,752,774,781,782$ 
dose assessment dose equivalent

App 2C, 348, 521, 522, 543, 555, 782, G-5, G-6, G-7, G-8, G-9, G-10, G-11, G-13, G-14, G-15

dose limits dose rate 2-Part 1, 213, Table 2-1, 214, 215, 216, App 2A, 611 $126,222,231,234$, Table 2-3, 312, 333, 334, 343, 347, 364, 365, $464,513,552,553,752$

dose reduction 652 dose reports dose summary dosimeter

dosimetry 5-Part $1,511,512,514,515,5 P 2,522,523,654,712,722,781, G-4, G-8$ dosimetry program drillback drilling elbow $512,514,515,522,722,781$ 122 [Poster], 133, Table 1-1, 221, 234, Table 2-3, 322, 334, 346, App 3C, App 3D, 511, 512, 513, 514, 515, 553, 561, 621, 722, $761,781, \mathrm{G}-8, \mathrm{G}-9, \mathrm{G}-13$ electronic dosimeter embryo/fetus emergency

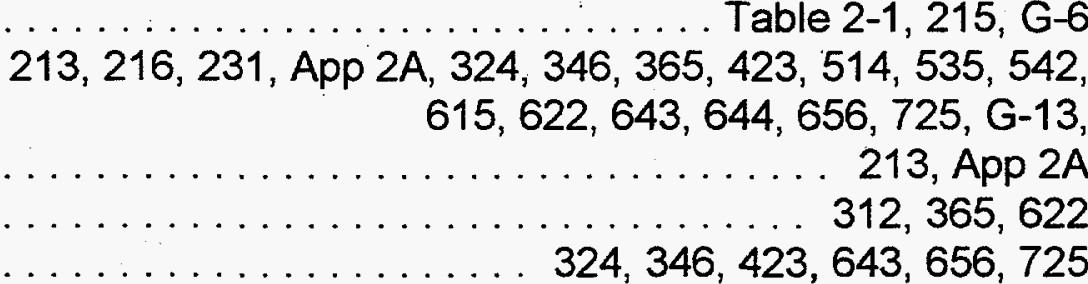

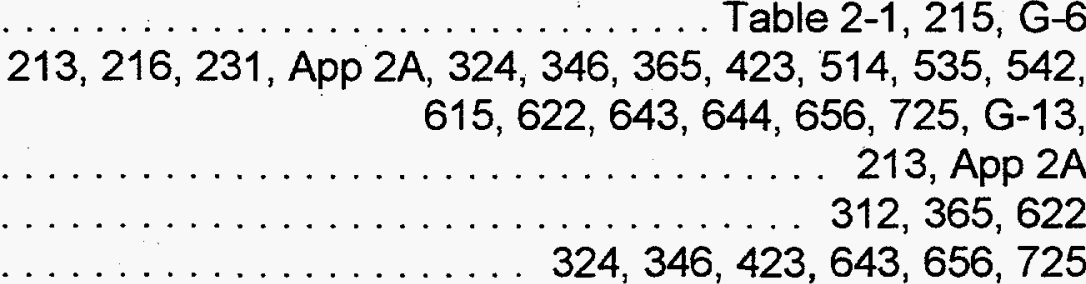

emergency exposure

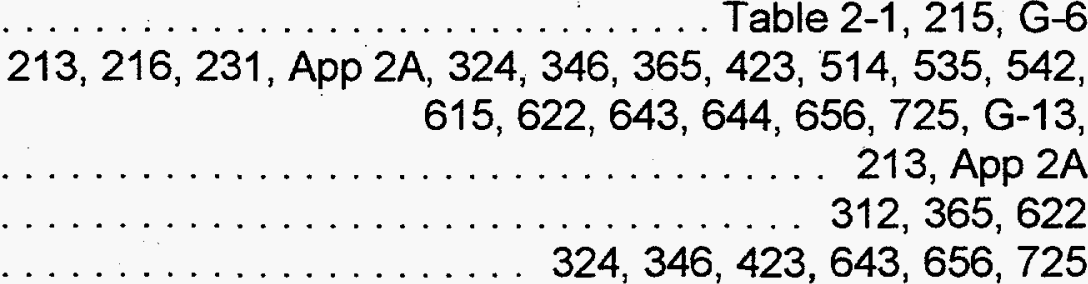
emergency procedures emergency response

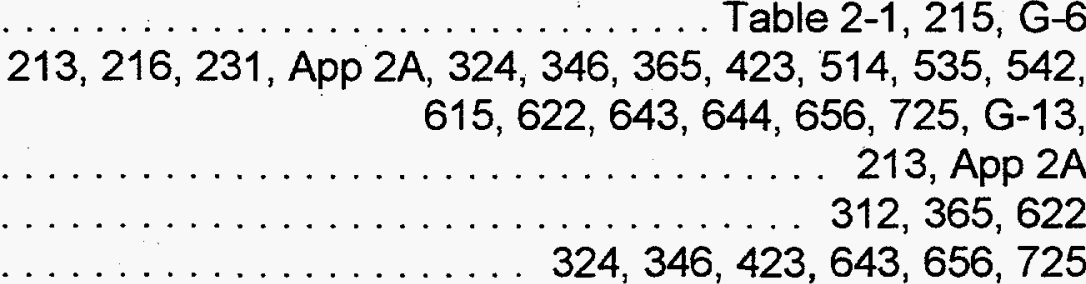
emergency workers employee 2-Part 2, 312, 342, 343, 371, 554 Table 2-1, 3D, G-6 322, App 3C, 513, 562, 761

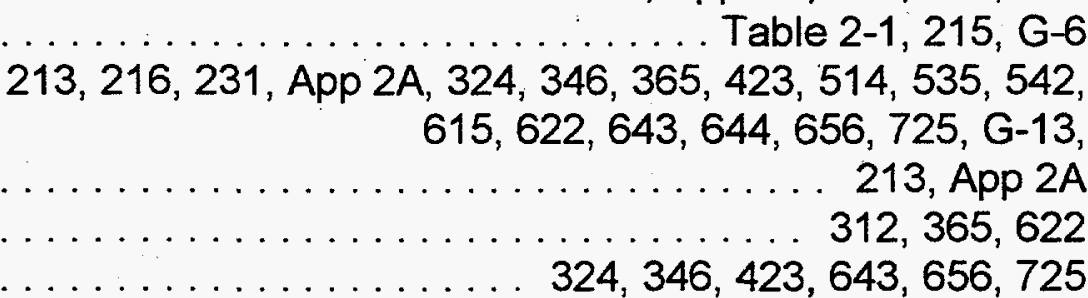
$324,346,423,643,656,725$ $114,156,211,216,321,331,511,522,611$ $612,613,621,721,722,723,725,781,782, \mathrm{G}-3$

employee records 7-Part 2 entry

2-Part 1, 221, 222, 231, 234 [Table 2-3], 235 [Table 2-4], 237, App 2C, 312, 316, 321, 322, 331, 333, 334, 335, 336, 365, App 3B, 513, 552, 553, 554, 611, 621, 631, 633, Table 6-1, 642, 773 entry and exit requirements 222, 237, 3-Part 3, 333, 334, App 3B entry requirements 231, 321, 336, Table 6-1 environmental equipment $116,131,371,372,373,452,562, \mathrm{G}-1, \mathrm{G}-2$ 123 [Poster], 2-Part 1, 221, 222, 316, 325, 333, 335, $338,342,348,365,371,373$, 4-Part 1, 411, 412, Table 4-1, 413, 414, $421,422,431,453,461,463,464,511,5$-Part 3, 531, $535,551,553,554,555,564,633,642,645,752,761,783, \mathrm{G}-3, \mathrm{G}-7$, G-8, G-10, G-12 escort, escorted, unescorted

$213,332-336,613,631,632$
$222,231,234,237,3 P 3,335$ exit 


\begin{tabular}{lr}
\hline NV/YMP Radiological Control Manual, Rev. 2: & November 13, 1996 \\
INDEX & INDEX \\
\hline
\end{tabular}

338, 346, App 3A, 511, 632, 612, 633

exit requirements $222,237,3-P a r t 3$ exposure 1-Part 1, 111, 121, 131, 133 [Table 1-1], 138, 142, 2-Part 1, 211, 212, 213, Table 2-1, 215, 216, 222, 223, 231, App 2A, App 2C, 311, 314, $315,316,321,334,342,346,348,523,531,541,543$, $551,552,553,564,611,621,622,661,662,663$, 781, G-1, G-3, G-4, G-5, G-8, G-9

exposure control 133, 133 [Table 1-1], 216, App 2A, 661, 662, 663

exposure history 523,781

exposure information 133,523

external dose 722 external dosimetry 136, 5-Part 1, 512, 712 external exposure extremity $136,316,661,662, \mathrm{G}-5, \mathrm{G}-12, \mathrm{G}-13$
$312,347,511,512,722,781, \mathrm{G}-12$ facial contamination facility $112,113,114,1$-Part 2, 125, 128, 132, 141, 142, 156, 2-Part 1, $211,222,231,234,325,334,338,346,384,414,463,531$, $541,551,554,612,645,654,713,721,781$, G-1, G-3, G-7, G-12

facility procedures

feet 131, 133 [Table 1-1], Table 2-1, 347, G-6

female 215,725

Field Office Table 2-1, App 2C, 312, 347, 511, 512, 722, 781, G-12 film 1-Part 1, 113, 114, 1-Part 2, 155 fissile material $512, \mathrm{G}-8$ fission products fixed 2-Part 2, 222, Table 2-2, 235 [Table 2-4], 334, 365, 412, Table 4-1, 423, 554, 555, 753, 752, 761, G-6, G-12

fixed air sampling equipment fixed contamination . 555 fixed fire suppression 222, 235 [Table 2-4], 412, Table 4-1, 554, G-6 fixed installations 775 fixed radiation measuring equipment 365 frisk . . . . . . 123 [Poster], 221, 321, 335, 338, 347, App 3C, App 3D, 632, 633, G-6

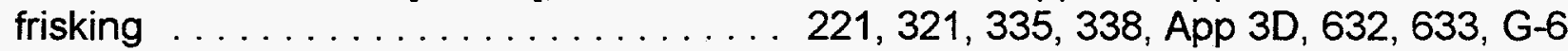
fume hood 335,347 gamma 137, 222, Table 2-2, 365, App 3D, 412, 461, 511, G-4 gas $221,411,5$-Part 3, 531, G-10 general employee radiological training $331,612,613,621,725$ general manager GERT 613 gestation $215, \mathrm{G}-6$ hand 123 [Poster], 338, 342, 346, 347, App 3D, 511, 554, G-6 
hazardous properties

head

Headquarters

141, App 3D

health

113,612

$112,113,116,138,142,143,213,216,222$ $316,325,338,364,3-P a r t 7$, App 3C, 531, 541, 551, 711, 721,

health and safety plans G-1, G-3, G-12, G-13 heat stress (hyperthermia)

HEPA $342,371,373, \mathrm{G}-9$

high contamination area $464,552, \mathrm{G}-6, \mathrm{G}-7, \mathrm{G}-9$ high radiation area .......

high radiation area

235 [Table 2-4], 322, 335, 337, 338, 342, 633, G-1, G-7, G-10

high surface contamination $126,128,234$, Table 2-3, 3-4, 334, 336, 365, App 3B, 513, 552, 633, G-7, G-10, G-13 hold point App 3C hot particle $312,315,324,345$, App 3A, G-11

hot spot App 2C, 348, 554, 752, G-7 HPD

... 234, Table 2-3, G-7

hypothermia (cold stress)

ICRP

indication App 38

indicator

individual exposure

$152,211,213,216,222,231,325,431,511,725,781,783$ $371,372,373, \mathrm{G}-9$ 213, App 2B, G-1

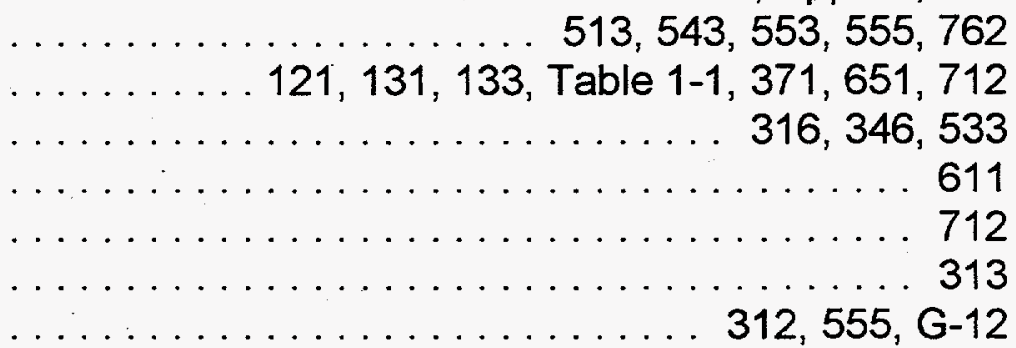
individual radiation exposure individual records infrequent or first-time activities inhalation injured person installation instrument

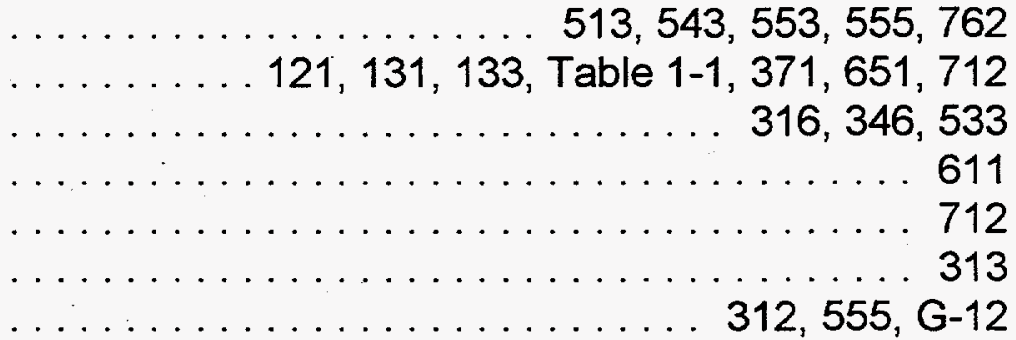

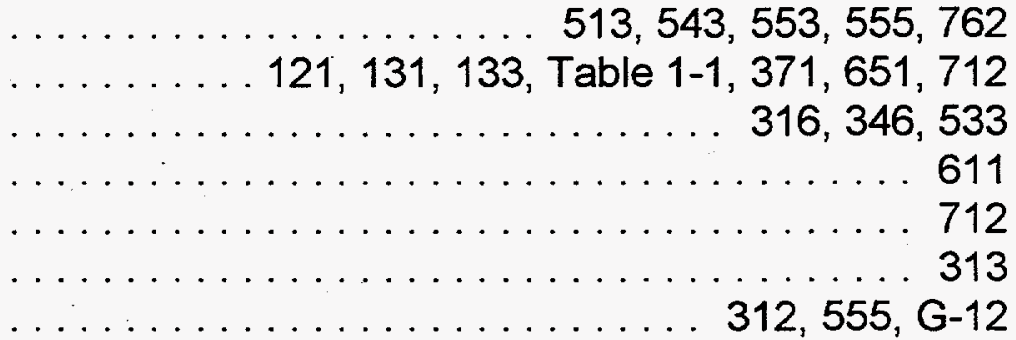
.

instrumentation

interlock

internal contamination

internal deposition

internal dose

internal dosimetry

internal exposure

inventory control

investigation

job assignments $312,555, \mathrm{G}-12$ 314, 365, App 3A, 452 136, 222, Table 2-2, 232, 338, 343, App 3D, 411, 421, $551,554,555,561,562,564,661,662,664,725,752,753,761$, $762,783, \mathrm{G}-2, \mathrm{G}-3, \mathrm{G}-6$ 143, 2-Part 2, 461, 551, 553, 5-Part 6, 561, 562, $563,564,712,7-P a r t 6$, G-4, G-9 $364,365,431,553,664$ 333, 412 [Table 4-1], 522 136 136, 2-Part 1, 212, Table 2-1, 316, 522, 542, 722, G-8 5-Part 2, 522 133 [Table 1-1], 223, 316, 522, 661, G-5, G-13 $661,662,663$ 134, 3-Part 5, 411, 513, 514, 781 $534,632,633, \mathrm{G}-11$ 
job function

knee

label

laundry

leak

legs

lens of the eye

lessons learned

lifetime dose

line management

line manager

line organization

maintain $236,314,333,335,411,412$, Table 4-1, 414, 421, 422, 431, 461,

Table 2-1, App 3D, G-6 $562,622, \mathrm{G}-6$ $\ldots \ldots \ldots \ldots \ldots \ldots 2$ $125,431,451,452,554,783, \mathrm{G}-6$ Table 2-1, App 3C, App 3D, G-6 211, Table 2-1, App 2A, 511, 512, G-6 $112,3 P 5,613,643,651$ $212, \mathrm{G}-8$ $121,141,312,323,344,346,365$, $463,511,551,615,654$ $145,345,611,651$ $136,141,316$ $111,121,132,211$, Table 2-1, 222, 231, 311, 324, $325,334,335,342,343,411,412,431,451,453,513,514$, $531,554,555,611,613,622,654,655,656,657,713,721,722$, $723,725,731,742,743,751,761,783, \mathrm{G}-3$

maintenance $128,138,142,311,312$, App 3 A, 412, 452, 453, 514, 553, $561,562,564,613,642,761,773$ medical $112,213,216,316,365,511,522,531,542$, $654,656, \mathrm{G}-3, \mathrm{G}-8$ 532

medical assessment $316,531,724$ medical evaluations 654,656 medical personnel medical records mineback $221,343,554$ minimize $121,128,131,2$-Part 2, 312, 316, 342, 346, App 3A, 413, 443, 451, 463, 514, 541, 555, 564, G-9

minor 134, Table 2-1, 214, 322 mixed fission products 223, Table 2-2, 541 mixed waste $443, \mathrm{G}-8$ modesty garments 325,372 , App 3C, G-10 modifications planning monitor 125, 1-Part 2, 338, 342, 344, 346, 347, 372, App 3C, App 3D, 451, 511, 512, 522, 551, 553, 562, 722, 761, 781, 782, G-3 monitoring 122 [Poster]; 128, 2-Part 2, 222, 231, 232, 312, $335,338,346,348,371$, App 3A, App 3D, 423, 441, 512, 514, 521, 522, $542,551,553,554,555,712,731, \mathrm{G}-5, \mathrm{G}-6, \mathrm{G}-8, \mathrm{G}-11$, Table 6-13 monitoring program $512,514,521,551,553$ multiple dosimeter 
nasal contamination

522

National Institute of Standards and Technology (NIST)

522,562

NCRP

213, App 2B

neutron

128, 131, 133 [Table 1-1], 222, 431, 511, 512, 551,

661, Table 6-1, G-4, G-7, G-8

new personnel

651

non-ionizing radiation

562,564

non-uniform exposure

213, App $2 \mathrm{C}$

notification

$411,431,551,611$

NRRPT

642

nuclear accident dosimetry

515

Nuclear Regulatory Commission (NRC) requirements

$112,613,621$

nuclear weapon

$222,412,431$

NUREG

136,316

NV

$111,112,128,138,141,2-P a r t 1,211,214,215$,

216, 2-Part 2, 221, 214, 215, 216, 2-Part 2, 221, 222, 231, 232,

$312,313,314,321,325,331,343,361,362,363,364$,

$365,423,431,463,511,522,5$-Part $3,541,551,554,561$,

$611,612,613,621,634,654,661,663,712,725,781,782$

NV/YMP RadCon Managers' (RCM) Council . . . . . . . . . . . 116, 613, G-10 occupational dose $216, \mathrm{G}-8$ occupational exposure $111,213,216, \mathrm{G}-1, \mathrm{G}-8$ occurrence reporting 127,613

Office of Nuclear Safety 154 office space $128,552,554$ on-the-job-training $131,141,365,431,514,552,555,564,643,645,654,661$ operating 662,663 operational check 555,761 operations

$113,116,1$-Part $2,125,128,131,138,141,142$ 2-Part 1, App 2A, 311, 312, 313, 314, 321, 322, 325, 331, 334, $337,338,341,347,348,3-P a r t 6,361,362,363$, $364,365,371,431,441,453,514,541,551,552,561,613,615$, $634,641,642,664,725, \mathrm{G}-3, \mathrm{G}-7, \mathrm{G}-13$

optimization oral examination boards $615,642,643,644$ orientation oversight $121,331,612,613,622,657,725,731$ package $143,313,651$ packaging $312,315,325,333,412,413,421,423,431,441$, G-13
$\ldots \ldots \ldots \ldots \ldots \ldots \ldots \ldots \ldots \ldots \ldots \ldots \ldots \ldots \ldots \ldots \ldots \ldots \ldots \ldots \ldots \ldots$
$\ldots \ldots \ldots \ldots \ldots \ldots$ performance indicator program $312,315,325,333,412,413,421,423,431,441$, G-13
$\ldots \ldots \ldots \ldots \ldots \ldots \ldots \ldots \ldots \ldots \ldots \ldots \ldots \ldots \ldots \ldots \ldots \ldots \ldots \ldots \ldots \ldots$
$\ldots \ldots \ldots \ldots \ldots \ldots$ performance indicators $312,315,325,333,412,413,421,423,431,441$, G-13
$\ldots \ldots \ldots \ldots \ldots \ldots \ldots \ldots \ldots \ldots \ldots \ldots \ldots \ldots \ldots \ldots \ldots \ldots \ldots \ldots \ldots \ldots$
$\ldots \ldots \ldots \ldots \ldots \ldots$ performance test $121,131,133$ [Table 1-1], 651, 712 564 
performance test requirements . . . . . . . . . . . . . . . . . . 562

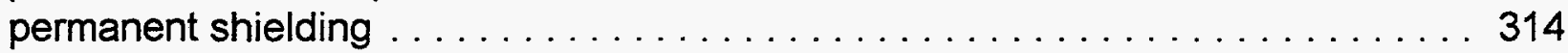
person-rem ..................... 116, 131, 133, App 3A, G-4 personal breathing-zone air sampling . . . . . . . . . . . . . 551 personal clothing .........131, 133 [Table 1-1], 221, 325, 338, App 3C, 541, G-2 personal clothing contamination . . . . . . . . . . . . . 133 [Table 1-1], 131 personal protective equipment .......... 123 [Poster], 325, 348, 371, 412, 461, $534,642, \mathrm{G}-8$

personal street clothing 461 personnel contamination personnel dosimeter 131, 133 [Table 1-1], 221, 335, 346, 761 personnel monitoring $234,511,512,514,722$ personnel protection 123 [Poster], 128, 348, App 3D, G-8 personnel radiation exposure $661,662,663$ personnel radiological records 722,723 personnel training $613,712,725$ personnel training records 725 physical access controls 334, App 3B physical condition 642 physical examination

physical examination reports . . . . . . . . . . . . . . . . . . . . . . . . . . 724

physical form .............................. 523, G-1

physical requirements . . . . . . . . . . . . . . . . . . . . . 642

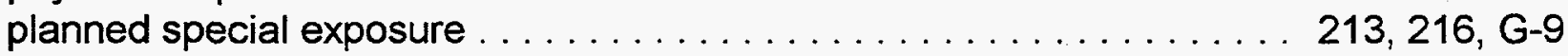
plutonium $\ldots \ldots \ldots \ldots \ldots \ldots \ldots \ldots \ldots \ldots \ldots \ldots \ldots \ldots \ldots \ldots, 361,535,612,661$, G-8 policy $\ldots \ldots \ldots \ldots \ldots \ldots 111,213,214,215,216,2$-Part 2, 321, 324, 325, 423, 522,5 -Part 3, 541, 654, 712, G-1

positive control 365,531 post-job . 352,521 post-job evaluations . . . . . . . . . . . . . . . . . . . . . . 551

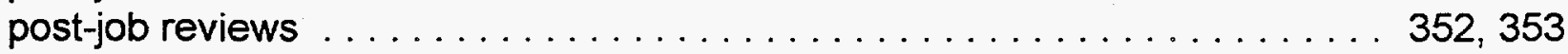
posted boundaries . . . . . . . . . . . . . . . . . . . . . 552 posting $\ldots \ldots \ldots \ldots \ldots 123$ [Poster], 2-Part 1, 221, 222, 231, 232, 234, Table 2-3, 235, Table 2-4, 236, 237, 344, 348, 372, 551, 551, 621, 622, 657, G-10, G-11

posting controlled areas 232 posting contaminated soil areas . . . . . . . . . . . . . . . . . . . . . . 222 posting contamination, high contamination, \& airborne radioactivity areas 235 , Table $2-4$ posting radiation areas 234, Table 2-3

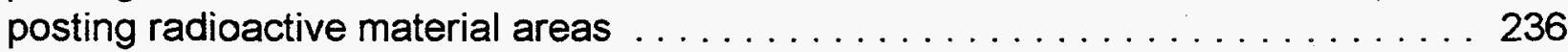

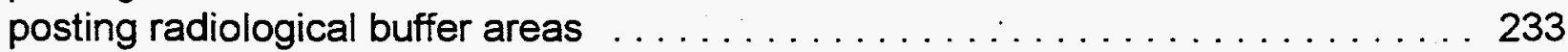

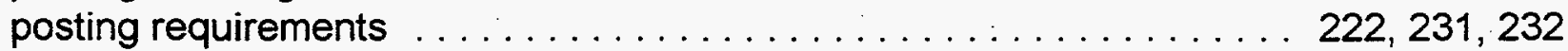
posting underground radioactive material areas $\ldots \ldots \ldots \ldots \ldots \ldots \ldots \ldots . \ldots \ldots$ 
process control

program

Program Office 151,152

Program Secretarial Office protective clothing

protective clothing removal protective coverings public qualification program qualification records Qualification Standard qualified escort $112,113,114,211,213, \mathrm{G}-12$ $128,221,315,321,325,335,338,346,347,348$, App 3C, App 3C [Table 3-1], 461, 633, 761, G-9 qualified personnel quality assurance quality assurance organization quality assurance records quality assurance requirements quality assurance reviews quality audits 348, App 3C quality control quantities 
rad

radiation area

radiation exposure

$234,231,234,334,336$, App 3B, 411, 513, 552, 633, 761

\section{radiation exposure}

$211,212,213,215,216,311$, App $3 A, 513,551,552,553,564,611$

radiation field $334,365,431$ radiation generating device ( $\&$ producing equipment) $365,552,655$ radiation level App 3B radiation measuring equipment 761 radiation monitoring radiation protection radiation safety $111,213,5$-Part 3, 541, 542, 551, 662, 642 radiation source radiation surveys radiation symbol radioactive contamination $\ldots \ldots \ldots$
$\ldots \ldots \ldots$
$\ldots \ldots$
$138,221,3$
$\ldots \ldots \ldots$ . 314, App 3A, 431, 464, 551, 552, 741

\section{radioactive contamination.}

radioactive discharge 2-Part 2, 222, 223, Table 2-2, 231, 335,411 radioactive drain 412, Table 4-1, 631, G-3, G-10 radioactive liquid radioactive material $128,451,452$ $111,112,128,223$, Table 2-2, 231, 232, 236, 237, App 2C, 315, 316, 333, 342, 346, 348, 371, 4-Part 1, $411,412,413,414,421,422,423,431,464,531,535$, $542,543,551,552,554,621,631,653,654,712, \mathrm{G}-1, \mathrm{G}-2, \mathrm{G}-4$, G-5, G-6, G-7, G-8, G-10, G-11, G-12 radioactive material area $236,414, \mathrm{G}-10$ radioactive material packaging 
radiological control coordinating committee

112,155

radiological control deficiencies 125

radiological control hold point . .

$312,324,345, \mathrm{G}-9$

radiological control instructions

123 [Poster]

radiological control manager

$113,133,141,142,213,222,316$

$345,371,414,612,613,615,657$

radiological control manager qualifications 142 radiological control manual 1-Part 1, 111, 112, 141, 156, 311, 312,

radiological control operations $346,348,364$ radiological control organization

$141,143,221,222,312,323,325,333,334,338,342,344$, $348,365,411,414,422,423,431,453,511,513,523,541$, $551,561,621,713, \mathrm{G}-3, \mathrm{G}-11$

radiological control performance $113,121,128,154$ radiological control personnel 123 [Poster], 141, 324, 343, 344, 346, App 3D, 412, Table 4-1, 654, 725, G-11

radiological control procedures 712, 7-Part 4 radiological control program . $111,112,114,116,121,125,134,138$ $141,142,651,751$

radiological control program advisor 112,155 radiological control records radiological control technician qualifications $144,614,615,641-5$ radiological control training 613,657 radiological deficiencies 125 radiological design . . . . . . . . . . . . . . . . . . . . . . . . . 128 radiological engineering . . . . . . . . . . . . . . . . . . . . . . . . 143

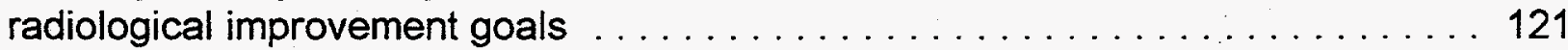
radiological incident 712,723 radiological instruments $561,562,563$ radiological matters $\ldots \ldots 125$ radiological operations $125,371,441$ radiological performance 1-Part 2, 1-Part 3, 131, 132, 133, Table 1-1, 145,712 radiological performance goals $131,132,133$ radiological performance indicators 133 [Table 1-1] radiological performance record. . . 1-Part 2 radiological performance reports radiological posting 231,622 radiological program 711,724 radiological records $712,722,774$ radiological support personnel 143,654 radiological surveys $126,222,322,323,411,431,554,661,662,664$ 
radiological waste

radiological work permit (RWP) . . . . . . 123 [Poster], 231, 312, 321, 322, 323, 324, $334,341,343,347$, App 3A, App 3C, 412, 463, 464, 512, 513, 551, 554,

$712,725,751$

RWP for training exercises 322 radiological work practices radiological worker
Radiological Worker I

Radiological Worker II

radiological worker training radionuclides

RAMATROL RCT
$144,211,213,214,215,333,334,335,612,613$ 6-Part $3,631,632,633,643,651,653,654,656,657,725$ $213,333,334,612,613,631,632$, Table 6-1,

$651,654,657$ $213,334,335,612,613,631,633,634,643,651$, $653,654,657$ $634,653,656,725$ 2-Part 1, Table 2-1, 215, 221, 223, 338, 3-Part 6, 521, 522, 523, 541, 542, 543 $365,423,431,783$ $211,221,335,338,347,611,612,613,614,615,641,642$, $643,644,645,654, \mathrm{G}-6$ 116,613

reactors . . 431 receipt surveys 421 recontamination record 1-Part 2, 213, 216, 221, 222, 232, App 2C, 325, $332,344,411,421,431,512,514,551,554,561,564,613,622$, $654,656,657,711,712,713,7$-Part $2,721,722,723,725,731$, $741,742,743,751,752,753,7$-Part 6, 761, 7-Part 7, $773,774,781,783$

recordkeeping $611,613,713,783$ records clerks 654 records management 712, 7-Part 7 records management program 712 records system 771 reduction 126, 131, 133 [Table 1-1], 312, 321, 371, 652 reentry 511 refresher training 613 regulations release to controlled areas 112, 412 [Table 4-1], 423, 654 release to uncontrolled areas 421 rem . . . Th. $2116,128,131,211,212$, Table $2-1,214,215,216,222,223$, 
232, App 2B, 312, 334, 348, App 3B, 511, 513, 521, 522, 781 removable contamination ......... 222, 234 [Table 2-3], 235 [Table 2-4], 312, 316, $322,325,333,337$, App 3C, App 3C [Table 3-1], 413, 423, 554

report $133,211,231$, App 2B, 325, 342, 343, 346, 431, $511,512,542,554,561,642,712,723,725,732,781,782,783$

reporting $121,141,343,3$-Part 5, 411, 431, 613, 7-Part 8, 781, 782

reporting requirements 782 rescue personnel App $2 A$ respirator $231,316,325,461,5$-Part 3, 531, 535, 555,724

respiratory protection $136,316,321,325,335,347,371$, App 3C, 453,5 -Part $3,531,543,555,613$, Table 6-1, 725

respiratory protection equipment 316, 325, 5-Part 3, 531 respiratory protection program 5-Part 3, 531 respiratory protection training $531,613,725$ response 324, 346, 348, App 3C [Table 3-1], 411, 423, 551, 555, 562, $615,621,633,643,656,725$ retention $335,348,711,725,774$ RSPC $222,231,316,321,325,331,338,343,511,531,541$, $551,554,611,613,725,781,782,783$

RSPC will $222,511,781,782$ RWP see "radiological work permit" safety plans 3-Part 7 sealed source $334,365,4-P a r t 1,411,431,511,712,783$ self-assessment 651 self-contained breathing apparatus 5-Part 3 Senior Nuclear Managers Group $155, \mathrm{G}-12$ Senior Site Executive . . . . . . 114, 116, 1-Part 2, 132, 133, 141, 211, 213, 216, G-2 shallow dose App 2C, 348, G-12 shielding $312,314,342,364$, App 3A, 552, G-6 site emergency plan 423 site personnel 372,621 site radiological control program 114,353 site-specific procedures 651 site-specific training skin 131, 133 [Table 1-1], 221, App 2A, App 2C, 316, 338,348, App 3C, 511, 512, 521, 541, 722

skin contamination $348,541, \mathrm{G}-3$ skin decontamination 541 soil contamination 222,235 [Table 2-4], 371, G-1 solid radioactive waste 4-Part 4, 441, 451 source controls 431,552 
source custodian

statutory and regulatory requirements 342, App 3C, G-6 step-off pad 112 sticky pad $325,335,338$, App 3C, 554, G-12, G-13 stop work storage 348, G-13 student 371 , 4-Part 1, 412, Table 4-1, 414, 451, 621, 712,
772,775

student supervision Table 2-1, 612, 613 supervisor $145,221,342,345,551,614,651,725,774$ $121,125,133,134,323,324,345$, App 3A, $551,613,615,641,644,645,725$

supervisory $142,644,713$

supplemental dosimeter 133, 234 [Table 2-3], 334, 346, App 3D, 513 surface coatings $222,231,371$, App 3C, 412, 464, 554 surface contamination $\ldots \ldots \ldots \ldots \ldots$ Table $2-2$ surfaces contaminated

surveillance $152,312,365,453$ survey frequency 371,464 survey instruments App 3D, 761, G-6 survey maps $551,642,751$

survey meter 334 survey points 551 survey results $411,421,751,753,783$ survey techniques $541,554,555$ surveyor swipe/smear $412,751,783$ technical work document 221, Table 2-2, 231, 412, 431, 553, 554, G-2 $312,315,324,341,342,343$, App 3A, 551, G-11, G-13 temporary shielding, exemptions

Tenant Organization [definition] G-14 TLD 234, Table 2-3, 511, 512, 621, G-8, G-13 transportation of radioactive materials 413,423 trigger levels $312,324,541$ tunnel 365,554 unusual occurrence $211, \mathrm{G}-13$ vacuum cleaner requirements 464 visitor

Table $2-1,214,331,336,511,613,622,725,731,732$, $781,782, \mathrm{G}$ 
whole body ....... 136, 2-Part 1, 211, Table 2-1, App 2A, App 2B, 316, 333, 334, $335,338,347$, App 3B, App 3D, 512, 521, 552, 621, 654, 722,

G-2, G-5, G-9, G-13

worker responsibilities

123 
NV/YMP Radiological Control Manual, Rev. 2:

November 13, 1996

INDEX

INDEX

THIS PAGE INTENTIONALLY LEFT BLANK 


\title{
APPENDIX
}

FOR REFERENCE ONLY

10 CFR 835

\author{
NOT PART OF THE TEXT \\ OF THE APPENDED DOCUMENT
}




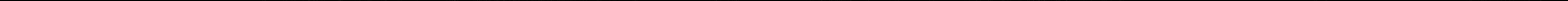




\section{TITLE 10 CODE OF FEDERAL REGULATIONS \\ PART 835- OCCUPATIONAL RADIATION PROTECTION}

\section{Subpart A - General Provisions}

Sec.

835.1 Scope.

835.2 Definitions.

835.3 General rule.

835.4 Radiological units.

\section{Subpart B - Radiation \\ Protection Programs}

835.101 Radiation protection programs.

835.102 Internal audits.

Subpart C - Standards for

Internal and

External Exposure

835.201 [Reserved]

835.202 Occupational exposure limits for general employees.

835.203 Combining internal and external dose equivalents resulting from DOE activities.

835.204 Planned special exposures.

835.205 Determination of compliance for non-uniform exposure of the skin.

835.206 Limits for the embryo/fetus.

835.207 Limits for minors.

835.208 Limits for members of the public entering a controlled area.

835.209 Concentrations of radioactive material in air.

Subpart D - [Reserved]

Subpart E -- Monitoring in the Workplace

835.401 General requirements. 835.402 Individual monitoring. 835.403 Area monitoring. 835.404 Radioactive contamination

control and monitoring.

\section{Subpart F - Entry Control Program}

835.501 Radiological areas.

835.502 High and very high radiation areas.

\section{Subpart G -- Posting and Labeling}

835.601 General requirements.

835.602 Controlled areas.

835.603 Radiological areas.

\section{Subpart H - Records \\ 835.701 General provisions. \\ 835.702 Individual monitoring records. \\ 835.703 Monitoring and workplace records.}

835.704 Administrative records.

\section{Subpart I - Reports to \\ Individuals}

835.801 Reports to individuals.

\section{Subpart J - Radiation Safety \\ Training}

835.901 General employees.

835.902 Radiological workers.

835.903 Radiological control technicians.

\section{Subpart K - Design and Control}

835.1001 Design and control.

835.1002 Facility design and modifications.

835.1003 Control procedures.

Subpart L - Releases of Materials and Equipment From Radiological Areas

835.1101 Releases of materials and equipment from radiological areas.

\author{
Subpart M - [Reserved] \\ Subpart N - Accidents and \\ Emergencies
}

835.1301 General provisions.

835.1302 Emergency exposure situations.

835.1303 [Reserved]

835.1304 Nuclear accident dosimetry.

Appendix A to Part 835 - Derived Air Concentrations (DAC) for

Controlling Radiation Exposure to

Workers at DOE Facilities

Appendix B to Part 835 --

Alternative Absorption Factors and

Lung Retention Classes for Specific

Compounds

Appendix C to Part 835 - Derived Air Concentrations (DAC) for Workers From External Exposure During Immersion in a Contaminated Atmospheric Cloud

Appendix D to Part 835 - Surface Radioactivity Values

\section{Appendix E to Part 835 --}

[Reserved]

Authority: 42 U.S.C. 2201; 7191 :

Source: 58 FR 65485, Dec. 14, 1993 , unless otherwise noted.

Effective Date Note: At 58 FR 65485, Dec. 14, 1993, part 835 was added effective January 13, 1993. At 58 FR 67442, Dec. 21, 1993, the effective date was corrected to January 14 , 1994. 
Subpart A - General Provisions

\section{§835.1 Scope.}

(a) General. The rules in this part establish radiation protection standards, limits, and program requirements for protecting individuals from ionizing radiation resulting from the conduct of DOE activities.

(b) Exclusion. The requirements in this part do not apply to:

(1) Activities that are regulated through a license by the Nuclear Regulatory Commission or a State under an Agreement with the Nuclear Regulatory Commission, including activities certified by the Nuclear Regulatory Commission under section 1701 of the Atomic Energy Act;

(2) Activities conducted under the authority of the Director, Naval Nuclear Propulsion Program, as described in Pub. L. 98-525

(3) Activities conducted under the Nuclear Explosives and Weapons Safety Program relating to the prevention of accidental or unauthorized nuclear detonations; or

(4) Background radiation, radiation doses received as a patient for the purposes of medical diagnosis or therapy, or radiation doses received from voluntary participation in medical research programs.

\section{$\$ 835.2$ Definitions.}

(a) As used in this part:

\section{Airborne radioactive material or} airborne radioactivity means radioactive material in any chemical or physical form that is dissolved, mixed, suspended, or otherwise entrained in air.

\footnotetext{
Airborne radioactivity area means any area where the measured concentration of airborne radioactivity, above natural background, exceeds or is likely to exceed 10 percent of the derived air concentration (DAC) values listed in appendix $A$ or appendix $\mathrm{C}$ of this part.
}

ALARA means "As Low As is Reasonably Achievable," which is the approach to radiation protection to manage and control exposures (both individual and collective) to the work force and to the general public to as low as is reasonable, taking into account social, technical, economic, practical, and public policy considerations. As used in this part, ALARA is not a dose limit but a process which has the objective of attaining doses as far below the applicable limits of this part as is reasonably achievable.

Ambient air means the general air in the area of interest (e.g., the general room atmosphere), as distinct from a specific stream or volume of air that may have different properties.

\section{Annual limit on intake ( $A L I$ ) means} the derived limit for the amount of radioactive material taken into the body of an adult worker by inhalation or ingestion in a year. ALI is the smaller value of intake of a given radionuclide in a year by the reference man (ICRP Publication 23) that would result in a committed effective dose equivalent of 5 rems $(0.05$ sievert) or a committed dose equivalent of 50 rems ( 0.5 sievert) to any individual organ or tissue. ALI values for intake by ingestion and inhalation of selected radionuclides are based on Table 1 of the U.S.

Environmental Protection Agency's Federal Guidance Report No. 11, Limiting Values of Radionuclide Intake and Air Concentration and Dose Conversion Factors for Inhalation, Submersion, and Ingestion, published September 1988. This document is available from the National Technical Information Service, Springfield, VA.

Background means radiation from:

(i) Naturally occurring radioactive materials which have not been technologically enhanced;

(ii) Cosmic sources;

(iii) Global fallout as it exists in the environment (such as from the testing of nuclear explosive devices);

(iv) Radon and its progeny in concentrations or levels existing in buildings or the environment which have not been elevated as a result of current or prior activities; and

(v) Consumer products containing nominal amounts of radioactive material or producing nominal amounts of radiation.

Bioassay means the determination of kinds, quantities, or concentrations, and, in some cases, locations of radioactive material in the human body, whether by direct measurement or by analysis, and evaluation of radioactive materials excreted or removed from the human body.
Calibration means to adjust and/or determine either:

(i) The response or reading of an instrument relative to a standard (e.g., primary, secondary, or tertiary) or to a series of conventionally true values; or

(ii) The strength of a radiation source relative to a standard (e.g., primary, secondary, or tertiary) or conventionally true value.

Contamination area means any area where contamination levels are greater than the values specified in appendix $D$ of this part, but less than or equal to 100 times those levels.

Continuous air monitor (CAM) means an instrument that continuously samples and measures the levels of airborne radioactive materials on a "real-time" basis and has alarm capabilities at preset levels.

Contractor means any entity under contract with the Department of Energy with the responsibility to perform activities at a DOE site or facility.

Controlled area means any area to which access is managed in order to protect individuals from exposure to radiation and/or radioactive material. Individuals who enter only the controlled area without entering radiological areas are not expected to receive a total effective dose equivalent of more than $100 \mathrm{mrem}(0.001$ sievert $)$ in a year.

Declared pregnant worker means a woman who has voluntarily declared to her employer, in writing, her pregnancy for the purpose of being subject to the occupational exposure limits to the embryo/fetus as provided in 835.206. This declaration may be revoked, in writing, at any time by the declared pregnant worker.

Derived air concentration (DAC) means, for the radionuclides listed in appendix $A$ of this part, the airborne concentration that equals the ALI divided by the volume of air breathed by an average worker for a working year of 2000 hours (assuming a breathing volume of $2400 \mathrm{~m}^{3}$ ). For the radionuclides listed in appendix $\mathrm{C}$ of this part, the air immersion DACs were calculated for a continuous, non-shielded exposure via immersion in a semi-infinite atmospheric cloud. The value is based upon the derived 
airborne concentration found in Table 1 of the U.S. Environmental Protection Agency's Federal Guidance Report No. 11, Limiting Values of Radionuclide Intake and Air Concentration and Dose Conversion Factors for Inhalation, Submersion, and Ingestion, published September 1988. This document is available from the National Technical Information Service, Springfield, VA.

$D O E$ activities means an activity taken for or by the DOE that has the potential to result in the occupational exposure of an individual to radiation or radioactive material. The activity may be, but is not limited to, design, construction, operation, or decommissioning. To the extent appropriate, the activity may involve a single DOE facility or operation or a combination of facilities and operations, possibly including an entire site.

Entrance or access point means any location through which an individual could gain access to areas controlled for the purposes of radiation protection. This includes entry or exit portals of sufficient size to permit human entry, irrespective of their intended use.

General employee means an individual who is either a DOE or DOE contractor employee; an employee of a subcontractor to a DOE contractor; or a visitor who performs work for or in conjunction with DOE or utilizes DOE facilities.

High contamination area means any area where contamination levels are greater than 100 times the values specified in appendix $D$ of this part.

High radiation area means any area, accessible to individuals, in which radiation levels could result in an individual receiving a deep dose equivalent in excess of $0.1 \mathrm{rem}(0.001$ sievert) in 1 hour at 30 centimeters from the radiation source or from any surface that the radiation penetrates.

Individual means any human being.

Member of the public means an individual who is not occupationally exposed to radiation or radioactive material. An individual is not a "member of the public" during any period in which the individual receives occupational exposure.

Minor means an individual less than 18 years of age.

Monitoring means actions intended to detect and quantify radiological conditions.

Nonstochastic effects means effects due to radiation exposure for which the severity varies with the dose and for which a threshold normally exists (e.g., radiation -induced opacities within the lens of the eye).

Occupational exposure means an individual's exposure to ionizing radiation (external and internal) as a result of that individual's work assignment. Occupational exposure does not include planned special exposures, exposure received as a medical patient, background radiation, or voluntary participation in medical research programs.

Person means any individual, corporation, partmership, firm, association, trust, estate, public or private institution, group, Government agency, any State or political subdivision of, or any political entity within a State, any foreign government or nation or other entity, and any legal successor, representative, agent or agency of the foregoing; provided that person does not include the Department or the United States Nuclear Regulatory Commission.

Radiation means ionizing radiation: alpha particles, beta particles, gamma rays, $\mathrm{X}$-rays, neutrons, high-speed electrons, high-speed protons, and other particles capable of producing ions. Radiation as used in this part, does not include non-ionizing radiation, such as radio- or micro-waves, or visible, infrared, or ultraviolet light.

Radiation area means any area accessible to individuals in which radiation levels could result in an individual receiving a deep dose equivalent in excess of $0.005 \mathrm{rem}(0.05$ millisievert) in 1 hour at 30 centimeters from the source or from any surface that the radiation penetrates.

Radiological area means any area within a controlled area which must be posted as a "radiation area," "high radiation area," "very high radiation area," "contamination area," "high contamination area, "or "airborne radioactivity area" in accordance with $\$ 835.603$.

Radiological worker means a general employee whose job assignment involves operation of radiation producing devices or working with radioactive materials, or who is likely to be routinely occupationally exposed above 0.1 rem $(0.001$ sievert) per year total effective dose equivalent.

Representative, as applied to the sampling of radioactive material, means sampling in such a manner that the sample closely approximates both the amount of activity and the physical and chemical properties of the material (e.g., particle size and solubility in the case of air sampling of the aerosol to which workers may be exposed).

Stochastic effects means malignant and hereditary diseases for which the probability of an effect occurring, rather than its severity, is regarded as a function of dose without a threshold for radiation protection purposes.

Survey means an evaluation of the radiological conditions and potential hazards incident to the production, use, transfer, release, disposal, or presence of radioactive material or other sources of radiation. When appropriate, such an evaluation includes a physical survey of the location of radioactive material and measurements or calculations of levels of radiation, or concentrations or quantities of radioactive material present.

Very high radiation area means any area accessible to individuals in which radiation levels could result in an individual receiving an absorbed dose in excess of 500 rads ( 5 grays) in one hour at 1 meter from a radiation source or from any surface that the radiation penetrates.

Year means the period of time beginning on or near January 1 used to determine compliance with the provisions of this part. The starting date of the year used to determine compliance may be changed provided that the change is made at the beginning of the year and that no day is omitted or duplicated in consecutive years.

(b) As used in this part to describe various aspects of radiation dose: 
Absorbed dose $(D)$ means the energy absorbed by matter from ionizing radiation per unit mass of irradiated material at the place of interest in that material. The absorbed dose is expressed in units of rad (or gray) (1 $\mathrm{rad}=0.01$ gray)

Collective dose means the sum of the total effective dose equivalent values for all individuals in a specified population. Collective dose is expressed in units of person-rem (or person-sievert).

Committed dose equivalent ( $H T, 50)$ means the dose equivalent calculated to be received by a tissue or organ over a 50-year period after the intake of a radionuclide into the body. It does not include contributions from radiation sources external to the body. Committed dose equivalent is expressed in units of rem (or sievert).

Committed effective dose equivalent (HE,50) means the sum of the committed dose equivalents to various tissues in the body (HT,50), each multiplied by the appropriate weighting factor (WT) -- that is, HE, 50 $=$ SwTHT,50. Committed effective dose equivalent is expressed in units of rem (or sievert).

Cumulative total effective dose equivalent means the sum of the total effective dose equivalents recorded for an individual for each year of employment at a DOE or DOE contractor site or facility, effective January $1,1989$.

Deep dose equivalent means the dose equivalent derived from external radiation at a depth of $1 \mathrm{~cm}$ in tissue.

Dose equivalent $(H)$ means the product of absorbed dose (D) in rad (or gray) in tissue, a quality factor $(\mathrm{Q})$, and other modifying factors $(\mathrm{N})$. Dose equivalent is expressed in units of rem (or sievert) $(1 \mathrm{rem}=0.01$ sievert).

Effective dose equivalent (HE) means the summation of the products of the dose equivalent received by specified tissues of the body (HT) and the appropriate weighting factor $\left(\mathrm{W}_{\mathrm{T}}\right)$ that is, HE = SwTHT. It includes the dose from radiation sources internal and/or external to the body. The effective dose equivalent is expressed in units of rem (or sievert).
External dose or exposure means that portion of the dose equivalent received from radiation sources (e.g., "external sources") outside the body.

Extremity means hands and arms below the elbow or feet and legs below the knee.

Internal dose or exposure means that portion of the dose equivalent received from radioactive material taken into the body (e.g., "internal sources").

Lens of the eye dose equivalent means the external exposure of the lens of the eye and is taken as the dose equivalent at a tissue depth of $0.3 \mathrm{~cm}$.

Quality factor means the principal modifying factor used to calculate the dose equivalent from the absorbed dose; the absorbed dose (expressed in rad or gray) is multiplied by the appropriate quality factor (Q).

(i) The quality factors to be used for determining dose equivalent in rem are shown below:

\section{QUALTTY FACTORS}

Radiation type Quality factor

$\mathrm{X}$-rays, gamma rays, positrons, electrons (including tritium beta particles) $\ldots \ldots \ldots \ldots \ldots 1$ Neutrons, $\leq 10 \mathrm{keV} \ldots \ldots \ldots \ldots 3$

Neutrons, $>10 \mathrm{keV} \ldots \ldots \ldots .10$

Protons and singly-charged particles of unknown energy with rest mass greater than one atomic mass unit ....... Alpha particles and multiplecharged particles (and particles of unknown charge) of unknown energy $\ldots \ldots \ldots \ldots 20$

When spectral data are insufficient to identify the energy of the neutrons, a quality factor of 10 shall be used.

(ii) When spectral data are sufficient to identify the energy of the neutrons, the following mean quality factor values may be used:

Quality Factors For Neutrons [Mean quality factors, $Q$ (maximum value in a $30-\mathrm{cm}$ dosimetry phantom), and values of neutron flux density that deliver in 40 hours, a maximum dose equivalent of 100 mrem $(0.001$ sievert).]

\begin{tabular}{lrr}
$\begin{array}{l}\text { Neutron } \\
\text { Energy } \\
(\mathrm{MeV})\end{array}$ & $\begin{array}{c}\text { Mean } \\
\text { Quality } \\
\text { Factor }\end{array}$ & $\begin{array}{c}\text { Neutron Flux } \\
\text { Density } \\
\text { (cm - }{ }^{2} \text { s-1) }\end{array}$ \\
\hline $2.5 \times 10^{-8}$ & & \\
thermal & 2 & 680 \\
$1 \times 10^{-7}$ & 2 & 680 \\
$1 \times 10^{-6}$ & 2 & 560 \\
$1 \times 10^{-5}$ & 2 & 560 \\
$1 \times 10^{-4}$ & 2 & 580 \\
$1 \times 10^{-3}$ & 2 & 680 \\
$1 \times 10^{-2}$ & 2.5 & 700 \\
$1 \times 10^{-1}$ & 7.5 & 115 \\
$5 \times 10^{-1}$ & 11 & 27 \\
1 & 11 & 19 \\
2.5 & 9 & 20 \\
5 & 8 & 16 \\
7 & 7 & 17 \\
10 & 6.5 & 17 \\
14 & 7.5 & 12 \\
20 & 8 & 11 \\
40 & 7 & 10 \\
60 & 5.5 & 11 \\
$1 \times 10^{2}$ & 4 & 14 \\
$2 \times 10^{2}$ & 3.5 & 13 \\
$3 \times 10^{2}$ & 3.5 & 11 \\
$4 \times 10^{2}$ & 3.5 & 10 \\
\hline & &
\end{tabular}

Shallow dose equivalent means the dose equivalent deriving from external radiation at a depth of $0.007 \mathrm{~cm}$ in tissue.

Total effective dose equivalent (TEDE) means the sum of the effective dose equivalent (for external exposures) and the committed effective dose equivalent (for internal exposures). For purposes of compliance with this part, deep dose equivalent to the whole body may be used as effective dose equivalent for external exposures.

Weighting factor $\left(\mathrm{W}_{\tau}\right)$ means the fraction of the overall health risk, resulting from uniform, whole body irradiation, attributable to specific tissue $(T)$. The dose equivalent to tissue, $T$, is multiplied by the appropriate weighting factor to obtain the effective dose equivalent contribution from that tissue. The weighting factors are as follows:

WEIGHTING FACTORS FOR VARIOUS TISSUES

Organs or tissues, $\mathrm{T}$

Weighting 
factor, $\mathrm{w}_{\mathrm{T}}$

Gonads ............ 0.25

Breasts . . . . . . . . . 0.15

Red bone marrow $\ldots \ldots \ldots \ldots .12$

Lungs . . . . . . . . . . 0.12

Thyroid . . . . . . . . 0.03

Bone surfaces $\ldots \ldots \ldots \ldots .0 .03$

Remainder $^{1} \ldots \ldots \ldots \ldots .0 .30$

Whole body ${ }^{2} \ldots \ldots \ldots \ldots \ldots . .1 .00$

"Remainder" means the five other organs or tissues with the highest dose (e.g., liver, kidney, spleen, thymus, adrenal, pancreas, stomach, small intestine, and upper large intestine).

The weighting factor for each remaining organ or tissue is 0.06 .

${ }^{2}$ For the case of uniform external irradiation of the whole body, a weighting factor $\left(\mathrm{w}_{\mathrm{T}}\right)$ equal to 1 may be used in determination of the effective dose equivalent.

Whole body means, for the purposes of external exposure, head, trunk (including male gonads), arms above and including the elbow, or legs above and including the knee.

(c) Terms defined in the Atomic Energy Act and not defined in this part are used consistent with the meanings given in the Act.

(d) As used in this part, words in the singular also include the plural and words in the masculine gender also include the feminine and vice versa, as the case may be.

\section{$\$ 835.3$ General rule.}

(a) No person or DOE personnel shall take or cause to be taken any action inconsistent with the requirements of:

(1) This part; or

(2) Any program, plan, schedule, or other process established by this part.

(b) With respect to a particular DOE activity, contractor management shall be responsible for compliance with the requirements of this part.

(c) Where there is no contractor for a DOE activity, DOE shall ensure implementation of and compliance with the requirements of this part.

(d) Nothing in this part shall be construed as limiting actions that may be necessary to protect health and safety.

\section{\$835.4 Radiological units.}

Unless otherwise specified, the quantities used in the records required by this part shall be clearly indicated in special units of curie, rad, or rem, including multiples and subdivisions of these units. The SI units, becquerel $(\mathrm{Bq})$, gray $(\mathrm{Gy})$, and sievert $(\mathrm{Sv})$, are only provided parenthetically in this part for reference with scientific standards. These SI units are not authorized for use in records required under this part.

\section{Subpart B -- Radiation Protection Programs}

\section{$\$ 835.101$ Radiation protection programs.}

(a) A DOE activity shall be conducted in compliance with a documented radiation protection program (RPP) as approved by the DOE.

(b) The DOE may direct or make modifications to a RPP.

(c) The content of each RPP shall be commensurate with the nature of the activities performed and shall include formal plans and measures for applying the as low as reasonably achievable (ALARA) process to occupational exposure.

(d) The RPP shall specify the existing and/or anticipated operational tasks that are intended to be within the scope of the RPP. Except as provided in $\$ 835.101(\mathrm{i})$, any task outside the scope of a RPP. shall not be initiated until an update of the RPP is approved by DOE.

(e) The content of the RPP shall address, but shall not necessarily be limited to, each requirement in this part.

(f) The RPP shall inciude plans, schedules, and other measures for achieving compliance with regulations of this part. Compliance with this part shall be achieved no later than January 1, 1996.

(g) The RPP for an existing activity shall be submitted to DOE no later than January 1, 1995.

(h) An update of the RPP shall be submitted to DOE:

(1) Whenever a change or an addition to the RPP is made;

(2) Prior to the initiation of a task not within the scope of the RPP; or

(3) Within 180 days of the effective date of any modifications to this part.

(i) Changes, additions, or updates to the RPP may become effective without prior Department approval only if the changes do not decrease the effectiveness of the RPP and the RPP, as changed, continues to meet the requirements of this part. Proposed changes that decrease the effectiveness of the RPP shall not be implemented without submittal to and approval by the Department.

(j) An initial RPP or an update shall be considered approved 180 days after its submission unless rejected by DOE at an earlier date.

\section{$\$ 835.102$ Internal audits.}

Internal audits of all functional elements of the radiation protection program shall be conducted no less frequently than every 3 years and shall include program content and implementation.

\section{Subpart C - Standards for Internal and External Exposure}

\section{$\$ 835.201$ [Reserved]}

$\S 835.202$ Occupational exposure limits for general employees.

(a) The occupational exposure to general employees resulting from DOE activities, other than planned special exposures under $\$ 835.204$ and emergency exposure situations under $\$ 835.1302$, shall be controlled so the following annual limits are not exceeded:

(1) A total effective dose equivalent of 5 rems ( 0.05 sievert);

(2) The sum of the deep dose equivalent for external exposures and the committed dose equivalent to any organ or tissue other than the lens of the eye of 50 rems ( 0.5 sievert);

(3) $\mathrm{A}$ lens of the eye dose equivalent of 15 rems (0.15 sievert); and

(4) A shallow dose equivalent of 50 rems ( 0.5 sievert) to the skin or to any extremity.

(b) All occupational exposure received during the current year shall be included when demonstrating compliance with $\$ 835.202$ (a).

(c) Exposures from background, therapeutic and diagnostic medical radiation, and voluntary participation in medical research programs shall not be included in dose records or in the assessment of compliance with the occupational exposure limits. 
\$835.203 Combining internal and external dose equivalents resulting from DOE activities.

(a) The total effective dose equivalent during a year shall be determined by summing the effective dose equivalent from external exposures and the committed effective dose equivalent from intakes during the year. For purposes of compliance with this part, deep dose equivalent to the whole body may be used as effective dose equivalent for external exposures.

(b) Determinations of the effective dose equivalent shall be made using the weighting factor values provided in $\S 835.2$.

(c) For the case of uniform external irradiation of the whole body, a weighting factor $\left(W_{T}\right)$ equal to 1 may be used in the determination of the effective dose equivalent.

\section{\$835.204 Planned special exposures.}

(a) A planned special exposure may be authorized for a radiological worker to receive doses in addition to and accounted for separately from the doses received under the limits specified in $\$ 835.202(a)$, provided that each of the following conditions is satisfied:

(1) The planned special exposure is considered only in an exceptional situation when alternatives that might prevent a radiological worker from exceeding the limit in $\$ 835.202$ (a)(1) are unavailable or impractical;

(2) The contractor management (and employer, if the employer is not the contractor) specifically requests the planned special exposure, in writing; and

(3) Joint written approval from the appropriate DOE Headquarters program office and the Assistant Secretary for Environment, Safety and Health is received.

(b) Prior to requesting an individual to participate in an authorized planned special exposure, the individual's dose from all previous planned special exposures and all doses in excess of the occupational dose limits shall be determined.

(c) An individual shall not receive a planned special exposure that, in addition to the doses determined in $\$ 835.204(\mathrm{~b})$, would result in a dose exceeding the following:

(1) A total effective dose equivalent of 5 rems $(0.05$ sievert $)$ in the current year; and

(2) A cumulative total effective dose equivalent of 25 rems ( 0.25 sievert).

(d) Prior to a planned special exposure, written consent shall be obtained from each individual involved. Each individual shall be:

(1) Informed of the purpose of the planned operations and procedures to be used;

(2) Informed of the estimated doses and associated potential risks and specific radiological conditions and other hazards which might be involved in performing the task; and

(3) Instructed in the measures to be taken to keep the dose ALARA considering other risks that may be present.

(e) Records of the conduct of a planned special exposure shall be maintained and a written report submitted within 30 days after the planned special exposure to the approving organizations identified in $\S 835.204(\mathrm{a})(3)$.

(f) The dose from planned special exposures is not to be considered in controlling future occupational dose of the individual under $\$ 835.202$ (a), but is to be included in records and reports required under this part.

\section{$\$ 835.205$ Determination of compliance for non-uniform exposure of the.skin.}

(a) Non-uniform exposures of the skin from X-rays, beta radiation, and/or radioactive material on the skin are to be assessed as specified in this section.

(b) For purposes of demonstrating compliance with $\$ 835.202$ (a)(4), assessments shall be conducted as follows:

(1) Area of skin irradiated is $100 \mathrm{~cm}^{2}$ or more. The non-uniform dose equivalent received during the year shall be averaged over the $100 \mathrm{~cm}^{2}$ of the skin receiving the maximum dose, added to any uniform dose equivalent also received by the skin, and recorded as the shallow dose equivalent to any extremity or skin for the year.

(2) Area of skin irradiated is $10 \mathrm{~cm}^{2}$ or more, but is less than $100 \mathrm{~cm}^{2}$. The non-uniform dose equivalent $(H)$ to the irradiated area received during the year shall be added to any uniform dose equivalent also received by the skin and recorded as the shallow dose equivalent to any extremity or skin for the year. $\mathrm{H}$ is the dose equivalent averaged over the $1 \mathrm{~cm}^{2}$ of skin receiving the maximum absorbed dose, D, reduced by the fraction $f$, which is the irradiated area in $\mathrm{cm}^{2}$ divided by $100 \mathrm{~cm}^{2}$ (i.e., $H=f D$ ). In no case shall a value of $f$ less than 0.1 be used.

(3) Area of skin irradiated is less than $10 \mathrm{~cm}^{2}$. The non-uniform dose equivalent shall be averaged over the 1 $\mathrm{cm}^{2}$ of skin receiving the maximum dose. This dose equivalent shall:

(i) Be recorded in the individual's occupational exposure history as a special entry; and

(ii) Not be added to any other shallow dose equivalent to any extremity or skin recorded as the dose equivalent for the year.

\$835.206 Limits for the embryo/fetus.

(a) The dose equivalent limit for the embryo/ferus from the period of conception to birth, as a result of occupational exposure of a deciared pregnant worker, is $0.5 \mathrm{rem}(0.005$ sievert).

(b) Substantial variation above a uniform exposure rate that would satisfy the limits provided in $\$ 835.206$ (a) shall be avoided.

(c) If the dose equivalent to the embryo/fetus is determined to have already exceeded $0.5 \mathrm{rem}(0.005$ sievert) by the time a worker declares her pregnancy, the declared pregnant worker shall not be assigned to tasks where additional occupational exposure is likely during the remaining gestation period.

\section{\$835.207 Limits for minors.}

Any minor exposed to radiation and/or radioactive material during direct on-site access at a DOE site or facility shall not exceed 0.1 rem $(0.00$ sievert) total effective dose equivalent in a year.

$\$ 835.208$ Limits for members of the public entering a controlled area.

Any member of the public exposed to radiation and/or radioactive material during direct on-site access at a DOE site or facility shall not exceed $0.1 \mathrm{rem}$ ( 0.001 sievert) total effective dose equivalent in a year. 
\$835.209 Concentrations of radioactive material in air.

(a) The derived air concentration (DAC) values given in appendices A and $C$ to this part shall be used in the control of occupational exposures to airborne radioactive material.

(b) With regard to inhalation exposures and external exposures from airborne radionuclides, compliance with this part shall be demonstrated through conformity with $\$ 835.101$ and $\$ 835.202$ which establishes the applicable regulatory limits.

(c) The estimation of internal dose shall be based on bioassay data rather than air concentration values unless bioassay data are:

(1) unavailable;

(2) inadequate; or

(3) internal dose estimates based on representative air concentration values are demonstrated to be as or more accurate.

\section{Subpart D -- [Reserved]}

\section{Subpart E - Monitoring in the Workplace}

\section{\$835.401 General requirements.}

(a) Monitoring of individuals and areas shall be performed to:

(1) Demonstrate compliance with the regulations in this part;

(2) Document radiological conditions in the workplace

(3) Detect changes in radiological conditions;

(4) Detect the gradual buildup of radioactive material in the workplace; and

(5) Verify the effectiveness of engineering and process controls in containing radioactive material and reducing radiation exposure.

(b) Area monitoring in the workplace shall be routinely performed, as necessary, to identify and control potential sources of personnel exposure to radiation and/or radioactive material.

(c) Instruments used for monitoring and contamination control shall be:

(1) Periodically maintained and

calibrated on an established frequency of at least once per year;

(2) Appropriate for the type(s), levels, and energies of the radiation(s) encountered;

(3) Appropriate for existing environmental conditions; and

(4) Routinely tested for operability.

\section{$\$ 835.402$ Individual monitoring.}

(a) For the purpose of monitoring individual exposures to external radiation, personnel cosimetry shall be provided to and used by:

(1) Radiological workers who, under typical conditions, are likely to receive one or more of the following:

(i) An effective dose equivalent to the whole body of 0.1 rem $(0.001$ sievert $)$ or more in a year;

(ii) A shallow dose equivalent to the skin or to any extremity of 5 rems ( 0.05 sievert) or more in a year;

(iii) $\mathrm{A}$ lens of the eye dose equivalent of 1.5 rems ( 0.015 sievert) or more in a year;

(iv) $\mathrm{A}$ deep dose equivalent from external exposures to any organ or tissue other than the lens of the eye of 5 rems ( 0.05 sievert)

(2) Declared pregnant workers who are likely to receive from external sources a dose equivalent to the embryo/fetus in excess of 10 percent of the applicable limit in $\$ 835.206$;

(3) Minors and members of the public likely to receive, in 1 year, from external sources, a dose in excess of 50 percent of the applicable limits in $\S 835.207$ or $\$ 835.208$, respectively;

(4) Individuals entering a high or very high radiation area.

(b) Personnel external dosimetry programs shall be adequate to demonstrate compliance with $\$ 835.202$, including routine dosimeter calibration and conformance with the requirements of the DOE Laboratory Accreditation Program for Personnel Dosimetry,

(c) For the purpose of monitoring individual exposures to internal radiation, internal dose evaluation programs (including routine bioassay programs) shall be conducted for:

(1) Radiological workers who, under typical conditions, are likely to receive 0.1 rem $(0.001$ sievert) or more committed effective dose equivalent, and/or 5 rems ( 0.05 sievert) or more committed dose equivalent to any organ or tissue, from all occupational radionuclide intakes in a year:

(2) Declared pregnant workers likely to receive an intake resulting in a dose equivalent to the embryo/fetus in excess of 10 percent of the limit stated in $\S 835.206$; or

(3) Minors and members of the public who are likely to receive, in 1 year, an intake resulting in a committed effective dose equivalent in excess of 50 percent of the limits stated in $\S 835.207$ or $\$ 835.208$, respectively.

(d) Internal dose evaluation programs shall be adequate to demonstrate compliance with $\$ 835.202$.

\section{$\$ 835.403$ Area monitoring.}

(a) Measurements of radioactivity concentrations in the ambient air of the workplace shall be performed as follows:

(1) Air sampling shall be performed in occupied areas where, under typical conditions, an individual is likely to receive an annual intake of 2 percent or more of the specified ALI values. For a given radionuclide and lung retention class, the ALI is the product of the DAC listed in appendix A of this part and the constant $2.4 \times 10^{9} \mathrm{ml}$. Samples shall be taken as necessary to detect and evaluate the level or concentration of airborne radioactive material at work locations.

(2) Real-time air monitoring, using continuous air monitors as defined in $\$ 835.2$, shall be performed in normally occupied areas where an individual is likely to be exposed to a concentration of airborne radioactivity exceeding 1 $\mathrm{DAC}$ as specified in appendix $\mathrm{A}$ of this part or where there is a need to alert potentially exposed individuals to unexpected increases in airborne radioactivity levels.

(3) For the airborne radioactive material that could be encountered, real-time air monitors shall have alarm capability and sufficient sensitivity to alert potentially exposed individuals that immediate action is necessary in order to minimize or terminate inhalation exposures.

(b) Monitoring of radiation in the workplace shall be performed using stationary (area) or portable radiation instruments, or a combination thereof. The instruments shall be readily available and shall be capable of measuring ambient radiation dose rates for the purpose of controlling radiation exposures.

\section{$\$ 835.404$ Radioactive contamination control and monitoring.}

(a) Instruments and techniques used for radioactive contamination monitoring and control shall be 
adequate to ensure compliance with the requirements specified in this section.

(b) Appropriate controls shall be maintained and verified which prevent the inadvertent transfer of removable contamination to locations outside of radiological areas under normal operating conditions.

(c) Any area in which contamination levels exceed the values specified in appendix $D$ of this part shall be:

(1) Posted in accordance with $\$ 835.603$; and

(2) Controlled in a manner commensurate with the physical and chemical characteristics of the contaminant, the radionuclides present, and the fixed and removable contamination levels.

(d) Areas with fixed contamination exceeding the total radioactivity values specified in appendix $D$ of this part may be located outside of radiological areas provided the following conditions are met:

(1) Removable contamination levels are below the levels specified in appendix D of this part;

(2) Unrestricted access to the area is not likely to cause any individual to receive a total effective dose equivalent in excess of 0.1 rem $(0.001$ sievert) in a year;

(3) The area is routinely monitored;

(4) The area is clearly marked to alert personnel of the contaminated status:

(5) Appropriate administrative procedures are established and exercised to maintain control of these areas; and

(6) Dose rates do not exceed levels which would require posting in accordance with $\$ 835.603$.

(e) Entry control pursuant to $\$ 835.501$ and posting pursuant to $\$ 835.603$ are not required for areas with fixed contamination meeting the conditions of $\$ 835.404$ (d).

(f) Appropriate monitoring to detect and prevent the spread of contamination shall be performed by individuals exiting radiological areas established to control removable contamination and/or airborne radioactivity.

(g) Protective clothing shall be required for entry to areas in which removable contamination exists at levels exceeding those specified in appendix D to this part.

Subpart F - Entry Control
Program

$\$ 835.501$ Radiological areas.

(a) Personnel entry control shall be maintained for each radiological area. (b) The degree of control shall be commensurate with existing and potential radiological hazards within the area.

(c) One or more of the following methods shall be used to ensure control:

(1) Signs and barricades;

(2) Control devices on entrances;

(3) Conspicuous visual and/or.audible alarms;

(4) Locked entrance ways; or

(5) Administrative controls.

(d) Administrative procedures shall be written as necessary to demonstrate compliance with the provisions of this section. These administrative procedures shall include actions essential to ensure the effectiveness and operability of barricades, devices, alarms, and locks. Authorizations shall be required to perform specific work within the area and shall include specific radiation protection measures.

(e) No control(s) shall be installed at any radiological area exit that would prevent rapid evacuation of personnel under emergency conditions.

\section{$\$ 835.502$ High and very high radiation areas.}

(a) High radiation areas. One or more of the following features shall be used for each entrance or access point to a high radiation area where radiation levels exist such that an individual could exceed a deep dose equivalent to the whole body of $1 \mathrm{rem}(0.01$ sievert) in any one hour at 30 centimeters from the source or from any surface that the radiation penetrates:

(1) A control device that prevents entry to the area when high radiation levels exist or upon entry causes the radiation level to be reduced below that level defining a high radiation area;

(2) A device that functions automatically to prevent use or operation of the radiation source or field while personnel are in the area;

(3) A control device that energizes a conspicuous visible or audible alarm signal so that the individual entering the high radiation area and the supervisor of the activity are made aware of the entry;

(4) Entryways that are locked. During periods when access to the area is required, positive control over each entry is maintained;
(5) Continuous direct or electronic surveillance that is capable of preventing unauthorized entry;

(6) A control device that will automatically generate audible and visual alarm signals to alert personnel in the area before use or operation of the radiation source and in sufficient time to permit evacuation of the area or activation of a secondary control device that will prevent use or operation of the source.

(b) Very high radiation areas. In addition to the above requirements, additional measures shall be implemented to ensure individuals are not able to gain access to very high radiation areas when dose rates are in excess of the posting requirements of $\S 835.603(\mathrm{c})$.

(c) No control(s) shall be established in a high or very high radiation area that would prevent rapid evacuation of personnel.

\section{Subpart G -- Posting and Labeling}

$\$ 835.601$ General requirements.

(a) Working areas that require posting because of the presence, or potential presence, of radiation and/or radioactive material are delineated in the subsequent paragraphs of this section. Radioactive items or containers of radioactive materials, shall be individually labeled if adequate warning is not provided by control measures and required posting.

(b) DOE approved signs, labels, and radiation symbols shall be used to identify areas specified in this subpart.

(c) Required signs and labels shall have a yellow background. The radiation symbol shall be black or magenta.

(d) Signs required by this subpart shall be clear and conspicuousiy posted and may include radiological protection instructions.

(e) The posting requirements in this section may be modified to reflect the special considerations of DOE activities conducted at private residences. Such modifications shall provide the same level of protection to individuals as the existing provisions in this section.

\section{$\$ 835.602$ Controlled areas.}

(a) Each access point to a controlled 
area (as defined in $\$ 835.2$ ) shall be posted, identifying it as a controlled area, whenever radioactive material and/or radiation fields which would require posting under $\$ 835.603$ may be present in the area.

(b) Signs used for this purpose may be selected by the contractor to avoid conflict with local security requirements.

\subsection{Radiological areas.}

Each access point to a radiological area (as defined in $\$ 835.2$ ) shall be posted with conspicuous signs bearing the wording provided in this section.

(a) Radiation Area. The words "Caution, Radiation Area" shall be posted at any area accessible to individuals in which radiation levels could result in an individual receiving a deep dose equivalent in excess of $0.005 \mathrm{rem}$ ( 0.05 millisievert) in 1 hour at 30 centimeters from the source or from any surface that the radiation penetrates.

(b) High Radiation Area. The words "Danger, High Radiation Area" shall be posted at any area accessible to individuals in which radiation levels could result in an individual receiving a deep dose equivalent in excess of 0.1 rem (0.001 sievert) in 1 hour at 30 centimeters from the radiation source or from any surface that the radiation penetrates.

(c) Very High Radiation Area. The words "Grave Danger, Very High Radiation Area" shall be posted at any area accessible to individuals in which radiation levels could result in an individual receiving an absorbed dose in excess of 500 rads ( 5 grays) in one hour at 1 meter from the radiation source or from any surface that the radiation penetrates.

(d) Airborne Radioactivity Area. The words "Caution, Airborne

Radioactivity Area" shall be posted for any occupied area in which airborne radioactivity levels exceed, or are likely to exceed, 10 percent of the DAC value listed in appendix $A$ or appendix $\mathrm{C}$ of this part.

(e) Contamination Area. The words "Caution, Contamination Area" shall be posted where contamination levels exceed values listed in appendix $D$ of this part, but are less than or equal to 100 times those values.

(f) High Contamination Area. The words "Danger, High Contamination Area" shall be posted where contamination levels are greater than
100 times the values listed in appendix $\mathrm{D}$ of this part.

\section{Subpart H -- Records}

\section{\$835.701 General provisions.}

(a) Records shall be maintained to document compliance with this part and with radiation protection programs required by $\S 835.101$.

(b) Unless otherwise specified in this subpart, records shall be retained until final disposition is authorized by DOE.

\section{$\$ 835.702$ Individual monitoring records.}

(a) Records shall be maintained to document doses received by all individuals for whom monitoring was required pursuant to $\$ 835.402$ and doses received during planned special exposures, accidents, and emergency conditions.

(b) The results of individual external and internal dose measurements that are performed, but are not required by $\$ 835.402$, shall be recorded. Recording of the non-uniform shallow dose equivalent to the skin caused by contamination on the skin (see $\$ 835.205$ ) is not required if the dose is less than 2 percent of the limit specified for the skin in $\$ 835.202(a)(4)$.

(c) The records required by this section shall:

(1) Be sufficient to evaluate

compliance with $\$ 835.202$;

(2) Be sufficient to provide dose information necessary to complete reports required by subpart I of this part and by Departmental requirements for occurrence reporting and processing;

(3) Include the following quantities for external dose received during the year:

(i) The effective dose equivalent from external sources of radiation (deep dose equivalent may be used as effective dose equivalent for external exposure);

(ii) The lens of the eye dose equivalent;

(iii) The shallow dose equivalent to the skin; and

(iv) The shallow dose equivalent to the extremities.

(4) Include the following quantities for internal dose resulting from intakes received during the year:

(i) Committed effective dose equivalent;

(ii) Committed dose equivalent to any organ or tissue of concern; and (iii) Estimated intake and identity of radionuclides.

(5) Include the following quantities for the summation of the external and internal dose:

(i) Total effective dose equivalent in a year;

(ii) For any organ or tissue assigned an internal dose during the year, the sum of the deep dose equivalent from external exposures and the committed dose equivalent to that organ or tissue; and

(iii) Cumulative total effective dose equivalent received from external and internal sources while employed at the site or facility, since January 1, 1989.

(6) Include the dose equivalent to the embryo/fetus of a declared pregnant worker.

(d) Documentation of all occupational exposure received during the current year shall be obtained when demonstrating compliance with $\$ 835.202$ (a). In the absence of formal records of previous occupational exposure during the year, a written estimate signed by the individual may be accepted.

(e) Efforts shall be made to obtain records of prior years occupational internal and external exposure.

(f) The records specified in this section that are identified with a specific individual shall be readily available to that individual.

(g) Data necessary to allow future verification or reassessment of the recorded doses shall be recorded.

(h) All records required by this section shall be transferred to the DOE upon cessation of activities at the site that could cause exposure to individuals.

\section{$\$ 835.703$ Monitoring and workplace records.}

The following information shall be documented and maintained:

(a) Results of surveys for radiation and radioactive material in the workplace as required by $\$ 835.401$, $\$ 835.403$, and $\$ 835.404$;

(b) Results of surveys, measurements, and calculations used to determine individual occupational exposure from external and internal sources;

(c) Results of surveys for the release of material and equipment as required by $\$ 835.1101(d)$; and

(d) Results of maintenance and calibration performed on:

(1) Instruments used for area monitoring and contamination control 
as required by $\$ 835.401$; and

(2) Devices used for individual monitoring as required by $\$ 835.401$ and $\$ 835.402$.

\section{$\$ 835.704$ Administrative records.}

(a) Training records shall be maintained, as necessary, to demonstrate compliance with $\$ 835.901, \S 835.902$, and $\$ 835.903$.

(b) Actions taken to maintain occupational exposures as low as reasonably achievable, including the actions required for this purpose by $\$ 835.101$, as well as facility design and control actions required by $\$ 835.1001, \$ 835.1002$, and $\$ 835.1003$, shall be documented.

(c) Records shall be maintained to document the results of internal audits and other reviews of program content and implementation

(d) Written declarations of pregnancy shall be maintained.

(e) Changes in equipment, techniques, and procedures used for monitoring in the workplace shall be documented.

\section{Subpart I - Reports to Individuals}

\section{$\$ 835.801$ Reports to Individuals.}

(a) Radiation exposure data for individuals monitored in accordance with $\$ 835.402$ shall be reported as specified in this section. The information shall include the data required under \$835.702(c). Each notification and report shall be in writing and include: the $\overline{D O E}$ site or facility name, the name of the individual, and the individual's social security number or employee number.

(b) Upon the request from an individual terminating employment, records of exposure shall be provided to that individual as soon as the data are available, but not later than 90 days after termination. A written estimate of the radiation dose received by that employee based on available information shall be provided at the time of termination, if requested.

(c) Each DOE- or DOE-contractoroperated site or facility shall, on an annual basis, provide a radiation dose report to each individual monitored during the year at that site or facility in accordance with $\$ 835.402$.

(d) Detailed information concerning any individual's exposure shall be made available to the individual upon request of that individual, consistent with the provisions of the Privacy Act (5 U.S.C. 552a).

(e) When a DOE contractor is required to report to the Department, pursuant to Departmental requirements for occurrence reporting and processing, any exposure of an individual to radiation and/or radioactive material, or planned special exposure in accordance with $\$ 835.204(\mathrm{e})$, the contractor shall also provide that individual with a report on his or her exposure data included therein. Such report shall be transmitted at a time not later than the transmittal to the Department.

\section{Subpart J -- Radiation Safety Training}

\section{$\$ 835.901$ General employees.}

(a) All general employees shall be trained in radiation safety prior to receiving occupational exposure during access to controlled areas at a DOE site or facility. Allowance may be made for previous DOE training on generic radiation safety topics (i.e., those not specific to a site or facility), provided the training was received at another DOE site or facility within the past 2 years. Documentation of the previous training shall clearly identify the individual's name, date of training. topics covered, and name of the certifying individual. The knowledge of radiation safety possessed by general employees shall be verified by examination.

(b) Retraining shall be provided when there is a significant change to radiation protection policies and procedures that affect general employees and shall be conducted at intervals not to exceed 2 years.

\section{$\$ 835.902$ Radiological workers.}

Radiological worker training programs and retraining shall be established and conducted at intervals not to exceed 2 years to familiarize the worker with the fundamentals of radiation protection and the ALARA process. Training shall include both classroom and applied training.
Training shall either precede assignment as a radiological worker or be concurrent with assignment as a radiological worker if the worker is accompanied by and under the direct supervision of a trained radiological worker. Radiological worker training not specific to a given site or facility may be waived provided that: This training has been received at another DOE site or facility within the past 2 years; there is provision of proof-of-training in the form of a certification document containing the individual's name, date of training, and specific topics covered; and an appropriate official has certified the training of the individual. The knowledge of radiation safety possessed by radiological workers shall be verified by examination prior to an unsupervised assignment. The training shall include procedures specific to an individual's job assignment. The level of training is to be commensurate with each worker's assignment.

\section{$\S 835.903$ Radiological control technicians.}

Training and retraining programs for radiological control technicians shall be established and conducted at intervals not to exceed 2 years to familiarize technicians with the fundamentals of radiation protection and the proper procedures for maintaining exposures ALARA. This program shall include both classroom and applied training. The training shall either precede performance of tasks assigned to radiological control technicians or be concurrent with such task assignments if the individual is accompanied by and under the direct supervision of a trained individual. The required level of knowledge of radiation safety possessed by radiological control technicians shall be verified by examination to include demonstration prior to any unsupervised work assignment. The training program shall include procedures specific to the site or facility where the technician is assigned. The level of training shall be commensurate with the technician's assignment. Allowance may be made for previous DOE training on generic radiation safety topics (i.e., those not specific to a site or facility), provided the training was received within the past 2 years. Documentation of the previous training shall clearly identify the individual's name, date of training, topics covered, and name of the 
certifying individual.

\section{Subpart K -- Design and Control}

$\$ 835.1001$ Design and control.

(a) Measures shall be taken to maintain radiation exposure in controlled areas as low as is reasonably achievable through facility and equipment design and administrative control. The primary methods used shall be physical design features (e.g., confinement, ventilation, remote handling, and shielding). Administrative controls and procedural requirements shall be employed only as supplemental methods to control radiation exposure.

(b) For specific activities where use of physical design features are demonstrated to be impractical, administrative controls and procedural requirements shall be used to maintain radiation exposures ALARA.

\section{$\$ 835.1002$ Facility design and modifications.}

During the design of new facilities or modification of old facilities, the following objectives shall be adopted:

(a) Optimization methods shall be used to assure that occupational exposure is maintained ALARA in developing and justifying facility design and physical controls.

(b) The design objective for controlling personnel exposure from external sources of radiation in areas of continuous occupational occupancy (2000 hours per year) shall be to maintain exposure levels below an average of 0.5 mrem ( 5 microsieverts) per hour and as far below this average as is reasonably achievable. The design objectives for exposure rates for potential exposure to a radiological worker where occupancy differs from the above shall be ALARA and shall not exceed 20 percent of the applicable standards in $\$ 835.202$.

(c) Regarding the control of airborne radioactive material, the design objective shall be, under normal conditions, to avoid releases to the workplace atmosphere and in any situation, to control the inhalation of such material by workers to levels that are ALARA; confinement and ventilation shall normally be used.

(d) The design or modification of a facility and the selection of materials shall include features that facilitate operations, maintenance, decontamination, and decommissioning.

\section{$\S 835.1003$ Control procedures.}

(a) During routine operations, the combination of design features and administrative control procedures shall provide that:

(1) The anticipated magnitude of the total effective dose equivalent shall not exceed 5 rems ( 0.05 sievert) in a year;

(2) The anticipated magnitude of the committed dose equivalent to any organ or tissue, plus any deep dose equivalent from external exposure, shall not exceed 50 rems ( 0.5 sievert) in a year; and

(3) Exposure levels are as low as reasonably achievable.

(b) Compliance with the requirements in paragraph (a) of this section shall be demonstrated by appropriate monitoring pursuant to the provisions of subpart $E$ of this part.

\section{Subpart L -- Releases of Materials and Equipment From Radiological Areas}

$\$ 835.1101$ Releases of materials and equipment from radiological areas.

The following requirements apply for the release of materials and equipment from radiological areas for use in controlled areas:

(a) In radiological areas established to control surface or airborne radioactive material, material and equipment shall be treated as radioactive material and shall not be released from radiological areas to controlled areas if either of the following conditions exist:

(1) Measurements of accessible surfaces show that either the total or removable contamination levels exceed the values specified in appendix D to this part; or

(2) Prior use suggests that the contamination levels on inaccessible surfaces are likely to exceed the values specified in appendix $D$ to this part.

(b) Material and equipment exceeding the total or removable contamination leveis specified in appendix $D$ to this part may be conditionally released for movement on-site from one radiological area for immediate placement in another radiological area only if appropriate monitoring and control procedures are established and exercised.

(c) Material and equipment with fixed contamination levels that exceed the limits specified in appendix $D$ to this part may be released for use in controlled areas outside of the radiological areas with the following provisions:

(1) Removable contamination levels are below the level specified in appendix $\mathrm{D}$ of this part; and

(2) Materials shall be routinely monitored, clearly labeled, or tagged to alert personnel of the contaminated status; appropriate administrative procedures shall be established and exercised to maintain control of these items.

(d) The records for release of material and equipment shall describe the property, date on which the release survey was performed, identity of the individual who performed the survey, type and identification number of the survey instrument used, and results of the survey.

\section{Subpart M -- [Reserved] \\ Subpart N - Accidents and Emergencies}

\section{$\$ 835.1301$ General provisions.}

(a) A general employee whose occupational exposure has exceeded any of the limits specified in $\$ 835.202$ or $\$ 835.205$ may be permitted to return to work in radiological areas during the current year providing that all of the following conditions are met:

(1) Approval is first obtained from the contractor management and the Head of the responsible DOE field organization;

(2) The individual receives counseling from radiological protection and medical personnel regarding the consequences of receiving additional occupational exposure during the year; and

(3) The affected employee agrees to retum to radiological work.

(b) All exposures exceeding the limits specified in $\$ 835.202$ or $\$ 835.205$ shall be recorded in the affected individual's occupational exposure file and reported to the DOE in accordance with Departmental requirements for occurrence reporting and processing.

(c) When the conditions under which the emergency or accident exposures were received have been eliminated. 
operating management shall notify the Head of the responsible DOE field organization.

(d) Operations after an emergency or accidental exposure in excess of the limits specified in $\$ 835.202$ or $\$ 835.205$ may be resumed only with the approval of the DOE.

(e) Occurrence reports to DOE regarding emergencies and/or accidents shall be prepared and submitted in accordance with Departmental requirements for occurrence reporting and processing.

\section{$\$ 835.1302$ Emergency exposure situations.}

(a) The risk of injury to those individuals involved in rescue and recovery operations shall be minimized.

(b) Operating management shall weigh actual and potential risks to rescue and recover individuals against the benefits to be gained.

(c) Rescue action that might involve substantial personal risk shall be performed by volunteers.

(d) The dose limits for individuals performing these operations are as follows:

\section{GUIDELINES FOR CONTROL OF EMERGENCY EXPOSURES}

\begin{tabular}{|c|c|c|}
\hline $\begin{array}{l}\text { Dose } \\
\text { limit } \\
\text { (whole } \\
\text { body) }\end{array}$ & $\begin{array}{c}\text { Activity } \\
\text { Performed }\end{array}$ & Conditions \\
\hline $5 \mathrm{rem}$ & All & \\
\hline $10 \mathrm{rem}$ & $\begin{array}{l}\text { Protecting major } \\
\text { property. }\end{array}$ & $\begin{array}{r}\text { Where } \\
\text { lower dose } \\
\text { limit not } \\
\text { practicable. }\end{array}$ \\
\hline $25 \mathrm{rem}$ & $\begin{array}{l}\text { Lifesaving or } \\
\text { protection of } \\
\text { large } \\
\text { populations }\end{array}$ & $\begin{array}{r}\text { Where } \\
\text { lower dose } \\
\text { limit not } \\
\text { practicable. }\end{array}$ \\
\hline$>25$ rem & $\begin{array}{l}\text { Lifesaving or } \\
\text { protection of } \\
\text { large } \\
\text { populations }\end{array}$ & $\begin{array}{r}\text { Only on a } \\
\text { voluntary } \\
\text { basis to } \\
\text { personnel } \\
\text { fully aware } \\
\text { of the risks } \\
\text { involved. }\end{array}$ \\
\hline
\end{tabular}

'The lens of the eye dose limit is three times the listed values. The shallow dose limit to the skin of the whole body and the extremities is ten times the listed values. These doses are in addition to and accounted for separately from the doses received under the limits in $\$ 835.202$ and $\$ 835.205$.

(e) Each individual selected shall be trained in accordance with $\$ 835.902$ and briefed beforehand of the known or anticipated hazards to which the individual will be subjected.

\subsection{3 [Reserved]}

\subsection{Nuclear accident} dosimetry.

(a) Installations possessing sufficient quantities of fissile material to potentially constitute a critical mass, such that the excessive exposure of personnel to radiation from a nuclear accident is possible, shall provide nuclear accident dosimetry for those personnel.

(b) Nuclear accident dosimetry shall include the following:

(1) A method to conduct initial screening of personnel involved in a nuclear accident to determine whether significant exposures to radiation occurred;

(2) Methods and equipment for analysis of biological materials;

(3) A system of fixed nuclear accident dosimeter units; and

(4) Personal nuclear accident dosimeters worn by all personnel who enter locations in which installed criticality alarm systems are required. 


\section{Appendix A to Part 835 - Derived Air Concentrations (DAC) for Controlling Radiation Exposure to Workers at DOE Facilities}

The derived air concentrations (DAC) for limiting radiation exposures through inhalation of radionnclides by workers are listed in this appendix. The values are based on either a stochastic (committed effective dose equivalent) dose limit of 5 rems $(0.05$ Sv) or a non-stochastic (organ) dose limit of 50 rems $(0.5 \mathrm{~Sv})$ per year, whichever is more limiting.

Note: the 15 rems $[0.15 \mathrm{~Sv}]$ dose limit for the lens of the eye does not appear as a critical organ dose limit..

The columns in this appendix contain the following information: (1) Radionuclide; (2) inhaled air DAC for lung retention class $D, W$, and $Y$ in units of $\mu \mathrm{Ci} / \mathrm{ml}$; (3) inhaled air DAC for lung retention class $D, W$, and $Y$ in units of $B q / \mathrm{m}^{3}$; and (4) an indication of whether or not the DAC for each class is controlled by the stochastic (effective dose equivalent) or nonstochastic (issue) dose. The classes $D, W$, and $Y$ bave been established to describe the clearance of inhaled radionuclides from the lung. This classification refers to the approximate length of retention in the pulmonary region. Thus, the range of half-times for retention in the pulmonary region is less than 10 days for class $D$ (days), from 10 to 100 days for class $W$ (weeks), and greater than 100 days for class $Y$ (years). The DACs are listed by radionuclide, in order of increasing atomic mass, and are based on the assumption that the particle size distribution of the inhaled material is unknown and an assumed particle size distribution of $1 \mu \mathrm{m}$ is used. For situations where the particle size distribution is kaswn to differ significantly from $1 \mu \mathrm{m}$, appropriate corrections can be made to both the estimated dose to workers and the DACs.

\begin{tabular}{|c|c|c|c|c|c|c|c|}
\hline \multirow{3}{*}{ Radionuclide } & \multirow{2}{*}{\multicolumn{3}{|c|}{$\frac{\text { Inhaled air-lung retention class } 3}{\mu \mathrm{CV} / \mathrm{m}}$}} & \multirow{2}{*}{\multicolumn{3}{|c|}{$\frac{\text { Inthaled airfung retention class } 3}{\text { Bq/m } 3}$}} & \multirow{3}{*}{$\begin{array}{r}\begin{array}{r}\text { Stochastic } \\
\text { or organ ! }\end{array} \\
\text { ( D/W/ Y }\end{array}$} \\
\hline & & & & & & & \\
\hline & D & $w$ & $\mathbf{Y}$ & $\mathbf{D}$ & $w$ & $\mathbf{Y}$ & \\
\hline 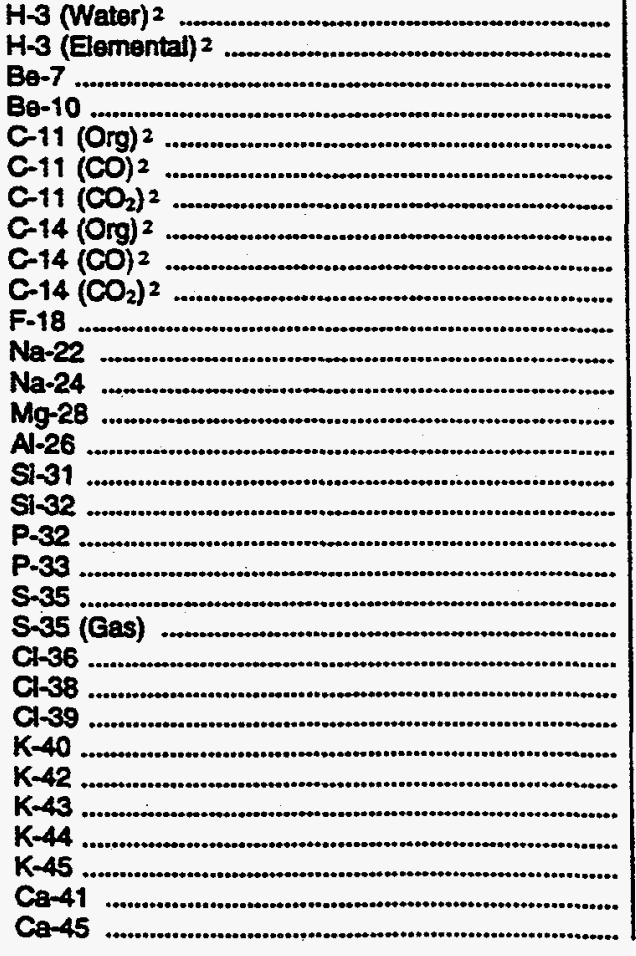 & $\begin{array}{l}\text { 2.E-05 } \\
5 . E-01 \\
- \\
2 . E-04 \\
5 . E-04 \\
3 . E-04 \\
1 . E-06 \\
7 . E-04 \\
9 . E-05 \\
3 . E-05 \\
3 . E-07 \\
2 . E-06 \\
7 . E-07 \\
3 . E-08 \\
1 . E-05 \\
1 . E-07 \\
4 . E-07 \\
3 . E-06 \\
7 . E-06 \\
1 . E-06 \\
2 . E-05 \\
2 . E-05 \\
2 . E-07 \\
2 . E-06 \\
4 . E-06 \\
3 . E-05 \\
5 . E-05 \\
- \\
-\end{array}$ & $\begin{array}{c}2 . E-05 \\
5 . E-01 \\
9 . E-06 \\
6 . E-08 \\
2 . E-04 \\
5 . E-04 \\
3 . E-04 \\
1 . E-06 \\
7 . E-04 \\
9 . E-05 \\
4 . E-05 \\
- \\
- \\
5 . E-07 \\
3 . E-08 \\
1 . E-05 \\
5 . E-08 \\
2 . E-07 \\
1 . E-06 \\
9 . E-07 \\
6 . E-06 \\
1 . E-07 \\
2 . E-05 \\
2 . E-05 \\
- \\
- \\
- \\
- \\
2 . E-06 \\
3 . E-07\end{array}$ & 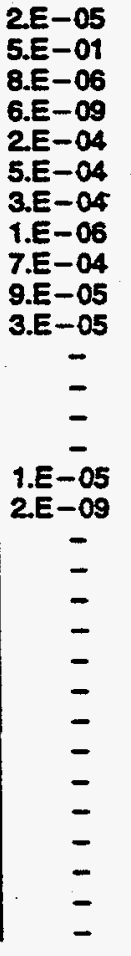 & $\begin{array}{r}8 . E+05 \\
2 . E+10 \\
- \\
6 . E+06 \\
2 . E+07 \\
1 . E+07 \\
4 . E+07 \\
3 . E+07 \\
3 . E+06 \\
1 . E+06 \\
1 . E+04 \\
8 . E+04 \\
3 . E+04 \\
1 . E+03 \\
4 . E+05 \\
4 . E+03 \\
1 . E+04 \\
1 . E+05 \\
3 . E+05 \\
- \\
4 . E+04 \\
6 . E+05 \\
6 . E+05 \\
6 . E+03 \\
7 . E+04 \\
1 . E+05 \\
1 . E+06 \\
2 . E+06 \\
- \\
-\end{array}$ & $\begin{array}{r}8 . E+05 \\
2 . E+10 \\
3 . E+05 \\
2 . E+03 \\
6 . E+06 \\
2 . E+07 \\
1 . E+07 \\
4 . E+04 \\
3 . E+07 \\
3 . E+06 \\
1 . E+06 \\
- \\
2 . E+04 \\
1 . E+03 \\
5 . E+05 \\
2 . E+03 \\
6 . E+03 \\
4 . E+04 \\
3 . E+04 \\
2 . E+05 \\
4 . E+03 \\
7 . E+05 \\
9 . E+05 \\
- \\
= \\
- \\
- \\
6 . E+04 \\
1 . E+04\end{array}$ & $\begin{array}{r}8 . E+05 \\
2 . E+10 \\
3 . E+05 \\
2 . E+02 \\
6 . E+06 \\
2 . E+07 \\
1 . E+07 \\
4 . E+07 \\
3 . E+07 \\
3 . E+06 \\
1 . E+06 \\
- \\
- \\
- \\
4 . E+05 \\
8 . E+01 \\
- \\
- \\
- \\
- \\
= \\
- \\
= \\
- \\
- \\
-\end{array}$ & 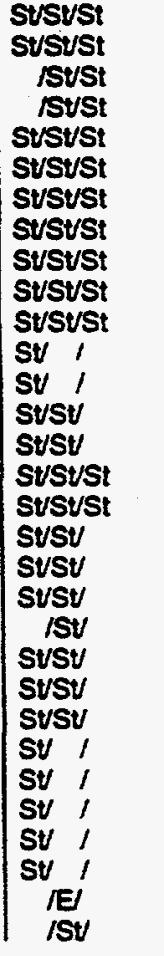 \\
\hline
\end{tabular}


65496 Federal Register / Vol. 58, No. 238 / Tuesday, December 14, 1993 / Rules and Regulations

\begin{tabular}{|c|c|c|c|c|c|c|c|}
\hline \multirow{3}{*}{ Radionuclide } & \multirow{2}{*}{\multicolumn{3}{|c|}{$\frac{\text { Inhaled air-lung retention class } 3}{\mu \mathrm{C} / \mathrm{ml}}$}} & \multirow{2}{*}{\multicolumn{3}{|c|}{$\frac{\text { Inhaled air-lung retention class } 3}{\mathrm{~Bq} / \mathrm{m}^{3}}$}} & \multirow{3}{*}{$\begin{array}{l}\text { Stochastic } \\
\text { or organ I }\end{array}$} \\
\hline & & & & & & & \\
\hline & D & $w$ & $Y$ & D & $w$ & $\mathbf{Y}$ & \\
\hline 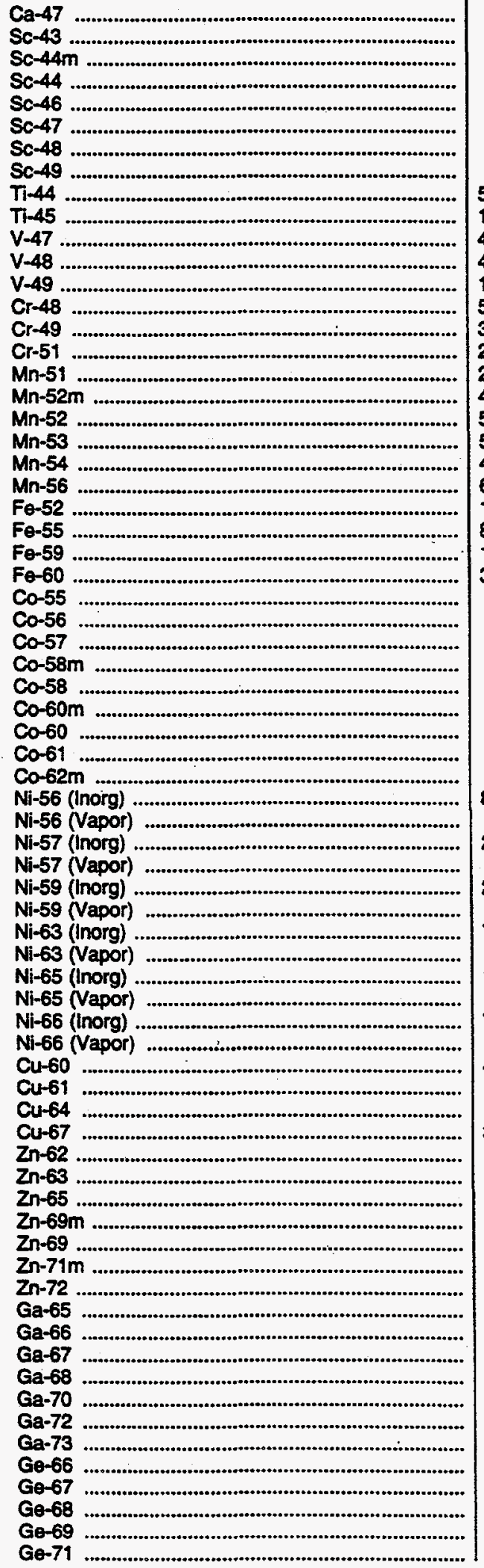 & $\begin{array}{c}- \\
- \\
- \\
- \\
- \\
- \\
- \\
5 . E-09 \\
1 . E-05 \\
4 . E-05 \\
4 . E-07 \\
1 . E-05 \\
5 . E-06 \\
3 . E-05 \\
2 . E-05 \\
2 . E-05 \\
4 . E-05 \\
5 . E-07 \\
5 . E-06 \\
4 . E-07 \\
6 . E-06 \\
1 . E-06 \\
8 . E-07 \\
1 . E-07 \\
3 . E-09 \\
- \\
- \\
- \\
\text { - }\end{array}$ & $\begin{array}{r}4 . E-07 \\
- \\
- \\
- \\
- \\
- \\
- \\
1 . E-08 \\
1 . E-05 \\
4 . E-05 \\
3 . E-07 \\
7 . E-06 \\
3 . E-06 \\
4 . E-05 \\
1 . E-05 \\
2 . E-05 \\
4 . E-05 \\
4 . E-07 \\
5 . E-06 \\
3 . E-07 \\
9 . E-06 \\
1 . E-06 \\
2 . E-06 \\
2 . E-07 \\
8 . E-09 \\
1 . E-06 \\
1 . E-07 \\
1 . E-06 \\
4 . E-05 \\
5 . E-07 \\
2 . E-03 \\
7 . E-08 \\
3 . E-05 \\
7 . E-05 \\
5 . E-07 \\
5 . E-07 \\
1 . E-06 \\
3 . E-06 \\
3 . E-06 \\
8 . E-07 \\
1 . E-06 \\
3 . E-07 \\
1 . E-05 \\
7 . E-06 \\
3 . E-07 \\
1 . E-06 \\
5 . E-05 \\
2 . E-05 \\
1 . E-05 \\
2 . E-06 \\
4 . E-05 \\
\text { 1.E-06 } \\
2 . E-05 \\
\text { 8.E-05 } \\
1 . E-06 \\
6 . E-06 \\
8 . E-06 \\
4 . E-05 \\
4 . E-08 \\
3 . E-06 \\
2 . E-05\end{array}$ & 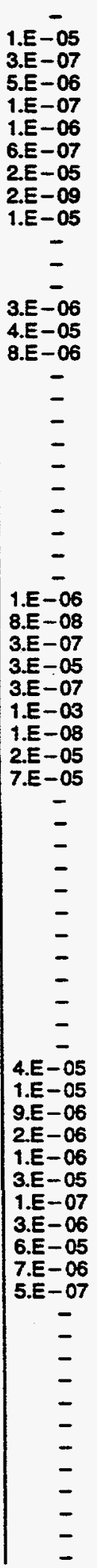 & 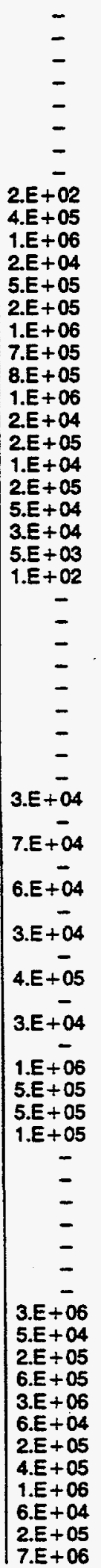 & 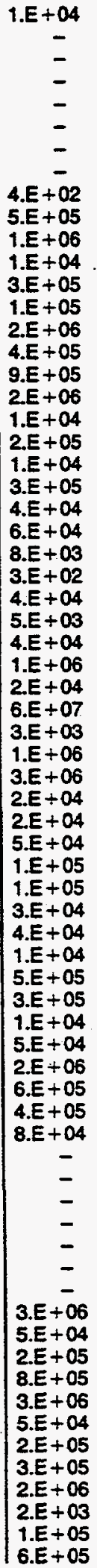 & 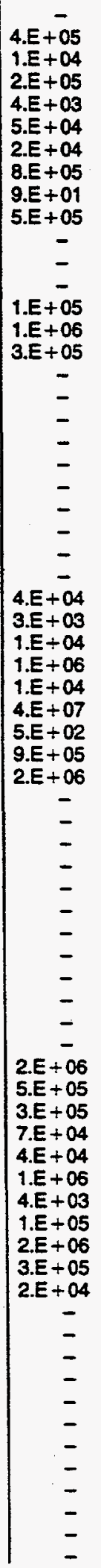 & 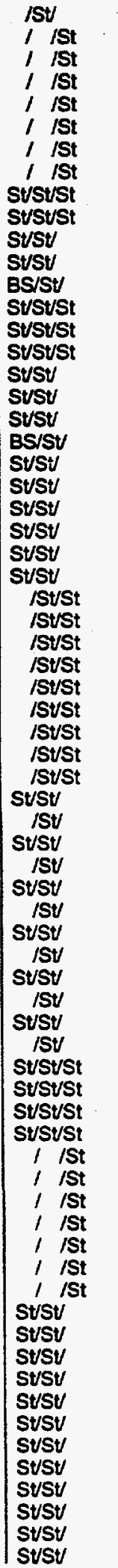 \\
\hline
\end{tabular}


Federal Register / Vol. 58, No. 238 / Tuesday, December 14, 1993 / Rules and Regulations

65497

\begin{tabular}{|c|c|c|c|c|c|c|c|}
\hline \multirow{3}{*}{ Radionuctide } & \multirow{2}{*}{\multicolumn{3}{|c|}{$\frac{\text { Inhaled air-tung retention class } 3}{\mu \mathrm{C} / \mathrm{mi}}$}} & \multicolumn{3}{|c|}{ Inhaled air-lung retention class 3} & \multirow{3}{*}{$\begin{array}{l}\begin{array}{l}\text { Stochastic } \\
\text { or organ } 1\end{array} \\
(D / W / Y)\end{array}$} \\
\hline & & & & \multicolumn{3}{|c|}{$\mathrm{Bq} / \mathrm{m}^{3}$} & \\
\hline & D & $w$ & $\mathbf{Y}$ & D & $w$ & $Y$ & \\
\hline 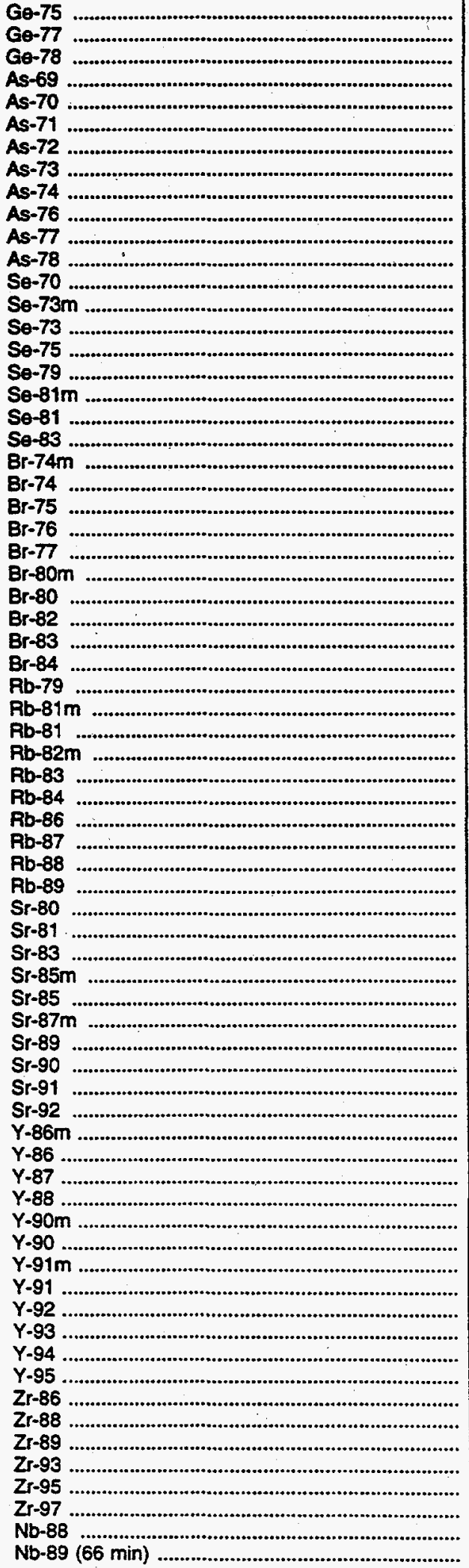 & $\begin{array}{r}\text { 3.E-05 } \\
4 . E-06 \\
9 . E-06 \\
- \\
- \\
- \\
- \\
- \\
- \\
- \\
- \\
1 . E-05 \\
6 . E-05 \\
6 . E-06 \\
3 . E-07 \\
3 . E-07 \\
3 . E-05 \\
9 . E-05 \\
5 . E-05 \\
1 . E-05 \\
3 . E-05 \\
2 . E-05 \\
2 . E-06 \\
1 . E-05 \\
7 . E-06 \\
\text { 8.E-05 } \\
2 . E-06 \\
3 . E-05 \\
2 . E-05 \\
5 . E-05 \\
1 . E-04 \\
2 . E-05 \\
7 . E-06 \\
4 . E-07 \\
3 . E-07 \\
3 . E-07 \\
6 . E-07 \\
3 . E-05 \\
6 . E-05 \\
5 . E-06 \\
3 . E-05 \\
3 . E-06 \\
3 . E-04 \\
1 . E-06 \\
5 . E-05 \\
3 . E-07 \\
8 . E-09 \\
2 . E-06 \\
4 . E-06 \\
- \\
2 . E-06 \\
9 . E-08 \\
2 . E-06 \\
3 . E-09 \\
6 . E-08 \\
8 . E-07 \\
- \\
- \\
- \\
-\end{array}$ & 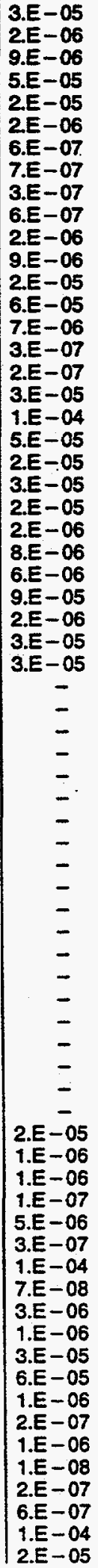 & 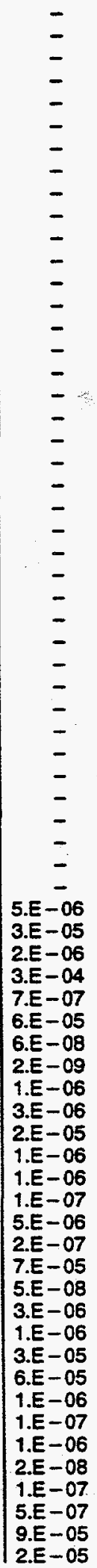 & 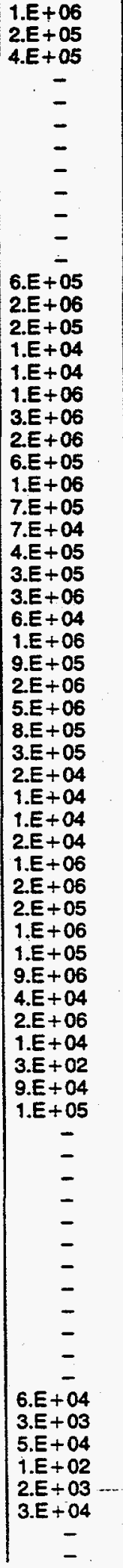 & 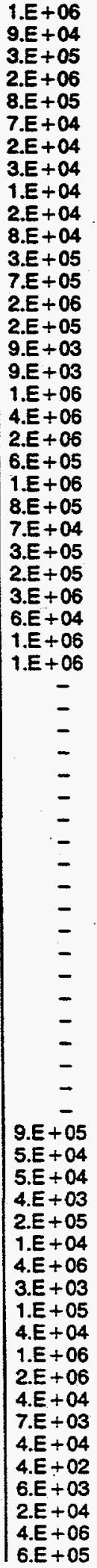 & 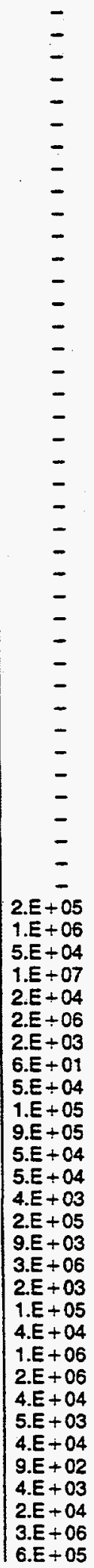 & 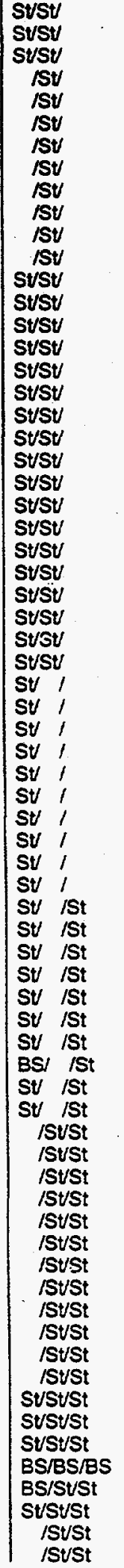 \\
\hline
\end{tabular}


65498 Federal Register / Vol. 58, No. 238 / Tuesday, December 14, 1993 / Rules and Regulations

\begin{tabular}{|c|c|c|c|c|c|c|c|}
\hline \multirow{3}{*}{ Radionuclide } & \multicolumn{3}{|c|}{ Inhaled air-lung retention class a } & \multicolumn{3}{|c|}{ Inhaled air-lung retention class 3} & \multirow{3}{*}{$\begin{array}{c}\begin{array}{c}\text { Stochastic } \\
\text { or organ } 1\end{array} \\
\text { (D/W/Y) }\end{array}$} \\
\hline & \multicolumn{3}{|c|}{$\mu \mathrm{Cl} / \mathrm{ml}-$} & \multicolumn{3}{|c|}{$\mathrm{Bq} / \mathrm{m}^{3}$} & \\
\hline & D & $\mathbf{w}$ & $\mathbf{Y}$ & D & $w$ & $\mathbf{Y}$ & \\
\hline 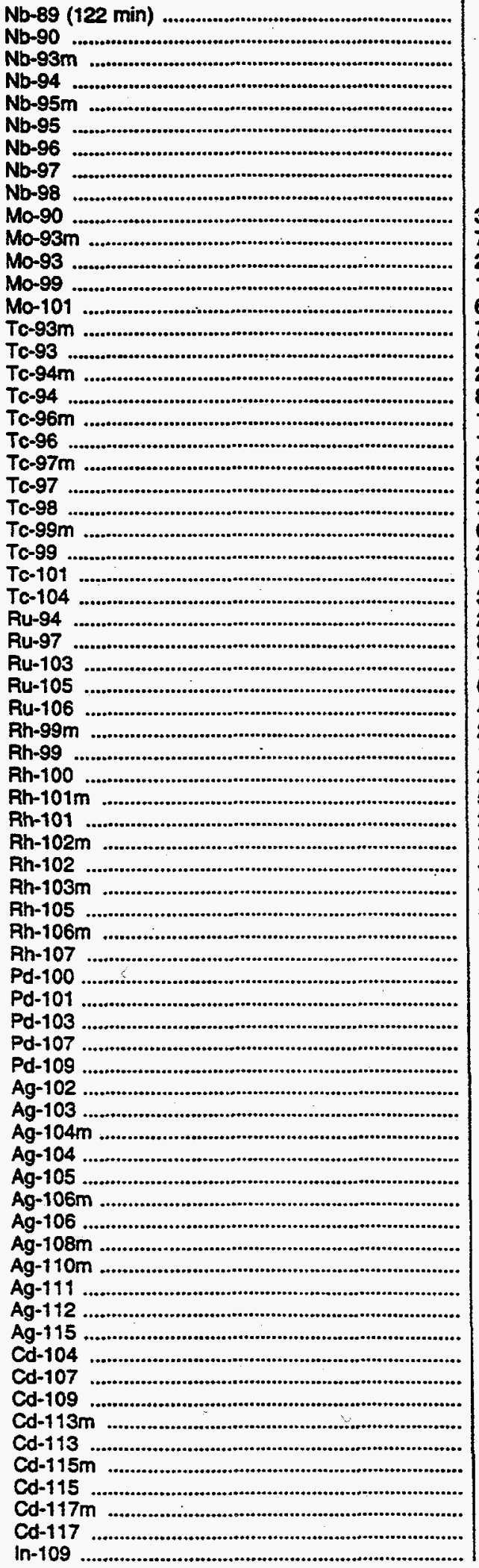 & 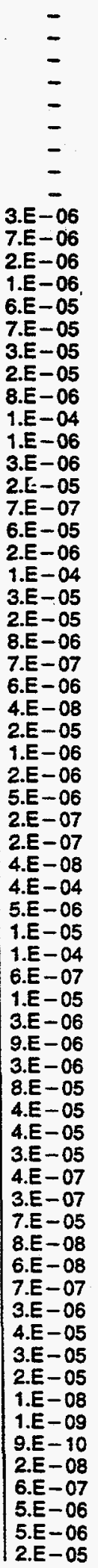 & $\begin{array}{r}8 . E-06 \\
1 . E-06 \\
5 . E-07 \\
8 . E-08 \\
1 . E-06 \\
5 . E-07 \\
1 . E-06 \\
3 . E-05 \\
2 . E-05 \\
- \\
- \\
- \\
- \\
1 . E-04 \\
4 . E-05 \\
2 . E-05 \\
1 . E-05 \\
1 . E-04 \\
9 . E-07 \\
5 . E-07 \\
2 . E-06 \\
1 . E-07 \\
1 . E-04 \\
3 . E-07 \\
2 . E-04 \\
4 . E-05 \\
3 . E-05 \\
5 . E-06 \\
4 . E-07 \\
6 . E-06 \\
2 . E-08 \\
3 . E-05 \\
9 . E-07 \\
2 . E-06 \\
3 . E-06 \\
3 . E-07 \\
2 . E-07 \\
7 . E-08 \\
5 . E-04 \\
3 . E-06 \\
1 . E-05 \\
1 . E-04 \\
5 . E-07 \\
1 . E-05 \\
2 . E-06 \\
3 . E-06 \\
2 . E-06 \\
9 . E-05 \\
6 . E-05 \\
5 . E-05 \\
6 . E-05 \\
7 . E-07 \\
4 . E-07 \\
8 . E-05 \\
1 . E-07 \\
8 . E-08 \\
4 . E-07 \\
4 . E-06 \\
4 . E-05 \\
5 . E-05 \\
2 . E-05 \\
5 . E-08 \\
4 . E-09 \\
3 . E-09 \\
5 . E-08 \\
3 . E-05 \\
\end{array}$ & 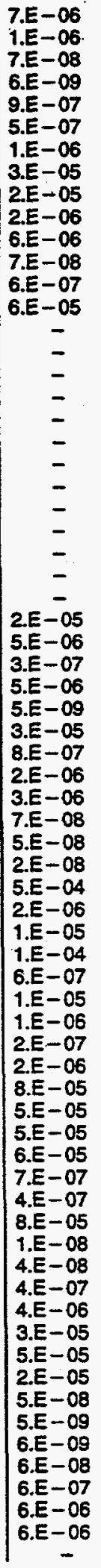 & 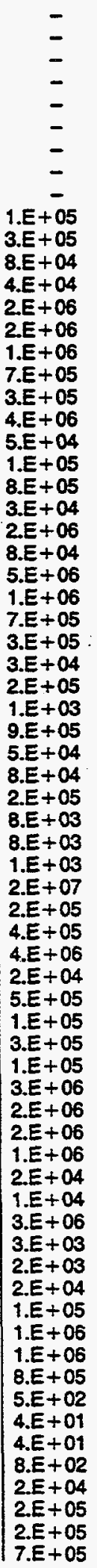 & 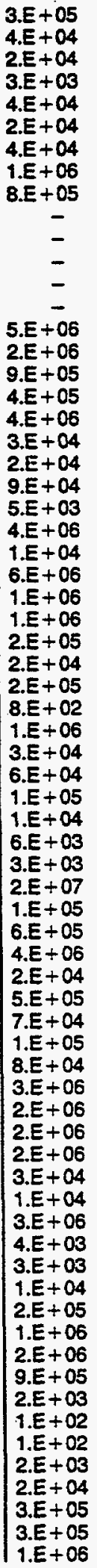 & 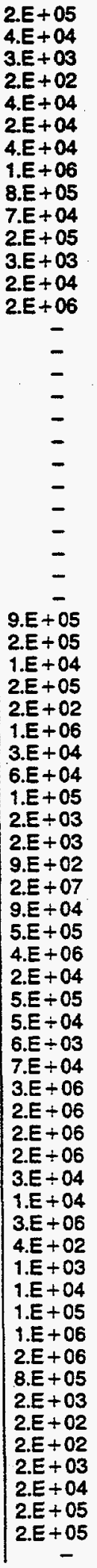 & 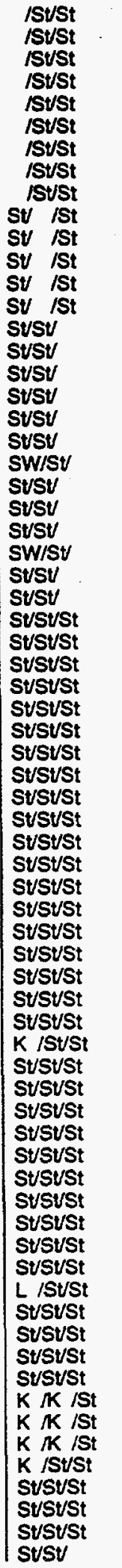 \\
\hline
\end{tabular}


Federal Register / Vol. 58, No. 238 / Tuesday, December 14, 1993 / Rules and Regulations

\begin{tabular}{|c|c|c|c|c|c|c|c|}
\hline \multirow{3}{*}{ Radionuclide } & \multicolumn{3}{|c|}{ Inhaled air-lung retention class 3} & \multicolumn{3}{|c|}{ Inhaled air-lung retention class 3} & \multirow{3}{*}{$\begin{array}{l}\begin{array}{l}\text { Stochastic } \\
\text { or organ } 1\end{array} \\
(\mathrm{D} / \mathrm{W} / \mathrm{Y})\end{array}$} \\
\hline & \multicolumn{3}{|c|}{$\mu \mathrm{Ci} / \mathrm{m}$} & \multicolumn{3}{|c|}{$\mathrm{Bq} / \mathrm{m}^{3}$} & \\
\hline & D & $\mathbf{W}$ & $Y$ & D & $w$ & $\mathbf{Y}$ & \\
\hline 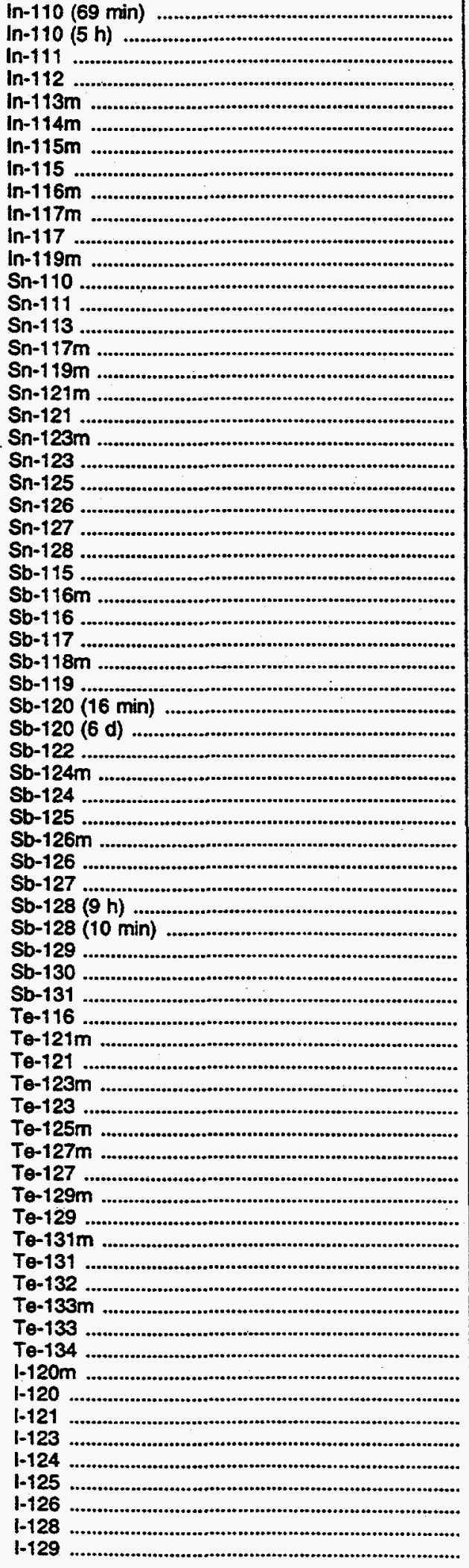 & 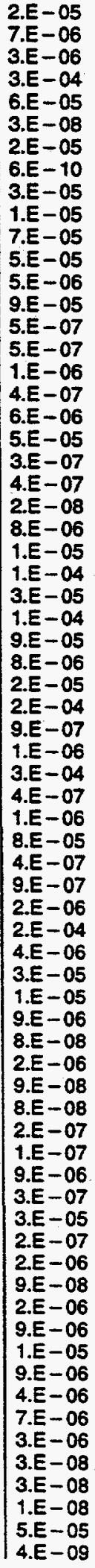 & 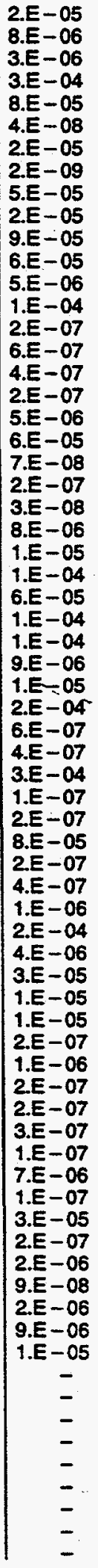 & 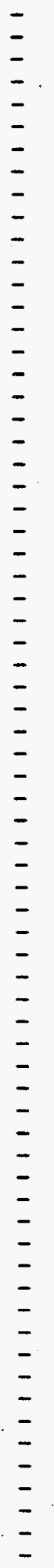 & 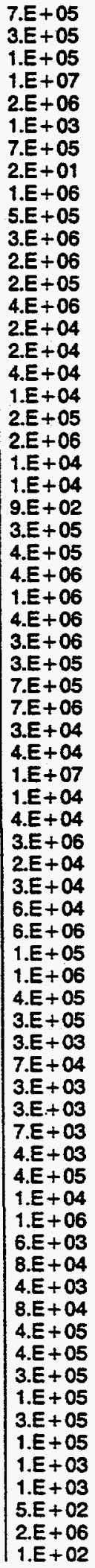 & 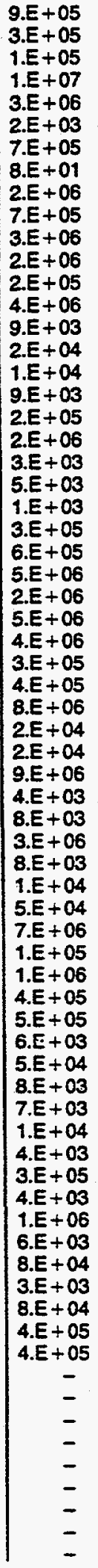 & 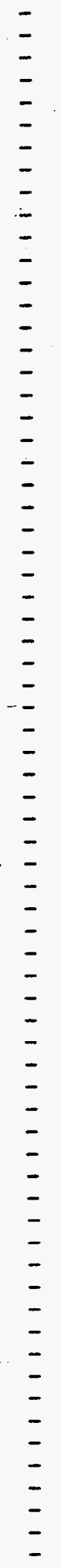 & 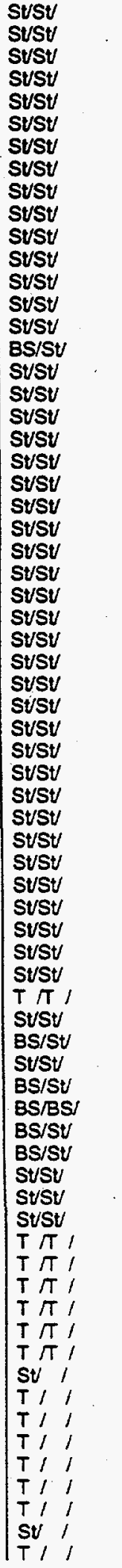 \\
\hline
\end{tabular}


65500 Federal Register / Vol. 58, No. 238 / Tuesday, December 14, 1993 / Rules and Regulations

\begin{tabular}{|c|c|c|c|c|c|c|c|}
\hline \multirow{3}{*}{ Radionuclide } & \multirow{2}{*}{\multicolumn{3}{|c|}{$\frac{\text { Inhaled air-lung retention class } 3}{\mu \mathrm{C} / \mathrm{ml}}$}} & \multicolumn{3}{|c|}{ Inhaled air-lung retention class 3} & \multirow{3}{*}{$\begin{array}{l}\begin{array}{c}\text { Stochastic } \\
\text { or organ I }\end{array} \\
(D / W / Y)\end{array}$} \\
\hline & & & & \multicolumn{3}{|c|}{$\mathrm{Bq} / \mathrm{m}^{3}$} & \\
\hline & $\mathbf{D}$ & $w$ & $\bar{Y}$ & D & $w$ & $\bar{Y}$ & \\
\hline 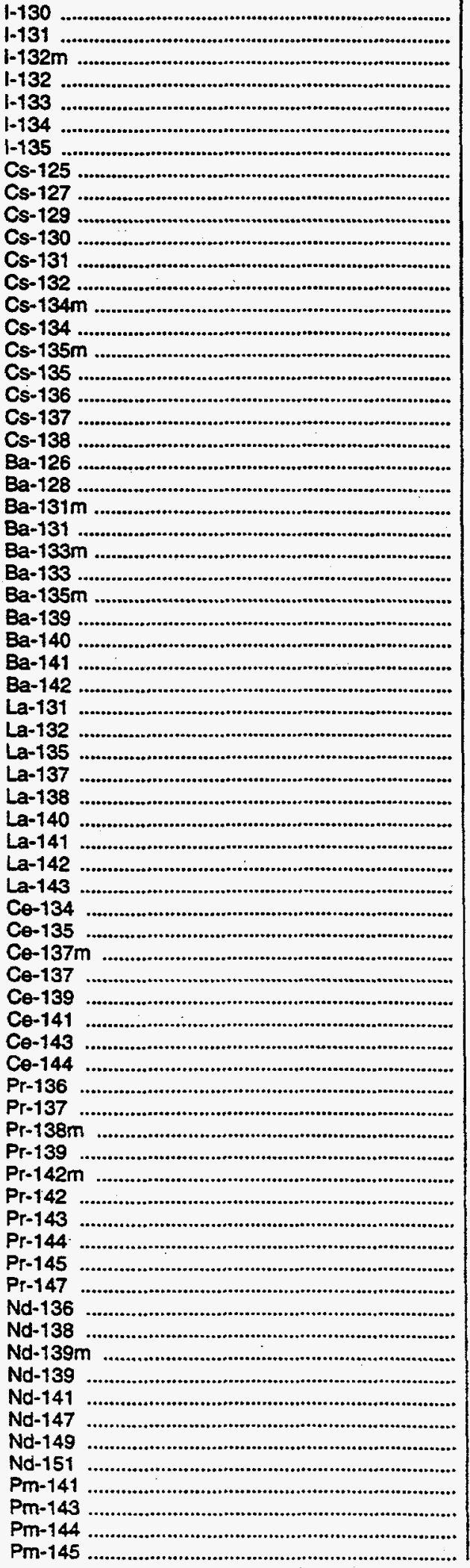 & 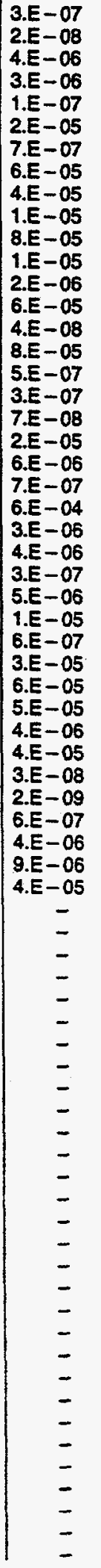 & 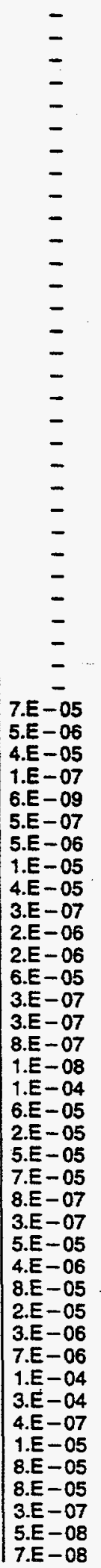 & 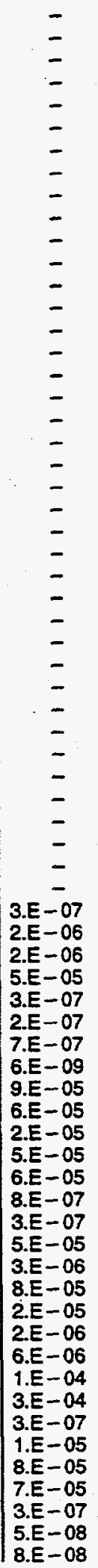 & 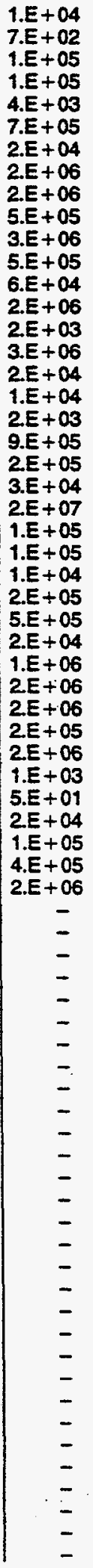 & 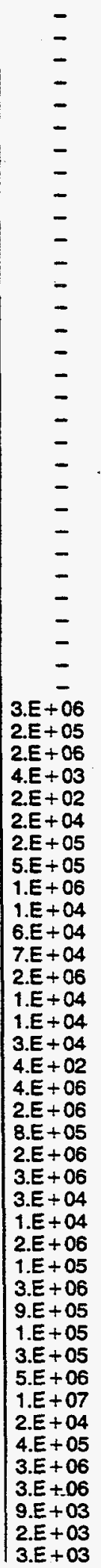 & 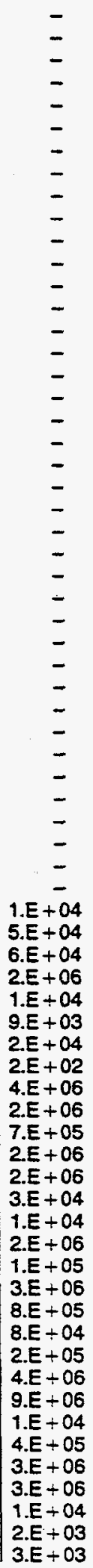 & 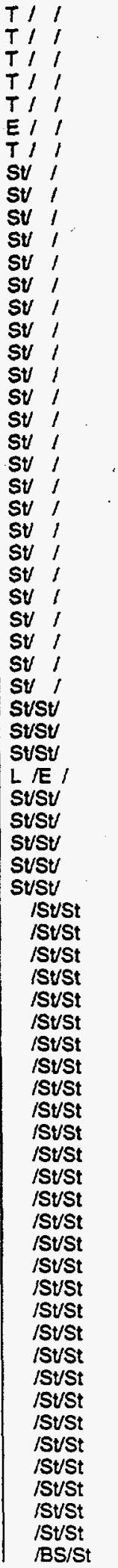 \\
\hline
\end{tabular}


Federal Register / Vol. 58, No. 238 / Tuesday, December 14, 1993 / Rules and Regulations

\begin{tabular}{|c|c|c|c|c|c|c|c|}
\hline \multirow{3}{*}{ Radionuclide } & \multirow{2}{*}{\multicolumn{3}{|c|}{$\frac{\text { Inthaled air-lung retention class } 3}{\mu \mathrm{Ci} / \mathrm{ml}}$}} & \multirow{2}{*}{\multicolumn{3}{|c|}{$\frac{\text { Inhalod air-lung retention class }{ }^{3}}{B q / \mathrm{m}^{3}}$}} & \multirow{3}{*}{$\begin{array}{c}\begin{array}{c}\text { Stochastic } \\
\text { or organ } 1\end{array} \\
(D / W / Y)\end{array}$} \\
\hline & & & & & & & \\
\hline & D & $w$ & $Y$ & D & $w$ & $\mathbf{Y}$ & \\
\hline 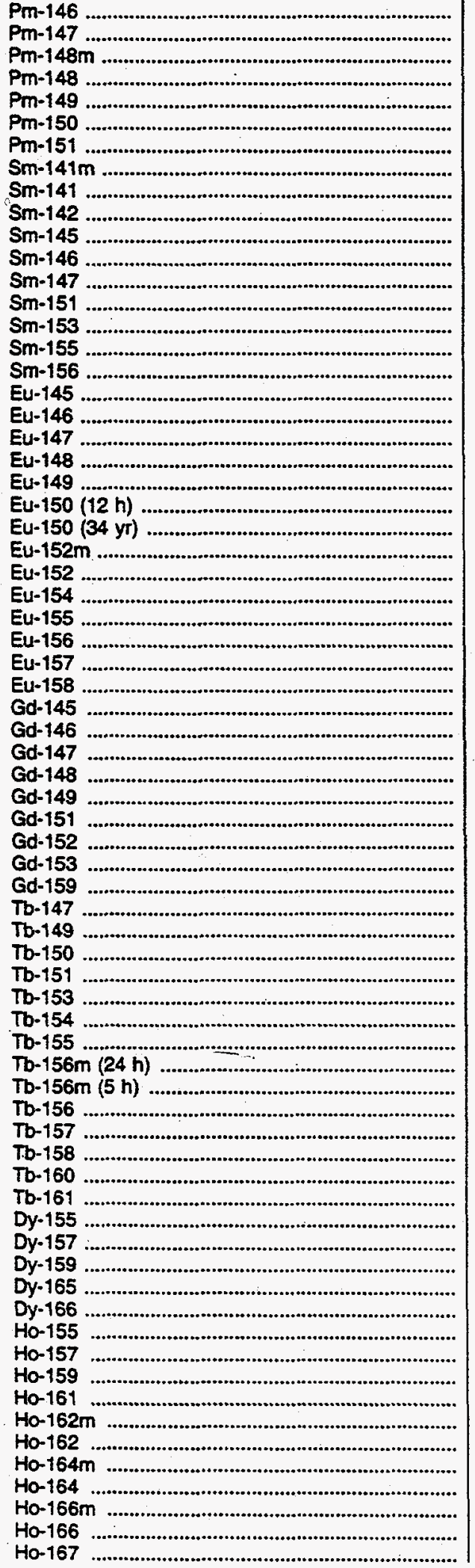 & 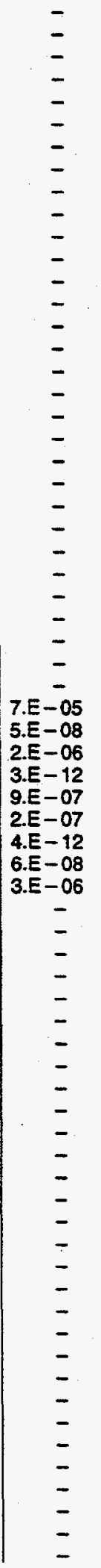 & $\begin{array}{l}2 . E-08 \\
6 . E-08 \\
1 . E-07 \\
2 . E-07 \\
8 . E-07 \\
8 . E-06 \\
2 . E-06 \\
4 . E-05 \\
7 . E-05 \\
1 . E-05 \\
2 . E-07 \\
1 . E-11 \\
2 . E-11 \\
4 . E-08 \\
1 . E-06 \\
9 . E-05 \\
4 . E-06 \\
8 . E-07 \\
5 . E-07 \\
7 . E-07 \\
2 . E-07 \\
1 . E-06 \\
3 . E-06 \\
8 . E-09 \\
3 . E-06 \\
1 . E-08 \\
8 . E-09 \\
4 . E-08 \\
2 . E-07 \\
2 . E-06 \\
2 . E-05 \\
7 . E-05 \\
1 . E-07 \\
2 . E-06 \\
1 . E-11 \\
1 . E-06 \\
5 . E-07 \\
2 . E-11 \\
3 . E-07 \\
2 . E-06 \\
1 . E-05 \\
3 . E-07 \\
9 . E-06 \\
4 . E-06 \\
3 . E-06 \\
2 . E-06 \\
3 . E-06 \\
3 . E-06 \\
1 . E-05 \\
6 . E-07 \\
1 . E-07 \\
8 . E-09 \\
1 . E-07 \\
7 . E-07 \\
1 . E-05 \\
3 . E-05 \\
1 . E-06 \\
2 . E-05 \\
3 . E-07 \\
7 . E-05 \\
6 . E-04 \\
4 . E-04 \\
2 . E-04 \\
1 . E-04 \\
1 . E-03 \\
1 . E-04 \\
3 . E-04 \\
3 . E-09 \\
7 . E-07 \\
2 . E-05\end{array}$ & 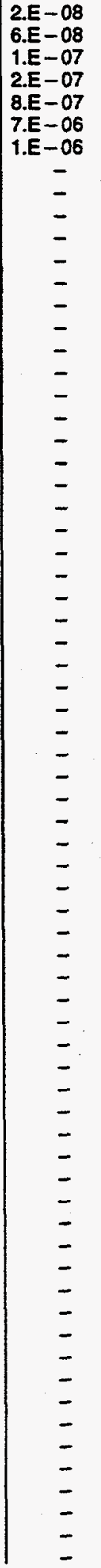 & 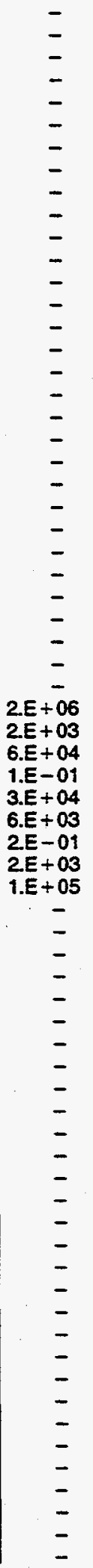 & $\begin{array}{l}8 . E+02 \\
2 . E+03 \\
5 . E+03 \\
8 . E+03 \\
3 . E+04 \\
3 . E+05 \\
6 . E+04 \\
2 . E+06 \\
3 . E+06 \\
4 . E+05 \\
8 . E+03 \\
6 . E-01 \\
6 . E-01 \\
2 . E+03 \\
4 . E+04 \\
3 . E+06 \\
1 . E+05 \\
3 . E+04 \\
2 . E+04 \\
3 . E+04 \\
6 . E+03 \\
5 . E+04 \\
1 . E+05 \\
3 . E+02 \\
1 . E+05 \\
4 . E+02 \\
3 . E+02 \\
1 . E+03 \\
7 . E+03 \\
7 . E+04 \\
9 . E+05 \\
3 . E+06 \\
4 . E+03 \\
5 . E+04 \\
5 . E-01 \\
4 . E+04 \\
2 . E+04 \\
6 . E-01 \\
9 . E+03 \\
9 . E+04 \\
5 . E+05 \\
1 . E+04 \\
3 . E+05 \\
1 . E+05 \\
1 . E+05 \\
7 . E+04 \\
1 . E+05 \\
1 . E+05 \\
4 . E+05 \\
2 . E+04 \\
5 . E+03 \\
3 . E+02 \\
4 . E+03 \\
2 . E+04 \\
4 . E+05 \\
1 . E+06 \\
4 . E+04 \\
7 . E+05 \\
1 . E+04 \\
2 . E+06 \\
2 . E+07 \\
2 . E+07 \\
7 . E+06 \\
4 . E+06 \\
4 . E+07 \\
5 . E+06 \\
1 . E+07 \\
1 . E+02 \\
3 . E+04 \\
9 . E+05\end{array}$ & 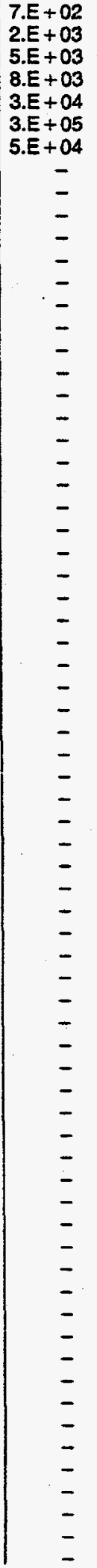 & 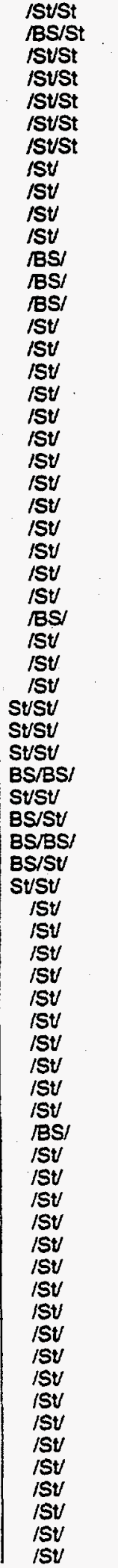 \\
\hline
\end{tabular}


65502 Federal Register / Vol. 58, No. 238 / Tuesday, December 14, 1993 / Rules and Regulations

\begin{tabular}{|c|c|c|c|c|c|c|c|}
\hline \multirow{3}{*}{ Radionuclide } & \multirow{2}{*}{\multicolumn{3}{|c|}{$\frac{\text { Inhaled air-lung retention class } 3}{\mu \mathrm{Ci} / \mathrm{mi}}$}} & \multirow{2}{*}{\multicolumn{3}{|c|}{$\frac{\text { Inhaled air-lung retention class } 3}{B q / \mathrm{m}^{3}}$}} & \multirow{3}{*}{$\frac{\begin{array}{c}\text { Stochastic } \\
\text { or organ I }\end{array}}{(D / W / Y)}$} \\
\hline & & & & & & & \\
\hline & D & $w$ & $\mathbf{Y}$ & D & $w$ & $Y$ & \\
\hline 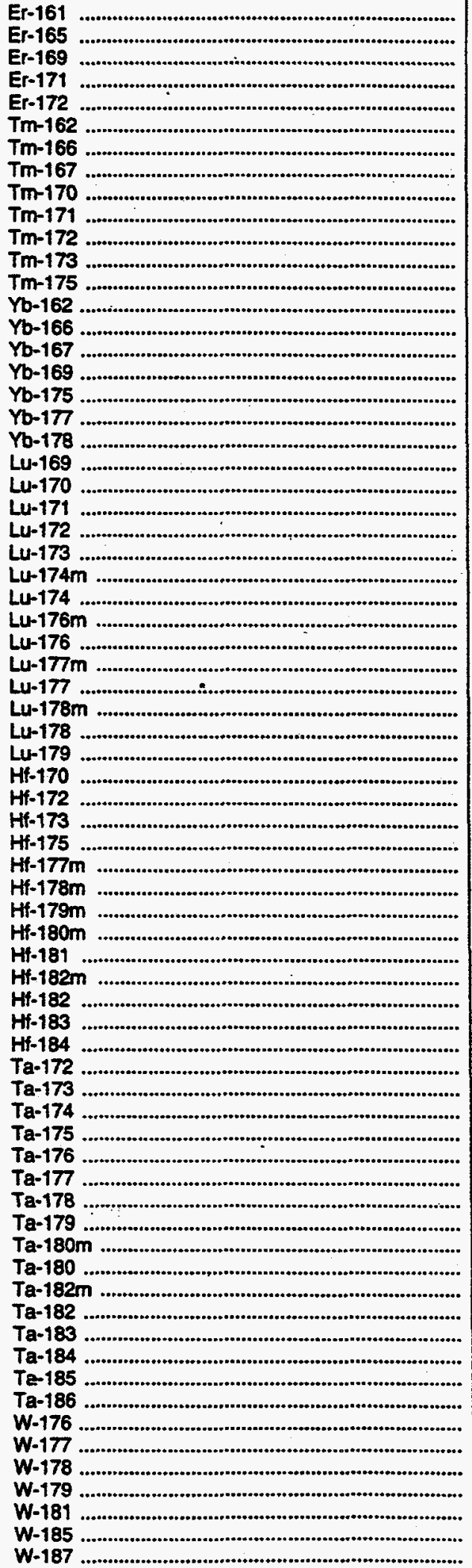 & 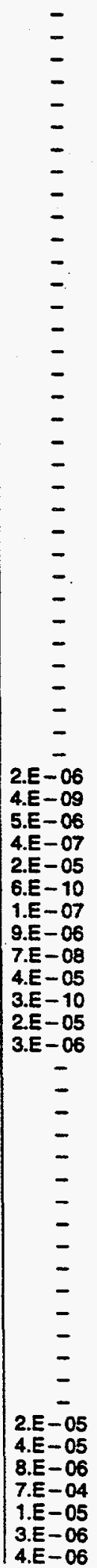 & 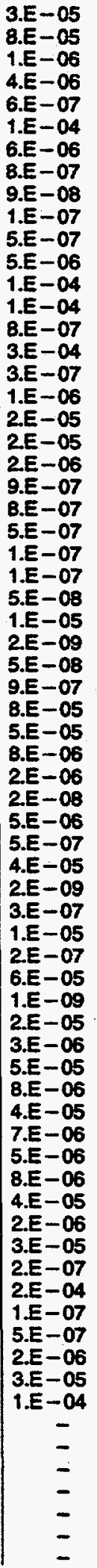 & 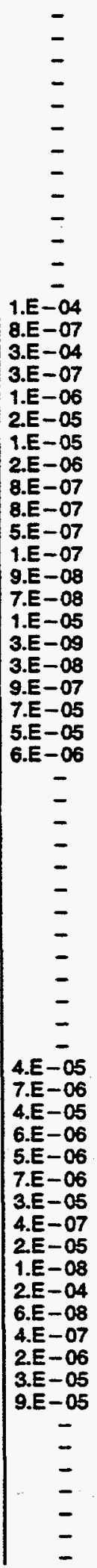 & 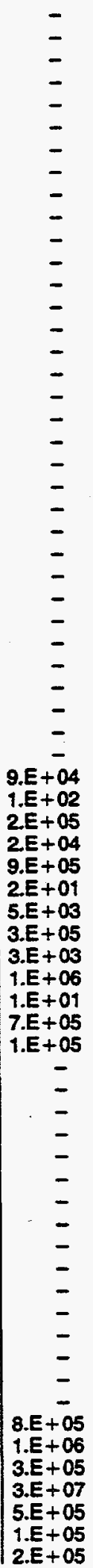 & 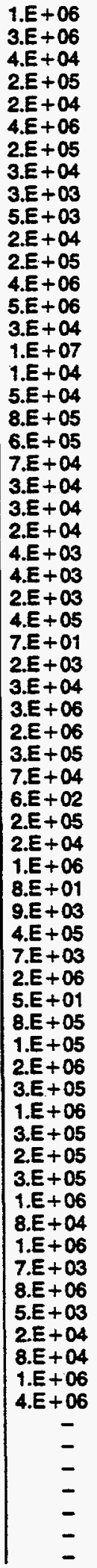 & 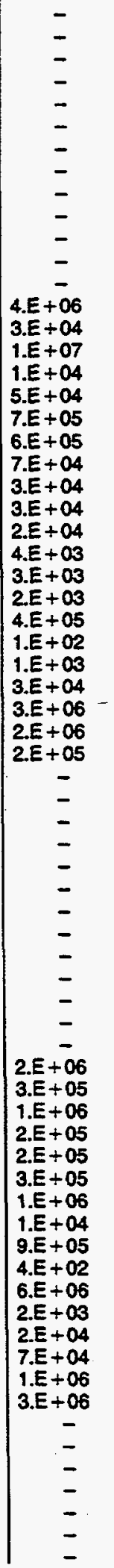 & 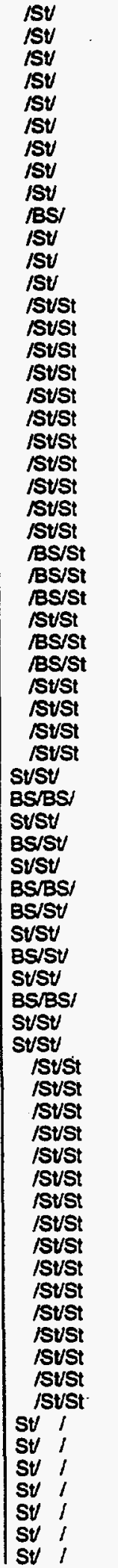 \\
\hline
\end{tabular}


Federal Register / Vol. 58, No. 238 / Tuesday, December 14, 1993 / Rules and Regulations

65503

\begin{tabular}{|c|c|c|c|c|c|c|c|}
\hline \multirow{3}{*}{ Radionuclide } & \multirow{2}{*}{\multicolumn{3}{|c|}{$\frac{\text { Inhaled air-lung retention class }{ }^{3}}{\mu \mathrm{Ci} / \mathrm{ml}}$}} & \multicolumn{3}{|c|}{ Inhaled air-lung retention class 3 . } & \multirow{3}{*}{$\begin{array}{c}\begin{array}{c}\text { Stochastic } \\
\text { or organ } 1\end{array} \\
\text { (D/W/ Y) }\end{array}$} \\
\hline & & & & \multicolumn{3}{|c|}{$\mathrm{Bq} / \mathrm{m}^{3}$} & \\
\hline & D & $w$ & $Y$ & D & $w$ & $Y$ & \\
\hline 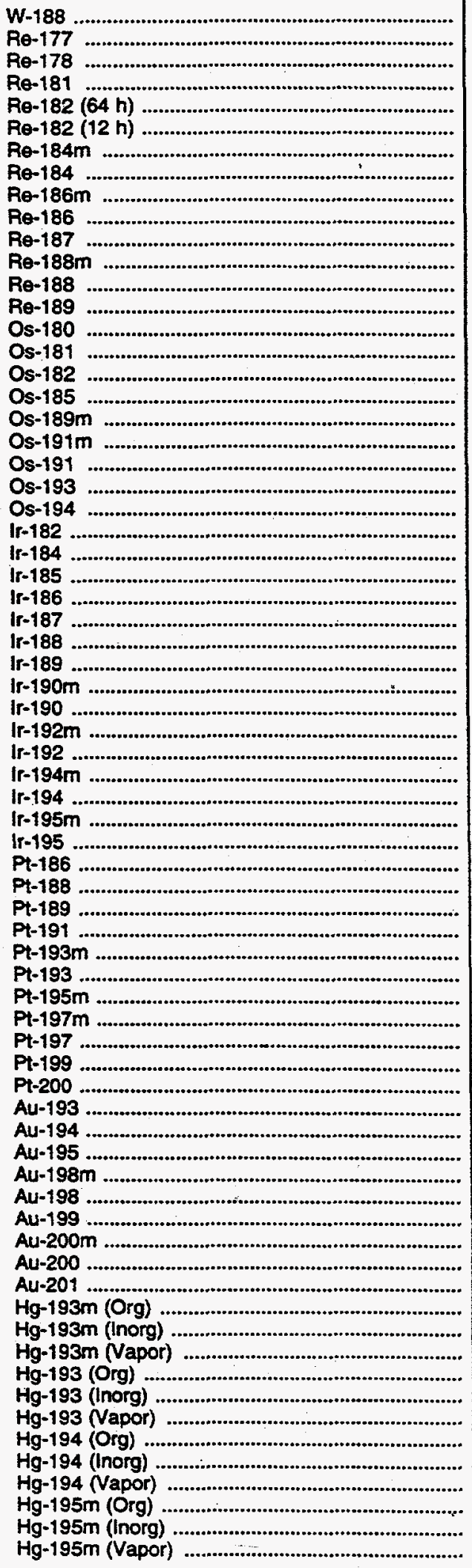 & $\begin{array}{l}5 . E-07 \\
1 . E-04 \\
1 . E-04 \\
4 . E-06 \\
1 . E-06 \\
5 . E-06 \\
1 . E-06 \\
2 . E-06 \\
7 . E-07 \\
1 . E-06 \\
3 . E-04 \\
6 . E-05 \\
1 . E-06 \\
2 . E-06 \\
2 . E-04 \\
2 . E-05 \\
2 . E-06 \\
2 . E-07 \\
1 . E-04 \\
1 . E-05 \\
9 . E-07 \\
2 . E-06 \\
2 . E-08 \\
6 . E-05 \\
1 . E-05 \\
5 . E-06 \\
3 . E-06 \\
1 . E-05 \\
2 . E-06 \\
2 . E-06 \\
8 . E-05 \\
4 . E-07 \\
4 . E-08 \\
1 . E-07 \\
4 . E-08 \\
1 . E-06 \\
1 . E-05 \\
2 . E-05 \\
2 . E-05 \\
7 . E-07 \\
1 . E-05 \\
3 . E-06 \\
2 . E-06 \\
1 . E-05 \\
2 . E-06 \\
2 . E-05 \\
4 . E-06 \\
6 . E-05 \\
1 . E-06 \\
1 . E-05 \\
3 . E-06 \\
5 . E-06 \\
1 . E-06 \\
2 . E-06 \\
4 . E-06 \\
1 . E-06 \\
3 . E-05 \\
9 . E-05 \\
6 . E-06 \\
4 . E-06 \\
3 . E-05 \\
2 . E-05 \\
1 . E-08 \\
2 . E-08 \\
3 . E-06 \\
2 . E-06 \\
\end{array}$ & 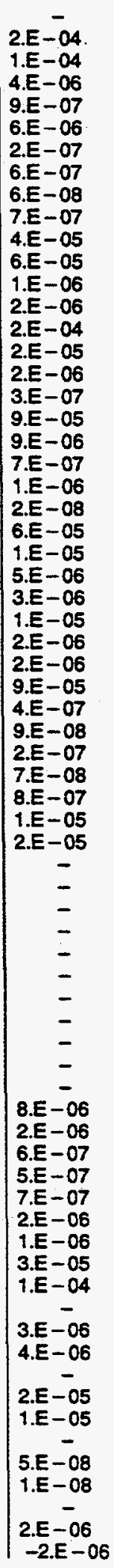 & $\begin{array}{c}- \\
- \\
- \\
- \\
- \\
- \\
- \\
- \\
- \\
- \\
- \\
- \\
- \\
2 . E-04 \\
2 . E-05 \\
2 . E-06 \\
3 . E-07 \\
7 . E-05 \\
7 . E-06 \\
6 . E-07 \\
1 . E-06 \\
3 . E-09 \\
5 . E-05 \\
1 . E-05 \\
4 . E-06 \\
2 . E-06 \\
1 . E-05 \\
1 . E-06 \\
2 . E-06 \\
8 . E-05 \\
4 . E-07 \\
6 . E-09 \\
9 . E-08 \\
4 . E-08 \\
8 . E-07 \\
9 . E-06 \\
2 . E-05 \\
- \\
- \\
- \\
\text { 8.E- } \\
2 . E-06 \\
2 . E-07 \\
\text { 5.E-07 } \\
7 . E-07 \\
2 . E-06 \\
1 . E-06 \\
3 . E-05 \\
9 . E-05 \\
- \\
- \\
- \\
- \\
- \\
- \\
- \\
- \\
- \\
- \\
- \\
-\end{array}$ & $\begin{array}{l}2 . E+04 \\
4 . E+06 \\
4 . E+06 \\
1 . E+05 \\
4 . E+04 \\
2 . E+05 \\
5 . E+04 \\
6 . E+04 \\
3 . E+04 \\
5 . E+04 \\
1 . E+07 \\
2 . E+06 \\
4 . E+04 \\
8 . E+04 \\
6 . E+06 \\
7 . E+05 \\
9 . E+04 \\
8 . E+03 \\
4 . E+06 \\
4 . E+05 \\
3 . E+04 \\
7 . E+04 \\
7 . E+02 \\
2 . E+06 \\
4 . E+05 \\
2 . E+05 \\
1 . E+05 \\
5 . E+05 \\
7 . E+04 \\
7 . E+04 \\
3 . E+06 \\
1 . E+04 \\
1 . E+03 \\
4 . E+03 \\
2 . E+03 \\
5 . E+04 \\
4 . E+05 \\
6 . E+05 \\
6 . E+05 \\
3 . E+04 \\
4 . E+05 \\
1 . E+05 \\
9 . E+04 \\
4 . E+05 \\
7 . E+04 \\
7 . E+05 \\
2 . E+05 \\
2 . E+06 \\
5 . E+04 \\
4 . E+05 \\
1 . E+05 \\
2 . E+05 \\
4 . E+04 \\
6 . E+04 \\
1 . E+05 \\
5 . E+04 \\
1 . E+06 \\
3 . E+06 \\
2 . E+05 \\
1 . E+05 \\
1 . E+06 \\
7 . E+05 \\
4 . E+02 \\
7 . E+02 \\
7 . E+02 \\
9 . E+04 \\
8 . E+04 \\
+ \\
-10\end{array}$ & 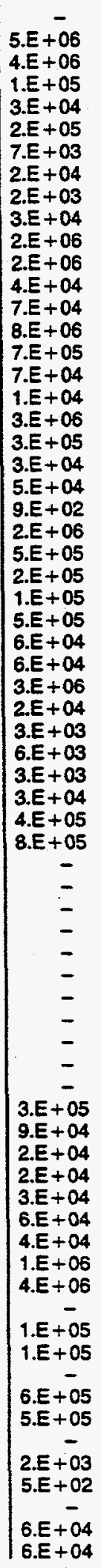 & 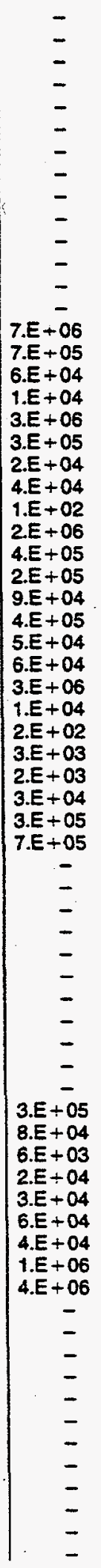 & 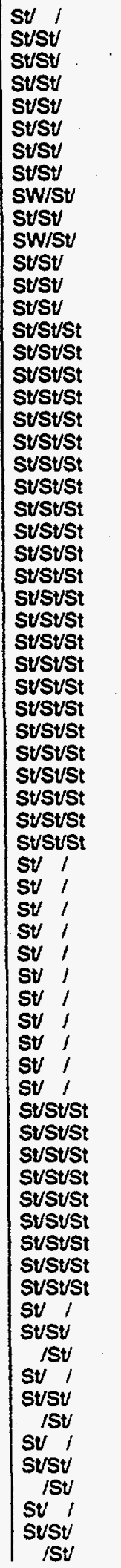 \\
\hline
\end{tabular}


65504 Federal Register / Vol. 58, No. 238 / Tuesday, December 14, 1993 / Rules and Regulations

\begin{tabular}{|c|c|c|c|c|c|c|c|}
\hline \multirow{3}{*}{ Radionuclide } & \multirow{2}{*}{\multicolumn{3}{|c|}{$\frac{T_{\text {Intaled air-lung retention class } 3}}{\mu \mathrm{C} / \mathrm{m} \mid}$}} & \multicolumn{3}{|c|}{ Inhaled air-lung retention class ${ }^{3}$} & \multirow{3}{*}{$\begin{array}{l}\begin{array}{l}\text { Stochastic } \\
\text { or organ 1 }\end{array} \\
\text { ( D/W/ } Y)\end{array}$} \\
\hline & & & & & $\mathrm{Bq} / \mathrm{m}^{3}$ & & \\
\hline & D & $\mathbf{w}$ & $Y$ & D & $w$ & $Y$ & \\
\hline Pg & $\begin{array}{r}2 . E-05 \\
1 . E-05 \\
4 . \\
4 . E-06 \\
3 . E-06 \\
\text { - } \\
6 . E-06 \\
5 . E-06 \\
7 . E-05 \\
6 . E-05 \\
3 . E-07 \\
5 . E-07 \\
6 . E-05 \\
3 . E-04 \\
5 . E-05 \\
5 . E-05 \\
2 . E-05 \\
1 . E-05 \\
3 . E-05 \\
5 . E-06 \\
9 . E-06 \\
2 . E-06 \\
9 . E-07 \\
8 . E-05 \\
3 . E-05 \\
3 . E-05 \\
3 . E-06 \\
9 . E-06 \\
1 . E-05 \\
2 . E-08 \\
4 . E-06 \\
6 . E-07 \\
2 . E-05 \\
1 . E-10 \\
3 . E-07 \\
1 . E-08 \\
3 . E-07 \\
3 . E-05 \\
1 . E-05 \\
2 . E-05 \\
3 . E-06 \\
1 . E-06 \\
6 . E-07 \\
7 . E-07 \\
2 . E-09 \\
1 . E-07 \\
1 . E-07 \\
1 . E-07 \\
3 . E-07 \\
3 . E-05 \\
2 . E-05 \\
1 . E-05 \\
3 . E-10 \\
1 . E-06 \\
3 . E-08 \\
8 . E-094 \\
3 . E-084 \\
2 . E-07 \\
3 . E-07 \\
- \\
\end{array}$ & 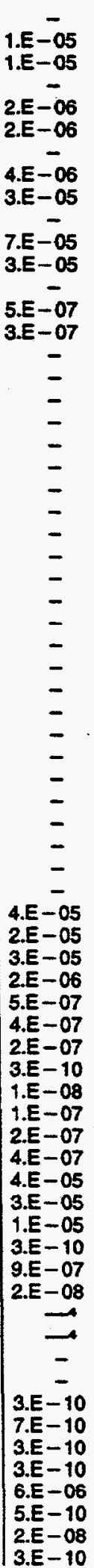 & 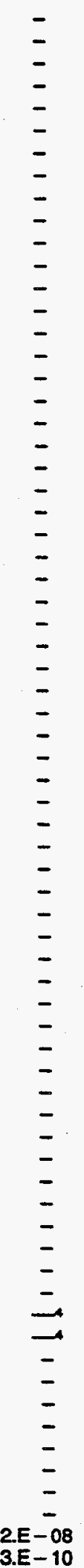 & $\begin{array}{r}7 . E+05 \\
5 . E+05 \\
1 . E+05 \\
1 . E+05 \\
1 . E+05 \\
2 . E+05 \\
2 . E+05 \\
3 . E+06 \\
2 . E+06 \\
1 . E+04 \\
2 . E+04 \\
2 . \\
2 . E+06 \\
9 . E+06 \\
2 . E+06 \\
2 . E+06 \\
9 . E+05 \\
5 . E+05 \\
1 . E+06 \\
2 . E+05 \\
3 . E+05 \\
8 . E+04 \\
3 . E+04 \\
3 . E+06 \\
1 . E+06 \\
1 . E+06 \\
1 . E+05 \\
3 . E+05 \\
4 . E+05 \\
8 . E+02 \\
2 . E+05 \\
2 . E+04 \\
9 . E+05 \\
4 . E+00 \\
1 . E+04 \\
5 . E+02 \\
1 . E+04 \\
1 . E+06 \\
4 . E+05 \\
6 . E+05 \\
1 . E+05 \\
4 . E+04 \\
2 . E+04 \\
3 . E+04 \\
7 . E+01 \\
4 . E+03 \\
4 . E+03 \\
5 . E+03 \\
1 . E+04 \\
1 . E+05 \\
6 . E+05 \\
4 . E+05 \\
1 . E+01 \\
4 . E+04 \\
1 . E+03 \\
3 . E+024 \\
1 . E+034 \\
7 . E+03 \\
1 . E+04 \\
- \\
+ \\
-10 \\
\end{array}$ & 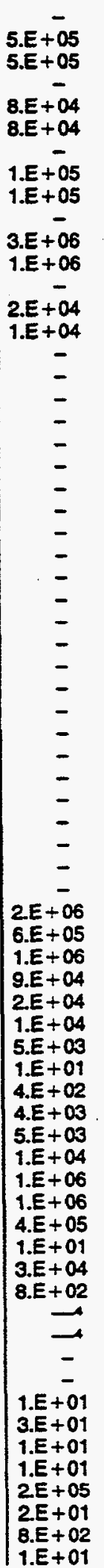 & 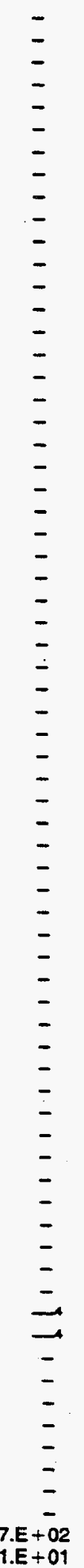 & 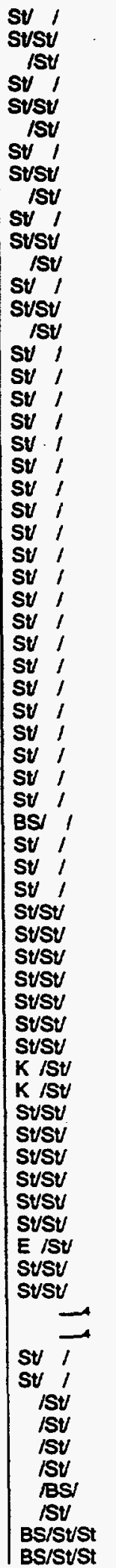 \\
\hline
\end{tabular}


Federal Register / Vol. 58, No. 238 / Tuesday, December 14, 1993 / Rules and Regulations

65505

\begin{tabular}{|c|c|c|c|c|c|c|c|}
\hline \multirow{3}{*}{ Radionuclide } & \multicolumn{3}{|c|}{ Inhaled air-lung retention class 3} & \multicolumn{3}{|c|}{ Inhaled airtung retention class 3} & \multirow{3}{*}{$\begin{array}{l}\begin{array}{l}\text { Stochastic } \\
\text { or organ } 1\end{array} \\
(D / W / Y)\end{array}$} \\
\hline & \multicolumn{3}{|c|}{$\mu \mathrm{CV} / \mathrm{mi}$} & \multicolumn{3}{|c|}{$\mathrm{Bq} / \mathrm{m}^{3}$} & \\
\hline & D & $w$ & $Y$ & D & $w$ & $Y$ & \\
\hline $\begin{array}{l}\text { Ac-226 } \\
\text { Ac-227 }\end{array}$ & 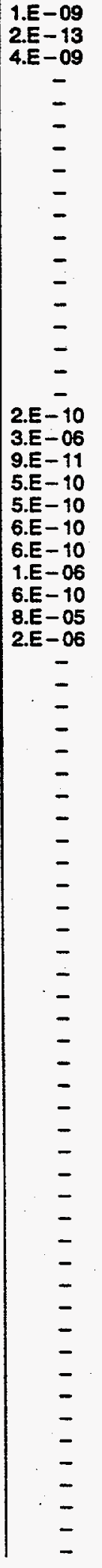 & $\begin{array}{l}2 . E-09 \\
7 . E-13 \\
2 . E-08 \\
7 . E-08 \\
1 . E-10 \\
4 . E-12 \\
4 . E-13 \\
3 . E-12 \\
3 . E-06 \\
5 . E-13 \\
9 . E-08 \\
5 . E-08 \\
5 . E-09 \\
2 . E-09 \\
7 . E-13 \\
9 . E-09 \\
3 . E-07 \\
3 . E-06 \\
1 . E-10 \\
2 . E-06 \\
2 . E-10 \\
3 . E-10 \\
3 . E-10 \\
3 . E-10 \\
3 . E-10 \\
7 . E-07 \\
3 . E-10 \\
7 . E-05 \\
1 . E-06 \\
1 . E-065 \\
1 . E-035 \\
1 . E-065 \\
5 . E-075 \\
1 . E-115 \\
2 . E-085 \\
2 . E-125 \\
4 . E-085 \\
1 . E-065 \\
3 . E-05 s \\
9 . E-085 \\
1 . E-035 \\
7 . E-125 \\
1 . E-065 \\
3 . E-125 \\
2 . E-125 \\
2 . E-125 \\
1 . E-105 \\
2 . E-125 \\
1 . E-055 \\
2 . E-125 \\
2 . E-065 \\
1 . E-045 \\
1 . E-065 \\
5 . E-065 \\
1 . E-065 \\
2 . E-125 \\
2 . E-125 \\
3 . E-085 \\
2 . E-125 \\
2 . E-065 \\
7 . E-085 \\
3 . E-05 s \\
7 . E-055 \\
4 . E-05 s \\
4 . E-075 \\
2 . E-105 \\
9 . E-095 \\
1 . E-105 \\
3 . E-125 \\
4 . E-125\end{array}$ & $\begin{array}{r}2 . E-09 \\
2 . E-12 \\
2 . E-08 \\
6 . E-08 \\
1 . E-10 \\
7 . E-12 \\
1 . E-12 \\
7 . E-12 \\
3 . E-06 \\
1 . E-12 \\
6 . E-08 \\
4 . E-08 \\
5 . E-09 \\
1 . E-09 \\
2 . E-12 \\
2 . E-08 \\
2 . E-07 \\
3 . E-06 \\
1 . E-10 \\
2 . E-05 \\
3 . E-12 \\
2 . E-11 \\
2 . E-11 \\
2 . E-11 \\
2 . E-11 \\
6 . E-07 \\
2 . E-11 \\
6 . E-05 \\
1 . E-06 \\
- \\
- \\
- \\
-12 \\
-\end{array}$ & 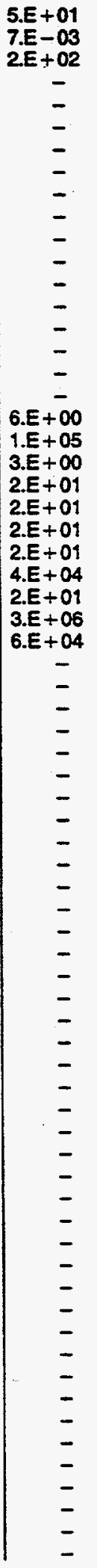 & $\begin{array}{l}8 . E+01 \\
3 . E-02 \\
6 . E+02 \\
2 . E+03 \\
5 . E+00 \\
2 . E-01 \\
1 . E-02 \\
9 . E-02 \\
1 . E+05 \\
2 . E-02 \\
3 . E+03 \\
2 . E+03 \\
2 . E+02 \\
7 . E+01 \\
2 . E-02 \\
3 . E+02 \\
1 . E+04 \\
1 . E+05 \\
5 . E+00 \\
9 . E+04 \\
6 . E+00 \\
1 . E+01 \\
1 . E+01 \\
1 . E+01 \\
1 . E+01 \\
3 . E+04 \\
1 . E+01 \\
3 . E+06 \\
4 . E+04 \\
4 . E+045 \\
5 . E+075 \\
4 . E+045 \\
2 . E+045 \\
4 . E-015 \\
6 . E+025 \\
9 . E-025 \\
1 . E+035 \\
4 . E+045 \\
1 . E+065 \\
3 . E+035 \\
5 . E+075 \\
3 . E-015 \\
5 . E+045 \\
9 . E-025 \\
8 . E-025 \\
8 . E-025 \\
4 . E+005 \\
9 . E-025 \\
5 . E+055 \\
9 . E-025 \\
7 . E+045 \\
4 . E+065 \\
4 . E+045 \\
2 . E+055 \\
4 . E+045 \\
8 . E-025 \\
8 . E-025 \\
1 . E+035 \\
8 . E-025 \\
6 . E+045 \\
3 . E+035 \\
1 . E+065 \\
3 . E+065 \\
2 . E+065 \\
2 . E+045 \\
8 . E+005 \\
4 . E+025 \\
4 . E+005 \\
1 . E-015 \\
2 . E-015\end{array}$ & $\begin{array}{r}7 . E+01 \\
6 . E-02 \\
7 . E+02 \\
2 . E+03 \\
5 . E+00 \\
3 . E-01 \\
4 . E-02 \\
2 . E-01 \\
1 . E+05 \\
4 . E-02 \\
2 . E+03 \\
2 . E+03 \\
2 . E+02 \\
5 . E+01 \\
6 . E-02 \\
9 . E+02 \\
9 . E+03 \\
1 . E+05 \\
4 . E+00 \\
7 . E+04 \\
1 . E-01 \\
6 . E-01 \\
6 . E-01 \\
6 . E-01 \\
6 . E-01 \\
2 . E+04 \\
6 . E-01 \\
2 . E+06 \\
4 . E+04 \\
- \\
- \\
- \\
- \\
- \\
- \\
- \\
- \\
- \\
- \\
- \\
- \\
- \\
- \\
- \\
- \\
- \\
- \\
3 . E+035 \\
4 . E+075 \\
6 . E-015 \\
5 . E+045 \\
3 . E-015 \\
2 . E-015 \\
2 . E-015 \\
1 . E+015 \\
2 . E-015 \\
6 . E+055 \\
2 . E-015 \\
6 . E+045 \\
- \\
- \\
- \\
- \\
- \\
-\end{array}$ & 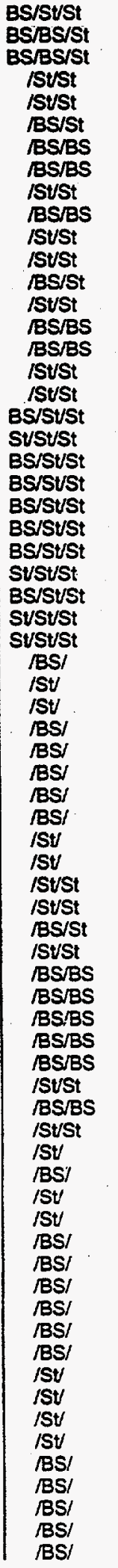 \\
\hline
\end{tabular}


65506 Federal Register / Vol. 58, No. 238 / Tuesday, December 14, 1993 / Rules and Regulations

\begin{tabular}{|c|c|c|c|c|c|c|c|}
\hline \multirow{3}{*}{ ladionuctide } & \multirow{2}{*}{\multicolumn{3}{|c|}{$\frac{\text { Inhaled air-lung retention class } 3 .}{\mu \mathrm{CV} / \mathrm{mt}}$}} & \multirow{2}{*}{\multicolumn{3}{|c|}{$\frac{\text { Inhaled air-lung retention class } 3}{\mathrm{~Bq} / \mathrm{m}^{3}}$}} & \multirow{3}{*}{$\begin{array}{l}\begin{array}{l}\text { Stochastic } \\
\text { or organ } 1\end{array} \\
(D / W / Y)\end{array}$} \\
\hline & & & & & & & \\
\hline & D & $\mathbf{w}$ & $\mathbf{Y}$ & $D$ & $w$ & $Y$ & \\
\hline $\begin{array}{l}C m-245 \\
C m-246 \\
C m-247 \\
C_{m}-249 \\
B k-245 \\
B k-2467 \\
B k-249 \\
B R-250 \\
C-244\end{array}$ & $\begin{array}{l}\bar{z} \\
\bar{z} \\
\bar{z} \\
\bar{z} \\
\bar{z} \\
\bar{z} \\
\bar{z} \\
\bar{z} \\
\bar{z} \\
\bar{z} \\
\bar{z} \\
\bar{z}\end{array}$ & $\begin{array}{l}2 . E-125 \\
2 . E-125 \\
2 . E-125 \\
6 . E-135 \\
6 . E-065 \\
5 . E-07 \\
1 . E-06 \\
2 . E-12 \\
9 . E-10 \\
2 . E-07 \\
2 . E-075 \\
4 . E-095 \\
4 . E-115 \\
2 . E-125 \\
5 . E-125 \\
2 . E-125 \\
1 . E-115 \\
8 . E-105 \\
9 . E-125 \\
3 . E-07 \\
4 . E-07 \\
6 . E-10 \\
4 . E-09 \\
4 . E-11 \\
6 . E-09 \\
4 . E-09 \\
4 . E-08 \\
9 . E-09 \\
1 . E-10 \\
4 . E-08 \\
1 . E-10\end{array}$ & 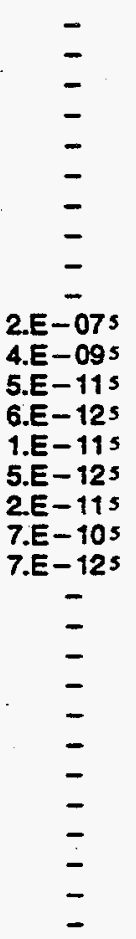 & 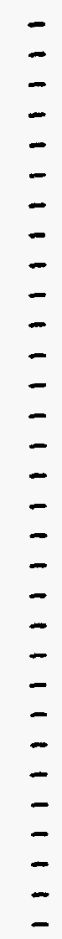 & $\begin{array}{l}8 . E-02 s \\
8 . E-025 \\
9 . E-025 \\
2 . E-025 \\
2 . E+055 \\
2 . E+04 \\
5 . E+04 \\
8 . E-02 \\
3 . E+01 \\
7 . E+03 \\
9 . E+035 \\
2 . E+025 \\
1 . E+00 s \\
8 . E-025 \\
2 . E-015 \\
8 . E-025 \\
4 . E-015 \\
3 . E+015 \\
3 . E-015 \\
1 . E+04 \\
2 . E+04 \\
2 . E+01 \\
2 . E+02 \\
2 . E+00 \\
2 . E+02 \\
2 . E+02 \\
2 . E+03 \\
3 . E+02 \\
4 . E+00 \\
2 . E+03 \\
4 . E+00\end{array}$ & $\begin{array}{c}- \\
z \\
z \\
z \\
z \\
\overline{-} \\
\text { 9.E+ } \\
1 . E+025 \\
2 . E+005 \\
2 . E-015 \\
4 . E-015 \\
2 . E-015 \\
6 . E-015 \\
3 . E+015 \\
3 . E-015 \\
- \\
- \\
- \\
- \\
- \\
- \\
- \\
- \\
- \\
- \\
-\end{array}$ & 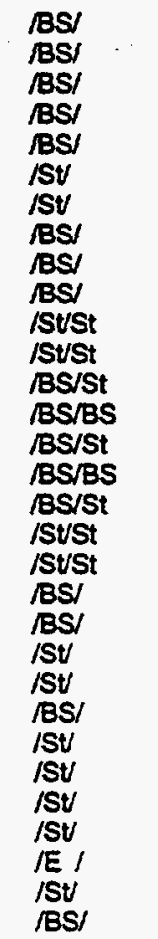 \\
\hline
\end{tabular}

Footnotes for Appendix A

A determination of whether the DACs are controlled by stochastic (St) or nonstoctrastic (organ) dose, or if they both give the same result (E), for each lung retention class, is given in this column. The key to the organ notation for nonstochastic dose is: $B S=B 0 n e$ surface, $K=K$ idney, $L=L i v e r, S W=S t o m a c h$ wall, and $T=T h y r o i d . A$ blank indicates that no calculations were performed for the lung retention class shown.

2 The ICRP identifies tritiated water and carbon as having immediate uptake and distribution; therefore no solubility classes are designated. For the purposes of this table, the DAC values are shown as being constant independent of solubility class. For tritiated water, the inhalation DAC values allow for an additional $50 \%$ absorption through the skin, as described in ICRP Publication No. 30 : Limits for Intakes of Radionuclides by Workers. For elemental tritium, the DAC values are based solely on consideration of the dose-equivalent rate to the tissues of the lung trom inhaled tritium gas contained within the lung, without absorption in the tissues.

3 A dash indicates no values given for this data category.

4 These values are appropriate for protection from radon combined with its short-lived daughters and are based on information given in ICRP Publication 32: Limits for Inhalation of Radon Daughters by Workers and Federal Guidance Report No. 11: Limiting Values of Radionuclide Intake and Air Concentrations, and Dose Conversion Factors for inhalation, Submersion, and Ingestion (EPA 520/1-88-020). The values given are for $100 \%$ equilibrium concentration conditions of the radon daughters with the parent. To allow for an actual measured equilibrium concentration or a demonstrated equilibrium concentration the values given in this table should be multiplied by the ratio (100\%) onstrated \%), respectively. Atternatively, the DAC values for Rn-220 and Rn-222 may be replaced by $1 \mathrm{WL}^{*}$ and $1 / 3 \mathrm{WL}^{*}$, respectively, for appropriate limiting of daughter concentrations. Because of the dosimetric considerations for radon, no $f_{1}$ or lung clearance values are listed.

"A "Working Level" (WL) is any combination of short-lived radon daughters, in one liter of air without regard to the degree of equilibrium, that will result in the ultimate emission of $1.3 E+05 \mathrm{MeV}$ of alpha energy.

5 For the calculations, $f_{1}$ values were obtained from ICAP Publication 48: The Metabolism of Plutonium and Related Elements. It is assumed that the effective dose equivalents for inhalation are unchanged even though the $f_{1}$ values have changed. This is because the contribution to organ dose from inhalation is dependent mainly on transfer from lung to blood when $f_{1}$ values are small. Also, the gastrointestinal tract dose would be unchanged because the fraction of activity passing through the tract is $\left(1.0-f_{1}\right)$.

Appendix B to Part 835-Alternative Absorption Factors and Lung Retention Classes for Specific Compounds

Alternative absorption factors and lung retention classes for specific compounds are listed by element in this appendix for cross-referencing with the inhalation DACs in appendix $A$ to this part. The data shown in this appendix are listed by element in alphabetical order.

\begin{tabular}{|c|c|c|c|c|}
\hline Elementsymbol & $\begin{array}{c}\text { Atomic } \\
\text { No. }\end{array}$ & Compound & $f_{1}$ & Lung retention class \\
\hline 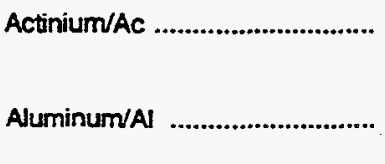 & 89 & 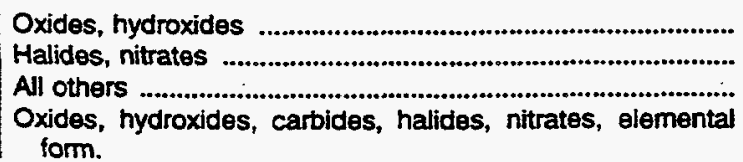 & $\begin{array}{l}1 . E-03 \\
1 . E-03 \\
1 . E-03 \\
1 . E-02\end{array}$ & $\begin{array}{l}Y \\
W \\
W\end{array}$ \\
\hline
\end{tabular}




\begin{tabular}{|c|c|c|c|c|}
\hline Element/symbol & $\begin{array}{l}\text { tomic } \\
\text { No. }\end{array}$ & Compound & $f_{1}$ & Lung retention class \\
\hline 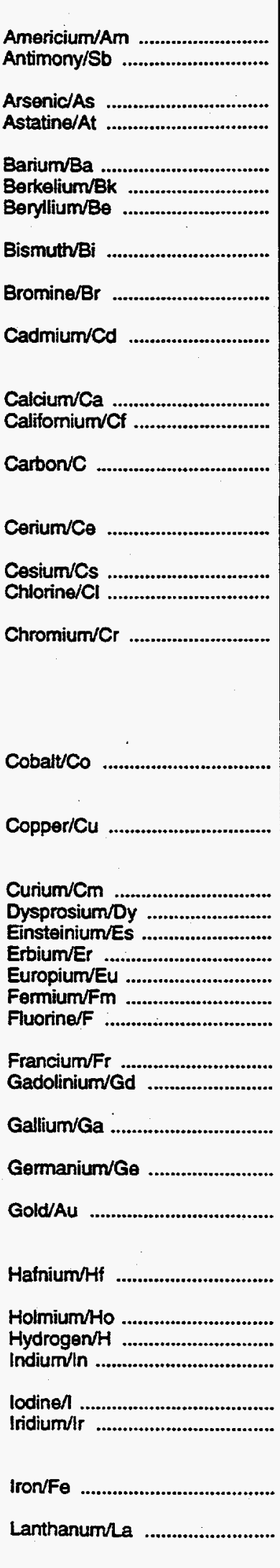 & $\begin{array}{r}96 \\
66 \\
99 \\
68 \\
63 \\
100 \\
9 \\
87 \\
64 \\
31\end{array}$ & 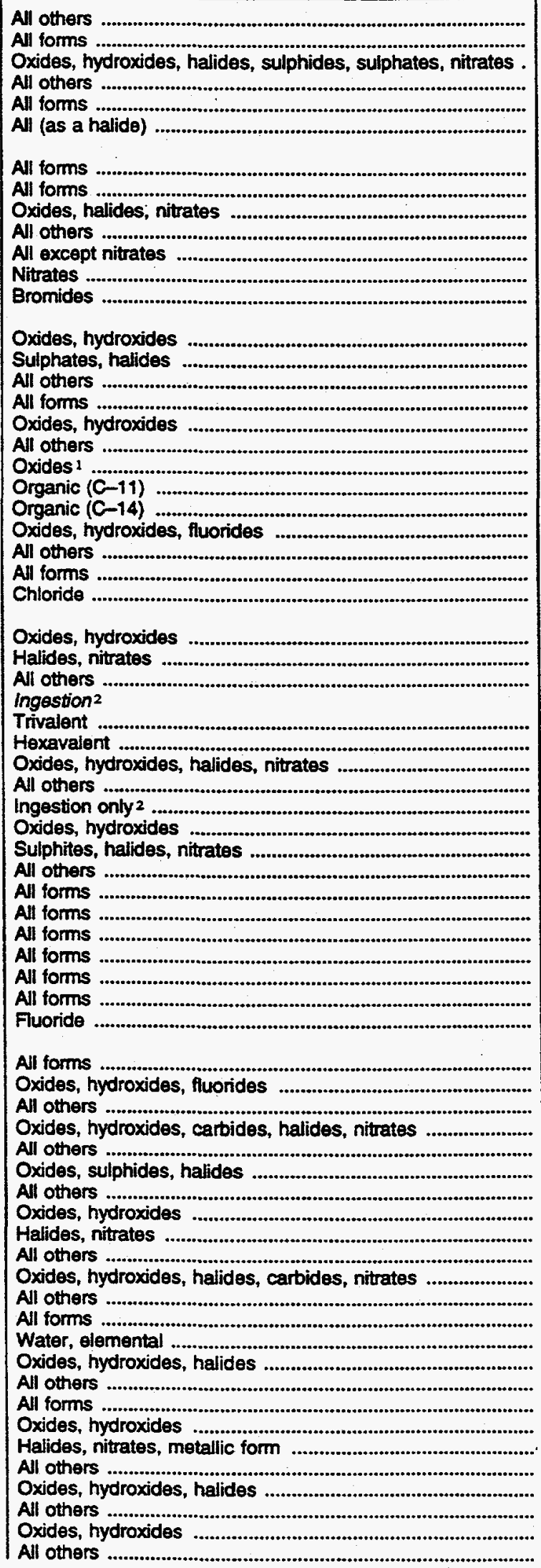 & 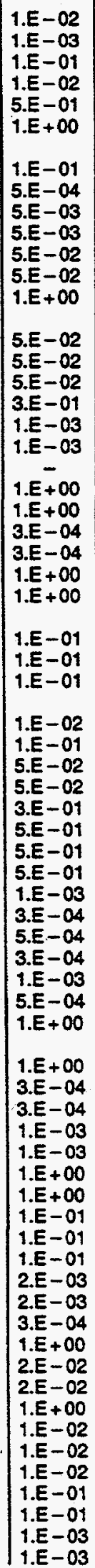 & $\begin{array}{l}D \\
W \\
D \\
W \\
W \\
W \text { or D; dependent upon as- } \\
\text { sociated element. } \\
D \\
W \\
Y \\
W \\
W \\
D \\
W \text { or D; dependent upon as- } \\
\text { sociated element. } \\
Y \\
W \\
D \\
W \\
Y \\
W \\
D \\
W \\
W \\
Y \\
W \\
D \\
W \text { or D; dependent upon as- } \\
\text { sociated element. } \\
\text { W } \\
D\end{array}$ \\
\hline
\end{tabular}




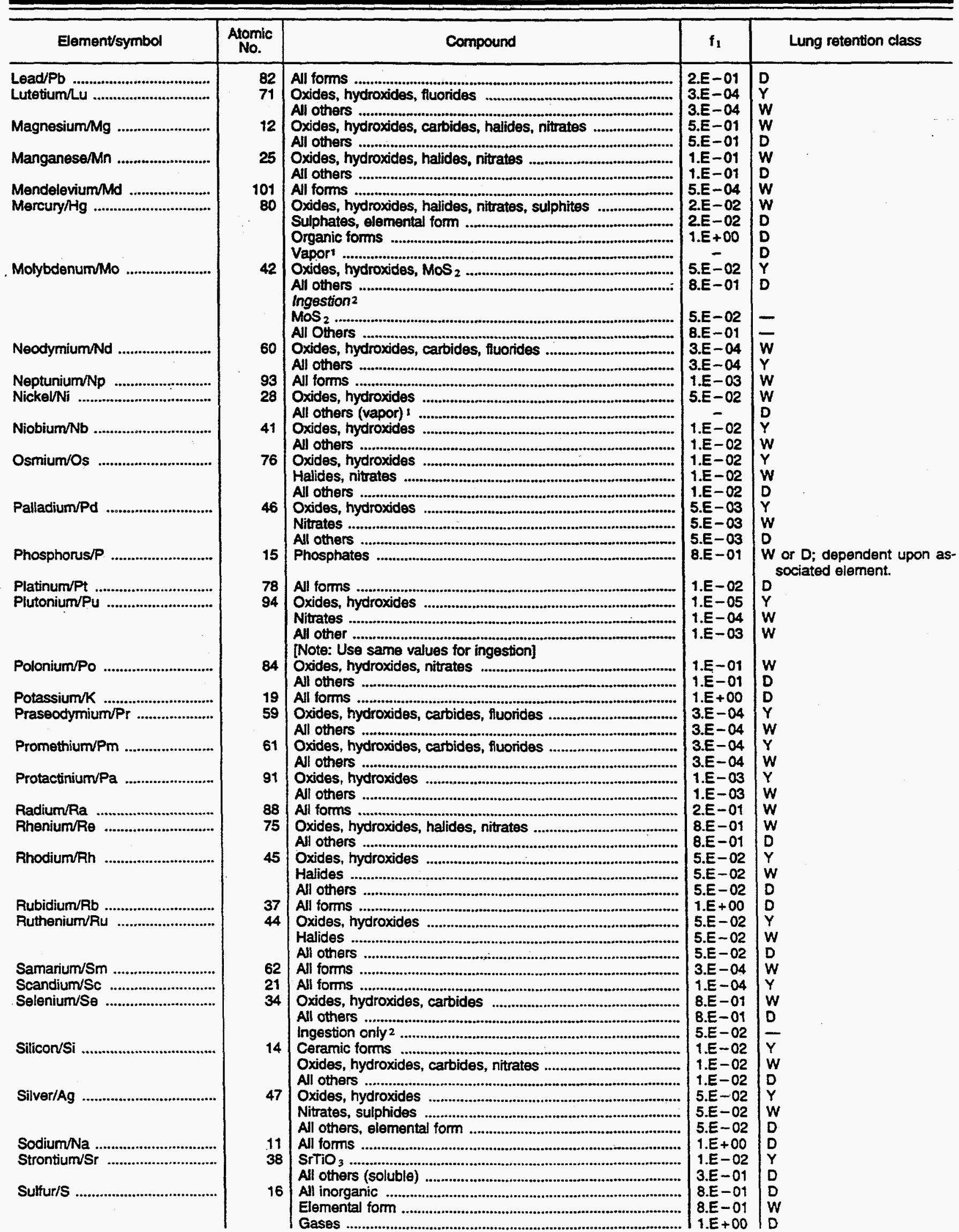




\begin{tabular}{|c|c|c|c|c|}
\hline Element/symbol & $\begin{array}{c}\text { Atomic } \\
\text { No. }\end{array}$ & Compound & $f_{t}$ & Lung retention class \\
\hline 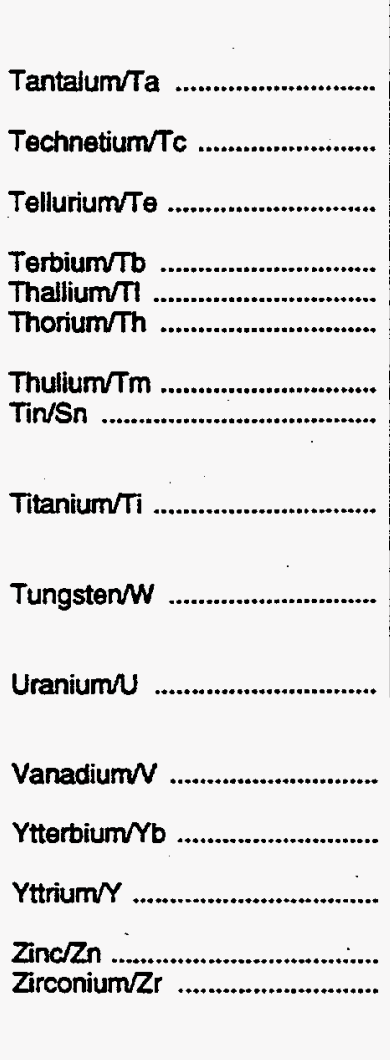 & $\begin{array}{l}73 \\
43 \\
52 \\
65 \\
81 \\
90 \\
69 \\
50 \\
22 \\
74 \\
92 \\
30 \\
30 \\
30\end{array}$ & 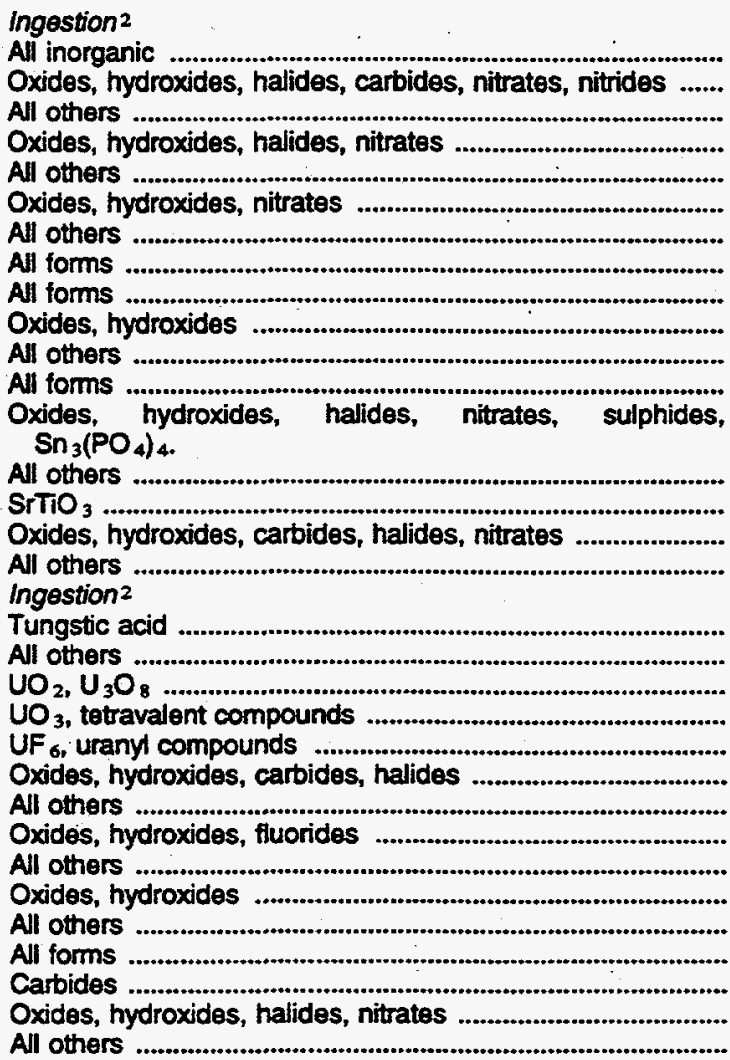 & $\begin{array}{l}1 . E-01 \\
1 . E-03 \\
1 . E-03 \\
8 . E-01 \\
8 . E-01 \\
2 . E-01 \\
2 . E-01 \\
3 . E-04 \\
1 . E+00 \\
2 . E-04 \\
2 . E-04 \\
3 . E-04 \\
2 . E-02 \\
2 . E-02 \\
1 . E-02 \\
1 . E-02 \\
1 . E-02 \\
1 . E-02 \\
3 . E-01 \\
2 . E-03 \\
5 . E-02 \\
5 . E-02 \\
1 . E-02 \\
1 . E-02 \\
3 . E-04 \\
3 . E-04 \\
1 . E-04 \\
1 . E-04 \\
5 . E-01 \\
2 . E-03 \\
2 . E-03 \\
2 . E-03\end{array}$ & $\begin{array}{l}\bar{Y} \\
W \\
W \\
D \\
W \\
D \\
W \\
D \\
Y \\
W \\
W \\
W \\
D \\
Y \\
W \\
D\end{array}$ \\
\hline
\end{tabular}

i A dash indicates no data for the value shown.

2 For ingestion, no lung retention classes are listed.

Appendix C to Part 835-Derived Air Concentration (DAC) for Workers From External Exposure During Immersion in a Contaminated Atmospheric Cloud

The air immersion DAC values shown in this appendix are based on a stochastic limit of 5 rems $(0.05 \mathrm{~Sv})$ per year or a nonstochastic (organ) dose limit of 50 rems (0.5 Sv) per year. Four columns of information are presented: (1) Radionuclide; (2) half-life in units of seconds (s), minutes (min), hours (h), days (d), or years (yr); (3) air immersion DAC in units of $\mu \mathrm{Ci} / \mathrm{ml}$; and (4) air immersion DAC in units of $\mathrm{Bq} / \mathrm{m}^{3}$. The data are listed by radionuclide in order of increasing atomic mass. The air immersion DACs were calculated for a continuous, nonshielded exposure via immersion in a semi-infinite atmospheric cloud.

The DAC value for air immersion listed for a given radionuclide is determined either by a yearly limit on effective dose equivalent, which provides a limit on stochastic radiation effects, or by a limit on yearly dose equivalent to any organ, which provides a limit on nonstochastic radiation effects. For most of the radionuclides listed, the DAC value is determined by the yearly limit on effective dose equivalent. Thus, the few cases where the DAC value is determined by the yearly limit on shallow dose equivalent to the skin are indicated in the table by an appropriate footnote. Again, the DACs listed in this appendix account only for immersion in a semi-infinite cloud and do not account for inhalation or ingestion exposures.

Three classes of radionuclides are included in the air immersion DACs as described below.

(1) Class 1. The first class of radionuclides includes selected noble gases and short-lived activation products that occur in gaseous form. For these radionuclides, inhalation doses are negligible compared to the external dose from immersion in an atmospheric cloud.

(2) Class 2. The second class of radionuclides includes those for which a DAC value for inhalation has been calculated, but for which the DAC value for external exposure to a contaminated atmospheric cloud is more restrictive (i.e., results in a lower DAC value). These radionuclides generally have half-lives of a few hours or less, or are eliminated from the body following inhalation sufficiently rapidly to limit the inhalation dose.

(3) Class 3. The third class of radionuclides includes selected isotopes with relatively short half-lives. These radionuclides typically have half-lives that are less than 10 minutes, they do not occur as a decay product of a longer lived radionuclide, or they lack sufficient decay data to permit internal dose calculations. These radionuclides are also typified by a radioactive emission of bighly intense, highenergy photons and rapid removal from the body following inhalation.

The DAC values are given for individual radionuclides. For known mixtures of radionuclides, the sum of the ratio of the observed concentration of a particular radionuclide and its corresponding DAC for all radionuclides in the mixture must not exceed 1.0. For unknown radionuclides, the most restrictive DAC (lowest value) for those isotopes not known to be absent shall be used.

\begin{tabular}{|c|c|c|c|}
\hline \multirow{2}{*}{$\begin{array}{l}\text { Radio- } \\
\text { nuclide }\end{array}$} & \multirow{2}{*}{ Halt-Life } & \multicolumn{2}{|c|}{ Air Immersion DAC } \\
\hline & & $(\mu \mathrm{Ci} / \mathrm{ml})$ & $\left(\mathrm{Bq} / \mathrm{m}^{3}\right)$ \\
\hline $\begin{array}{l}C-11 \\
N-13\end{array}$ & $20.48 \min$ & $\begin{array}{l}4 . E-06 \\
4 . E-06\end{array}$ & $\begin{array}{l}\text { 1.E+05 } \\
\text { 1. E+05 }\end{array}$ \\
\hline
\end{tabular}


65510 Federal Register / Vol. 58, No. 238 / Tuesday, December 14, 1993 / Rules and Regulations

\begin{tabular}{|c|c|c|c|}
\hline \multirow{2}{*}{$\begin{array}{l}\text { Radio- } \\
\text { nuclide }\end{array}$} & \multirow{2}{*}{ Half-Life } & \multicolumn{2}{|c|}{ Air Immersion DAC } \\
\hline & & $(\mu \mathrm{Ci} / \mathrm{ml})$ & $\left(B q / m^{3}\right)$ \\
\hline 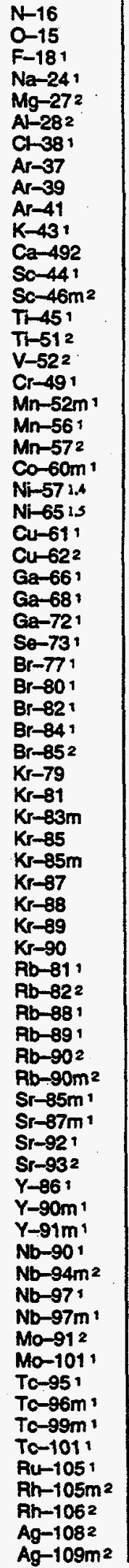 & 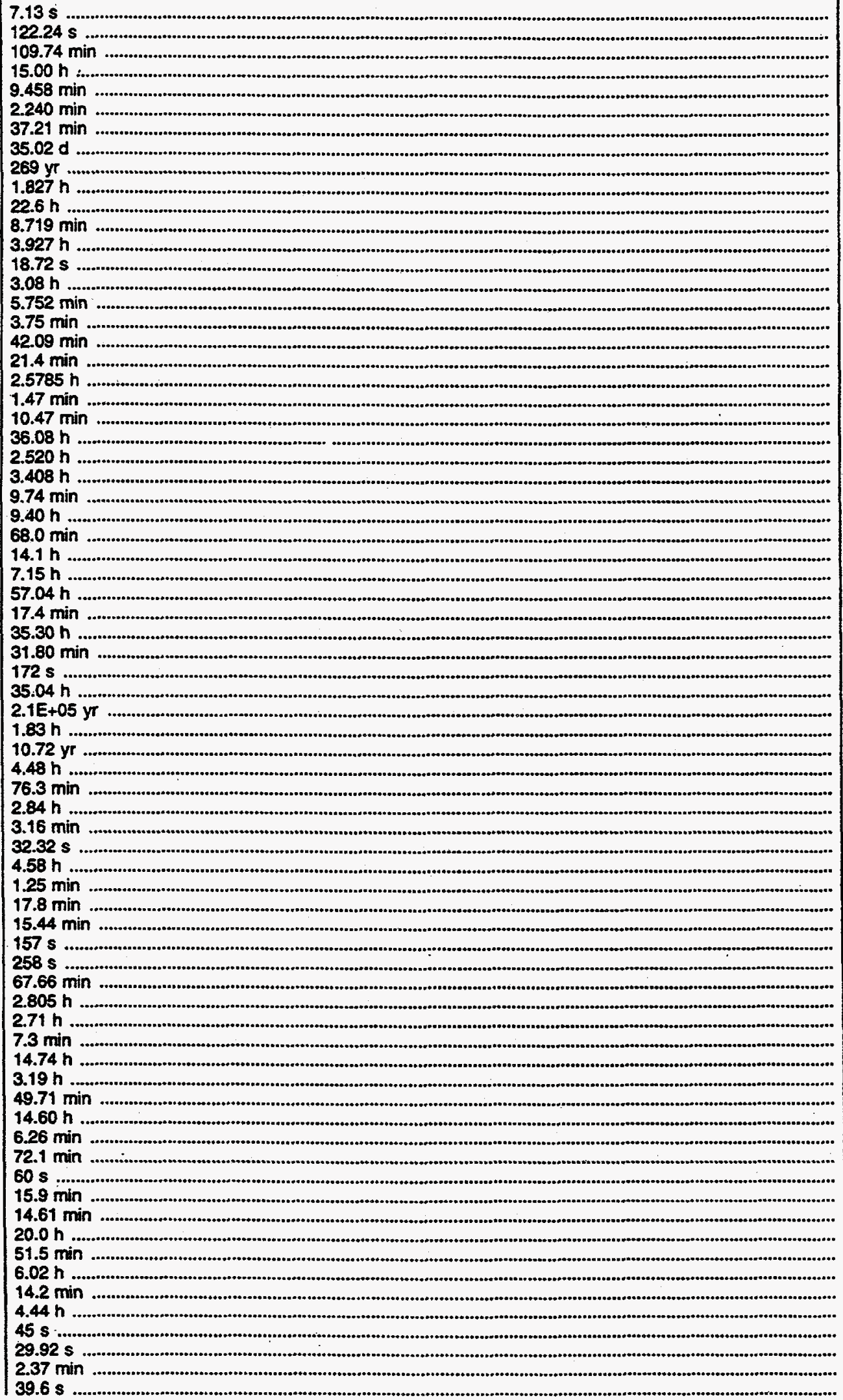 & $\begin{array}{l}7 . E-07 \\
4 . E-06 \\
4 . E-06 \\
9 . E-07 \\
5 . E-06 \\
2 . E-06 \\
3 . E-06 \\
3 . E+00 \\
2 . E-043 \\
3 . E-06 \\
5 . E-06 \\
1 . E-06 \\
2 . E-06 \\
5 . E-05 \\
5 . E-06 \\
1 . E-05 \\
3 . E-06 \\
5 . E-06 \\
2 . E-06 \\
2 . E-06 \\
6 . E-05 \\
1 . E-03 \\
2 . E-06 \\
8 . E-06 \\
5 . E-06 \\
5 . E-06 \\
2 . E-06 \\
5 . E-06 \\
1 . E-06 \\
4 . E-06 \\
1 . E-05 \\
5 . E-05 \\
1 . E-06 \\
2 . E-06 \\
5 . E-05 \\
2 . E-05 \\
5 . E-04 \\
5 . E-02 \\
1 . E-043 \\
3 . E-05 \\
5 . E-05 \\
2 . E-06 \\
2 . E-06 \\
3 . E-06 \\
8 . E-06 \\
2 . E-06 \\
7 . E-06 \\
2 . E-06 \\
2 . E-06 \\
1 . E-06 \\
2 . E-05 \\
6 . E-05 \\
3 . E-06 \\
2 . E-06 \\
1 . E-06 \\
5 . E-06 \\
9 . E-06 \\
1 . E-06 \\
9 . E-04 \\
7 . E-06 \\
6 . E-06 \\
4 . E-06 \\
3 . E-06 \\
5 . E-06 \\
1 . E-04 \\
3 . E-05 \\
1 . E-05 \\
5 . E-06 \\
1 . E-04 \\
2 . E-05 \\
2 . E-04 \\
1 . E-03\end{array}$ & $\begin{array}{l}3 . E+04 \\
1 . E+05 \\
1 . E+05 \\
3 . E+04 \\
2 . E+05 \\
7 . E+04 \\
1 . E+05 \\
1 . E+11 \\
7 . E+063 \\
1 . E+05 \\
2 . E+05 \\
4 . E+04 \\
7 . E+04 \\
2 . E+06 \\
2 . E+05 \\
4 . E+05 \\
1 . E+05 \\
2 . E+05 \\
7 . E+04 \\
7 . E+04 \\
2 . E+06 \\
4 . E+07 \\
7 . E+04 \\
3 . E+05 \\
2 . E+05 \\
2 . E+05 \\
7 . E+04 \\
2 . E+05 \\
4 . E+04 \\
1 . E+05 \\
4 . E+056 \\
2 . E+06 \\
4 . E+04 \\
7 . E+04 \\
2 . E+06 \\
7 . E+05 \\
2 . E+07 \\
2 . E+09 \\
4 . E+063 \\
1 . E+06 \\
2 . E+05 \\
7 . E+04 \\
7 . E+04 \\
1 . E+05 \\
3 . E+05 \\
7 . E+04 \\
3 . E+05 \\
7 . E+04 \\
7 . E+04 \\
4 . E+04 \\
7 . E+04 \\
2 . E+06 \\
1 . E+05 \\
7 . E+04 \\
4 . E+04 \\
2 . E+056 \\
3 . E+05 \\
4 . E+03 \\
3 . E+07 \\
3 . E+05 \\
2 . E+05 \\
1 . E+05 \\
1 . E+05 \\
2 . E+05 \\
4 . E+06 \\
1 . E+06 \\
4 . E+05 \\
2 . E+05 \\
4 . E+06 \\
7 . E+05 \\
7 . E+06 \\
4 . E+07\end{array}$ \\
\hline
\end{tabular}


Federal Register / Vol. 58, No. 238 / Tuesday, December 14, 1993 / Rules and Regulations

\begin{tabular}{|c|c|c|c|}
\hline \multirow{2}{*}{$\begin{array}{l}\text { Radio- } \\
\text { nuclide }\end{array}$} & \multirow{2}{*}{ Half-Lite } & \multicolumn{2}{|c|}{ Air Immersion DAC } \\
\hline & & $(\mu \mathrm{Ci} / \mathrm{ml})$ & $\left(\mathrm{Bq} / \mathrm{m}^{3}\right)$ \\
\hline 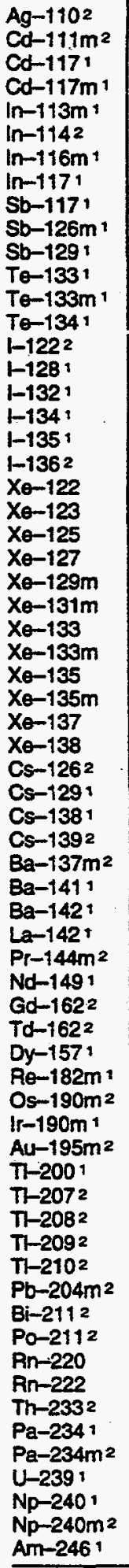 & 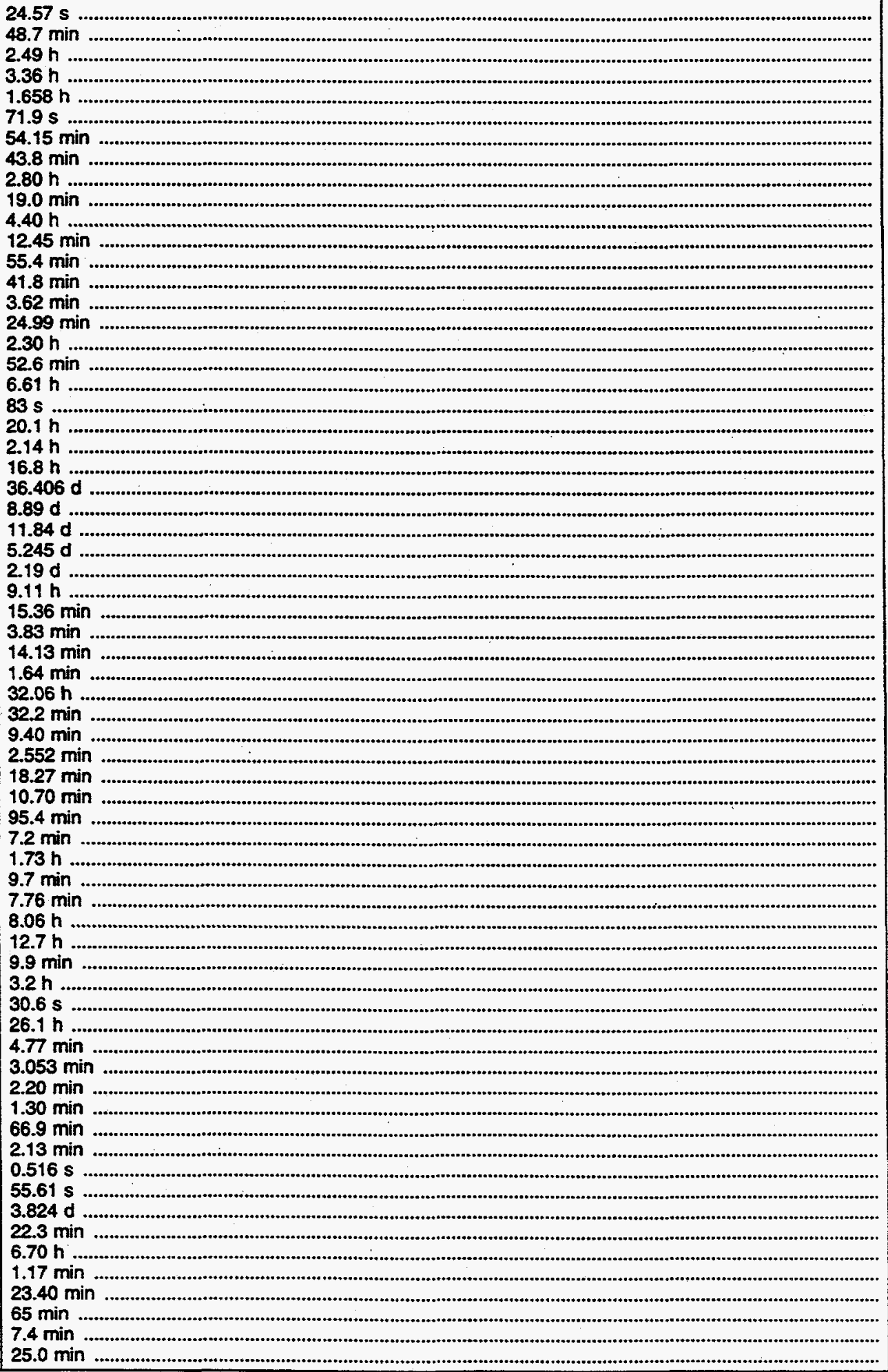 & $\begin{array}{l}9 . E-05 \\
1 . E-05 \\
4 . E-06 \\
2 . E-06 \\
2 . E-05 \\
1 . E-04 \\
2 . E-06 \\
7 . E-06 \\
3 . E-05 \\
3 . E-06 \\
3 . E-06 \\
5 . E-06 \\
2 . E-06 \\
5 . E-06 \\
5 . E-06 \\
5 . E-05 \\
2 . E-06 \\
1 . E-06 \\
7 . E-078 \\
1 . E-06 \\
8 . E-05 \\
7 . E-06 \\
2 . E-05 \\
1 . E-05 \\
2 . E-04 \\
5 . E-04 \\
1 . E-04 \\
1 . E-04 \\
2 . E-05 \\
1 . E-05 \\
2 . E-05 \\
4 . E-06 \\
4 . E-06 \\
1 . E-056 \\
2 . E-06 \\
1 . E-05 \\
7 . E-06 \\
5 . E-06 \\
5 . E-06 \\
1 . E-06 \\
9 . E-04 \\
1 . E-05 \\
1 . E-05 \\
4 . E-06 \\
1 . E-05 \\
4 . E-06 \\
3 . E-06 \\
8 . E-056 \\
2 . E-05 \\
3 . E-06 \\
4 . E-053 \\
1 . E-06 \\
2 . E-06 \\
1 . E-06 \\
2 . E-06 \\
1 . E-04 \\
5 . E-04 \\
8 . E-09 . \\
3 . E-08 . \\
1 . E-04 \\
2 . E-06 \\
4 . E-053 \\
8 . E-056 \\
4 . E-06 \\
1 . E-05 \\
4 . E-06 \\
\end{array}$ & $\begin{array}{l}3 . E+06 \\
4 . E+05 \\
1 . E+05 \\
7 . E+04 \\
7 . E+05 \\
4 . E+06 \\
7 . E+04 \\
3 . E+05 \\
1 . E+06 \\
1 . E+05 \\
1 . E+05 \\
2 . E+05 \\
7 . E+04 \\
2 . E+05 \\
2 . E+05 \\
2 . E+06 \\
7 . E+04 \\
4 . E+04 \\
3 . E+046 \\
4 . E+04 \\
3 . E+06 \\
3 . E+05 \\
7 . E+05 \\
4 . E+05 \\
7 . E+06 \\
2 . E+07 \\
4 . E+06 \\
4 . E+06 \\
7 . E+05 \\
4 . E+05 \\
7 . E+05 \\
1 . E+05 \\
1 . E+05 \\
4 . E+056 \\
7 . E+04 \\
4 . E+05 \\
3 . E+05 \\
2 . E+05 \\
2 . E+05 \\
4 . E+04 \\
3 . E+07 \\
4 . E+05 \\
4 . E+05 \\
1 . E+05 \\
4 . E+05 \\
1 . E+05 \\
1 . E+05 \\
3 . E+066 \\
7 . E+05 \\
1 . E+05 \\
1 . E+063 \\
4 . E+04 \\
7 . E+04 \\
4 . E+04 \\
7 . E+04 \\
4 . E+06 \\
2 . E+07 \\
3 . E+026 \\
1 . E+038 \\
4 . E+06 \\
7 . E+04 \\
1 . E+063 \\
3 . E+066 \\
1 . E+05 \\
4 . E+05 \\
1 . E+05 \\
\end{array}$ \\
\hline
\end{tabular}

1 Committed effective dose equivalent from inhalation is calculated in ICRP Publication 30, but the DAC value for extemal exposure to a contaminated atmospheric cloud is more restrictive than the DAC value for inhalation.

2 Committed effective dose equivalent from inhalation is not calculated in ICRP Publication 30, but-DAC value for external exposure to contaminated cloud should be more restrictive then DAC value for inhalation due to relatively short half-life of radionuclide.

3DAC value is determined by limit on annual shallow dose equivalent to skin, ratter than yearly limit on effective dose equivalent.

4 DAC value applies to radionuclide in vapor form only; DAC value for inhalation is more restrictive for radionuclide in inorganic form. 
5DAC value applies to radionuclide in inorganic or vapor form.

- DAC value for exposure to contaminated atmospheric cloud is the same as DAC value for inhalation.

Appendix D to Part 835-Surface

Radioactivity Values

SURFACE RADIOACTIVTTY VALUES; 1 IN DPW/100 $\mathrm{CM}^{2}$

\begin{tabular}{|c|c|c|}
\hline Nuctide & Removable 2,4 & $\begin{array}{l}\text { Total (Fixed + } \\
\text { Removable) } 2,3\end{array}$ \\
\hline 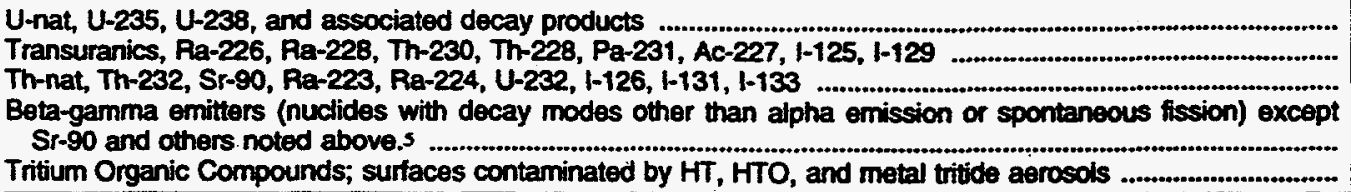 & $\begin{array}{r}1,000 \\
20 \\
200 \\
1,000 \\
\text { [Reserved] }\end{array}$ & $\begin{array}{r}5,000 \\
500 \\
1,000 \\
5,000 \\
{[\text { Reserved] }}\end{array}$ \\
\hline
\end{tabular}

I The values in this appendix apply to radioactive contamination deposited on, but not incorporated into the interior of, the contaminated item. Where surface contamination by both alpha- and beta-gamma-emitting nuclides exists, the limits established for alpha- and beta-gamma-emitting nuclides should apply independenty.

2 As used in this table, dpm (disintegrations per minute) means the rate of emission by radioactive material as detemined by correcting the counts per minute observed by an appropriate detector for background, efficiency, and geometric factors associated with the instrumentation.

3 The levels may be averaged over one square meter provided the maximum surface activity in any area of $100 \mathrm{~cm} 2$ is less than three times the value specified. For purposes of averaging, any square meter of surface shall be considered to be above the activity guide $G$ if: (1) From measurements of a representative number $n$ of sections it is determined that $1 / n \Sigma_{n} S_{i} \geq G$, where $S_{i}$ is the dpm/100 cm 2 determined from measurement of section $\mathrm{i}$; or (2) it is determined that the sum of the activity of all isolated spots or particles in any $100 \mathrm{~cm} 2$ area exceeds $3 G$.

4 The amount of removable radioactive material per $100 \mathrm{~cm}^{2}$ of surface area should be determined by swiping the area with dry filter or soft absorbent paper, applying moderate pressure, and then assessing the amount of radioactive material on the swipe with an appropriate instrument of known efficiency. (Note-The use of dry material may not be aporopriate for tritium.) When removable contamination on objects of surtace area less than $100 \mathrm{~cm} 2$ is determined, the activity per unit area should be based on the actual area and the entire surface should be wiped. Except for transuranies and Ra-228, Ac-227, Th-228, Th-230, Pa-23t and alpha emitters, it is not necessary to use swiping techniques to measure removable contamination levels if direct scan surveys indicate that the total resictual surface contamination levels are within the limits tor removable contamination.

5 This category of radionuclides includes mixed fission products, including the Sr-90 which is present in them. It does not apply to Sr-90 which has been separated from the other fission products or mixtures where the Sr-90 has been enriched.

Appendix E to Part 835-[Reserved]

[FR Doc. 93-27997 Filed 12-13-93; 8:45 am]

BULUNG CODE CUSO-OT-P 


\section{APPENDIX \\ FOR REFERENCE ONLY \\ DOE N 441.1}

\section{NOT PART OF THE TEXT \\ OF THE APPENDED DOCUMENT}




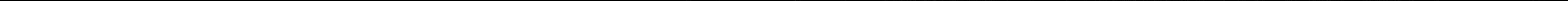


DOE N 44T.1

$9 / 29 / 95$

Expires: [ 1 year after initiation]

SUBJECT: RADIOLOGICAL PROTECTION FOR DOE ACTIVITIES

The Department of Energy (DOE) undertook an initiative to reduce the burden of unnecessary, repetitive, or conflicting requirements on DOE contractors that resulted in the elimination of numerous radiological protection requirements which were invoked via DOE Orders and Notices. The majority of pertinent radiological protection requirements have become codified through promulgation of Title 10 of the Code of Federal Regulations. Part 835. Occupational

Radiation Protection (10 CFR 835). However, 10 CFR 835 does not address al! essential areas, such as sealed radioactive source accountability, needed to form the basis of a comprehensive program for protection of individuals from the hazards of i onizing radiation in controlled areas.

The purpose of issuing this Notice is to establ ish radiological protection program requirements that, combined with 10 CFR 835 and its associated

implementation guidance, form the bas is for such a comprehensive radiological protection program. Accordingly, the Directives Management Board establ ished DOE concurrence on a set of 16 top-level, performance-based requirements that are now incorporated in this Notice. These 16 requirements supplement and enhance the requirements of 10 CFR 835 to provide critical direction in the areas of administrative controls, radiation safety training, work

authorizations, posting, exposure of minors, and sealed radioactive source accountability.

1. PURPOSE: To establish radiological. protection program requirements that, combined with 10 CFR 835 and its associated implementation guidance, form the basis for a comprehensive program for protection of individuals from the hazards of ionizing radiation in controlled areas. These requirements shall remain in effect pending completion of the Department's rulemaking efforts to codify these, or equivalent. requirements.

2. CANCELLATION: The Orders listed below are canceled. Cancellation of an Order does not, by itself, modify or otherwise affect any contractual obligation to comply with such an order. Canceled Orders that are incorporated by reference in a contract shall remain in effect until the contract is modified to delete the reference to the requirements in the canceled Orders. 
a. DOE 5480.11, RADIATION PROTECTION FOR OCCUPATIONAL WORKERS

b. DOE 5480.15, DEPARTMENT OF ENERGY LABORATORY ACCREDITATION PROGRAM FOR PERSONNEL DOSIMETRY

c. DOE N 5400.13, SEALED RADIOACTIVE SOURCE ACCOUNTABILITY

d. DOE N 5480.11, EXTENSION OF RADIOLOGICAL CONTROL MANUAL, REVISION 1 (DOE Radiological Control Manual (DOE/EH-0256T) remains as guidance)

3. APPLICABILITY:

a. DOE Elements. Except for the exclusions in paragraph 3c, this Notice applies to all defense nuclear facilities (defined in 10 CFR 830, as amended) classified as hazard categories 1, 2, or 3 which are subject to the requirements of 10 CFR 835.

b. Contractors. Except for the exclusions in paragraph 3c, this Notice applies to contractors that operate defense nuclear facilities and other contractors as determiried by the cognizant contracting officer. Contractor compliance with this Notice will be required to the extent set forth in a contract. Contractors shall be directed to continue to comply with the requirements of orders canceled by this Notice until their contracts are modified to de lete the reference to the requirements of the canceled orders.

c. Exclusions. Activities conducted under the authority of the Director, Naval Nuclear Propulsion Program, as described in Public Law 98-525.

4. BACKGROUND: The need for interim requirements for implementation of radiological protection programs arises from recent Departmental efforts to revise and streaml ine its directives system. The Department has ident ified certain requirements previously promulgated in the DOE Radiological Control Manual and DOE N 5400.13, SEALED RADIOACTIVE SOURCE ACCOUNTABILITY, and recommendations of recognized scient if ic organizations that it bel ieves are crucial to the accomplishment of its radiological protection objectives. This Notice establ ishes interim requirements for radiological protection programs that will remain in effect pending completion of the Department's rulemaking efforts to codify these, or equivalent, requirements. Other provisions, previously promulgated in the DOE Radiological Controls Manual and standards referenced therein, are considered acceptable methods to satisfy 10 CFR 835 and its associated Implementation Guides. Alternative methods to those contained in the Implementation Guides which provide equivalent margins of protection in satisfying the requirements of 10 CFR 835 are also acceptable. 
$9-29-95$

\section{DEFINITIONS.}

Terms used in this Notice are consistent with their definitions in 10 CFR 835. The following additional terms and definitions are provided:

a. Accountable sealed radioactive source means a sealed radioactive source having an activity equal to or greater than the applicable value provided in Attachment 1 of this Notice.

b. Administrative control level means a numerical dose constraint established at a level below the occupational exposure limits provided in 10 CFR 835 to administratively control and help reduce individual and collective doses.

c. Radiological work permit means an authorization to conduct work involving exposure to radiation or radioactive materials that identifies radiological conditions, establ ishes worker protection and monitoring requirements, and contains specific approvals.

d. Sealed radioactive source means a radioactive source specifically manufactured, obtained, or retained for the purpose of utilizing the emitted radiation. The sealed radioactive source consists of a known quantity of radioactive material contained within a sealed capsule, sealed between layers of non-radioactive material, or firmly fixed to a non-radioactive surface by electroplating or other means intended to prevent leakage or escape of the radioactive material.

e. Source integrity test means a test to determine if a sealed radioactive source is leaking radioactive material.

f. Technical work document means a formally approved document that directs work, such as a procedure, work package, laboratory protocol, or job or research plan and that also identifies radiological conditions, establishes worker protection and monitoring requirements, and contains specific approvals.

\section{REOUIREMENTS.}

\section{a. Administrative Control Leve/s}

A system of administrative control levels (ACLS) shall be implemented to control radiological worker doses at levels below the occupational exposure I imits provided in 10 CFR 835.202.

(1) A DOE ACL of 2 rem ( $0.02 \mathrm{SV}$ ) total effective dose equivalent (TEDE) per year shall be implemented. No individual shall be permitted to receive an occupational exposure during planned activities that would result in exceeding the DOE $A C L$ without the specific written authorization of the cognizant Secretarial Officer or designee.

(2) A cumulative total effective dose equivalent (CTEDE) ACL of 1 rem (0.01 SV) TEDE per year of age shall be implemented. When a radiological worker's CTEDE exceeds 1 rem TEDE per year of age, special ACLs shall be establ ished during ensuing years as necessary to cause that individual's CTEDE to approach and, if possible, fall below 1 rem per year of age. 
(3) A facility-specific ACL shall be approved each year by facility management to maintain radiological worker doses below the DOE ACL. Written authorization by facility management shall be required prior to allowing any radiological worker's dose resulting from planned activities to exceed the facility-specific ACL.

b. Work Authorizations

Authorizations to work in radiological areas shall be in accordance with the Radiological Protection Program, required by 10 CFR 835.101. This program, in part, shall describe a radiological work authorization program as specified in 835.501 which appropriately utilizes avai lable work documents and procedures. The level of detail included in these documents shall be commensurate with the nature and magnitude of the hazard and complexity of the required controls.

c. Radiation Safety Training

(1) Radiation safety training for general employees, radiological workers, and radiological control technicians shall utilize those portions of the standardized core training materials publ ished by DOE that are relevant to facility hazards and operations, augmented as necessary by site-specific materials. Documentation of satisfactory completion of the entire DOE standardized core course(s) shall be accepted by all DOE activities.

(2) Training requirements commensurate with the hazard within a posted area shal 1 be completed prior to permitting an individual unescorted access to that area.

d. Posting

Any accessible area in which radioactive material is used, handled, or stored shall be posted with the words "Caution, Radioactive Material." The posting shall meet the requirements of 10 CFR 835.601. The following areas are exempt from this posting requi rement:

(1) Areas containing ten or fewer sealed radioactive sources with activities below the accountability criteria established in Attachment 1:

(2) Areas containing only materials that are properly packaged and labeled for transport in conformance with Department of Transportation regulations or corresponding DOE directives and expected to enter into transportation in the immediate future (i.e., the current shift):

(3) Areas under continuous observation and control of an individual knowledgeable of and empowered to implement required access control measures: .

(4) Areas posted as a radiological area in accordance with 10 CFR 835.603;

(5) Other areas posted with radiological warning signs meeting the criteria establ ished in 10 CFR 835.601; and 
9-29-95

(6) Areas containing radioactive materials in quantities below the site- or facility-specified posting threshold. This threshold shall be establ ished at a level below that which is likely to cause any individual to receive a TEDE in excess of 0.1 rem in a year.

e. Control of Sealed Radioactive Sources

(1) Administrative procedures shall be developed and maintained to control sealed radioactive sources having values equal to or exceeding those in Attachment 1 (i.e., accountable sealed radioactive sources)

(2) Accountable sealed radioactive sources, or their storage containers or devices, shall be labeled with the standard radiation warning trefoil and the words, "Caution,

Radioactive Material."

(3) An individual shall be designated to maintain control of assigned accountable sealed radioactive sources. Prior to being designated, the individual selected shall be trained as a radiological worker in accordance with 10 CFR 835.902 and instructed on site-specific source control procedures.

(4) Each accountable sealed radioactive source shall be inventoried at intervals not to exceed six months. A 2 month grace period may be used to accommodate scheduling needs. This inventory shall establish:

(a) The physical location of each accountable sealed radioactive source:

(b) The adequacy of associated postings and labels; and

(c) The adequacy of storage locations, containers, and devices.

(5) Each accountable sealed radioactive source having an activity exceeding $0.005 \mathrm{mC} i$ shall be subject to a source integrity test upon receipt, when damage is suspected, and at intervals not to exceed six months. A 6 week grace period may be used to accommodate schedul ing needs. Source integrity tests shall be capable of detecting radioactive material leakage equal to or exceeding $0.005 \mathrm{mCi}$.

(6) Notwithstanding the requirements of paragraph 6.e. (5), an accountable sealed radioactive source is not subject to a periodic source integrity test if that source has been documented to have been removed from service. Such sources shall be stored in a controlled location, subject to periodic inventory as required by paragraph $6 . e .(4)$ of this section, and subject to a source integrity test prior to being returned to service.

(7) Notwithstanding the requirements of paragraph 6.e. (4) and $6 . e .(5)$, an accountable sealed radioactive source is not subject to periodic inventory and source integrity tests if that source is located in an area that is inaccessible to individuals due to operational or environmental constraints. 
(8) An accountable sealed radioactive source found to be leaking radioactive material at a level exceeding $0.005 \mathrm{mCi}$ shall be controlled in a manner that prevents the escape of radioactive material to the workplace.

f. Exposure of Minors

The exposure of minors during direct on-site access to a DOE site or facility shall be controlled such that the dose to the extremities, lens of the eye, and other organs and tissues does not exceed $10 \%$ of the corresponding occupational exposure I imits establ ished in 10 CFR 835.202. Appropriate monitoring of external and internal dose shal I be performed to demonstrate compl iance with these limits.

g. DOE Laboratory Accreditation Program. The DOE Laboratory Accreditation Program (DOELAP) shall be maintained consistent with the appl icable DOE standards, and dosimetry programs shall be accredited at periodic intervals consistent with the standards. Additional guidance for the various program elements are contained in the DOELAP Technical Standard. 


\section{RESPONSIBILITIES.}

a. Secretarial officers. Authorize exposures that exceed administrative control levels stated in paragraph $6 a(7)$.

b. Managers of Operations offices. Ensure through the contracting officer that contractors implement radiation protection programs that conform to the requirements of paragraph 6 above and 10 CFR 835 .

c. Contractors: Contractors that manage and operate DOE defense nuclear facilities and other contractors as determined by the contracting officer shall develop and implement radiological protection programs that conform to the requirements of paragraph 6, above.

8. REFERENCES. Title 10, Code of Federal Regulations, Part 835, Occupational Radiation Protection.

9. CONTACT. Questions concerning this Notice should be addressed to the Office of Worker Protection Programs and Hazards Management, EH-52, on (301) $903-2135$.

BY ORDER OF THE SECRETARY OF ENERGY:

ARCHER L. DURHAM

Assistant Secretary for

Human Resources and Administration 
DOE N 441.1

Attachment 1

9-29-95

Page 1 (and 2)

VALUES FOR EXEMPTION OF SEALED RADIOACTIVE SOURCES FROM INVENTORY AND SOURCE INTEGRITY TESTS

Less than $300 \mu \mathrm{Ci}(10 \mathrm{MBq})$

$\begin{array}{llllllll}\text { H-3 } & \text { Be-7 } & \text { C-14 } & \text { S-35 } & \text { Ca-41 } & \text { Ca-45 } & \text { V-49 } & \text { Mn-53 } \\ \text { Fe-55 } & \text { Ni-59 } & \text { Ni }-63 & \text { As-73 } & \text { Se-79 } & \text { Rb-87 } & \text { TC-99 } & \text { Pd-107 } \\ \text { Cd-113 } & \text { In-175 } & \text { Te-123 } & \text { CS }-135 & \text { Ce-141 } & \text { Gd-152 } & \text { Tb-157 } & \text { Tm-171 } \\ \text { Ta-180 } & \text { W-181 } & \text { W-185 } & \text { W-188 } & \text { Re-187 } & \text { Tl-204 } & & \end{array}$

Less than $30 \mu \mathrm{Ci}(1 \mathrm{MBq})$

$\begin{array}{llllllll}\text { CI-36 } & \text { K-40 } & \text { Fe-59 } & \text { Co-57 } & \text { Se-75 } & \text { Rb-84 } & \text { Sr-85 } & \text { Sr-89 } \\ \text { Y-91 } & \text { Zr-95 } & \text { Nb-93m } & \text { Nb-95 } & \text { TC-97m } & \text { Ru-103 } & \text { Ag-105 } & \text { In-114m } \\ \text { Sn-113 } & \text { Sn-119m } & \text { Sn-121m } & \text { Sn-123 } & \text { Te-123m } & \text { Te-125m } & \text { Te-127m } & \text { Te-129m } \\ \text { I-125 } & \text { La-137 } & \text { Ce-139 } & \text { Pm-143 } & \text { Pm-145 } & \text { Pm-147 } & \text { Sm-145 } & \text { Sm-151 } \\ \text { Eu-149 } & \text { Eu-155 } & \text { Gd-151 } & \text { Gd-153 } & \text { Dy-159 } & \text { Tm-170 } & \text { Yb-169 } & \text { Lu-173 } \\ \text { Lu-174 } & \text { Lu-174m } & \text { HF-175 } & \text { HF-181 } & \text { Ta-179 } & \text { Re-184 } & \text { Re-186m } & \text { Ir-192 } \\ \text { Pt-193 } & \text { Au-195 } & \text { Hg-203 } & \text { Pb-205 } & \text { Np-235 } & \text { Pu-237 } & & \end{array}$

Less than $3 \mu \mathrm{C} i(100 \mathrm{kBq})$

$\begin{array}{llllllll}\mathrm{Be}-10 & \mathrm{Na}-22 & \mathrm{Al}-26 & \mathrm{Si}-32 & \mathrm{Sc}-46 & \mathrm{Ti}-44 & \mathrm{Mn}-54 & \mathrm{Fe}-60 \\ \mathrm{Co}-56 & \mathrm{Co}-58 & \mathrm{Co}-60 & \mathrm{Zn}-65 & \mathrm{Ge}-68 & \mathrm{Rb}-83 & \mathrm{Y}-88 & \mathrm{Zr}-88 \\ \mathrm{Zr}-93 & \mathrm{Nb}-94 & \mathrm{Mo}-93 & \mathrm{TC}-95 \mathrm{~m} & \mathrm{TC}-97 & \mathrm{TC}-98 & \mathrm{Ru}-106 & \mathrm{Rh}-101 \\ \mathrm{Rh}-102 & \mathrm{Rh}-102 \mathrm{~m} & \mathrm{Ag}-108 \mathrm{~m} & \mathrm{Ag}-110 \mathrm{~m} & \mathrm{Cd}-109 & \mathrm{Sn}-126 & \mathrm{Sb}-124 & \mathrm{Sb}-125 \\ \mathrm{Te}-121 \mathrm{~m} & \mathrm{I}-129 & \mathrm{CS}-134 & \mathrm{CS}-137 & \mathrm{Ba}-133 & \mathrm{Ce}-144 & \mathrm{Pm}-144 & \mathrm{Pm}-146 \\ \mathrm{Pm}-148 \mathrm{~m} & \mathrm{Eu}-148 & \mathrm{Eu}-150 & \mathrm{Eu}-152 & \mathrm{Eu}-154 & \mathrm{Gd}-146 & \mathrm{~Tb}-158 & \mathrm{~Tb}-160 \\ \mathrm{Ho}-166 \mathrm{~m} & \mathrm{Lu}-176 & \mathrm{Lu}-177 \mathrm{~m} & \mathrm{Hf}-172 & \mathrm{Ta}-182 & \mathrm{Re}-184 \mathrm{~m} & \mathrm{Os}-185 & \mathrm{Os}-194 \\ \mathrm{Ir}-192 \mathrm{~m} & \mathrm{Ir}-194 \mathrm{~m} & \mathrm{Hg}-194 & \mathrm{~Pb}-202 & \mathrm{Bi}-207 & \mathrm{Bi}-210 \mathrm{~m} & \mathrm{Cm}-241 & \end{array}$

Less than $0.3 \mathrm{pCi}(10 \mathrm{kBq})$

$\begin{array}{lllllll}\mathrm{Sr}-90 \quad \mathrm{Cd}-113 \mathrm{~m} \quad \mathrm{La}-138 \quad \mathrm{Hf}-178 \mathrm{~m} & \mathrm{Hf}-182 & \text { Po-210 } & \mathrm{Ra}-226 & \mathrm{Ra}-228\end{array}$

Pu-241 Bk-249 ES-254

Less than $0.03 \mathrm{rCi}(1 \mathrm{kBq})$

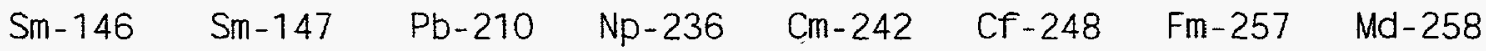

Less than $0.003 \mu \mathrm{Ci}(100 \mathrm{~Bq})$

$\begin{array}{llllllll}\text { Gd-148 } & \text { Th-228 } & \text { Th-230 } & \text { U-232 } & \text { U-233 } & \text { U-234 } & \text { U-235 } & \text { U-236 } \\ \text { U-238 } & \text { Np-237 } & \text { Pu-236 } & \text { Pu-238 } & \text { Pu-239 } & \text { Pu-240 } & \text { Pu-242 } & \text { Pu-244 } \\ \text { Am-241 } & \text { Am-242m } & \text { Am-243 } & \text { Cm-243 } & \text { Cm-244 } & \text { Cm-245 } & \text { Cm-246 } & \text { Cm-247 } \\ \text { Bk-247 } & \text { Cf -249 } & \text { Cf-250 } & \text { Cf }-251 & \text { Cf }-252 & \text { Cf }-254 & & \end{array}$

Less than $0.0003 \mu \mathrm{Ci}(10 \mathrm{~Bq})$

Ac-227 Th-229 Th-232 Pa-231 Cm-248 Cm-250 


\section{APPENDIX}

FOR REFERENCE ONLY

DOE N 441.2

\section{NOT PART OF THE TEXT \\ OF THE APPENDED DOCUMENT}





\section{U.S. Department of Energy Washington, D.C.}

NOTICE

DOE N 441.2

9-19-96

Expires: $9-19-97$

\section{SUBJECT: EXTENSION OF DOE N 441.1, RADIOLOGICAL PROTECTION FOR DOE ACTIVITIES}

This Notice extends DOE N 441.1, RADIOLOGICAL PROTECTION FOR DOE ACTIVITIES, dated 9-30-95, until 9-30-97, unless sooner rescinded.

The contents of DOE N 441.1 have been incorporated in the draft revision of 10 CFR 835, "Occupational Radiation Protection." This Notice will be rescinded when the amendment to 10 CFR 835 is issued as a final rulemaking.

Questions concerning this Notice should be directed to Steven Zobel, EH-52, 301-903-2305.

BY ORDER OF THE SECRETARY OF ENERGY:

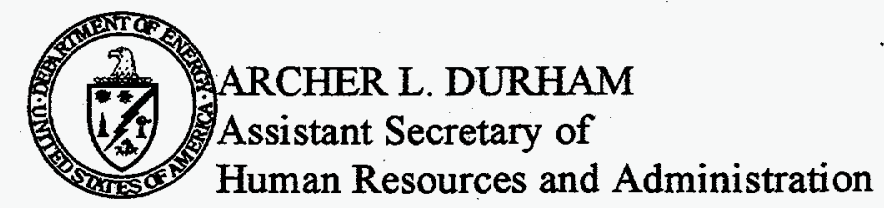

Distribution:

All Departmental Elements
Initiated by:

Office of Environment, Safety and Health 



\title{
APPENDIX
}

FOR REFERENCE ONLY

\author{
NEVADA TEST SITE \\ PERFORMANCE OBJECTIVE \\ FOR CERTIFICATION OF \\ NONRADIOACTIVE \\ HAZARDOUS WASTE
}

\author{
G-E11/96.01 \\ Revision 0 \\ December 1995
}

\section{PLEASE REFERENCE CONTROLLED COPY}

NOT PART OF THE TEXT OF THE APPENDED DOCUMENT 
